\title{
Extração de informação contextual utilizando mineração de textos para sistemas de recomendação sensíveis ao contexto
}



Data de Depósito: 19/05/2015

Assinatura:

\section{Extração de informação contextual utilizando mineração de textos para sistemas de recomendação sensíveis ao contexto}

\section{Camila Vaccari Sundermann}

Orientadora: Profa. Dra. Solange Oliveira Rezende

Dissertação apresentada ao Instituto de Ciências Matemáticas e de Computação - ICMC-USP, como parte dos requisitos para obtenção do título de Mestre em Ciências - Ciências de Computação e Matemática Computacional. VERSÃO REVISADA 
Ficha catalográfica elaborada pela Biblioteca Prof. Achille Bassi e Seção Técnica de Informática, ICMC/USP, com os dados fornecidos pelo(a) autor(a)

\begin{tabular}{|c|c|}
\hline \multirow[t]{3}{*}{ SS957e } & $\begin{array}{l}\text { Sundermann, Camila Vaccari } \\
\text { Extração de informação contextual utilizando } \\
\text { mineração de textos para sistemas de recomendação } \\
\text { sensiveis ao contexto / Camila Vaccari Sundermann; } \\
\text { orientadora Solange Oliveira Rezende. -- São } \\
\text { Carlos, } 2015 \text {. } \\
\quad 127 \mathrm{p} .\end{array}$ \\
\hline & $\begin{array}{l}\text { Dissertação (Mestrado - Programa de Pós-Graduação } \\
\text { em Ciências de Computação e Matemática } \\
\text { Computacional) -- Instituto de Ciências Matemáticas } \\
\text { e de Computação, Universidade de São Paulo, } 2015 .\end{array}$ \\
\hline & $\begin{array}{l}\text { 1. Contexto. 2. Sistemas de Recomendação Sensíveis } \\
\text { ao Contexto. 3. Mineração de Textos. 4. Hierarquias } \\
\text { de Tópicos. I. Rezende, Solange Oliveira, orient. } \\
\text { II. Título. }\end{array}$ \\
\hline
\end{tabular}




\section{Agradecimentos}

Agradeço primeiramente a Deus, que sempre está presente em minha vida trazendo presentes e surpresas maravilhosas.

Agradeço ao meu filho Kauê, por toda alegria que me dá, pela inocência de um lindo anjo e pelo amor incondicional. Quando tudo parece difícil, encontro forças em seus sorrisos, beijos, abraços e brincadeiras.

Agradeço aos meus pais, Arnaldo e Cidinha, meus maiores mestres e amigos, que me ajudam em todos os momentos e estão sempre dispostos a me ouvir. Nos momentos que mais precisei de amparo, quando pensei que não havia mais chão, eles me ergueram e me incentivaram a lutar. Graças aos dois eu sei qual é o verdadeiro significado de família, de amor, de educação, de bondade... Tudo que conquistei até agora devo aos dois. É um amor inexplicável.

Agradeço ao meu noivo Febirson, que chegou em minha vida trazendo muitos ensinamentos e me incentivando sempre a seguir em frente e lutar. Muito calmo e compreensivo, sabe sempre entender minha falta de tempo ocasionada pelos estudos. Não tenho nem palavras para agradecer tudo que ele já fez por mim, por meu filho e por meus pais. Feber, estranho seria se eu não me apaixonasse por você, obrigada por tudo! Amo muito você!

Agradeço aos meus amigos, que trazem muita alegria aos meus dias, muitos risos e energias positivas.

Agradeço à minha orientadora Solange, por vários motivos: por ter me aceito no mestrado, pela ótima orientação na minha pesquisa, pelas orientações da vida pessoal, por ter sacrificado suas férias para ajudar seus alunos, por ser tão mãe e amiga, por ter me ensinado tantas coisas, pela paciência, pela compreensão, pelo sexto sentido que tem com as pessoas ao redor, e por tantas outras coisas que não cabem nesta seção.

Agradeço às minhas amigas queridas Roberta, Ivone e Jéssica pela amizade sincera que temos. Pela força, pela ajuda e pelas risadas. Pelos choros e pela compreensão. Pela noite em claro me ajudando. Enfim, agradeço a elas por tudo de bom que trouxeram pra mim. Não sei o que seria se não fosse a nossa amizade.

Agradeço ao Marcos Aurélio Domingues por ter sido meu coorientador neste mestrado, mesmo que não oficialmente. Aprendi muito com sua orientação e devo muito a ele pelos resultados alcançados na minha pesquisa. Agradeço pela compreensão e paciência nos momentos de desespero e pela ajuda no trabalho e com as revisões.

Agradeço aos meus amigos do LABIC. Muitas risadas e descontrações. Somos real- 
mente uma equipe.

Agradeço aos pesquisadores e parceiros que colaboraram com meu mestrado e com trabalhos paralelos. Considero a colaboração entre as pessoas algo muito importante na vida, tanto profissional quanto pessoal. Como o ditado já diz: "A união faz a força!" e "Unidos venceremos". A esses pesquisadores e amigos, muito obrigada! E que continuemos com muitos trabalhos.

Agradeço aos membros da minha banca do exame de qualificação, Stanley Robson de Oliveira Medeiros e Marcelo Garcia Manzato, pelas críticas e sugestões oferecidas. Foi tudo de extrema importância na execução e finalização do meu trabalho. Obrigada!

Agradeço, antecipadamente, aos membros da minha banca de defesa por terem aceito ler minha dissertação e participar desse momento tão importante na minha vida.

Agradeço à USP pela minha formação e pelos 8 anos de estudos. Agradeço a todos os professores do ICMC, que muito me ensinaram durante estes anos todos, de graduação e de mestrado.

Por fim, agradeço a todos que ajudaram direta ou indiretamente e à CAPES (Coordenação de Aperfeiçoamento de Pessoal de Nível Superior) e à FAPESP (Fundação de Amparo à Pesquisa do Estado de São Paulo) pelo apoio financeiro. 


\section{Resumo}

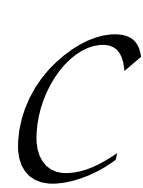

om a grande variedade de produtos e serviços disponíveis na Web, os usuários possuem, em geral, muita liberdade de escolha, o que poderia ser considerado uma vantagem se não fosse pela dificuldade encontrada em escolher o produto ou serviço que mais atenda a suas necessidades dentro do vasto conjunto de opções disponíveis. Sistemas de recomendação são sistemas que têm como objetivo auxiliar esses usuários a identificarem itens de interesse em um conjunto de opções. A maioria das abordagens de sistemas de recomendação foca em recomendar itens mais relevantes para usuários individuais, não levando em consideração o contexto dos usuários. Porém, em muitas aplicações é importante também considerar informações contextuais para fazer as recomendações. Por exemplo, um usuário pode desejar assistir um filme com a sua namorada no sábado à noite ou com os seus amigos durante um dia de semana, e uma locadora de filmes na Web pode recomendar diferentes tipos de filmes para este usuário dependendo do contexto no qual este se encontra. Um grande desafio para o uso de sistemas de recomendação sensíveis ao contexto é a falta de métodos para aquisição automática de informação contextual para estes sistemas. Diante desse cenário, neste trabalho é proposto um método para extrair informações contextuais do conteúdo de páginas Web que consiste em construir hierarquias de tópicos do conteúdo textual das páginas considerando, além da bag-of-words tradicional (informação técnica), também informações mais valiosas dos textos como entidades nomeadas e termos do domínio (informação privilegiada). Os tópicos extraídos das hierarquias das páginas Web são utilizados como informações de contexto em sistemas de recomendação sensíveis ao contexto. Neste trabalho foram realizados experimentos para avaliação do contexto extraído pelo método proposto em que foram considerados dois baselines: um sistema de recomendação que não considera informação de contexto e um método da literatura de extração de contexto implementado e adaptado para este mestrado. Além disso, foram utilizadas duas bases de dados. Os resultados obtidos foram, de forma geral, muito bons apresentando ganhos significativos sobre o baseline sem contexto. Com relação ao baseline que extrai informação contextual, o método proposto se mostrou equivalente ou melhor que o mesmo. 



\section{Abstract}

$\mathcal{W}$ ith the wide variety of products and services available on the web, it is difficult for users to choose the option that most meets their needs. In order to reduce or even eliminate this difficulty, recommender systems have emerged. A recommender system is used in various fields to recommend items of interest to users. Most recommender approaches focus only on users and items to make the recommendations. However, in many applications it is also important to incorporate contextual information into the recommendation process. For example, a user may want to watch a movie with his girlfriend on Saturday night or with his friends during a weekday, and a video store on the Web can recommend different types of movies for this user depending on his context. Although the use of contextual information by recommendation systems has received great focus in recent years, there is a lack of automatic methods to obtain such information for context-aware recommender systems. For this reason, the acquisition of contextual information is a research area that needs to be better explored. In this scenario, this work proposes a method to extract contextual information of Web page content. This method builds topic hierarchies of the pages textual content considering, besides the traditional bag-of-words, valuable information of texts as named entities and domain terms (privileged information). The topics extracted from the hierarchies are used as contextual information in context-aware recommender systems. By using two databases, experiments were conducted to evaluate the contextual information extracted by the proposed method. Two baselines were considered: a recommendation system that does not use contextual information (IBCF) and a method proposed in literature to extract contextual information ("methodological" baseline), adapted for this research. The results are, in general, very good and show significant gains over the baseline without context. Regarding the "methodological" baseline, the proposed method is equivalent to or better than this baseline. 



\section{Sumário}

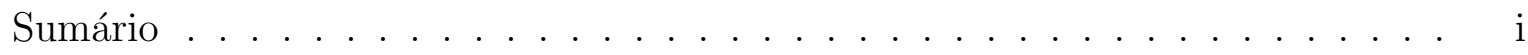

Lista de Figuras . . . . . . . . . . . . . . . . . . . iv

Lista de Tabelas . . . . . . . . . . . . . . . . . . . . . . vii

1 Introdução 1

1.1 Hipótese e Objetivo . . . . . . . . . . . . . . . . . . . . 3

1.2 Proposta e Contribuições . . . . . . . . . . . . . . . . . . . 4

1.3 Organização do Texto . . . . . . . . . . . . . . . 5

2 Sistemas de Recomendação $\quad 7$

2.1 Considerações Iniciais . . . . . . . . . . . . . . . . . . . 7

2.2 Técnicas Utilizadas em Sistemas de Recomendação . . . . . . . . . . . . . 11

2.2.1 Filtragem Colaborativa . . . . . . . . . . . . . . . . 11

2.2.2 Filtragem Baseada em Conteúdo . . . . . . . . . . . . . . . . 15

2.2 .3 Abordagens Híbridas . . . . . . . . . . . . . . . . . . . . . . . . . 17

2.3 Sistemas de Recomendação Sensíveis ao Contexto . . . . . . . . . . . . . . 18

2.3.1 Classificação dos Sistemas de Recomendação Sensíveis ao Contexto 20

2.3.2 Aquisição Automática de Contexto . . . . . . . . . . . . . . . . . . 24

2.4 Avaliação de Sistemas de Recomendação . . . . . . . . . . . . . . . . . . . 32

2.5 Considerações Finais . . . . . . . . . . . . . . . . . . . . 36

3 Mineração de Textos $\quad 37$

3.1 Considerações Iniciais . . . . . . . . . . . . . . . . . . . . 37

3.2 O Processo de Mineração de Textos . . . . . . . . . . . . . . . . . . . 37

3.3 Abordagens para Extração de Contexto . . . . . . . . . . . . . . . . . . . . 41

3.3.1 Hierarquia de Tópicos . . . . . . . . . . . . . . . . . . . 41

3.3.2 Reconhecimento de Entidades Nomeadas . . . . . . . . . . . . . . . 43

3.3.3 Extração de Termos . . . . . . . . . . . . . . . . . . . 45

3.4 Considerações Finais . . . . . . . . . . . . . . . . . . . . . 47 
4 Extração Automática de Contexto Utilizando Mineração de Textos para Sistemas de Recomendação $\quad 49$

4.1 Considerações Iniciais . . . . . . . . . . . . . . . . . . . . . . . . 49

4.2 Descrição do Método para Extração Automática de Contexto Utilizando Abordagens de Mineração de Textos . . . . . . . . . . . . . . . . . 50

4.2.1 Pré-Processamento da Base de Logs . . . . . . . . . . . . . . . . . . 50

4.2.2 Método Proposto para Extração de Contexto . . . . . . . . . . . . 52

4.2 .3 Utilização do Contexto Extraído . . . . . . . . . . . . . . . . . . . . 60

4.3 Avaliação . . . . . . . . . . . . . . . . . . . . . . . 61

4.4 Considerações Finais . . . . . . . . . . . . . . . . . . . . . . . . . . . . 62

5 Avaliação do Método Proposto $\quad 63$

5.1 Considerações Iniciais . . . . . . . . . . . . . . . . . . . . . 63

5.2 Bases de Logs de Acessos . . . . . . . . . . . . . . . . . . . . . 64

5.3 Pré-Processamento das Bases de Logs . . . . . . . . . . . . . . . . . . . . . 66

5.4 Método de Extração de Contexto . . . . . . . . . . . . . . . . . 66

5.5 Utilização do Contexto Extraído . . . . . . . . . . . . . . . . . . . . . 69

5.6 Metodologia de Avaliação das Recomendações com Uso de Contexto . . . . 69

5.6.1 Avaliação Considerando o Baseline IBCF . . . . . . . . . . . 70

5.6.2 Avaliação Considerando o Baseline Metodológico . . . . . . 75

5.7 Análise Geral da Utilização do Contexto Extraído . . . . . . . . . . . . . . 81

5.8 Considerações Finais . . . . . . . . . . . . . . . . . . . . . . . . . 87

6 Conclusão $\quad 89$

6.1 Contribuições e Trabalhos Futuros . . . . . . . . . . . . . . . . . . . . 91

$\begin{array}{ll}\text { Referências } & 94\end{array}$

A Resultados Obtidos nos Experimentos da Avaliação Considerando o Baseline IBCF

B Resultados Obtidos nos Experimentos da Avaliação Considerando o $B a$ seline "Metodológico" 


\section{Lista de Figuras}

1.1 Visão geral do processo proposto neste trabalho. . . . . . . . . . . . . . 4

2.1 Formas de combinar filtragem colaborativa (FC) com filtragem baseada em conteúdo (FBC) (Adaptado de Bobadilla et al. (2013)) . . . . . . . . . . . . 18

2.2 Categorias de sistemas de recomendação sensíveis ao contexto (Adaptado de Panniello e Gorgoglione (2012)) . . . . . . . . . . . . . . . . . . 21

2.3 Gráficos dos resultados da avaliação do desempenho das top- $K$ recomendações (Li et al., 2010) . . . . . . . . . . . . . . . . . . . . 27

2.4 Valores de precisão para diferentes categorias (Hariri et al., 2011). . . . . . 28

2.5 Valores de revocação para diferentes categorias (Hariri et al., 2011). . . . . 29

2.6 Comparação Hit Ratio para $k N N$ baseado em item e sistema de recomendação baseado em contexto (Hariri et al., 2011) . . . . . . . . . . . . . . . . 29

3.1 Processo de mineração de textos (Rezende, 2003) . . . . . . . . . . . . . . 38

3.2 Esquema da etapa de pré-processamento (Conrado, 2009). . . . . . . . . . 39

3.3 Matriz Atributo-Valor. . . . . . . . . . . . . . . . . . . . . . . . 39

3.4 Exemplo de um dendrograma do agrupamento hierárquico de documentos (Rossi, 2011). . . . . . . . . . . . . . . . . . . 42

4.1 Visão geral da proposta deste trabalho de mestrado. . . . . . . . . . . . . . 51

4.2 Extração do conteúdo textual das páginas da Web. . . . . . . . . . . . . . 52

4.3 Estrutura hierárquica do atributo contextual "periodo do ano" (Panniello e Gorgoglione, 2012) . . . . . . . . . . . . . . . 53

4.4 Método LIHC proposto por Marcacini e Rezende (2013). . . . . . . . . . . 54

4.5 Processo de extração de entidades nomeadas. . . . . . . . . . . . . . 56

4.6 Uso do Wikipédia pelo sistema REMBRANDT (Adaptado de Oliveira (2010)). 56

4.7 Etapas do funcionamento do REMBRANDT (Adaptado de Cardoso (2008)). 57

4.8 Processo de extração de termos do domínio. . . . . . . . . . . . . . . . . . 59

4.9 Visão geral da abordagem de extração automática de termos (Conrado et al., 2013) . . . . . . . . . . . . . . . . . . . . . 59 
5.1 Visão geral do processo experimental deste trabalho. . . . . . . . . . . . . 65

5.2 Construção das hierarquias de tópicos utilizando as entidades nomeadas ou os termos do domínio como informação privilegiada. . . . . . . . . . . . . . 67

5.3 Cálculo da MAP para as recomendações geradas pelos sistemas de recomendação sensíveis ao contexto utilizando os tópicos como contexto. . . . . 70

5.4 Avaliação das recomendações geradas pelo algoritmo IBCF. . . . . . . . . . 70

5.5 Avaliação das recomendações geradas pelos sistemas de recomendação sensíveis ao contexto utilizando as "Estações do Ano" ou os "Dias da Semana" como informações de contexto. . . . . . . . . . . . . . . . . . . . 71

5.6 Gráficos dos valores da MAP@10 para o experimento dos tópicos com entidades nomeadas da base da Embrapa e considerando o baseline IBCF. I - Granularidade $\{2,7\}$; II - Granularidade $\{10,50\}$; III - Granularidade $\{15,20\}$ e IV - Granularidade $\{50,100\} . \quad \ldots \ldots$. . . . . . . . 82

5.7 Gráficos dos valores da MAP@10 para o experimento dos tópicos com termos da base da Embrapa e considerando o baseline IBCF. I - Granularidade $\{2,7\}$; II - Granularidade $\{10,50\}$; III - Granularidade $\{15,20\}$ e IV - Granularidade $\{50,100\} \ldots \ldots \ldots \ldots$. . . . . . . . . . . 83

5.8 Gráficos dos valores da MAP@10 para o experimento dos tópicos com entidades nomeadas da base do Dicionário Informal e considerando o baseline IBCF. I - Granularidade $\{2,7\}$; II - Granularidade $\{10,50\}$; III - Granularidade $\{15,20\}$ e IV - Granularidade $\{50,100\}$. . . . . . . . . . . . . . 84

5.9 Gráficos dos valores da MAP@10 para o experimento dos tópicos com termos da base do Dicionário Informal e considerando o baseline IBCF. I - Granularidade $\{2,7\}$; II - Granularidade $\{10,50\}$; III - Granularidade $\{15,20\}$ e IV - Granularidade $\{50,100\}$

5.10 Gráficos dos valores de MAP@10 para os experimentos com os tópicos da base da Embrapa, considerando o baseline "metodológico" e o fator de combinação $\alpha=0$.

5.11 Gráficos dos valores de MAP@10 para os experimentos com os tópicos com entidades da base do Dicionário Informal, considerando o baseline "metodológico" e o fator de combinação $\alpha=0,3 \ldots$. . . . . . . . . . . . 86

5.12 Gráficos dos valores de MAP@10 para os experimentos com os tópicos com termos da base do Dicionário Informal, considerando o baseline "metodológico" e o fator de combinação $\alpha=1$. 


\section{Lista de Tabelas}

2.1 Alguns sites populares que utilizam sistemas de recomendação (Adaptado de Lu et al. (2012)). . . . . . . . . . . . . . . . . . . . 9 9

2.2 Avaliações dadas por cinco usuários a cinco restaurantes (Pazzani, 1999). . 13

2.3 Matriz de similaridade. . . . . . . . . . . . . . . . . . . . . . 14

2.4 Resultados da avaliação para o classificador baseado em bag-of-words (Palavras), o classificador baseado em regras (Regras) e o classificador híbrido (Híbrido) (Li et al., 2010). . . . . . . . . . . . . . . . 26

5.1 Árvores do Conhecimento da Agência Embrapa de Informação Tecnológica por categoria . . . . . . . . . . . . . . . . . 64

5.2 Número de Tópicos (Informação Contextual) Extraídos das Hierarquias Construídas com Entidades Nomeadas e com Termos . . . . . . . . . . . . 68

5.3 Resultados Selecionados do Primeiro Experimento . . . . . . . . . . . . . 73

5.4 Resultados Selecionados do Segundo Experimento . . . . . . . . . . . . . 74

5.5 Resultados Selecionados do Terceiro Experimento . . . . . . . . . . . . 75

5.6 Resultados Selecionados do Quarto Experimento . . . . . . . . . . . 76

5.7 Experimentos Realizados Considerando o Baseline "Metodológico" . . . . . 76

5.8 Resultados do Primeiro Experimento para o Fator de Combinação $\alpha=0 \quad$. 77

5.9 Resultados do Segundo Experimento para o Fator de Combinação $\alpha=0 \quad$. 78

5.10 Resultados do Terceiro Experimento para o Fator de Combinação $\alpha=0$. . 78

5.11 Resultados do Quarto Experimento para o Fator de Combinação $\alpha=0$. . 79

5.12 Resultados do Quinto Experimento para o Fator de Combinação $\alpha=0,3 \quad$. 79

5.13 Resultados do Sexto Experimento para o Fator de Combinação $\alpha=0,3$. . 80

5.14 Resultados do Sétimo Experimento para o fator de combinação $\alpha=1$. . . 80

5.15 Resultados do Oitavo Experimento para o Fator de Combinação $\alpha=1$. . 81

A.1 Resultados Completos do Primeiro Experimento na Avaliação Baseline IBCF106

A.2 Resultados Completos do Segundo Experimento na Avaliação Baseline IBCF 107

A.3 Resultados Completos do Terceiro Experimento na Avaliação Baseline IBCF108

A.4 Resultados Completos do Quarto Experimento na Avaliação Baseline IBCF 109 
B.1 Experimentos Realizados Considerando o Baseline "Metodológico" e Suas Respectivas Tabelas de Resultados . . . . . . . . . . . . . . . . . . . . . . 111

B.2 Resultados do Primeiro Experimento da Avaliação Comparando com o Baseline "Metodológico" para os Fatores de Combinação $\alpha=0$ e $\alpha=0,3$. . . 112

B.3 Resultados do Primeiro Experimento da Avaliação Comparando com o Baseline "Metodológico" para os Fatores de Combinação $\alpha=0,5, \alpha=0,7$ e $\alpha=1$.

B.4 Resultados do Segundo Experimento da Avaliação Comparando com o Baseline "Metodológico" para os Fatores de Combinação $\alpha=0$ e $\alpha=0,3$. . . 114

B.5 Resultados do Segundo Experimento da Avaliação Comparando com o Baseline "Metodológico" para os Fatores de Combinação $\alpha=0,5, \alpha=0,7$ e $\alpha=1$

B.6 Resultados do Terceiro Experimento da Avaliação Comparando com o Baseline "Metodológico" para os Fatores de Combinação $\alpha=0$ e $\alpha=0,3$. . . 116

B.7 Resultados do Terceiro Experimento da Avaliação Comparando com o Baseline "Metodológico" para os Fatores de Combinação $\alpha=0,5, \alpha=0,7$ e

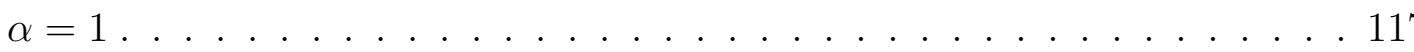

B.8 Resultados do Quarto Experimento da Avaliação Comparando com o Baseline "Metodológico" para os Fatores de Combinação $\alpha=0$ e $\alpha=0,3 \ldots .118$

B.9 Resultados do Terceiro Experimento da Avaliação Comparando com o Baseline "Metodológico" para os Fatores de Combinação $\alpha=0,5, \alpha=0,7$ e $\alpha=1$.

B.10 Resultados do Quinto Experimento da Avaliação Comparando com o Baseline "Metodológico" para os Fatores de Combinação $\alpha=0$ e $\alpha=0,3$. . . 120

B.11 Resultados do Quinto Experimento da Avaliação Comparando com o Baseline "Metodológico" para os Fatores de Combinação $\alpha=0,5, \alpha=0,7$ e $\alpha=1$

B.12 Resultados do Sexto Experimento da Avaliação Comparando com o Baseline "Metodológico" para os Fatores de Combinação $\alpha=0$ e $\alpha=0,3$. . . . 122

B.13 Resultados do Sexto Experimento da Avaliação Comparando com o Baseline "Metodológico" para os Fatores de Combinação $\alpha=0,5, \alpha=0,7$ e $\alpha=1 \ldots \ldots \ldots \ldots$

B.14 Resultados do Sétimo Experimento da Avaliação Comparando com o Baseline "Metodológico" para os Fatores de Combinação $\alpha=0$ e $\alpha=0,3$. . .

B.15 Resultados do Sétimo Experimento da Avaliação Comparando com o Baseline "Metodológico" para os Fatores de Combinação $\alpha=0,5, \alpha=0,7$ e

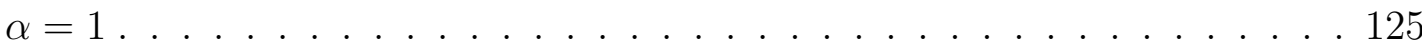

B.16 Resultados do Oitavo Experimento da Avaliação Comparando com o Baseline "Metodológico" para os Fatores de Combinação $\alpha=0$ e $\alpha=0,3$. . . 126 
B.17 Resultados do Oitavo Experimento da Avaliação Comparando com o Baseline "Metodológico" para os Fatores de Combinação $\alpha=0,5, \alpha=0,7$ e

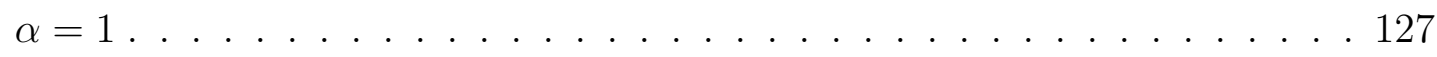





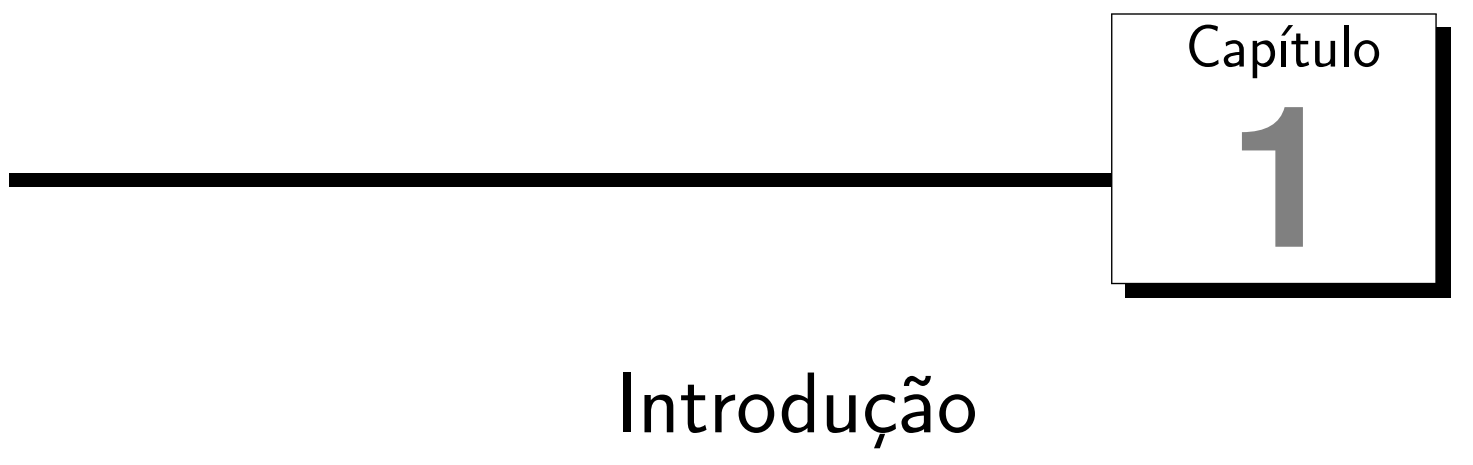

Com a grande variedade de produtos e serviços disponíveis na Web, os usuários possuem, em geral, muita liberdade de escolha, o que poderia ser considerado uma vantagem se não fosse pela dificuldade encontrada em escolher o produto ou serviço que mais atenda a suas necessidades dentro do vasto conjunto de opções disponíveis. Uma forma de amenizar ou até mesmo eliminar essa dificuldade é o uso de sistemas de recomendação, que são sistemas utilizados em vários domínios para sugerir itens (livros, produtos, serviços, etc) de interesse aos usuários (Ricci et al., 2011). Um dos principais domínios que, atualmente, utilizam esses sistemas é o e-commerce, no qual sites interagem diretamente com os clientes sugerindo produtos de interesse com o objetivo de aumentar suas vendas. Como exemplo, pode ser citado o sistema de recomendação do site da $A_{m a z o n}{ }^{1}$, que faz recomendações a um usuário que acessa um determinado item na forma: "Clientes que compraram esse item também compraram..." ou "Clientes que visualizaram esse item também visualizaram..." (Linden et al., 2003; Ricci et al., 2011).

Entre os produtos/itens ou serviços recomendados, podem estar livros, filmes, serviços, produtos eletrônicos e também páginas da Web, que é o domínio abordado neste trabalho de mestrado. As formas de recomendação incluem sugerir produtos a clientes, oferecer informação do produto de forma personalizada, resumir opinião da comunidade, entre outras. Essas técnicas podem ser consideradas como uma personalização do site, já que dão elementos para o mesmo se adaptar a cada cliente (Ricci et al., 2011; Bobadilla et al., 2013).

A maior parte das abordagens de sistemas de recomendação foca apenas nos usuários e nos itens para construir um modelo que é usado para recomendar uma lista ordenada de $N$ itens que podem ser de interesse do usuário (Bobadilla et al., 2013). Entretanto, em muitas aplicações também é importante incorporar informação contextual dentro do processo de

\footnotetext{
${ }^{1}$ WWW . amazon . com
} 
recomendação. Pesquisadores começaram a perceber que a qualidade das recomendações aumenta quando são utilizadas informações adicionais, como, por exemplo, tempo e local. Assim, a integração dessa informação contextual nos sistemas de recomendação tornou-se um tópico de crescente importância em pesquisas (Adomavicius et al., 2005; Li et al., 2010; Adomavicius e Tuzhilin, 2011; Hariri et al., 2011; Domingues et al., 2013). Exemplos de aplicações em que o uso de contexto resulta em recomendações mais relevantes aos usuários são os sistemas de recomendações de filmes, estabelecimentos, pacotes de viagens, etc.

Dependendo da área na qual está inserido, contexto é um conceito que pode assumir diferentes definições. Neste projeto de pesquisa, é considerada a definição de contexto dada por Dey (2001), muito utilizada em trabalhos da literatura, na qual contexto é definido como qualquer informação que pode ser utilizada para caracterizar a situação de uma entidade, que neste trabalho é o item ou página da Web. Um sistema de recomendação sensível ao contexto é uma tecnologia de filtragem de informação que, além do comportamento e interesse do usuário, utiliza também informação contextual (contexto) para recomendar a este uma lista ordenada de itens/recomendações que lhe é de interesse (Adomavicius e Tuzhilin, 2011).

Um dos grandes desafios nas pesquisas de sistemas de recomendação sensíveis ao contexto é a falta de métodos para aquisição de informação contextual para estes sistemas. Embora o uso de informação contextual por sistemas de recomendação tenha recebido grande foco nos últimos anos, a aquisição de tal informação é uma área de pesquisa que necessita ser explorada. Alguns trabalhos abordam essa problemática propondo métodos para extração de contexto (Li et al., 2010; Aciar, 2010; Hariri et al., 2011; Ho et al., 2012; Bauman e Tuzhilin, 2014), porém, com resultados não tão satisfatórios, que precisam ser melhorados. Além disso, enquanto a maioria dos métodos são supervisionados e o contexto extraído é referente aos usuários, neste trabalho, o objetivo é propôr um método não supervisionado para extrair informações contextuais dos itens (páginas da Web).

A informação contextual, além de ter diversas definições, também pode ser estruturada de várias formas. Em alguns trabalhos, tal informação é organizada em uma estrutura hierárquica, que pode ser representada como árvores (Adomavicius et al., 2005; Panniello e Gorgoglione, 2012). Diante dessa possibilidade de organização hierárquica do contexto, neste trabalho são utilizadas hierarquias de tópicos como forma de organizar e extrair o contexto do conteúdo textual das páginas da Web.

As hierarquias de tópicos podem ser construídas por meio do agrupamento hierárquico dos textos, um método não-supervisionado que permite a extração automática de conhecimento de grandes coleções textuais. Nessa representação, os textos são organizados em grupos e subgrupos. Para cada grupo de documentos, são extraídos tópicos ou descritores que indicam o conteúdo dos mesmos, e são esses tópicos que, neste trabalho, são considerados contexto das páginas da Web.

Muitos métodos existentes na literatura para construir hierarquias de tópicos utilizando agrupamento hierárquico, representam a coleção de textos considerando somente 
uma bag-of-words tradicional. Tal representação considera os termos ou atributos dos textos como um conjunto desordenado de palavras e não considera as relações existentes entre cada palavra (Feldman e Sanger, 2007). Entretanto é possível, em alguns casos, extrair dos textos um tipo de informação mais valiosa conhecida como informação privilegiada (Vapnik e Vashist, 2009). Neste trabalho são construídas hierarquias de tópicos dos conteúdos textuais das páginas da Web, utilizando o método LUPI-based Incremental Hierarchical Clustering (LIHC) (Marcacini e Rezende, 2013), que considera, além da bagof-words tradicional (informação técnica), a informação privilegiada extraída dos textos.

Neste trabalho são consideradas como informações privilegiadas entidades nomeadas ou termos do domínio extraídos do texto. O reconhecimento de entidades nomeadas (Mikheev et al., 1999; Kozareva, 2006; Oliveira, 2010; Nothman et al., 2013; Liu et al., 2013) envolve processar um texto e identificar ocorrências de palavras ou expressões que pertencem a categorias particulares de entidades nomeadas (que podem ser identificadas por um nome próprio) além de expressões temporais e numéricas. A extração automática de termos é uma abordagem de mineração de textos que tem como objetivo identificar unidades terminológicas em coleções de textos de domínio específico. Essa informação é utilizada em aplicações computacionais como recuperação de informação, extração e sumarização (Conrado et al., 2013). Na construção das hierarquias de tópicos utilizando informações privilegiadas, é possível atribuir diferentes pesos para cada tipo de informação para serem considerados no modelo final do agrupamento. Tal peso é atribuído por meio da escolha do fator de combinação.

Por meio das hierarquias de tópicos construídas, as páginas da Web são organizadas em grupos e subgrupos e ainda são extraídos tópicos que indicam o tema/conteúdo dos grupos. Assim sendo, tais tópicos são excelentes candidatos à informação contextual de cada página, que neste trabalho é um item da recomendação. Seguindo esse raciocínio, as páginas dentro de um grupo são consideradas pertencentes ao mesmo contexto. Por exemplo, uma hierarquia de tópicos construída com páginas da Web do domínio da agricultura apresenta o grupo cujo tópico/descritor é "ElaboradoVinhoSucoUvaDestilado". As

páginas desse grupo pertencem ao mesmo contexto (viticultura), representado pelo tópico extraído.

\subsection{Hipótese e Objetivo}

Diante do cenário descrito na seção anterior, a hipótese levantada neste trabalho é que a qualidade da recomendação é melhorada quando são utilizadas hierarquias de tópicos como informações contextuais.

Assim, o principal objetivo deste trabalho é propôr um método para extrair informações contextuais a partir de hierarquias de tópicos construídas com o uso de informação privilegiada. Tais hierarquias serão obtidas por meio de uma instanciação do processo de mineração de textos. Assim as informações contextuais serão extraídas do conteúdo 
textual de páginas da Web e serão utilizadas em sistemas de recomendação de conteúdo Web sensíveis ao contexto.

\subsection{Proposta e Contribuições}

Considerando a falta de métodos automáticos de extração de contexto, a hipótese e o objetivo deste trabalho, é proposto um processo para extração e avaliação do contexto de páginas Web que consiste nas etapas ilustradas na Figuta 1.1.

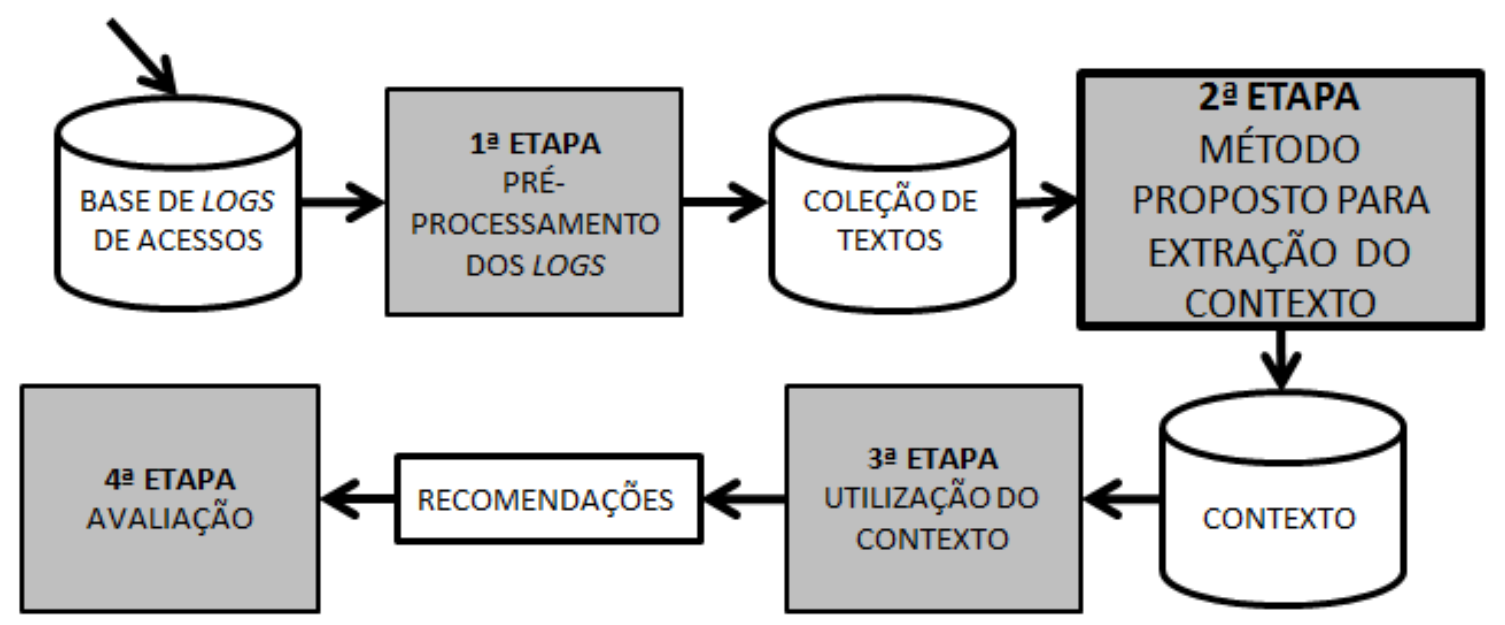

Figura 1.1: Visão geral do processo proposto neste trabalho.

A entrada do processo é a Base de Logs de Acessos. A $\mathbf{1}^{\text {a }}$ Etapa consiste em pré-processar esses logs de forma a obter uma Coleção de Textos referente ao conteúdo das páginas da Web acessadas. Essa Coleção de Textos é a entrada da $\mathbf{2}^{\mathbf{a}}$ Etapa, que para este trabalho é a mais importante, pois é o Método Proposto para Extração de Contexto. Esse método consiste em construir hierarquias de tópicos da Coleção de Textos utilizando o método LIHC (Marcacini e Rezende, 2013), o qual considera além da informação técnica (bag-of-words tradicional), também a informação privilegiada dos textos. Como informações privilegiadas são consideras as entidades nomeadas (reconhecidas por meio do sistema REMBRANDT (Cardoso, 2008)) extraídas dos textos e os termos do domínio (extraídos utilizando a abordagem de Conrado et al. (2013)). São construídas diferentes hierarquias de tópicos combinando as entidades nomeadas com a informação técnica e também combinando os termos do domínio com a informação técnica. Tais combinações são feitas variando o valor do fator de combinação, o qual indica o peso da informação privilegiada no agrupamento hierárquico final. Das hierarquias de tópicos construídas, são extraídos os tópicos/descritores dos grupos, e estes são utilizados como Contexto das páginas da Web em sistemas de recomendações sensíveis ao contexto na $3^{\mathbf{a}}$ Etapa do processo proposto neste trabalho. Os sistemas de recomendação utilizados neste trabalho são: cReduction (Adomavicius et al., 2005) (pré-filtragem contextual), DaVI-BEST (Domingues et al., 2013) (modelagem contextual), Filter PoF e Weight PoF (Panniello e Gorgoglione, 2012) (ambos pertencentes à categoria de pós-filtragem con- 
textual). A $4^{\mathrm{a}}$ e última etapa do processo, consiste na avaliação do método proposto para extração de contexto. Nesta etapa, as recomendações geradas utilizando o contexto extraído na $2^{\text {a }}$ Etapa, são avaliadas de forma offline utilizando a medida MAP (Mean Average Precision) como medida de avaliação. Tanto a medida MAP como a avaliação do tipo offline são explicadas no Capítulo 2, Seção 2.4. São utilizados dois baselines em análises comparativas. O primeiro baseline é o Item-Based Collaborative Filtering (IBCF), um sistema de recomendação tradicional que não utiliza contexto, portanto os resultados das recomendações contextuais são comparados com os resultados das recomendações geradas sem o uso de contexto. O segundo baseline, é denominado neste trabalho como baseline "metodológico". Este baseline é uma adaptação do método de extração de contexto apresentado por Li et al. (2010). Na análise comparativa que utiliza o baseline "metodológico", os resultados das recomendações geradas utilizando o contexto extraído pelo método proposto neste mestrado são comparados com os resultados das recomendações geradas utilizando o contexto extraído pelo baseline "metodológico".

A principal contribuição deste trabalho é o método proposto para extração de contexto. Tal método permite a extração automática de informações contextuais do conteúdo de páginas da Web por meio da construção de hierarquia de tópicos. Para enriquecer o contexto, também são utilizados as entidades nomeadas e os termos extraídos no momento em que é feito o agrupamento hierárquico. Além disso, no Capítulo 5 é comprovado que é viável utilizar a informação contextual extraída em sistemas de recomendação sensíveis ao contexto e são apresentados bons resultados das recomendações geradas considerando tal informação adicional. Alguns dos resultados obtidos nos experimentos deste trabalho, foram publicados em Sundermann et al. (2014).

\subsection{Organização do Texto}

Esta dissertação está dividida em seis capítulos. Neste primeiro capítulo foi apresentada uma introdução ao tema de pesquisa, incluindo o contexto em que está inserido, a hipótese e o objetivo deste trabalho, assim como o processo proposto para extração e avaliação do contexto. No Capítulo 2 é apresentada uma revisão da literatura de sistemas de recomendação tradicionais, com as técnicas de filtragem utilizadas e as formas possíveis de avaliar tais sistemas. Além dos sistemas tradicionais, também é feita no Capítulo 2, uma revisão da literatura de sistemas de recomendação sensíveis ao contexto, apresentando sua classificação e alguns métodos já utilizados para a extração automática de contexto. No Capítulo 3 o processo de mineração de textos é apresentado assim como suas etapas e as abordagens que são utilizadas nesta pesquisa. No Capítulo 4 é apresentado o processo proposto neste trabalho que inclui o método para extração de contexto. Os experimentos realizados para avaliar o método proposto para a extração de contexto e os resultados obtidos são descritos no Capítulo 5. Por fim, no Capítulo 6, são apresentadas as conclusões deste trabalho de mestrado, alguns artigos publicados e, também, alguns trabalhos 
futuros. 


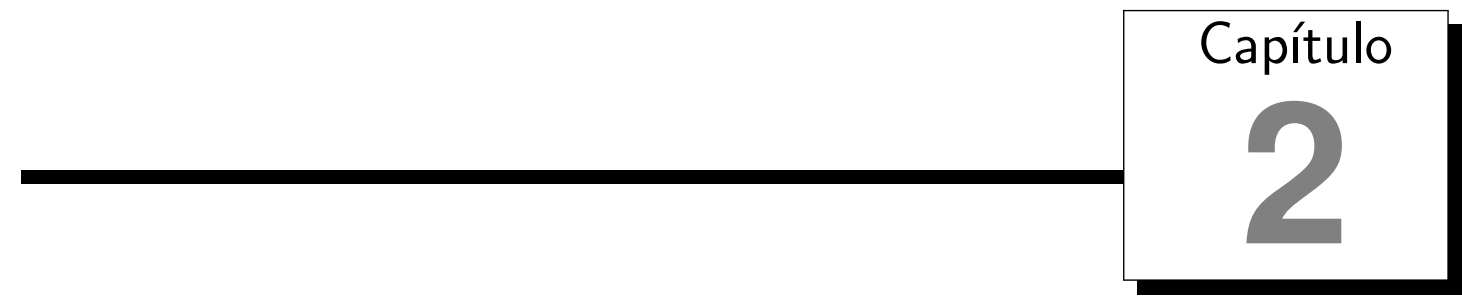

\section{Sistemas de Recomendação}

\subsection{Considerações Iniciais}

Um sistema de recomendação é uma tecnologia de filtragem de informação que pode ser utilizada para prever avaliações de itens e/ou gerar um ranking de itens que podem ser do interesse do usuário (Ricci et al., 2011). Em sites de comércio eletrônico, em geral, os itens são produtos recomendados para compra. Já em uma biblioteca digital eles podem ser textos ou outras mídias que sejam relevantes às preferências dos usuários (Burke, 2007). Os sistemas de recomendação surgiram como uma área independente de pesquisa em meados da década de 90 (Adomavicius e Tuzhilin, 2005b) e desde então são utilizados para recomendar filmes, músicas, livros, documentos, entre outros (Bobadilla et al., 2013).

De acordo com Ricci et al. (2011), existem várias razões pelas quais os prestadores de serviços podem querer explorar os sistemas de recomendação:

- Aumentar o número de itens vendidos - ocorre o aumento no número de itens vendidos porque os itens recomendados, provavelmente, atendem mais às necessidades e desejos dos usuários. Os usuários reconhecem isso após testarem muitas recomendações;

- Vender itens mais diversificados - sistemas de recomendações permitem que os usuários selecionem itens que podem ser difíceis de encontrar sem uma recomendação precisa. Eles não recomendam somente os itens mais populares, mas também itens pouco acessados, e sabem quais são os usuários adequados para fazer as recomendações;

- Aumentar a satisfação do usuário - um sistema de recomendação bem projetado e que faça recomendações precisas pode melhorar a experiência do usuário com o site. Quando o usuário encontra recomendações interessantes e relevantes, ele se torna um usuário satisfeito e que, em geral, aprecia o uso do sistema. Isso aumenta 
o uso do sistema e a probabilidade das recomendações serem aceitas;

- Aumentar a fidelidade do usuário - quanto mais o usuário interage com o sistema, mais o sistema aprende sobre seus interesses, mais as recomendações se relacionam com suas preferências e mais ele se torna fiel ao uso do sistema, retornando com mais frequência ao site em busca de itens de seu interesse;

- Melhorar o entendimento das necessidades e interesses do usuário - as preferências dos usuários, coletadas explícita ou implicitamente, transferem ao sistema conhecimento que pode ser utilizado para vários objetivos, como por exemplo para melhorar o gerenciamento de itens em estoque ou produção.

Existem vários sites de e-commerce que utilizam sistemas de recomendação em sua estrutura (Schafer et al., 2001). O exemplo mais citado na literatura é o site da Amazon ${ }^{1}$ (Linden et al., 2003). Quando um usuário clica em algum de seus produtos, além das informações do item selecionado, também são exibidas informações do tipo: "Clientes que compraram esse item também compraram", em que novos itens são recomendados. A Amazon também incentiva seus clientes a darem um feedback dos produtos comprados, atribuindo a eles uma nota de 0 ("odiei") a 5 ("amei"). Outro exemplo é o site da Drugstore $^{2}$, uma loja de varejo que tem características de farmácia, em que o usuário pode indicar suas preferências quando está comprando produtos de uma categoria, ou seja, se ele está comprando remédios para gripe ele pode indicar os sintomas que quer aliviar, a forma que quer o remédio (comprimido, cápsula ou outro), e a idade do paciente que vai tomar o remédio. Com todas essas informações o sistema retorna uma lista de produtos recomendados para as condições informadas. Além desses exemplos, a Netflix ${ }^{3}$, empresa de aluguel de DVDs e de filmes digitais, e muitos outros sites e empresas também utilizam recomendações em seus serviços. Na Tabela 2.1 pode-se observar alguns exemplos de sites que utilizam essa tecnologia, seguidos dos tipos de itens que são recomendados.

Os sistemas de recomendação são sistemas de processamento de informação que reúnem vários tipos de dados para construir recomendações. Nas formas tradicionais esses dados são relacionados aos itens que serão sugeridos e aos usuários que receberão as recomendações (Ricci et al., 2011). O interesse de um usuário em um item é medido, geralmente, por uma avaliação que pode ser obtida de forma explícita ou implícita. Na forma explícita, o usuário diz ao sistema qual é sua opinião sobre algum item (música, produto, artigo, etc.). De acordo com Schafer et al. (2007), as avaliações explícitas podem ser:

- Numéricas - quando são atribuídos valores numéricos aos produtos/serviços, como, por exemplo, as 5 estrelas no site da Amazon;

- Ordinais - quando o usuário é solicitado a selecionar um termo que melhor indique sua opinião sobre um item, como "Concordo, Sou neutro, Discordo";

\footnotetext{
$1_{\text {WWW . amazon.com }}$

$2_{\text {WWW. drugstore.com }}$

3 ww. netflix.com
} 
Tabela 2.1: Alguns sites populares que utilizam sistemas de recomendação (Adaptado de Lu et al. (2012)).

\begin{tabular}{|c|c|c|}
\hline Sites & Endereço & O que é recomendado \\
\hline Amazon & www.amazon.com & Livros/Outros produtos \\
\hline Facebook & www.facebook.com & Amigos \\
\hline WeFollow & www.wefollow.com & Amigos \\
\hline MovieLens & www.movielens.org & Filmes \\
\hline Nanocrowd & www.nanocrow.com & Filmes \\
\hline Jinni & www.jinni.com & Filmes \\
\hline Digg & www.digg.com & Notícias \\
\hline Zite & www.zite.com & Notícias \\
\hline Netflix & www.netflix.com & DVDs \\
\hline eHarmony & www.eharmony.com & Encontros \\
\hline Chemistry & www.chemistry.com & Encontros \\
\hline True.com & www.true.com & Encontros \\
\hline Perfectmatch & www.perfectmatch.com & Encontros \\
\hline CareerBuilder & www.careerbuilder.com & Empregos \\
\hline Monster & www.monster.com & Empregos \\
\hline Pandora & www.pandora.com & Músicas \\
\hline Mufin & www.mufin.com & Músicas \\
\hline StumbleUpon & www.stumbleupon.com & Sites da Web \\
\hline
\end{tabular}

- Binárias - quando o usuário simplesmente decide se um item é bom ou ruim;

- Unárias - foram popularizadas pelo Facebook em que os usuários podem marcar um interesse em uma postagem ou foto clicando em um botão "Curtir" (Sparling e Sen, 2011).

Na forma implícita, os interesses e as opiniões dos usuários são capturados enquanto ele navega no site, por meio de seu comportamento (Claypool et al., 2001). Por exemplo, se um usuário acessa um item, o sistema pode inferir que ele está de alguma forma interessado naquele item (Ricci et al., 2011). Além disso, o sistema pode levar em consideração o tempo de permanência do usuário em determinada página para medir seu interesse na mesma. Neste trabalho, é considerado se o usuário acessou ou não o item ou página da Web, ou seja, o valor da avaliação é binário, sendo igual a 1 caso o usuário acessou o item ou igual a 0 caso contrário.

De acordo com Adomavicius e Tuzhilin (2005b), na formulação mais comum, o problema de recomendação é reduzido ao problema de estimar avaliações para itens que ainda não foram vistos ou avaliados por um usuário. Uma vez estimadas as avaliações para itens ainda não avaliados, podem ser recomendados aos usuários itens com valores de avaliações mais altos. Formalmente, o problema de recomendação pode ser formulado como (Adomavicius e Tuzhilin, 2005b):

Seja $U$ o conjunto de todos os usuários e I o conjunto de todos os itens que podem ser recomendados. Seja $r$ a função de utilidade que mede o quão útil um item $i$ é para o usuário $u$, isto é, $r: U \times I \longrightarrow R$, em que $R$ é um conjunto 
ordenado, por exemplo, inteiros não negativos ou números reais dentro de um determinado intervalo. Então para cada usuário $u \in U$, o objetivo é encontrar um item $i^{\prime} \in I$ que maximiza a utilidade do usuário, isto é, que seja mais interessante a ele:

$$
\forall u \in U, i_{u}^{\prime}=\underset{i \in I}{\arg \max } r(u, i)
$$

A utilidade de um item indica o quanto um usuário se interessa por esse item, e como mencionado anteriormente, isso é medido pelas avaliações implícitas ou explícitas, ou seja, a utilidade de um item é geralmente representada por uma avaliação. De acordo com Desrosiers e Karypis (2011), tal formulação é conhecida como "best item" e é um dos dois problemas mais importantes associados com sistemas de recomendação. O segundo problema, o qual é abordado neste trabalho, é conhecido como "top- $N$ ", que é a tarefa de recomendar a um usuário $u_{a}$ uma lista $L\left(u_{a}\right)$ contendo $N$ itens que podem ser de interesse dele.

Os algoritmos utilizados por sistemas de recomendação podem ser classificados em categorias (Adomavicius e Tuzhilin, 2005a; Bobadilla et al., 2013; Pazzani, 1999; Ricci et al., 2011):

- Filtragem colaborativa - os itens (conteúdo, serviços, produtos, etc) recomendados ao usuário são itens que outros usuários, com preferências similares às dele, já escolheram anteriormente. Os métodos colaborativos primeiro encontram os pares mais próximos para cada usuário, ou seja, aqueles com gostos e preferências mais similares. E então, somente os itens que são os preferidos pelos pares são recomendados;

- Filtragem baseada em conteúdo - os itens recomendados ao usuário são similares aos itens que o usuário preferiu no passado, ou seja, somente os itens de alta similaridade com as preferências passadas do usuário são recomendados;

- Abordagens híbridas - esses métodos combinam os métodos colaborativo e baseado em conteúdo. A combinação pode ser feita de várias maneiras. Uma forma de combinação é implementar tais métodos separadamente e combinar os resultados para produzir as recomendações finais. Outra forma é utilizá-los em um único modelo de recomendação.

De acordo com Bobadilla et al. (2013); Pazzani (1999); Ricci et al. (2011) existe uma quarta categoria conhecida como Filtragem Demográfica, que é justificada no princípio que indivíduos com certos atributos em comum (sexo, idade, país, etc) terão preferências em comum. Para Adomavicius e Tuzhilin (2005b) esta quarta categoria é apenas uma extensão das técnicas tradicionais de filtragem colaborativa.

Na próxima seção as técnicas de filtragem utilizadas nos sistemas de recomendação são apresentadas com mais detalhes. 


\subsection{Técnicas Utilizadas em Sistemas de Recomendação}

Como mencionado na seção anterior, as técnicas utilizadas por algoritmos de sistemas de recomendação podem ser classificadas como: filtragem colaborativa, filtragem baseada em conteúdo e abordagens híbridas. Essas técnicas são descritas em detalhes nesta seção.

\subsubsection{Filtragem Colaborativa}

A filtragem colaborativa é uma técnica para fazer recomendações que encontra correlações entre usuários de um sistema de recomendação (Desrosiers e Karypis, 2011). Ela tenta prever as utilidades/avaliações e/ou gerar uma lista de itens para um usuário baseando-se nos itens previamente avaliados por outros usuários (Adomavicius e Tuzhilin, 2005b). A utilidade/avaliação $r(u, i)$ de um item $i$ para um usuário $u$ é estimada nas utilidades $r\left(u_{j}, i\right)$ atribuídas ao item $i$ por aqueles usuários $u_{j} \in U$ que são similares ao usuário $u$. A ideia dessa abordagem é que as pessoas não tomam decisões levando em consideração apenas as suas próprias experiências, mas também sofrem influência de experiências e conhecimentos dos membros do grupo no qual estão inseridas (Bobadilla et al., 2013).

Algoritmos de filtragem colaborativa podem ser agrupados em duas classes gerais (Breese et al., 1998; Desrosiers e Karypis, 2011; Bobadilla et al., 2013): baseados em memória (ou baseados em heurística) e baseados em modelo. Devido à popularidade, simplicidade, eficiência e habilidade de produzir recomendações precisas (Desrosiers e Karypis, 2011), neste trabalho é utilizado um algoritmo de filtragem colaborativa baseado em memória, que será descrito ainda nesta seção. Portanto, os algoritmos baseados em memória são apresentados com mais detalhes nesta seção, já os métodos baseados em modelo são descritos brevemente.

Algoritmos baseados em memória utilizam heurísticas que, por meio da coleção de itens já avaliados pelos usuários, fazem previsões de avaliações e/ou geram um conjunto de recomendações. De acordo com Bobadilla et al. (2013), o algoritmo kNN (k Nearest Neighbors) é o algoritmo de referência para o processo de filtragem colaborativa baseada em memória. O kNN é baseado nos seguintes passos:

(a) Usar alguma medida de similaridade para produzir o conjunto dos $k$ vizinhos mais próximos/similares ao usuário $u$ que já avaliaram um determinado item;

(b) Para calcular a avaliação não conhecida $r_{u, i}$ para o usuário $u$ do item $i$ é feita, geralmente, uma agregação das avaliações de outros usuários para o mesmo item,

$$
r_{u, i}=\underset{u^{\prime} \in \hat{U}}{\operatorname{aggr}} r_{u^{\prime}, i}
$$

em que $\hat{U}$ é o conjunto dos $k$ usuários formado no passo anterior; 
(c) Para obter as top- $N$ recomendações, são escolhidos os $N$ itens com as melhores avaliações calculadas no passo anterior.

Alguns exemplos da função de agregação utilizada no passo (b) são: média, soma ponderada e soma ponderada ajustada (desvio da média) (Adomavicius e Tuzhilin, 2005b). A média é o caso mais simples e é calculada como:

$$
r_{u, i}=\frac{1}{S} \sum_{u^{\prime} \in \hat{U}} r_{u^{\prime}, i}
$$

em que $S$ é o número de usuários mais similares ao usuário $u$.

Porém, a abordagem mais comum é a soma ponderada, calculada da seguinte forma:

$$
r_{u, i}=f \sum_{u^{\prime} \in \hat{U}} \operatorname{sim}\left(u, u^{\prime}\right) \times r_{u^{\prime}, i}
$$

em que $\operatorname{sim}\left(u, u^{\prime}\right)$ é a medida de similaridade entre os usuários $u$ e $u^{\prime}$ e é usada como um peso (quanto mais similares são os usuários, mais peso terá a avaliação $r_{u^{\prime}, i}$ na previsão de $\left.r_{u, i}\right)$. A terceira abordagem de agregação é a soma ponderada ajustada, que ao invés de utilizar os valores absolutos das avaliações, utiliza os desvios da avaliação média $\bar{r}_{u}$ do usuário:

$$
r_{u, i}=\bar{r}_{u}+f \sum_{u^{\prime} \in \hat{U}} \operatorname{sim}\left(u, u^{\prime}\right) \times\left(r_{u^{\prime}, i}-\bar{r}_{u^{\prime}}\right)
$$

O $f$ das duas equações representa um fator de normalização e é geralmente selecionado como $f=\frac{1}{\sum_{u^{\prime} \in \hat{U}}\left|\operatorname{sim}\left(u, u^{\prime}\right)\right|}$. A média das avaliações do usuário $u$ é definida como:

$$
\bar{r}_{u}=\left(1 /\left|I_{u}\right|\right) \sum_{i \in I_{u}} r_{u, i}
$$

em que $I_{u}=\left\{i \in I \mid r_{u, i} \neq \emptyset\right\}$, ou seja, $I_{u}$ é o conjunto dos itens que já foram avaliados.

Existem duas abordagens mais utilizadas para calcular a similaridade entre usuários em sistemas de recomendação colaborativos: abordagem baseada em correlação e abordagem baseada em cosseno (Adomavicius e Tuzhilin, 2005b; Bobadilla et al., 2013; Pazzani, 1999). Na abordagem baseada em correlação, o coeficiente de correlação de Pearson é usado para medir a similaridade:

$$
\operatorname{sim}\left(u, u^{\prime}\right)=\frac{\sum_{i \in I_{u u^{\prime}}}\left(r_{u, i}-\bar{r}_{u}\right)\left(r_{u^{\prime}, i}-\bar{r}_{u^{\prime}}\right)}{\sqrt{\sum_{i \in I_{u u^{\prime}}}\left(r_{u, i}-\bar{r}_{u}\right)^{2} \sum_{u \in U_{u u^{\prime}}}\left(r_{u^{\prime}, i}-\bar{r}_{u^{\prime}}\right)^{2}}}
$$

em que $I_{u, u^{\prime}}$ é o conjunto de todos os itens avaliados por ambos os usuários $u$ e $u^{\prime}, r_{u, i}$ é a avaliação que o usuário $u$ deu ao item $i$ e $\bar{r}_{u}$ é a média dos valores de avaliação dados pelo usuário (ver Equação 2.6).

Na abordagem baseada em cosseno, os dois usuários $u$ e $u^{\prime}$ são tratados como dois vetores, portanto a similaridade entre eles pode ser medida por meio do cálculo do cosseno 
do ângulo entre eles:

$$
\operatorname{sim}\left(u, u^{\prime}\right)=\cos \left(\vec{u}, \overrightarrow{u^{\prime}}\right)=\frac{\vec{u} \cdot \overrightarrow{u^{\prime}}}{\|\vec{u}\| *\left\|\overrightarrow{u^{\prime}}\right\|}
$$

em que $\vec{u} \cdot \overrightarrow{u^{\prime}}$ é o produto escalar entre os vetores $\vec{u}$ e $\overrightarrow{u^{\prime}}$

Um exemplo dado por Pazzani (1999) é apresentado na Tabela 2.2, na qual são visualizadas as avaliações de 5 restaurantes feitas por 5 usuários. O símbolo "+" indica que o usuário gostou do restaurante e o símbolo "-" indica que ele não gostou. Para prever a avaliação que o usuário Jill dará para o restaurante Dolce, podem ser executados os passos do algoritmo kNN. O primeiro passo é usar uma medida de similaridade para encontrar o conjunto de usuários mais similares a Jill. De acordo com Pazzani (1999), considerando "+" como "+1" e "-" como "-1" e calculando o coeficiente de correlação Pearson, tem-se os valores: entre Jill e Karen igual a 1, entre Jill e Lynn igual a -0,577, entre Jill e Chris igual a 0,577 e entre Jill e Mike igual a -0,577. O segundo passo é calcular o valor desconhecido da avaliação $r_{(J i l l, \text { Dolce })}$, utilizando uma das funções de agregação apresentadas e os $k$ usuários mais similares a Jill. Se o número de vizinhos mais próximos fosse igual a 1 ficaria fácil prever a avaliação, já que o usuário mais similar a Jill é Karen que avaliou o restaurante Dolce como "+", porém, o número $k$ de vizinhos mais próximos pode ser qualquer valor maior ou igual a 1 .

Tabela 2.2: Avaliações dadas por cinco usuários a cinco restaurantes (Pazzani, 1999).

\begin{tabular}{|c|c|c|c|c|c|}
\hline & Karen & Lynn & Chris & Mike & Jill \\
\hline Kitima & - & + & + & + & - \\
\hline Marco Polo & + & + & + & + & + \\
\hline Spiga & + & - & + & - & + \\
\hline Thai Touch & - & + & - & + & - \\
\hline Dolce & + & - & + & - & $?$ \\
\hline
\end{tabular}

Esses passos do exemplo anterior são característicos da versão mais tradicional do algoritmo kNN conhecida como "user-to-user" ou "baseada no usuário", em que a similaridade é calculada entre os usuários. Porém, existe uma versão desse algoritmo conhecida como "item-to-item" ou "baseada no item" que calcula a similaridade entre os itens e não entre os usuários. Esse método é o método utilizado pelo sistema de recomendação da Amazon (Linden et al., 2003). Seus passos são (Bobadilla et al., 2013):

(a) Determinar $k$ itens vizinhos para cada item da base;

(b) Para cada item $i$ não avaliado pelo usuário $u$, calcular as previsões baseadas nas avaliações que $u$ fez aos $k$ vizinhos de $i$;

(c) Selecionar as top- $N$ recomendações para o usuário $u$.

Portanto a filtragem colaborativa pode também ser utilizada para encontrar similaridades entre os objetos avaliados. Retomando o exemplo das avaliações dos restaurantes, 
existe uma similaridade perfeita entre as avaliações dos restaurantes Dolce e Spiga. É possível, dessa forma, prever que como Jill gosta de Spiga ele também gostaria de Dolce. O cálculo dessas previsões pode ser feito encontrando as similaridades entre os restaurantes (utilizando Pearson ou Cosseno) e utilizando uma das funções de agregação das avaliações dos outros restaurantes.

Foi utilizado neste trabalho o algoritmo de filtragem colaborativa baseada no item (IBCF) (Deshpande e Karypis, 2004), tanto como "baseline", quanto nos próprios algoritmos de recomendação sensíveis ao contexto. Para uma melhor compreensão do seu funcionamento, seguem alguns detalhes.

Seja $m$ o número de usuários do conjunto $U=\left\{u_{1}, u_{2}, \ldots, u_{m}\right\}$ e $n$ o número de itens que podem ser recomendados do conjunto $I=\left\{i_{1}, i_{2}, \ldots, i_{n}\right\}$, um modelo $M$ de filtragem colaborativa baseada no item é uma matriz que representa as similaridades entre todos os pares de itens, de acordo com uma métrica de similaridade. Na Tabela 2.3 é ilustrada a matriz de similaridade, na qual cada item $i \in I$ é um item acessado, por exemplo, uma página da Web.

Tabela 2.3: Matriz de similaridade.

\begin{tabular}{|c|c|c|c|c|}
\hline & $i_{1}$ & $i_{2}$ & $\cdots$ & $i_{n}$ \\
\hline$i_{1}$ & 1 & $\operatorname{sim}\left(i_{1}, i_{2}\right)$ & $\cdots$ & $\operatorname{sim}\left(i_{1}, i_{n}\right)$ \\
\hline$i_{2}$ & $\operatorname{sim}\left(i_{2}, i_{1}\right)$ & 1 & $\cdots$ & $\operatorname{sim}\left(i_{2}, i_{n}\right)$ \\
\hline$\vdots$ & $\vdots$ & $\ddots$ & 1 & $\vdots$ \\
\hline$i_{n}$ & $\operatorname{sim}\left(i_{n}, i_{1}\right)$ & $\operatorname{sim}\left(i_{n}, i_{2}\right)$ & $\cdots$ & 1 \\
\hline
\end{tabular}

Para calcular a similaridade $\operatorname{sim}\left(i_{1}, i_{2}\right)$ entre os itens $i_{1}$ e $i_{2}$, neste trabalho, são isoladas as avaliações que foram dadas pelos mesmos usuários aos dois itens, e então, aplica-se como métrica de similaridade entre ambos os vetores de avaliações a medida do ângulo do cosseno, calculada como:

$$
\operatorname{sim}\left(i_{1}, i_{2}\right)=\cos \left(\overrightarrow{i_{1}}, \overrightarrow{i_{2}}\right)=\frac{\overrightarrow{i_{1}} \cdot \overrightarrow{i_{2}}}{\left\|\overrightarrow{i_{1}}\right\| *\left\|\overrightarrow{i_{2}}\right\|}
$$

em que $\overrightarrow{i_{1}}$ e $\overrightarrow{i_{2}}$ são vetores de avaliações com o número de posições correspondente ao número de usuários do conjunto $U$. O operador "." denota o produto escalar entre os dois vetores. Como já mencionado na Seção 2.1, neste trabalho são consideradas avaliações implícitas e seus valores são binários: o valor 1 significa que o usuário acessou o item, enquanto que o valor 0 significa que o usuário não acessou o item.

Dado um usuário ativo $u_{a}$ e seu conjunto de itens observáveis $O \subseteq I$, as $N$ recomendações são geradas da seguinte forma: o conjunto de itens candidatos a recomendação $R$ é selecionado considerando $i \notin O$. Então, para cada item candidato $r \in R$, o score de recomendação é calculado como:

$$
\operatorname{score}\left(u_{a}, O, r\right)=\frac{\sum_{i \in K_{r} \cap O} \operatorname{sim}(r, i)}{\sum_{i \in K_{r}} \operatorname{sim}(r, i)},
$$


em que $K_{r}$ é o conjunto com os $k$ itens mais similares ao item candidato $r$. Os $N$ itens candidatos com maiores valores de score são recomendados ao usuário $u_{a}$.

Os algoritmos baseados em modelo, de acordo com Adomavicius e Tuzhilin (2005b), usam a coleção de todas as avaliações para construir um modelo. Eles utilizam técnicas de estatística e aprendizado de máquina para aprenderem um modelo a partir dos dados disponíveis e poderem, desta forma, calcular as previsões das avaliações. Os modelos mais conhecidos são (Bobadilla et al., 2013): classificadores bayesianos, redes neurais, sistemas fuzzy e algoritmos genéticos.

Embora os sistemas de recomendação que utilizam técnicas de filtragem colaborativa sejam precisos, eles apresentam um problema conhecido como "cold-start". Esse problema ocorre quando não é possível fazer recomendações confiáveis devido a uma falta inicial de avaliações ou informações necessárias (Bobadilla et al., 2013). O problema cold-start pode ser de três tipos:

- Problema da nova comunidade - ao construir um sistema de recomendação, existe a dificuldade de obter dados e avaliações em quantidades suficientes para que as recomendações sejam feitas de forma confiável;

- Problema do novo item - novos itens são inseridos regularmente nos sistemas de recomendação. Esses itens, geralmente, não apresentam avaliações iniciais e provavelmente não serão recomendados, já que sistemas colaborativos dependem das avaliações/preferências dos usuários para fazer recomendações;

- Problema do novo usuário - para fazer recomendações confiáveis o sistema deve saber quais são as preferências dos usuários, o que, nos sistemas colaborativos, é feito por meio das avaliações. Uma vez que os novos usuários no sistema ainda não forneceram avaliações, torna-se uma tarefa difícil para o sistema recomendar itens de forma personalizada.

Outro problema enfrentado pelos sistemas colaborativos é a esparsidade, pois o número de avaliações disponíveis é geralmente muito pequeno se comparado ao número de avaliações que precisam ser previstas. O sucesso do sistema depende da quantidade de avaliações (Adomavicius e Tuzhilin, 2005b). Por exemplo, em um sistema de recomendação de filmes, pode haver muitos filmes que foram avaliados apenas por poucas pessoas e esses filmes seriam recomendados muito raramente, mesmo se as avaliações fossem boas.

\subsubsection{Filtragem Baseada em Conteúdo}

A filtragem baseada em conteúdo faz recomendações baseadas nas escolhas que os usuários fizeram no passado (Bobadilla et al., 2013). Ela utiliza o conteúdo dos itens a serem recomendados e dos itens já avaliados positivamente para gerar as recomendações. Formalmente, neste método de recomendação a utilidade/avaliação $r(u, i)$ do item $i$ para o usuário $u$ é calculada baseada nas utilidades $r\left(u, i_{j}\right)$ atribuídas pelo usuário $u$ para os itens $i_{j} \in I$ que são similares ao item $i$ (Adomavicius e Tuzhilin, 2005b). Como já 
mencionado, a utilidade de um item indica o quanto um usuário se interessa por esse item e pode ser representada pelas avaliações implícitas ou explícitas.

A abordagem baseada em conteúdo tem suas raízes na comunidade de recuperação de informação (Balabanovic e Shoham, 1997; Adomavicius e Tuzhilin, 2005b). Ela é executada em três passos (Bobadilla et al., 2013):

(a) Extrair os atributos dos itens para recomendação, construindo os perfis;

(b) Comparar os atributos dos itens com as preferências do usuário;

(c) Recomendar itens com características que atendam aos interesses do usuário.

Um sistema de recomendação é considerado baseado em conteúdo se as recomendações são feitas considerando apenas o perfil do usuário, que foi construído analisando o conteúdo dos itens que o usuário avaliou anteriormente (Balabanovic e Shoham, 1997). Eles são desenvolvidos principalmente para recomendar itens baseados em texto, portanto o conteúdo nesses sistemas é geralmente descrito com atributos/palavras chaves (Adomavicius e Tuzhilin, 2005b). Como as recomendações são feitas comparando-se o conteúdo do item e o perfil do usuário, é necessário que uma estrutura seja construída para ambos. O perfil de um item Conteudo( $i)$ é o conjunto de palavras-chave que caracterizam o item $i$. Normalmente alguma medida é utilizada para atribuir pesos a essas palavras, indicando seus graus de importância dentro de um determinado item. Uma possibilidade é utilizar as frequências das palavras-chave dentro do conteúdo textual do item. A frequência $f_{p, i}$ de uma palavra chave $p$ em um item $i$ é o número de vezes que ela aparece no conteúdo desse item. Entretanto, palavras que aparecem em muitos itens não são úteis para distinguir um item relevante de um irrelevante. Portanto, uma das medidas mais utilizadas nesse contexto é a TF-IDF (Term Frequency - Inverse Document Frequency), que pondera a frequência dos termos, de tal forma que termos que aparecem na maioria dos itens tenham um peso de representação menor (Robertson, 2004). Essa medida, TF-IDF, é definida como:

$$
T F-I D F_{p, i}=T F_{p, i} \times I D F_{i}
$$

em que $T F_{p, i}$ é a frequência normalizada da palavra chave. Essa normalização é feita da seguinte forma:

$$
T F_{p, i}=\frac{f_{p, i}}{\max _{z} f_{p_{z}, i}},
$$

em que o máximo é calculado sobre todas as frequências $f_{p_{z}, i}$ de todas as palavras chaves $p_{z}$ que aparecem no documento $i . I D F_{i}$ é a medida da frequência inversa do item e é calculada como:

$$
I D F_{i}=\log \frac{n}{n_{p}}
$$

sendo $n_{p}$ o número de itens em que $p$ aparece e $n$ o número total de itens. Dessa forma, o peso da palavra chave $p$ no conteúdo do item $i$ é o próprio valor $T F-I D F_{p, i}$. Com os pesos das palavras chaves calculados, o conteúdo do item $i$ é definido como 
Conteudo $(i)=\left(w_{p_{1}, i}, \ldots, w_{p_{z}, i}\right)$. O perfil do usuário, ConteudoPerfilUsuario $(u)$, também pode ser definido como um vetor de pesos no qual cada peso, assim como no perfil dos itens, representa a relevância das palavras chaves para o usuário. Esse perfil pode ser obtido analisando o conteúdo dos itens já avaliados ou vistos pelo usuário e utilizando técnicas de recuperação de informação para extrair as palavras chaves e calcular seus pesos. A função $r(u, i)$ é definida como $r(u, i)=\operatorname{score}($ ConteudoPerfilUsuario $(u)$, Conteudo $(i))$ (Adomavicius e Tuzhilin, 2005b) e seu cálculo pode ser feito utilizando alguma medida de score da área de recuperação de informação, como a medida de similaridade cosseno, já definida anteriormente na Seção 2.2.1, Equação 2.8.

Métodos de filtragem baseados em conteúdo possuem alguns problemas, sendo que os dois principais são (Bobadilla et al., 2013; Balabanovic e Shoham, 1997; Adomavicius e Tuzhilin, 2005b; Pazzani, 1999):

- Análise limitada do conteúdo: refere-se à dificuldade em extrair informações confiáveis de forma automática de vários conteúdos como imagens, vídeos, áudios, textos, etc;

- Superespecialização: como o sistema recomenda itens analisando o perfil do usuário, este fica restrito a ver itens similares aos que já foram avaliados/vistos anteriormente.

\subsubsection{Abordagens Híbridas}

Como ambas, filtragem colaborativa e filtragem baseada em conteúdo, possuem limitações, elas podem ser combinadas resultando em abordagens híbridas que evitam tais limitações. De acordo com Adomavicius e Tuzhilin (2005b), essas técnicas podem ser combinadas de diversas formas: (a) métodos que calculam as recomendações utilizando as técnicas de filtragem baseada em conteúdo e filtragem colaborativa separadamente e posteriormente as combinam; (b) métodos que incorporam as características da filtragem baseada em conteúdo dentro da filtragem colaborativa; (c) métodos que constroem um modelo unificado com características de ambas as técnicas e, por fim, (d) métodos que incorporam características da filtragem colaborativa dentro de uma abordagem baseada em conteúdo. Essas possibilidades são ilustradas na Figura 2.1.

Como é possível observar, as abordagens híbridas, assim como as abordagens de filtragem colaborativa e baseadas em conteúdo, quando nas formas tradicionais, focam somente nas entidades, item e usuário, para construir o modelo de recomendação (Schafer et al., 2001; Ricci et al., 2011). Esse processo de recomendação é conhecido como bidimensional, pois considera somente duas dimensões Usuário $\times$ Item para gerar as recomendações. Entretanto, em muitas aplicações também é importante incorporar informação contextual dentro do processo de recomendação (Adomavicius et al., 2005; Domingues et al., 2013). Por exemplo, um pacote de viagem recomendado no verão pode ser diferente do pacote recomendado no inverno; uma pessoa pode preferir ler notícias de economia e política 
(a)

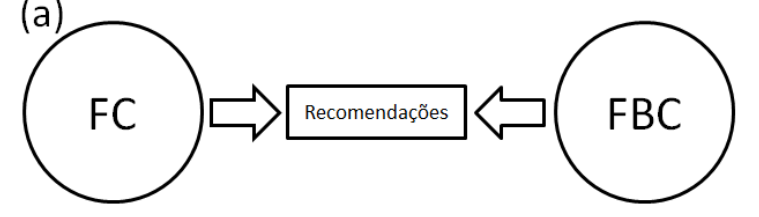

(c)

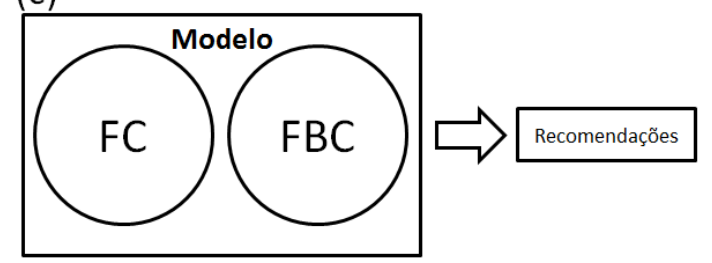

(b)

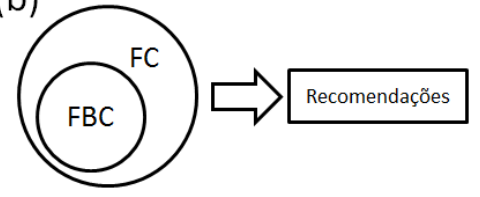

(d)

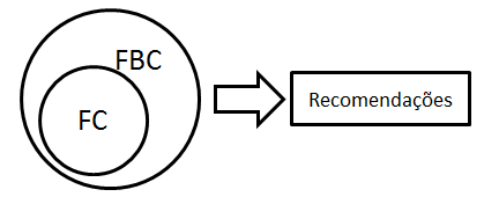

Figura 2.1: Formas de combinar filtragem colaborativa (FC) com filtragem baseada em conteúdo (FBC) (Adaptado de Bobadilla et al. (2013)).

durante a semana, mas no final de semana pode querer ler notícias de esportes ou celebridades; o filme indicado a uma pessoa pode depender do período do dia, talvez à noite a preferência seja filmes de terror, enquanto que durante o dia seja comédia. Os sistemas de recomendação que utilizam esse tipo de informação para fazer as recomendações são conhecidos como sistemas de recomendação sensíveis ao contexto.

\subsection{Sistemas de Recomendação Sensíveis ao Contexto}

Os sistemas de recomendação sensíveis ao contexto são sistemas que fazem recomendações considerando também informações de contexto. A importância da informação contextual tem sido reconhecida por pesquisadores e profissionais em muitas disciplinas, como personalização de sites de comércio virtual, recuperação de informação e computação móvel (Adomavicius e Tuzhilin, 2011). Embora uma grande parte das pesquisas em contexto esteja voltada para a área de sistemas de recomendação e tais informações sejam importantes para recomendar itens relevantes aos usuários em certas circunstâncias, ainda assim, faltam métodos automáticos para adquirir informações contextuais para esses sistemas.

Os sistemas de recomendação sensíveis ao contexto, de acordo com Bobadilla et al. (2013), fazem parte de uma terceira geração na evolução dos sistemas de recomendação. Segundo os autores, nessa evolução existe uma tendência de se utilizar mais e diferentes tipos de dados para fazer as recomendações. A evolução dos sistemas de recomendação segue em paralelo com a evolução da Web, e pode ser dividida em três fases:

- Origem da Web - em que os sistemas de recomendação utilizavam somente avaliações, informações de conteúdo e informações demográficas dos usuários;

- Web 2.0 - em que, além das informações já utilizadas, os sistemas de recomendação passaram a coletar e usar informações sociais, como amigos, seguidores, seguidos, etc; 
- Web 3.0 - fase em que informações contextuais, originadas de uma variedade de dispositivos e sensores, são empregadas juntamente com as informações já utilizadas para fazer recomendações.

Os sistemas de recomendação sensíveis ao contexto modelam e preveem os gostos e as preferências dos usuários incorporando informação contextual disponível dentro do processo de recomendação. De acordo com Adomavicius e Tuzhilin (2011), os gostos e preferências dos usuários são geralmente expressos como avaliações e modelados em função dos itens, usuários e contexto, ou seja, as avaliações são definidas com a função de avaliação:

\section{$R:$ Usuário $\times$ Item $\times$ Contexto $\longrightarrow$ Avaliação}

em que Usuário representa o domínio dos usuários, Item é o domínio dos itens, Avaliação representa o domínio das avaliações e Contexto é a informação contextual associada à aplicação.

Contexto é um conceito que pode assumir diferentes definições dependendo da área em que está inserido. A definição mais utilizada foi sugerida por Dey (2001): "Contexto é qualquer informação que pode ser usada para caracterizar a situação de uma entidade. Uma entidade é uma pessoa, lugar, ou objeto que é considerado relevante para a interação entre um usuário e uma aplicação, incluindo o próprio usuário e as próprias aplicações". Ainda de acordo com Dey (2001), "um sistema é sensível ao contexto se ele usa contexto para fornecer informações relevantes e/ou serviços para o usuário, onde relevância depende da tarefa do usuário".

Sistemas de recomendação sensíveis ao contexto podem ser sistemas multidimensionais. De acordo com Adomavicius et al. (2005), esses sistemas são extensões dos sistemas de recomendação tradicionais bi-dimensionais e seguem o modelo de dados multidimensionais usados por data warehouses e aplicações $\mathrm{OLAP}^{4}$. Mais formalmente, seja $D_{1}, D_{2}, \ldots D_{n}$ dimensões, cada dimensão $D_{i}$ representa um conjunto de valores de atributos. O espaço de recomendação para essas dimensões é definido como um produto cartesiano $S=D_{1} \times$ $D_{2} \times \ldots \times D_{n}$. A função de avaliação é definida sobre o espaço de recomendação como:

$$
R: D_{1} \times \ldots \times D_{n} \longrightarrow \text { Avaliações }
$$

em que Avaliações é o domínio das avaliações que representa o conjunto ordenado de todos os possíveis valores de avaliação.

Um exemplo apresentado por Adomavicius et al. (2005) é uma aplicação de recomendação de filmes, que tem como espaço de recomendação: Filme $\times$ Pessoa $\times$ Lugar $\times$ Tempo $\times$ Companhia, em que:

- Filme - dimensão que representa todos os filmes que podem ser recomendados em uma aplicação e é definida pelos atributos Filme (FilmeID, Nome, Estúdio, Diretor, Ano, Gênero, Atores Principais);

\footnotetext{
${ }^{4}$ On-line Analytical Processing
} 
- Pessoa - dimensão que representa todas as pessoas para as quais os filmes serão recomendados e é definida pelos atributos Pessoa (UsuárioID, Nome, Endereço, Idade, Ocupação);

- Lugar - dimensão que representa os lugares onde o filme pode ser visto. Seus atributos podem ser uma lista de cinemas e as opções para ser assistido em casa como TV, videocassete e DVD;

- Tempo - dimensão que representa o tempo que o filme pode ser ou foi visto; é definido pelos atributos Tempo (HoraDoDia, DiaDaSemana, Mês, Ano);

- Companhia - dimensão que representa uma pessoa ou um grupo de pessoas com quem a pessoa pode ver o filme. Consiste de um único atributo que pode ter valores como "sozinho", "amigos", "namorada/namorado", "família", "colegas de trabalho" e outros.

Neste exemplo, a função de avaliação no espaço de recomendação Filme $\times$ Pessoa $\times$ Lugar $\times$ Tempo $\times$ Companhia que especifica o quanto a pessoa $p \in$ Pessoa gostou do filme $f \in$ Filme é $R(f, p, l, t, c)$, ou seja, não depende apenas da pessoa e do filme, como seria em um sistema de recomendação tradicional, mas também depende do lugar $l \in$ Lugar, do tempo $t \in$ Tempo e da companhia $c \in$ Companhia.

Esses sistemas, além de serem classificados como filtragem baseada em conteúdo, filtragem colaborativa e/ou abordagens híbridas, podem também ser categorizados de acordo com a forma em que a informação contextual é utilizada, ou seja, em qual estágio do processo de recomendação ela é aplicada. Na próxima seção essas categorias são apresentadas.

\subsubsection{Classificação dos Sistemas de Recomendação Sensíveis ao Contexto}

Como mencionado anteriormente, um sistema de recomendação tradicional ou bidimensional pode ser descrito, de forma geral, como uma função que recebe como entrada dados das preferências dos usuários e gera como saída uma lista de recomendações. Essas preferências podem ser da forma 〈usuário, item, avaliação $\rangle$. Já para os sistemas de recomendação baseados em contexto, as preferências são da forma 〈usuário, item, contexto, avaliação $\rangle$, pois não consideram somente o quanto o usuário gostou de um determinado item, mas também em qual contexto ele gostou. De acordo com Adomavicius e Tuzhilin (2011), a informação contextual pode ser aplicada em vários estágios do processo de recomendação, e de acordo com esse critério, os sistemas podem ser divididos em três categorias, como observado na Figura 2.2: i) pré-filtragem contextual, ii) modelagem contextual e iii) pós-filtragem contextual.

Na pré-filtragem contextual a informação contextual é usada para selecionar o conjunto de dados que será utilizado para o aprendizado dos modelos de recomendação. As recomendações podem ser feitas utilizando um sistema de recomendação tradicional e tendo como entrada os dados selecionados. Uma vantagem dessa abordagem é que ela 


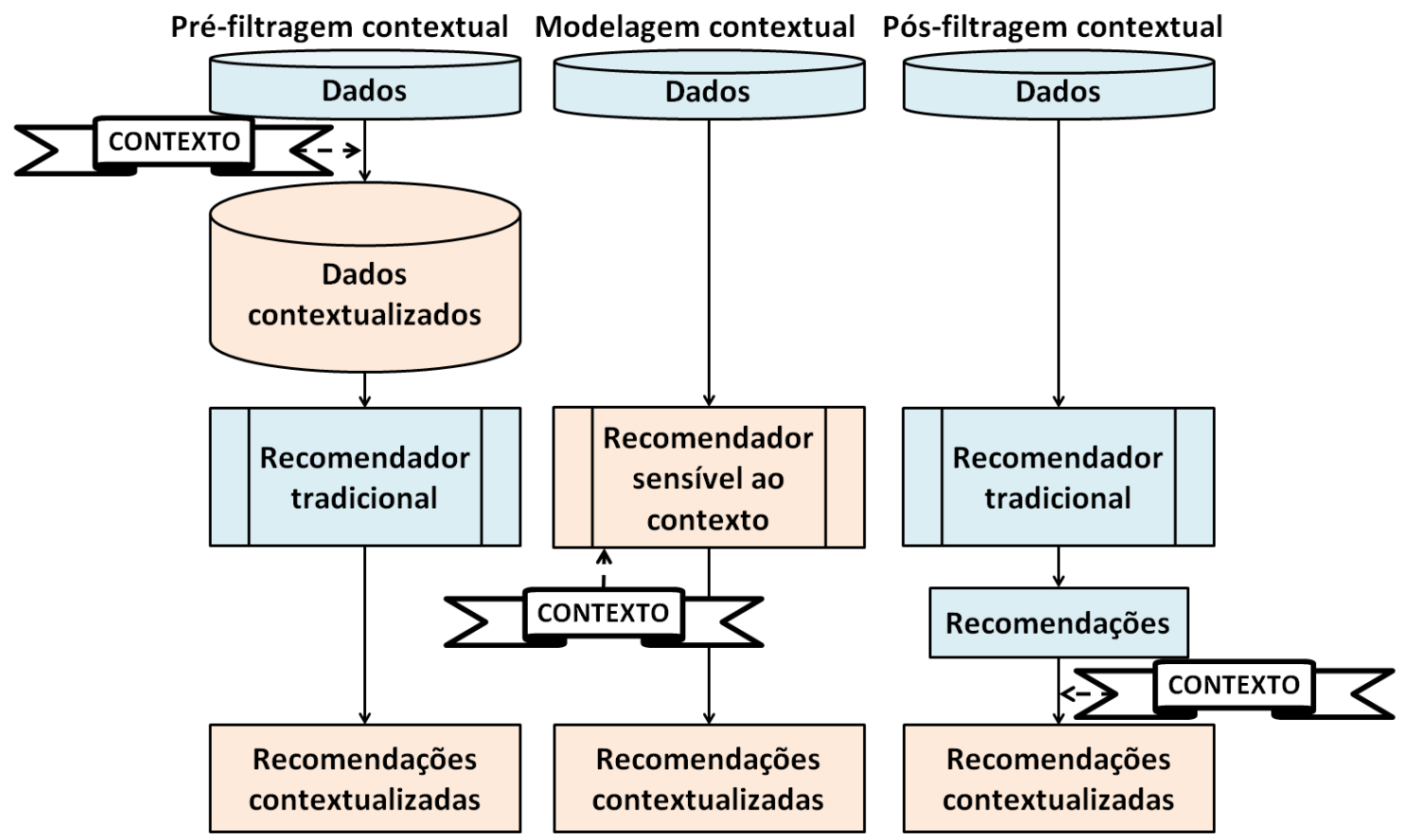

Figura 2.2: Categorias de sistemas de recomendação sensíveis ao contexto (Adaptado de Panniello e Gorgoglione (2012)).

permite a implantação de qualquer uma das várias técnicas tradicionais de sistemas de recomendação já propostas. Por exemplo, se uma pessoa quer ver um filme no sábado, um sistema de recomendação sensível ao contexto de filmes pode utilizar, para gerar o conjunto de recomendações, uma das técnicas tradicionais e, como dados de entrada, avaliações feitas apenas aos sábados (Adomavicius e Tuzhilin, 2011).

Adomavicius et al. (2005) propuseram uma "abordagem baseada em redução" que reduz o espaço multidimensional dos sistemas de recomendação baseados em contexto em um espaço tradicional bidimensional Usuário $\times$ Item:

"Seja $R_{\text {Usuário } D \text { Item }}^{D} U \times I \longrightarrow$ Avaliações uma função para estimar avaliações que, dadas as avaliações existentes $D$, pode calcular uma previsão para qualquer avaliação. Então, uma função tridimensional de previsão de avaliações aceitando o contexto de tempo pode ser definida de forma similar como $R_{\text {Usuário } \times \text { Item } \times \text { Tempo }}^{D}: U \times I \times T \longrightarrow$ Avaliações. Ela pode ser expressa por meio de uma função bidimensional de previsão de várias formas, sendo que uma dessas formas é:

$\forall(u, i, t) \in U \times I \times T, R_{\text {Usuário } \times \text { Item } \times \text { Tempo }}^{D}(u, i, t)=R_{\text {Usuário } \times \text { Item }}^{D[\text { Tempário,Item,Avaliação })}(u, i)$.

em que $[$ Tempo $=t]$ denota um pré-filtro contextual simples, e $D[$ Tempo $=$ t] (Usuário, Item, Avaliação) denota um conjunto de avaliações $D$ selecionando somente os registros nos quais a dimensão $T$ tem valor $t$ e guardando somente os valores para as dimensões Usuário e Item, assim como o próprio valor da avaliação". 
De acordo com Adomavicius et al. (2005), a abordagem baseada em redução pode ser melhor que uma abordagem tradicional em algumas situações, enquanto que em outras situações isso pode não ocorrer. Ainda de acordo com Adomavicius et al. (2005), talvez seja melhor usar a abordagem baseada em redução para recomendar filmes no cinema em finais de semana e utilizar filtragem colaborativa tradicional para recomendar filmes a serem vistos em casa. Isso porque a abordagem baseada em redução, por um lado, constrói um modelo de recomendação para um segmento em particular, mas por outro lado, faz as recomendações baseando-se em um número menor de acessos limitado a esse segmento em particular (Adomavicius et al., 2005). Os dados considerados podem ser mais relevantes, porém eles podem totalizar um número muito pequeno, o que causa o efeito de esparsidade. Como solução a esse problema, Adomavicius et al. (2005) também propuseram uma combinação da abordagem baseada em redução com abordagens de filtragem colaborativa tradicionais. Tal combinação é referida neste trabalho como cReduction.

Para combinar os dois métodos é necessário utilizar alguma medida de desempenho para determinar qual método é melhor que outro em vários segmentos. Existem várias medidas de desempenho que são utilizadas para avaliar o desempenho de sistemas de recomendação, tais como: Erro médio absoluto (MAE), Erro médio quadrático (MSE), precisão, revocação, medida F1, etc. Neste trabalho foi utilizada a medida F1 como medida de desempenho na combinação da abordagem baseada em redução com o algoritmo de filtragem colaborativa baseada no item (IBCF). A abordagem cReduction consiste em duas fases:

1. Utilizando o conjunto de treino, um método de recomendação é executado para cada segmento para determinar em qual segmento o desempenho é melhor que o modelo de recomendação tradicional (que utiliza apenas os dados de usuários e itens);

2. Considerando o contexto da sessão ativa, é escolhido o melhor modelo contextual para fazer a recomendação, ou seja, o modelo que apresenta o maior valor da medida F1.

Na categoria de pós-filtragem contextual a informação contextual é usada após a construção de um modelo de recomendação tradicional para filtrar ou reordenar as recomendações, ou seja, o contexto é inicialmente ignorado. Quando as top- $N$ recomendações são geradas, então a abordagem de pós-filtragem contextual ajusta a lista de recomendações obtida para cada usuário utilizando a informação contextual. De acordo com Adomavicius e Tuzhilin (2011), os ajustes na lista de recomendações podem ser feitos:

- Filtrando as recomendações que são irrelevantes em um determinado contexto; ou - Ajustando o ranking das recomendações na lista baseando-se em um certo contexto.

Por exemplo, se uma pessoa quer ver um filme no domingo e nos domingos ela só assiste a filmes de terror, então o sistema pode considerar apenas as recomendações de filmes de terror para exibir ao usuário. 
Panniello e Gorgoglione (2012) propuseram as abordagens de pós-filtragem contextual conhecidas como Weight PoF e Filter PoF. Ambas analisam os dados para um determinado usuário em um contexto específico calculando a probabilidade de o usuário escolher um dado item em tal contexto. Depois disso as recomendações obtidas utilizando uma abordagem tradicional são contextualizadas utilizando as probabilidades calculadas.

A probabilidade contextual $P_{C}(u, i)$, na qual o usuário $u$ acessa o item $i$ no contexto $C$, é calculada como o número de vizinhos (usuários similares a $u$ ) que acessaram o mesmo item no mesmo contexto, dividida pelo número total de vizinhos. As abordagens Weight PoF e Filter PoF diferem no jeito que as recomendações são contextualizadas. Em particular, na abordagem Weight PoF cada avaliação é multiplicada pela probabilidade $P_{C}(u, i)$ :

$$
\operatorname{Avaliacao}_{C}(u, i)=\operatorname{Avaliacao}(u, i) \times P_{C}(u, i)
$$

Enquanto que a abordagem Filter PoF filtra as avaliações utilizando um valor de limiar de $P_{C}(u, i)$ :

$$
\operatorname{Avaliacao}_{C}(u, i)= \begin{cases}\operatorname{Avaliacao}(u, i) & \text { if } P_{C}(u, i) \geq \mathrm{P}^{*} \\ 0 & \text { if } P_{C}(u, i)<\mathrm{P}^{*}\end{cases}
$$

Panniello e Gorgoglione (2012) variaram o limiar P* de 0,9 a 0,1 e obtiveram melhores resultados para $\mathrm{P}^{*}=0,1$.

Na categoria de modelagem contextual, o contexto é usado nos modelos de recomendação, ou seja, a informação contextual faz parte do modelo juntamente com os dados de usuários e itens. Enquanto nas abordagens de pré-filtragem e pós-filtragem contextual podem ser utilizadas funções bidimensionais tradicionais, a abordagem de modelagem de contexto utiliza, geralmente, funções de recomendação verdadeiramente multidimensionais. Essas funções podem representar modelos preditivos, como árvores de decisão, regressão, modelos probabilísticos ou outros, ou podem representar cálculos heurísticos que incorporam informação contextual.

Domingues et al. (2013) propuseram uma abordagem que usa o atributo de contexto como um item virtual, ou seja, esse atributo é tratado como um item comum para construir o modelo de recomendação. Assim sendo, tal abordagem chamada DaVI (Dimensions as Virtual Item), permite o uso de algoritmos de recomendação tradicionais.

Formalmente, sejam os conjuntos já mencionados de usuários $U=\left\{u_{1}, u_{2}, \ldots, u_{m}\right\}$ e de itens $I=\left\{i_{1}, i_{2}, \ldots, i_{n}\right\}$, existem outras dimensões, como por exemplo, informações contextuais, $D=\left\{D_{1}, D_{2}, \ldots, D_{t}\right\}$, em que cada dimensão $D$ compreende um conjunto de valores, isto é, $D=\left\{d_{1}, d_{2}, \ldots, d f\right\}$. Seja $j$ o número de sessões multidimensionais do site da Web $S^{\prime}=\left\{s_{1}^{\prime}, s_{2}^{\prime}, \ldots, s_{j}^{\prime}\right\}$. Cada sessão $s^{\prime}$ é uma tupla definida por um usuário $u \in U$, um conjunto de itens acessados $I_{s^{\prime}} \subset I$ e um conjunto $D_{s^{\prime}} \subseteq D_{1} \cup D_{2} \cup \ldots \cup D_{t}$ contendo todos os valores das dimensões associados com a sessão $s^{\prime}$, isto é, $s^{\prime}=\left\langle u, I_{s^{\prime}}, D_{s^{\prime}}\right\rangle$.

A abordagem $D a V I$ consiste em converter cada sessão multidimensional $s^{\prime}=\left\langle u, I_{s^{\prime}}, D_{s^{\prime}}\right\rangle$ 
em uma sessão bidimensional estendida $s^{\prime \prime}=\left\langle u, I_{s^{\prime \prime}} \cup D_{s^{\prime \prime}}\right\rangle$, na qual os valores das dimensões adicionais em $D_{s^{\prime \prime}}$ são usados como itens virtuais juntamente com o itens reais em $I_{s}^{\prime \prime}$.

É importante determinar quais dimensões devem ser incluídas em um modelo de recomendação, dado que algumas dimensões são mais informativas que outras. Por esse motivo, Domingues et al. (2013) propuseram diferentes algoritmos para a abordagem DaVI. O algoritmo DaVI-BEST avalia e seleciona a melhor dimensão em um conjunto de dados para construir o modelo de recomendação multidimensional. Para determinar a melhor dimensão para um dado algoritmo de recomendação $A$, o algoritmo DaVI-BEST primeiro aplica a abordagem $D a V I$ em cada dimensão candidata e constrói o respectivo modelo de recomendação multidimensional. Então, ele avalia o modelo e seleciona a melhor dimensão, aquela cujo modelo de recomendação apresenta o melhor desempenho. Neste algoritmo, para avaliar cada modelo de recomendação é utilizada a medida F1.

A grande lacuna dentro da área de sistemas de recomendação sensíveis ao contexto é a falta de métodos automáticos para aquisição de informação contextual. Na próxima seção são apresentadas as formas em que tal informação pode ser obtida, assim como alguns trabalhos da literatura que abordam a aquisição de contexto para sistemas de recomendação sensíveis ao contexto.

\subsubsection{Aquisição Automática de Contexto}

Segundo Adomavicius e Tuzhilin (2011), a informação contextual pode ser obtida de diversas formas, entre elas:

- Explicitamente - os métodos de aquisição explícitos abordam diretamente o usuário e coletam as informações contextuais por meio de perguntas diretas. Por exemplo, um site pode obter informação contextual solicitando que o usuário preencha um formulário;

- Implicitamente - os métodos de aquisição implícitos obtém a informação contextual diretamente dos dados ou do ambiente Web. Eles não interagem com o usuário e acessam diretamente a fonte de informação contextual. Por exemplo, a informação de tempo, como dia, horário, e outros, pode ser obtida por meio do timestamp do $\log$ de acesso Web;

- Inferida - nos métodos de inferência a informação contextual é obtida usando técnicas de mineração de dados e de textos. Técnicas de mineração de textos podem ser aplicadas, por exemplo, em revisões e comentários de usuários.

Alguns problemas são percebidos quando são utilizados os métodos de aquisição explícitos e implícitos. Nos métodos explícitos os usuários muitas vezes não querem preencher formulários Web se não há uma motivação para isso. Já nos métodos implícitos a informação contextual disponível não pode ser usada diretamente por sistemas de recomendação 
sensíveis ao contexto, pois, geralmente, se tratam de valores numéricos ou contínuos obtidos de logs. Uma possível solução a esses problemas é a utilização de técnicas de mineração de dados e de textos que podem ser aplicadas a dados como logs de acesso e conteúdo de páginas Web para extrair contexto de modo automático (Lee et al., 2010).

Li et al. (2010) descrevem em seu artigo métodos para extrair informação contextual de revisões online e seus impactos na qualidade da recomendação. Eles investigaram dados disponíveis de revisões de restaurantes e quatro tipos de informação contextual para uma refeição: companhia (se a refeição envolve múltiplas pessoas), ocasião (para quais ocasiões é o evento), tempo (em qual horário do dia) e localização (em qual cidade o evento acontece). Eles também desenvolveram algoritmos com ferramentas de processamento de linguagem natural existentes, como a ferramenta GATE ${ }^{5}$ (Cunningham et al., 2002). A seguir é feita uma breve descrição dos procedimentos que os pesquisadores utilizaram para extrair cada tipo de informação contextual:

- Tempo: os horários das refeições foram classificados nos seguintes tipos: "café da manhã", "almoço", "jantar", "refeição matinal", "chá da manhã" e "chá da tarde". Eles compilaram um dicionário para esses diferentes tipos de horários de refeições, e usaram um método de comparação de strings para encontrar os horários de refeições contidos nas revisões. Este horário foi extraído usando um módulo do GATE conhecido como $\mathrm{ANNIE}^{6}$, que é um reconhecedor de entidades nomeadas;

- Ocasião: o reconhecedor de entidades nomeadas ANNIE reconhece algumas datas especiais nos textos. Li et al. (2010) melhoraram a função da ANNIE inserindo uma lista de feriados dos Estados Unidos extraídos da Wikipédia assim como algumas ocasiões, como por exemplo, aniversários;

- Localização: tal informação dificilmente existe nos textos das revisões. Portanto eles utilizaram a informação de localização do perfil do usuário;

- Companhia: é a informação mais difícil de ser extraída e para isso Li et al. (2010) utilizaram dois métodos: "Referência de companhia" em que é gerado um dicionário de diferentes tipos de palavras ou frases de companhia usando padrões preposicionais como: "com meu/meus...", e por meio do dicionário é feita comparação de strings. Foram extraídos dessas frases substantivos como termos de companhia, o que levou a um dicionário de 167 entradas. Essas entradas foram agrupadas em seis características de companhia: "família", "amigo", "casal", "colega", "companheiro de refeição" e "animal de estimação". E, utilizando esse dicionário, as revisões são rotuladas entre essas categorias; "Classificador de companhia" no qual foram amostradas e anotadas 1000 frases do corpus com termos de companhia e foram construídos três classificadores: um classificador com atributos da bag-of-words, um classificador baseado em regras e um classificador híbrido. Para o classificador baseado em regras, foram coletadas estruturas das revisões que caracterizam companhia

\footnotetext{
${ }^{5}$ http://gate.ac.uk

${ }^{6}$ https://gate.ac.uk/ie/annie.html
} 
e foi construída uma lista de regras para decidir se um contexto de companhia existe baseado nas estruturas. Para o classificador híbrido, eles usaram os padrões identificados pelo classificador baseado em regras como atributos para o modelo do classificador com bag-of-words. Usando 5-fold cross validation ${ }^{7}$ o classificador híbrido teve melhor desempenho, como mostrado na Tabela 2.4.

Tabela 2.4: Resultados da avaliação para o classificador baseado em bag-of-words (Palavras), o classificador baseado em regras (Regras) e o classificador híbrido (Híbrido) (Li et al., 2010).

\begin{tabular}{|c|c|c|c|}
\hline & Palavras & Regras & Híbrido \\
\hline Precisão & 0,7181 & 0,7238 & 0,7379 \\
\hline Revocação & 0,8962 & 0,8947 & 0,9143 \\
\hline F-Score & 0,7973 & 0,8003 & 0,8167 \\
\hline
\end{tabular}

Para integrar o contexto, Li et al. (2010) consideraram duas formas: uma abordagem pré-filtragem conhecida como modelo Booleano e uma abordagem baseada em modelo probabilístico proposta por eles. Os experimentos foram projetados para responder às perguntas: 1) Incluir informação contextual melhora o desempenho da recomendação? 2) Como o modelo proposto no artigo se compara com abordagens de pré e pós filtragem? Como a qualidade da extração de informação contextual afeta o desempenho da recomendação?

Os autores avaliaram o desempenho do modelo proposto e do modelo Booleano e compararam os resultados com um sistema padrão de filtragem colaborativa. Na Figura 2.3 são exibidos gráficos que ilustram os resultados dos experimentos. Nesses gráficos "Nocontext" representa o sistema de filtragem colaborativa, "Context-X", o modelo probabilístico, em que $\mathrm{X}$ representa o tipo de informação contextual considerada (tempo, localização, ocasião, companhia ou todos), e "Boolean" representa o modelo booleano. O eixo horizontal é o rank (20\% do rank formado pelas primeiras posições) e o eixo vertical é a porção de itens relevantes considerados nessa porção do rank. De acordo com os gráficos, "ContextX" teve um melhor desempenho que "Nocontext" e o modelo de pré-filtragem "Boolean" não teve bons resultados. De acordo com Li et al. (2010), os resultados demonstraram que o contexto é um fator importante que afeta a escolha dos usuários, porém se ele é usado de maneira imprópria, como na pré-filtragem booleana, pode influenciar negativamente o desempenho da recomendação.

Aciar (2010) propôs uma técnica para detectar frases de revisões que apresentam informação de contexto. Ela aplica ferramentas de mineração de textos para definir conjuntos de regras que permitem identificar tais frases com contexto. Nesse trabalho as frases são classificadas em duas categorias: "Contextual" e "Preferências". A categoria "Contextual" agrupa frases que apresentam informação sobre o contexto no qual a revisão foi escrita. A

\footnotetext{
${ }^{7}$ Cross-Validation, ou Validação Cruzada, é um método estatístico de avaliar e comparar algoritmos de aprendizado dividindo os dados em duas partes: uma usada para treinar o modelo e outra usada para validá-lo (Refaeilzadeh et al., 2009).
} 


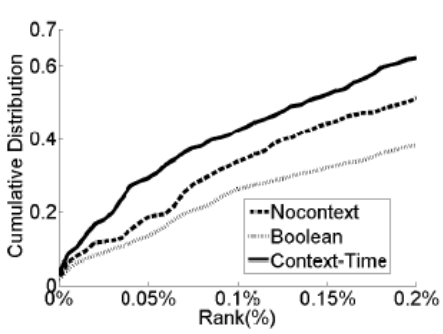

(a) Time

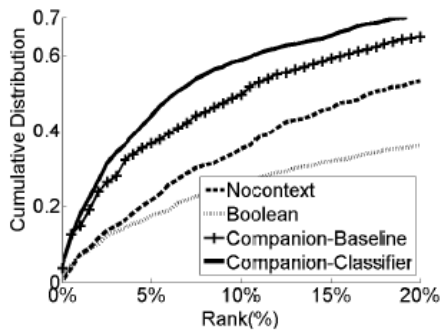

(d) Companion

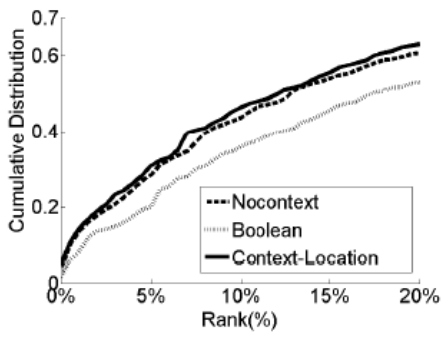

(b) Location

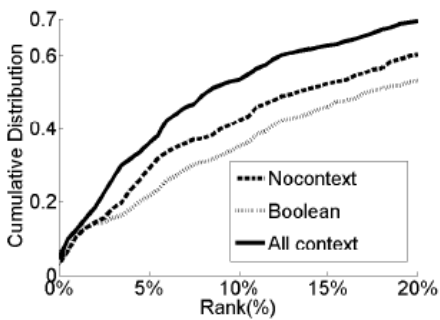

(e) All

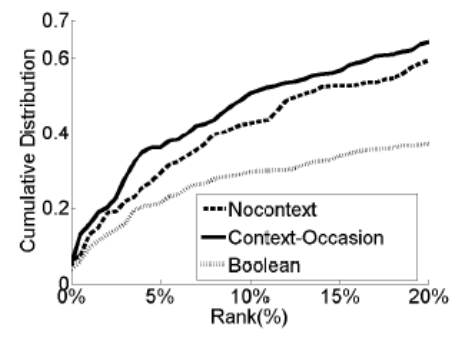

(c) Occasion

Figura 2.3: Gráficos dos resultados da avaliação do desempenho das top- $K$ recomendações (Li et al., 2010).

categoria "Preferências" agrupa frases que apresentam informação sobre as características que o consumidor avaliou.

Para obter os conjuntos de regras de classificação foram utilizados "Text-Miner Software Kit" (TMSK) e "Rule Induction Kit for Text" (RIKTEXT). Foram utilizadas 100 revisões do domínio de turismo do site "Trip Advisor" para treinamento e teste no processo de geração das regras. Foram utilizadas 50 novas revisões do mesmo site em um experimento para avaliar a acurácia das regras para classificar as revisões nas categorias "Contextual" e "Preferências". Os resultados obtidos são considerados bons devido ao alto valor obtido em precisão, revocação e $F$-measure e o baixo valor da medida MAE.

Hariri et al. (2011) introduziram um sistema de recomendação sensível ao contexto que obtém informação contextual minerando revisões de hotéis feitas pelos usuários e as combinam com o histórico de avaliações do usuário para calcular uma função de utilidade sobre um conjunto de itens. Eles utilizaram uma base de revisões de hotéis do website "Trip Advisor". A razão de selecionar esse conjunto de dados, segundo os pesquisadores, é que usuários geralmente fornecem algumas dicas de contexto em seus comentários. Por exemplo, eles podem mencionar se estão com a família ou em uma viagem de negócios, ou eles podem expressar suas opiniões sobre os serviços do hotel que são importantes para eles como Internet wireless ou salas de conferência.

Na base utilizada o atributo "tipo da viagem" atribuído a uma revisão de hotel mostra os tipos de viagens que o usuário sugere ao hotel. Esse atributo pode ser selecionado pelo usuário dentro de um conjunto de 5 opções: "família", "casal", "viagem desacompanhado", "negócios" e "viagem com amigos". Se o usuário especifica seu contexto explicitamente, então ele pode ser facilmente usado no algoritmo de recomendação. Por outro lado, se

\footnotetext{
${ }^{8}$ http: //www.tripadvisor.com
} 
ele expressa seu contexto em um conjunto de frases descrevendo seu estado atual ou seus atributos desejados para o hotel, então um método de inferência é necessário para determinar a probabilidade de cada tipo de viagem.

A abordagem que eles adotam para inferir contexto é baseada em usar um classificador que é treinado pelas amostras de descrições e seus contextos correspondentes. Como trata-se de um problema de classificação supervisionado multirrótulo, Hariri et al. (2011) utilizaram Labeled Latent Drichlet Allocation (Labeled-LDA $)^{9}$ como método de categorização. Dessa forma, o contexto é mostrado como uma distribuição sobre o conjunto de categorias de viagem, como o exemplo retirado de (Hariri et al., 2011): Context $t_{u}^{i}$ $=P($ família $)=0, P($ casal $)=0, P($ viagem desacompanhado $)=0.5, P($ negócios $)=0.5$, $P($ viagem com amigos $)=0$.

O sistema consiste de duas partes principais. O primeiro experimento focou em avaliar a acurácia do módulo de inferência de contexto na base de dados. O experimento foi configurado como um 5-fold cross validation. Para cada caso de teste, a distribuição de probabilidade sobre as categorias de viagens foi prevista. Uma categoria é atribuída a um caso de teste se a probabilidade prevista para aquela categoria excede um certo limiar. Os resultados foram avaliados medindo precisão e revocação e mostraram que a precisão tende a aumentar e a revocação a diminuir, conforme o limiar cresce (Figuras 2.4 e 2.5).

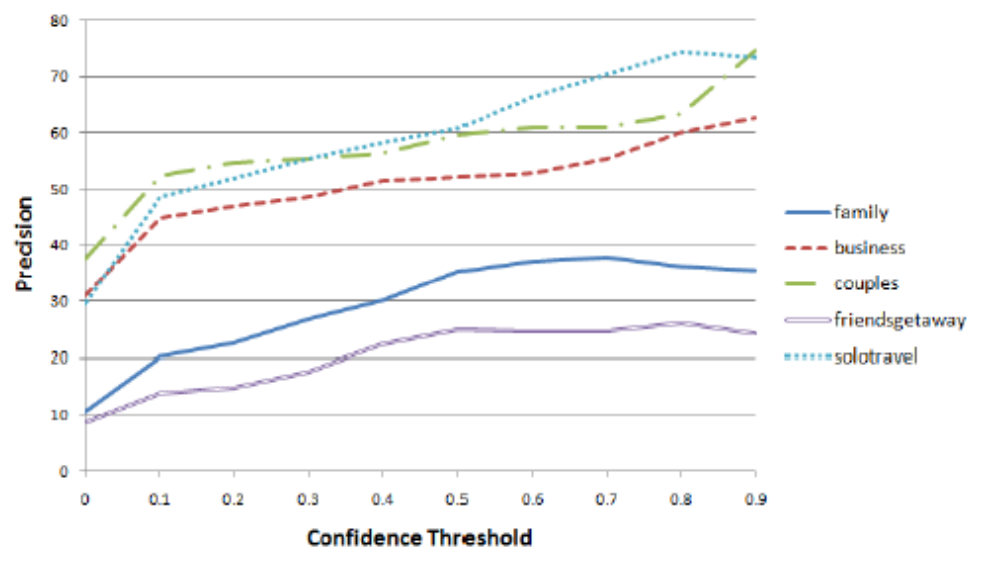

Figura 2.4: Valores de precisão para diferentes categorias (Hariri et al., 2011).

No segundo experimento o desempenho do sistema de recomendação é comparado com o recomendador $k N N$ padrão. Hit Ratio foi escolhida como medida de desempenho e foi realizado um experimento leave-one-out cross validation naquelas revisões que possuem avaliações melhores do que a média de avaliações dos revisores. Os resultados sugerem que recomendações feitas utilizando contexto possuem maiores valores da medida Hit Ratio (Figura 2.6).

\footnotetext{
${ }^{9}$ Latent Drichlet Allocation (LDA) é um modelo probabilístico generativo para coleções de dados discretos como texto corpora (Blei et al., 2003) e Labeled-LDA é um modelo de tópico que restringe LDA definindo uma correspondência de um-para-um entre tópicos latentes do LDA e tags do usuário (Ramage et al., 2009).
} 


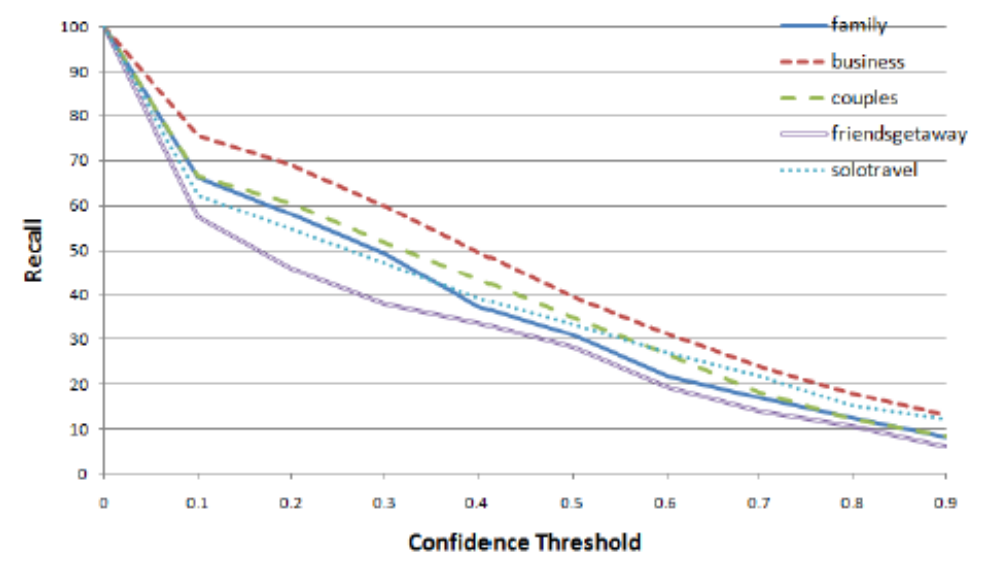

Figura 2.5: Valores de revocação para diferentes categorias (Hariri et al., 2011).

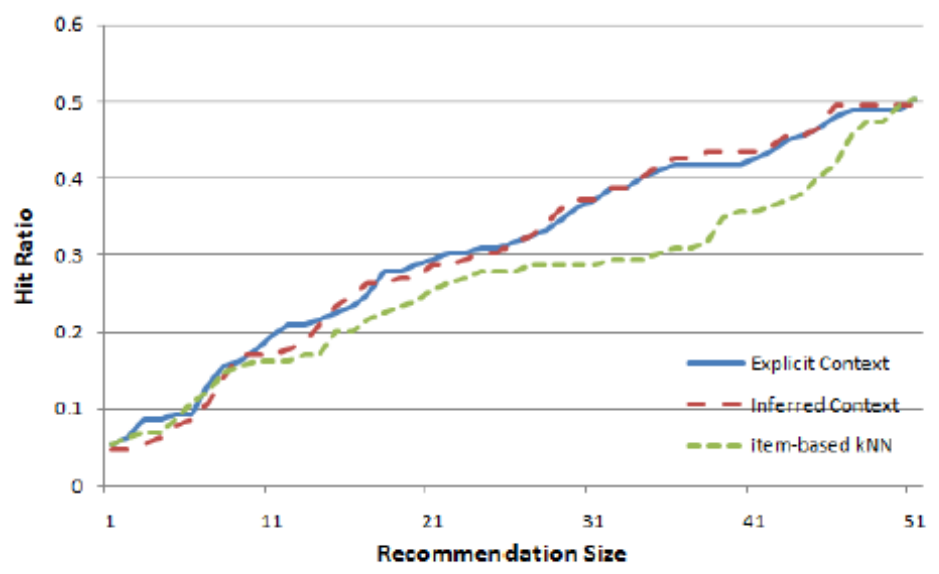

Figura 2.6: Comparação Hit Ratio para kNN baseado em item e sistema de recomendação baseado em contexto (Hariri et al., 2011).

Ho et al. (2012) propuseram uma abordagem para minerar eventos espaço-temporais futuros de artigos de notícias e assim fornecer informações a um sistema de recomendação sensível à localização. De acordo com os pesquisadores, um evento é extraído somente quando sua localização e tempo puderem ser identificados ou deduzidos e, além de tais informações, são extraídos os sentimentos dos eventos, ou seja, identifica-se se um evento é positivo, negativo ou neutro. O seguinte exemplo foi retirado de (Ho et al., 2012):

E: Washington Post (27 de setembro de 2010): um possivel tornado ocorrerá em Clarksville, Maryland, uma hora depois de um alerta (ao meio dia).

O evento $E$ é rotulado como negativo pois trata-se de um evento relacionado a mau tempo. Um cenário que serve de exemplo da aplicação da informação extraída para um sistema de recomendação sensível à localização pode ser (Ho et al., 2012): "John está na área suburbana de Baltimore. Ele utiliza um dispositivo móvel com uma aplicação que utiliza eventos futuros para fazer recomendações baseadas na localização do seu GPS". Diante deste cenário, se em 27 de setembro de 2010 John estivesse dirigindo perto de 
Clarksville, Maryland, o sistema de recomendação o aconselharia a dirigir para longe, devido ao sentimento negativo desse evento, no caso um possível tornado.

De acordo com Ho et al. (2012), um evento é composto por seis atributos: espacial (nome, longitude, latitude), temporal (dia, mês, ano, tempo[intervalo] - se disponível), frase chave (texto antes e depois de um padrão temporal), sentimento, fonte da informação (URL) e título do artigo de notícia. A abordagem proposta para minerar eventos é composta por quatro subtarefas:

- Reconhecimento de padrões temporais futuros e de passado próximo: são tratados os tempos absolutos como "16 de outubro de 2011 " e os tempos relativos como "na próxima semana", "amanhã", etc. Os padrões temporais considerados são referentes ao futuro e ao passado próximo com relação a um tempo de referência, que neste caso é o timestamp da publicação do artigo;

- Reconhecimento de resolução de topônimos: a principal ideia é a definição de um dicionário espacial local que consiste de um conjunto de topônimos de grande proximidade, anexado a uma fonte de notícias. Ho et al. (2012) utilizaram uma técnica híbrida de reconhecimento de topônimos consistindo de marcações Part-OfSpeech (POS), reconhecimento de entidades nomeadas (NER) e reconhecimento de heurísticas baseadas em regras, seguida por frases de correspondência que podem ser encontradas em um gazetteer ${ }^{10}$. O gazetteer utilizado foi o GeoNames ${ }^{11}$;

- Desambiguação e correspondência espaço-temporal: é necessário formar pares de topônimos com padrões temporais futuros para estabelecer a existência de um evento futuro. Esse processo de correspondência é definido por uma função $f: X \longrightarrow Y$, em que $X$ é o conjunto de padrões temporais futuros e $Y$ é o conjunto de topônimos;

- Análise dos sentimentos dos eventos: tarefa que envolve a determinação da atitude ou sentimento antecipado do usuário para um evento identificado. Para isso é construída uma bag-of-words dos artigos de notícias. São aplicadas duas abordagens de classificação na bag-of-words: "supervised Latent Dirichlet Allocation" (sLDA) e "Support Vector Machine" (SVM) para classificar o sentimento do evento. Artigos positivos possuem notícias relacionadas a tópicos como festivais, entretenimento e esportes. Artigos negativos possuem notícias relacionadas a tópicos como crimes, acidentes, tempo ruim e tráfego. O resto é incluído na categoria neutra. Um sistema de recomendação pode então aconselhar um usuário a evitar uma localização geográfica ou a comparecer a um evento futuro baseado no sentimento do evento.

Bauman e Tuzhilin (2014) apresenta um método para descobrir informação contextual relevante das revisões dos usuários. Nesse método, as revisões são classificadas em "específicas" e "genéricas". Eles observaram que a informação contextual está contida

\footnotetext{
${ }^{10} \mathrm{Um}$ gazetteer é uma base de dados de localizações geográficas com coordenadas e metadados associados.

${ }^{11}$ http://www. geonames.org/
} 
principalmente nas revisões específicas, que são aquelas que descrevem visitas específicas de um usuário para um estabelecimento. Já nas revisões "genéricas", que descrevem impressões gerais sobre algum estabelecimento, esse tipo de informação dificilmente aparece. Portanto, o contexto é extraído das revisões "específicas" por meio de dois métodos: "word-based" e "LDA-based". O primeiro método é baseado na identificação das palavras relacionadas ao contexto mais importantes e o segundo é baseado no método LDA.

O primeiro passo da abordagem proposta é separar as revisões "genéricas" das "específicas". Para isso, Bauman e Tuzhilin (2014) identificaram certas características que prevalecem em um tipo, mas não no outro tipo de revisões. De acordo com eles, usuários que descrevem experiências de restaurantes particulares tendem a escrever revisões longas e usam muitos verbos no passado, enquanto que nas revisões genéricas os usuários tendem a usar verbos no presente com maior frequência. Portanto, para separar as revisões genéricas das específicas são identificadas várias características como: o tamanho da revisão, o número total de verbos usados e número de verbos usados no passado. Com isso, o método de agrupamento K-means é utilizado para fazer a separação.

Com as revisões separadas em duas classes, o próximo passo é aplicar os métodos "word-based" e "LDA-based". A ideia do método "word-based" é identificar os substantivos que ocorrem com uma frequência maior nas revisões "específicas" do que nas "genéricas". Já no método "LDA-based", a principal ideia é gerar uma lista de tópicos sobre uma aplicação usando o método LDA e identificar entre esses tópicos aqueles que correspondem à informação contextual para aquela aplicação. O terceiro e último passo é percorrer as listas de palavras e tópicos gerados e selecionar a informação contextual dessas listas.

Para validar a abordagem proposta, eles utilizaram os dados do site $Y e l p^{12}$, que foram oferecidos para a competição RecSys 2013. A abordagem foi aplicada em três aplicações (Restaurantes, Hotéis e Beleza \& Spas). As revisões foram separadas em "específicas" e "genéricas". Para avaliar o agrupamento das revisões, os autores rotularam manualmente 900 revisões, sendo 300 de cada aplicação. A acurácia do método de separação foi em torno de 0,9 , o que indica um bom desempenho. Após a separação foi feita a extração das informações de contexto. Foram identificados os seguintes tipos de contexto para a categoria "Restaurante": Companhia, Período do dia, Dia da semana, Conselho, Visitas anteriores, Veio de carro, Cortesias, Ocasião, Reserva, Desconto, Sentar do lado de fora, Para viagem. Para a categoria "Hotéis" foram identificados: Companhia, Ocasião, Reserva, Período do ano, Veio de carro, Dia da semana, Avião, Desconto, Visitas anteriores, Evento da cidade, Conselho. E, por fim, para a categoria "Beleza \& Spas": Companhia, Dia da Semana, Visitas anteriores, Período do dia, Ocasião, Reserva, Desconto, Conselho, Permanência vs Visita, Veio de carro.

Os resultados mostraram que ambos os métodos ("word-based" e "LDA-based") são complementares, pois quando um deles não identificou um determinado contexto, o outro identificou e ambos descobriram todos os tipos de contexto nas diferentes aplicações.

\footnotetext{
$12_{\text {www }}$ yelp.com
} 
Assim como nos trabalhos apresentados nesta seção, sistemas de recomendação têm sido avaliados de várias formas. Para fazer uma avaliação boa e confiável desse tipo de sistema é importante entender seus objetivos e tarefas. Na próxima seção são apresentadas formas e métricas utilizadas para avaliar sistemas de recomendação.

\subsection{Avaliação de Sistemas de Recomendação}

Um desenvolvedor que deseja adicionar um sistema de recomendação em sua aplicação deve escolher, dentro de uma grande variedade de algoritmos, o que é mais apropriado para seus objetivos. Identificar o melhor algoritmo para um determinado objetivo é um desafio, pois é difícil avaliar sistemas de recomendação por várias razões (Herlocker et al., 2004): algoritmos diferentes de recomendação podem ser melhores ou piores em conjuntos de dados diferentes; os objetivos das avaliações podem ser diferentes; e é difícil decidir qual combinação de medidas usar na avaliação.

De acordo com Shani e Gunawardana (2011), existem três tipos diferentes de avaliação:

- Avaliação offline - é, geralmente, a avaliação mais fácil de ser conduzida utilizando conjunto de dados pré-coletados e um protocolo que modela o comportamento do usuário para estimar medidas de desempenho da recomendação. Esse conjunto de dados é coletado enquanto os usuários escolhem ou avaliam itens. Com ele, tenta-se simular o comportamento dos usuários que interagem com o sistema de recomendação. Experimentos nessa linha apresentam a vantagem de serem de baixo custo, já que não requerem interações com usuários reais. Como desvantagem temse o fato de que eles podem responder a um conjunto de questões muito estreito, geralmente questões sobre o poder de previsão do algoritmo;

- Estudos com usuários - opção mais cara que o teste offline e requer que um grupo de pessoas execute um conjunto de tarefas utilizando o sistema. Enquanto as pessoas executam as tarefas elas são observadas e seus comportamentos são gravados, o que permite a coleta de medidas quantitativas. Além disso, em muitos casos é possível que sejam feitas perguntas aos usuários antes, durante ou depois da execução da tarefa. Tais perguntas coletam dados qualitativos, como se a pessoa gostou da interface do sistema, ou se ela considerou a tarefa fácil. Suas vantagens são: permite testar o comportamento do usuário enquanto ele interage com o sistema de recomendação, e a influência das recomendações em seu comportamento; e também favorece a coleta de dados qualitativos. Suas desvantagens: estudos com usuários são muito caros, pois recrutar um conjunto de pessoas e solicitar que elas executem as tarefas é custoso em termos de tempo e/ou em termos monetários;

- Avaliação online - mede o impacto das recomendações quando estas são apresentadas a um usuário real. É um experimento de grande escala executado em um sistema já implantado e analisa a mudança no comportamento do usuário quando ele interage com diferentes sistemas de recomendação. Esta avaliação é a que oferece 
evidências mais fortes sobre o funcionamento e desempenho do sistema, já que as tarefas são executadas por usuários reais em um sistemas funcionando em tempo real. Uma desvantagem é que se o sistema apresentar recomendações irrelevantes durante o experimento pode desmotivar os usuários de teste a utilizarem o sistema real novamente.

Como as diferentes aplicações dos sistemas de recomendação possuem diferentes objetivos e necessidades, cabe ao desenvolvedor do sistema decidir quais são as propriedades mais importantes para serem avaliadas. De acordo com Herlocker et al. (2004); Shani e Gunawardana (2011), a acurácia da previsão é a propriedade mais utilizada e mencionada na literatura de sistemas de recomendação. As métricas de acurácia medem o quanto os rankings previstos pelos sistemas de recomendação se diferem dos rankings verdadeiros das preferências do usuário. Elas também podem medir o quão bem um sistema pode prever o valor da avaliação para um item específico. Geralmente assume-se que um sistema de recomendação que fornece previsões mais precisas será o preferido pelos usuários. O desafio de selecionar uma métrica apropriada é justificado pela grande quantidade de métricas publicadas e que têm sido utilizadas para avaliar quantitativamente a acurácia dos sistemas de recomendação.

Herlocker et al. (2004) classificam as métricas da acurácia da recomendação em três classes: acurácia da previsão, acurácia da classificação, e acurácia do ranking. As métricas de acurácia da previsão medem o quão similares são as avaliações previstas pelo sistema de recomendação das avaliações verdadeiras do usuário. Os avaliadores que desejam medir a acurácia da previsão podem utilizar uma métrica que calcula a diferença entre a avaliação prevista e a verdadeira avaliação. Exemplos de métricas para este contexto são: Erro Médio Absoluto (MAE) e Erro Quadrático Médio (MSE). O Erro Médio Absoluto é calculado como:

$$
M A E=\frac{\sum_{i=1}^{N}\left|p_{i}-r_{i}\right|}{N}
$$

em que $N$ é o número de itens avaliados, $p_{i}$ é a avaliação prevista para o item $i$ e $r_{i}$ é a avaliação real feita pelo usuário para o item $i$. Já o Erro Quadrático Médio é calculado como segue:

$$
M S E=\frac{\sum_{i=1}^{N}\left(p_{i}-r_{i}\right)^{2}}{N}
$$

As métricas de acurácia da classificação medem a frequência que o sistema de recomendação faz decisões corretas ou incorretas se um item é bom, ou seja, elas medem a eficácia do sistema para recomendar itens que os usuários possam gostar, assumindo que eles possuem preferências binárias (gosta/não gosta). As seguintes métricas, cujos valores variam de 0 a 1, pertencem a essa classe: Precisão, Revocação, Medida F1 e MAP.

Sendo $R R$ o conjunto de itens disponíveis que são relevantes e $R$ o conjunto de itens recomendados, a Precisão é a fração das recomendações feitas que são relevantes ao usuário com relação ao número total de recomendações feitas. Ela representa a probabilidade de 
um item selecionado ser relevante e é calculada como:

$$
\text { Precisão }=\frac{|R R \cap R|}{R}
$$

Já a Revocação representa a fração do número de itens relevantes recomendados ao usuário com relação ao número total de itens relevantes disponíveis:

$$
\text { Revocação }=\frac{|R R \cap R|}{R R}
$$

Um sistema de recomendação pode recomendar muitos itens e assim ter uma revocação alta, mas uma precisão baixa. Por outro lado, ele pode recomendar poucos itens, ter um baixo valor de revocação, mas um valor de precisão alto. Uma forma de equilibrar precisão e revocação é calcular a medida F1, que é a média harmônica da precisão e da revocação. Ela é calculada como:

$$
F 1=\frac{2 \times \text { Precisã o } \times \text { Revocação }}{\text { Precisão }+ \text { Revocação }}
$$

Uma outra abordagem para avaliar a acurácia da classificação em sistemas de recomendações, é calcular a precisão média em vários níveis diferentes de revocação ou a precisão média na posição de cada documento relevante no ranking. Essa abordagem é geralmente referida como Mean Average Precision (MAP). A métrica Mean Average Precision calcula a precisão considerando a respectiva posição na lista ordenada de itens recomendados. Com essa medida é calculado um único valor de acurácia para um conjunto $U$ de usuários:

$$
M A P(U)=\frac{1}{|U|} \sum_{u=1}^{|U|} A P\left(R_{u}\right),
$$

em que $|U|$ é o tamanho do conjunto de usuários, ou seja, o número total de usuários, $R_{u}$ é o ranking de itens para cada usuário $u$ e $A P\left(R_{u}\right)$ é a precisão média (Average Precision - AP) para o ranking $R_{u}$. A precisão média é calculada como:

$$
A P(R)=\frac{1}{I_{R R}} \sum_{i \in I_{R R}} \operatorname{Precis} \tilde{a} o(i),
$$

em que $I_{R R}$ é o conjunto dos itens recomendados que são de fato relevantes, $\left|I_{R R}\right|$ é o tamanho desse conjunto e Precisão(i) é a precisão do item $i$ em sua posição do ranking.

Por fim, as métricas de acurácia do ranking medem a habilidade do sistema recomendar itens ordenados ou rankings que correspondem às preferências dos usuários. Diferente das métricas de classificação, as métricas de ranking são apropriadas para avaliar algoritmos que serão usados para apresentar listas ordenadas de recomendações ao usuário. Exemplos de métricas dessa classe são: medidas de correlação como o coeficiente $\rho$ de Spearman e o coeficiente Tau de Kendall e a medida Utilidade Half-Life (Herlocker et al., 2004; Shani e Gunawardana, 2011).

De acordo com Herlocker et al. (2004), duas variáveis são correlacionadas se a variância 
em uma delas pode ser explicada pela variância na outra. Medidas de correlação de rankings, como os coeficientes $\rho$ de Spearman e Tau de Kendall, medem o quanto dois rankings diferentes concordam independente dos reais valores das variáveis. A correlação de Spearman é definida como o coeficiente de correlação Pearson entre as variáveis dos rankings:

$$
\rho=\frac{1}{N_{u}} \frac{\sum_{i}\left(r_{i}-\bar{r}\right)\left(\hat{r}_{i}-\overline{\hat{r}}\right)}{\sigma(r) \sigma(\hat{r})}
$$

sendo $N_{u}$ o número de itens $i$ para o usuário $u, r$ e $\hat{r}$ os rankings previsto e real, $\bar{r}$ e $\overline{\hat{r}}$ as médias dos rankings e $\sigma(r)$ e $\sigma(\hat{r})$ seus desvios padrões. Para valores idênticos de classificação, ou seja, empates, cada item empatado deve receber a classificação média. Por exemplo, se dois itens estão empatados na primeira e na segunda posição, eles recebem o valor de classificação igual a $1,5((1+2) / 2=1,5)$.

O coeficiente Tau de Kendall representa uma abordagem diferente para calcular a correlação entre os rankings, pois é independente dos valores das variáveis. Ele é definido como $\tau=(C-D) /(C+D)$, em que $C$ é o número de itens que o sistema prevê na ordem correta do ranking e $D$ representa o número de itens que o sistema prevê na ordem incorreta. O coeficiente $\tau$ é igual a 1 quando os rankings reais e previsto são idênticos e igual a -1 quando eles são exatamente o oposto. Herlocker et al. (2004) fizeram uma aproximação dessa medida para casos em que ocorram empates:

$$
\tau \approx \frac{C-D}{\sqrt{(C+D+T R)(C+D+T P)}},
$$

em que $T R$ é o número de itens na ordem correta que empatam e TP é o número de itens na ordem prevista que empatam.

Geralmente assume-se que o usuário percorre as listas de recomendações do começo ao fim e sua satisfação é melhor medida levando em consideração a posição de cada item relevante e atribuindo a eles pesos de maneira adequada (Lu et al., 2012; Herlocker et al., 2004; Shani e Gunawardana, 2011). A medida de utilidade Half-Life mede a utilidade esperada de uma lista de recomendações ordenadas, baseada na suposição que usuários preferem olhar os itens das primeiras posições na lista (Ekstrand et al., 2011). Portanto, quanto mais longe o item estiver da primeira posição menor é a probabilidade dos usuários examinarem este item. Assim a função de utilidade Half-Life é uma função de decaimento exponencial e utiliza o parâmetro $\alpha$ que descreve a força do decaimento. A utilidade esperada é calculada como:

$$
R_{u}=\sum_{i} \frac{\max \left(r_{u, i}-d, 0\right)}{2^{\frac{(i-1)}{(\alpha-1)}}}
$$

em que $r_{u, i}$ representa a avaliação do usuário $u$ para o item $i$ do ranking e $d$ é a avaliação prevista.

De acordo com Ekstrand et al. (2011); Herlocker et al. (2004); Shani e Gunawardana (2011), a acurácia não é o único critério de interesse na avaliação de um sistema de 
recomendação, e em alguns casos pode não ser o mais importante. Muitos outros critérios de avaliação podem ser considerados, alguns deles são:

- Novidade e acaso: novidade mede a habilidade de um sistema de recomendação recomendar itens que o usuário ainda não conhece e acaso mede o quão surpreendente é uma recomendação bem sucedida;

- Cobertura: mede a porcentagem do conjunto de itens que o sistema de recomendação é capaz de recomendar;

- Taxa de Aprendizagem: mede a quantidade de dados de treino que é necessária para o sistema tornar-se um previsor efetivo e gerar boas recomendações;

- Confiança: mede o quão certo está o sistema de recomendação de que suas recomendações ou previsões são precisas. Medir a confiança de um sistema é uma tarefa difícil, porém sistemas que não incluem algumas medidas de confiança são prováveis de conduzir os usuários a tomarem decisões mais pobres do que os sistemas que incluem confiança. Se a confiança das previsões pode ser calculada, ela pode ser exibida aos usuários para ajudá-los a decidir se a relação risco-retorno é apropriada;

- Avaliação do usuário: mede a reação do usuário utilizando um sistema de recomendação.

\subsection{Considerações Finais}

Conforme apresentado neste capítulo, os sistemas de recomendação são sistemas que recomendam itens a usuários considerando suas preferências. Os sistemas de recomendação utilizam técnicas de filtragem conhecidas como: colaborativa, baseada em conteúdo e abordagens híbridas.

Os sistemas de recomendação tradicionais consideram apenas usuários e itens para construir o conjunto de recomendações ou fazer previsões de valores de avaliações. Como já explicado anteriormente, estudos apontam que em algumas aplicações, o uso de informação contextual, como tempo, lugar e outras, pode melhorar a qualidade das recomendações e aumentar os níveis de satisfação dos usuários. Entretanto, a grande lacuna na área de sistemas de recomendação sensíveis ao contexto é a falta de métodos de aquisição automática de contexto para estes sistemas.

As formas de se obter informações de contexto são: explicitamente, implicitamente e utilizando métodos de inferência. Existem alguns problemas na utilização de métodos explícitos e implícitos. Para solucionar esses problemas, métodos de inferência, como o uso de técnicas de mineração de dados e de textos, podem ser empregados. Existem trabalhos nessa linha que documentaram bons resultados para os sistemas de recomendação sensíveis ao contexto. Portanto, no próximo capítulo é feita uma revisão bibliográfica da área de mineração de textos dando ênfase para as abordagens que são utilizadas neste projeto de mestrado para extrair/inferir contexto de forma automática de conteúdos de páginas Web para sistemas de recomendação sensíveis ao contexto. 


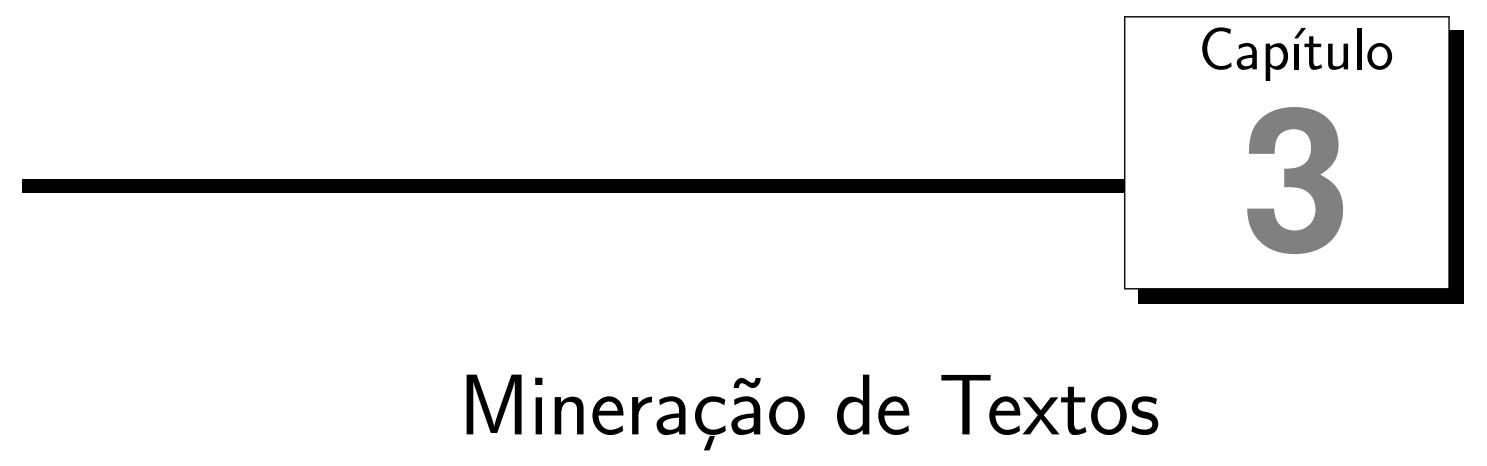

\subsection{Considerações Iniciais}

Uma grande quantidade de documentos são armazenados diariamente em formato textual em meios digitais (Rezende, 2003; Kroeze e Matthee, 2009). Entre esses documentos estão relatórios, atas de reuniões, dados acadêmicos, etc. Com esse crescimento contínuo no volume de dados eletrônicos disponíveis, torna-se cada vez mais necessário o uso de técnicas automáticas de extração de conhecimento, como, por exemplo, técnicas de mineração de textos.

A mineração de textos é um processo que tem como objetivo descobrir padrões desconhecidos em dados não-estruturados ou semi-estruturados. A mineração de textos é uma área interdisciplinar que engloba: aprendizado de máquina, recuperação de informação, estatística, visualização de informação e processamento de linguagem natural. Além disso, a mineração de textos pode ser utilizada em várias áreas aplicações, como: agrupamento de textos, recuperação de informação, fiscalização e filtragem de $e$-mails, detecção de anomalias e sistemas de recomendação (Berry e Castellanos, 2007; Ricci et al., 2011).

Neste trabalho, abordagens de mineração de textos são utilizadas para inferir informações contextuais de conteúdos de páginas da Web. No decorrer deste capítulo são apresentadas as etapas do processo de mineração de textos (Seção 3.2) assim como as abordagens que são utilizadas neste trabalho (Seções 3.3.2, 3.3.1 e 3.3.3).

\subsection{O Processo de Mineração de Textos}

Assim como a mineração de dados, o processo de mineração de textos pode ser dividido em cinco etapas principais (Rezende, 2003), como pode ser observado na Figura 3.1, sendo elas: Identificação do problema, Pré-processamento, Extração de padrões, Pós- 


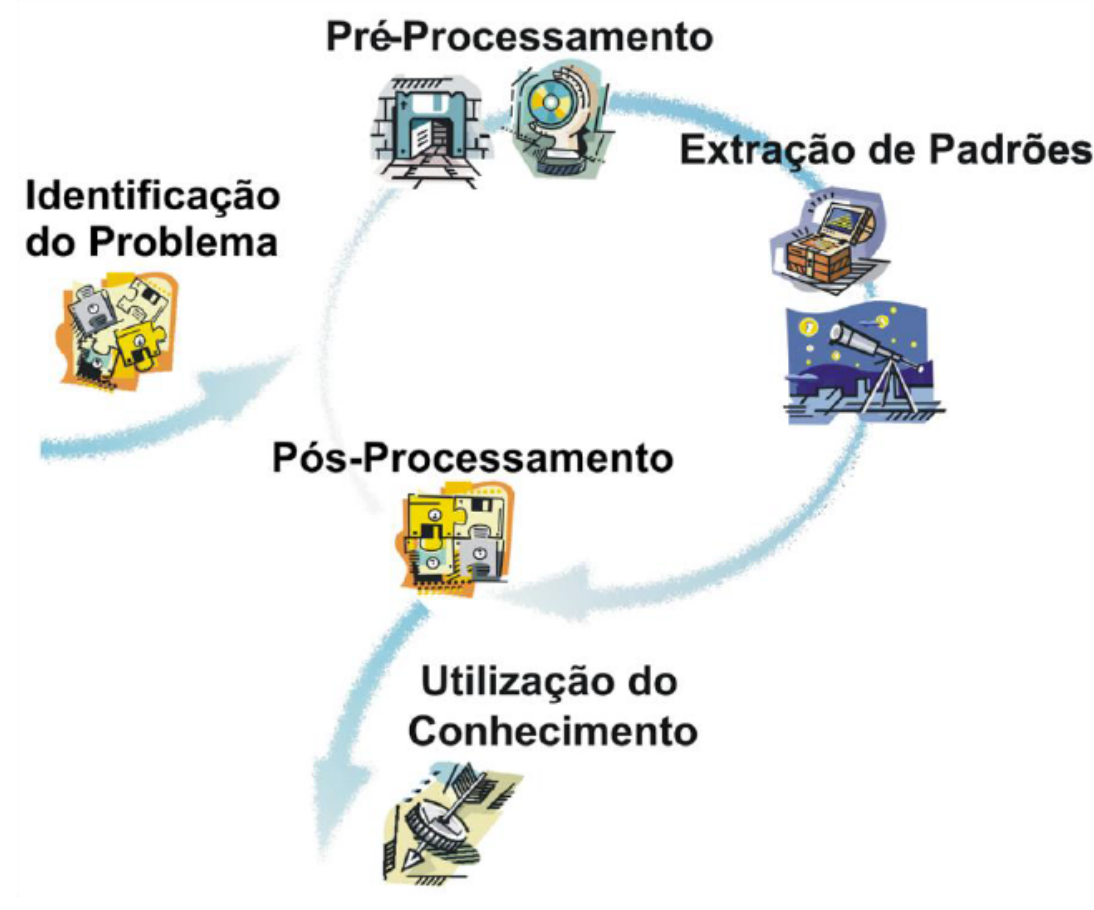

Figura 3.1: Processo de mineração de textos (Rezende, 2003).

processamento e Utilização do conhecimento.

$\mathrm{Na}$ identificação do problema, o especialista do domínio realiza um estudo do problema e define os objetivos e metas da mineração de textos. Além disso, ele identifica e seleciona a coleção de textos que será utilizada na extração de conhecimento e algum conhecimento prévio que pode ser utilizado durante o processo, caso exista. A identificação do problema é uma etapa muito importante para o decorrer da mineração, pois ela guia as etapas seguintes e produz reflexos positivos ou negativos no desempenho global.

O pré-processamento visa estruturar os textos de maneira a torná-los processáveis por algoritmos de aprendizado de máquina. É a etapa mais importante dentro do processo de mineração de textos, pois a qualidade da representação da coleção influencia o resultado final da extração de conhecimento. A partir da coleção de textos, é feita a preparação dos textos para viabilizar a extração dos termos importantes da coleção. Estes termos devem ser relevantes e devem discriminar a coleção. Na Figura 3.2 está esquematizado como é feito o pré-processamento dos textos.

A preparação do texto consiste na padronização e na limpeza dos textos da coleção. A padronização é necessária para converter textos que estão em formatos como hipertexto, $p d f$ ou outros, para o formato de texto plano sem formatação. Feita a padronização, o processo de limpeza é conduzido eliminando-se, em geral, as stopwords, que são palavras consideradas irrelevantes para a representação da coleção textual. Normalmente é utilizada nesse processo uma lista de stopwords, a stoplist. As stopwords podem ser divididas em duas categorias: stopwords gerais e específicas do domínio (Makrehchi e Kamel, 2008). As gerais incluem as stopwords padrões, como artigos, preposições, conjunções e outras. Já as stopwords específicas do domínio, são reconhecidas como um conjunto de palavras 


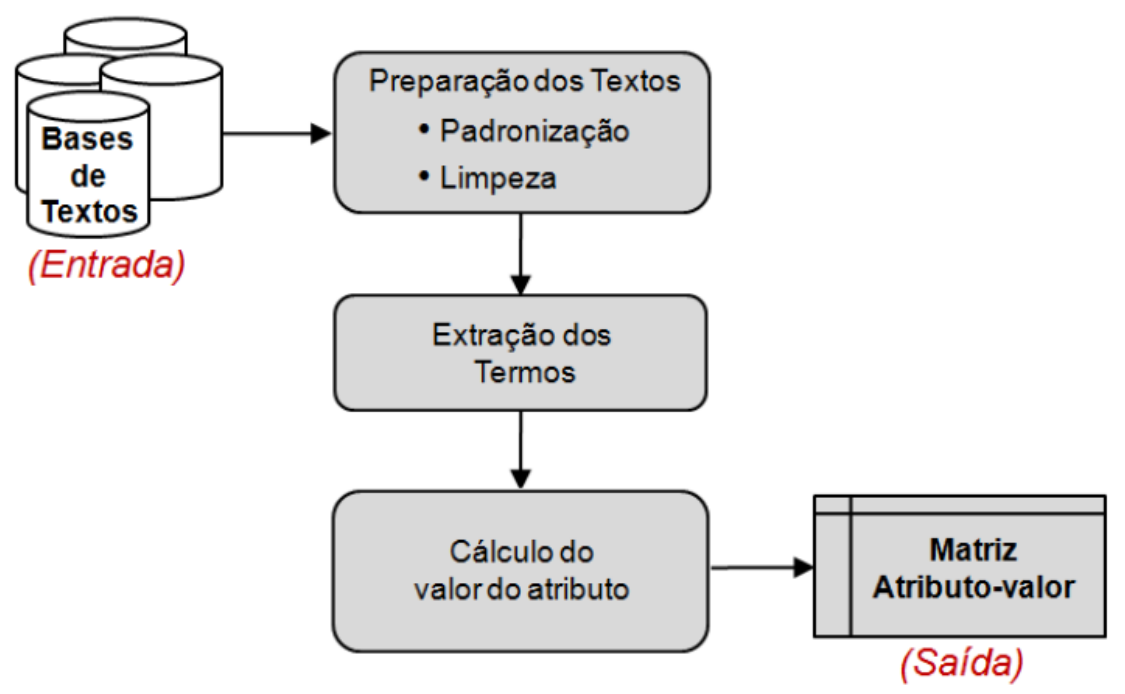

Figura 3.2: Esquema da etapa de pré-processamento (Conrado, 2009).

que não têm valor discriminativo dentro de um domínio ou contexto específico. Como exemplo considera-se o termo "aprendizado", que pode ser uma stopword no domínio da "educação", mas no domínio de ciência da computação pode ser um termo importante.

O próximo passo do pré-processamento é a extração de termos. Para essa extração algumas técnicas são utilizadas para buscar padrões que simplifiquem as formas de apresentação dos termos. Entre essas técnicas estão a radicalização, a lematização e a substantivação.

Normalmente os termos são tratados como um conjunto de palavras independentes, conhecido como bag-of-words. A estrutura mais utilizada para representar a bag-of-words é conhecida como Matriz Documento-Termo ou Matriz Atributo-Valor (Salton e McGill, 1983; Weiss et al., 2005), que é ilustrada na Figura 3.3.

\begin{tabular}{c|cccc|c}
\hline & $\mathrm{t}_{1}$ & $\mathrm{t}_{2}$ & $\ldots$ & $\mathrm{t}_{\mathrm{n}}$ & $\mathrm{y}$ \\
\hline $\mathrm{d}_{1}$ & $\mathrm{a}_{11}$ & $\mathrm{a}_{12}$ & $\ldots$ & $\mathrm{a}_{1 \mathrm{n}}$ & $\mathrm{y}_{1}$ \\
$\mathrm{~d}_{2}$ & $\mathrm{a}_{21}$ & $\mathrm{a}_{22}$ & $\ldots$ & $\mathrm{a}_{2 \mathrm{n}}$ & $\mathrm{y}_{2}$ \\
$\cdot$ & $\cdot$ & $\cdot$ & $\cdot$ & $\cdot$ & $\cdot$ \\
$\cdot$ & $\cdot$ & $\cdot$ & $\cdot$ & $\cdot$ & $\cdot$ \\
$\cdot$ & $\cdot$ & $\cdot$ &. & $\cdot$ & $\cdot$ \\
$\mathrm{d}_{\mathrm{m}}$ & $\mathrm{a}_{\mathrm{n} 1}$ & $\mathrm{a}_{\mathrm{n} 2}$ & $\ldots$ & $\mathrm{a}_{\mathrm{nm}}$ & $\mathrm{y}_{\mathrm{m}}$ \\
\hline
\end{tabular}

Figura 3.3: Matriz Atributo-Valor.

Essa matriz possui $m$ linhas e $n$ colunas. As $m$ linhas representam os documentos $d_{1}$ a $d_{m}$ da coleção e as $n$ colunas representam os termos $t_{1}$ a $t_{n}$ que descriminam os documentos. Quando os documentos possuem classes ou rótulos, eles aparecem na matriz como uma coluna especial $Y$. Os elementos da matriz $a_{11}$ a $a_{m n}$ são os valores dos atributos calculados na terceira etapa da Figura 3.2 e que relacionam os termos aos documentos, ou seja, são pesos que indicam o quanto o termo é relevante para representar o documento. Assim, por exemplo, o peso $a_{11}$ é o valor atribuído ao termo $t_{1}$ no documento $d_{1}$. Esses 
valores de pesos podem ser calculados considerando pesos binários, isto é, atribuindo-se 0 quando o termo não está presente no documento ou 1 quando o termo está presente ou pode-se usar medidas como: frequência do termo TF (Term Frequency), frequência do documento DF (document frequency) e TF-IDF (Term Frequency - Inverse Document Frequency). A frequência do termo, $T F\left(t_{x}, d_{y}\right)$, é o número de vezes que o termo $t_{x}$ aparece no documento $d_{y}$, a frequência do documento, $D F\left(t_{x}\right)$, é o número de documentos nos quais o termo $t_{x}$ está presente e a TF-IDF é uma ponderação da frequência dos termos, como já mencionado na Seção 2.2.2 (Equação 2.11).

A representação bag-of-words apresenta problemas como alta dimensionalidade e alta esparsidade. Alta dimensionalidade porque como ela considera cada termo da coleção como um atributo, o número de atributos na maioria das vezes é muito grande. Além disso, muitos desses termos aparecem em poucos documentos, o que caracteriza uma representação esparsa.

Nesse cenário, técnicas de seleção e extração de termos e de reconhecimento de entidades nomeadas podem ser utilizadas para reduzir o número de atributos e para construir uma representação com atributos mais representativos. A extração de termos e o reconhecimento de entidades nomeadas são utilizados neste trabalho no método proposto para extração de contexto e são apresentados na Seção 3.3.

Na extração de padrões são cumpridos os objetivos definidos na identificação do problema. Esta etapa consiste em escolher a tarefa de mineração de dados a ser empregada, escolher o algoritmo a ser aplicado e, por fim, extrair os padrões. A tarefa é escolhida de acordo com o objetivo do processo e pode ser preditiva ou descritiva (Rezende, 2003).

Tarefas preditivas generalizam exemplos ou experiências passadas, com respostas conhecidas, em um modelo capaz de identificar a classe de um exemplo novo. Entre as tarefas preditivas estão: classificação e regressão. O objetivo da classificação é, a partir de um conjunto de exemplos, que consistem de um conjunto de atributos e um atributo classe, encontrar relacionamentos entre os atributos e a classe e predizer a classe de um exemplo novo e desconhecido. A regressão é similar à classificação, com a diferença de que o atributo a ser predito é contínuo e não discreto como na classificação.

Já as tarefas descritivas consistem na identificação de comportamentos presentes no conjunto de dados, sendo que esses dados não apresentam rótulos especificados. Dentre elas estão: regras de associação, sumarização e agrupamento (clustering). O objetivo das regras de associação é encontrar associações entre os itens de dados. Sua aplicação tradicional está na análise das cestas de mercados, que tem como objetivo descobrir como os itens comprados por clientes em um supermercado estão associados. As regras podem nos dizer que um cliente que compra um produto $y$ em uma determinada situação, tende a comprar também o produto $x$. A sumarização envolve métodos para encontrar uma descrição compacta para um subconjunto de dados (Fayyad et al., 1996), como, por exemplo, definição da média e desvio padrão dos dados. A tarefa de agrupamento, ou clustering, que é utilizada neste trabalho no método proposto para extração de contexto, 
tem o objetivo de formar grupos com itens muito similares entre si e muito diferentes dos itens de outros grupos. O agrupamento utilizado neste trabalho, para extração de contexto, é conhecido como agrupamento hierárquico e é descrito na Seção 3.3.1.

O pós-processamento é a etapa na qual todas as descobertas feitas na etapa de extração de padrões são simplificadas, avaliadas, visualizadas ou apenas documentadas para o usuário final. É nesta etapa que o conhecimento extraído é validado por meio de avaliações. Nessas avaliações devem estar presentes o especialista do domínio e o especialista de mineração de textos para, juntos, verificarem se o objetivo do processo foi realmente atingido.

O conhecimento, após ser avaliado e validado na etapa de pós-processamento, é consolidado e pode ser utilizado. Ele é então aplicado para apoiar algum processo de tomada de decisão, conforme o objetivo definido na etapa de identificação do problema.

Nesta seção foram descritos o processo de mineração de textos e suas etapas. Na próxima seção são apresentadas as abordagens utilizadas neste trabalho para a extração de contexto. A construção de hierarquia de tópicos é uma tarefa descritiva, executada na etapa de extração de padrões. Já o reconhecimento de entidades nomeadas e a extração de termos são aplicados no pré-processamento de textos.

\subsection{Abordagens para Extração de Contexto}

Como já mencionado anteriormente, neste trabalho são utilizadas abordagens de mineração de textos para extrair informações contextuais dos itens, que neste caso são páginas da Web, para sistemas de recomendação sensíveis ao contexto. Tais abordagens são descritas nas próximas subseções.

\subsubsection{Hierarquia de Tópicos}

Hierarquias de tópicos são muito úteis para gerenciar, buscar e navegar em grandes repositórios de documentos textuais (Marcacini e Rezende, 2010). Construir uma hierarquia de tópicos significa organizar de forma automática uma coleção de textos e permitir que os usuários explorem a coleção interativamente por tópicos que indicam os conteúdos dos documentos disponíveis.

A hierarquia de tópicos nada mais é que um agrupamento dos textos, e, portanto, é feita na etapa de extração de padrões. O objetivo de tarefas de agrupamento é organizar um conjunto de objetos em grupos utilizando uma medida de proximidade, fazendo com que objetos similares pertençam ao mesmo grupo e sejam dissimilares a objetos de outros grupos (Everitt et al., 2011). Um exemplo retirado de (Feldman e Sanger, 2007) ilustra a importância do agrupamento de documentos na recuperação de informação: dada uma consulta formada pela palavra "carro", um processo de recuperação de informação poderia não retornar documentos contendo a palavra "automóvel", que também é utilizada para referenciar "carro". Entretanto, com o agrupamento dos documentos, esta consulta 
poderá retornar um grupo de documentos relacionados a "carro", o que também envolve "automóvel" e tudo que tem relação ao tema.

Para realizar a tarefa de agrupamento é necessário considerar dois fatores: uma medida de proximidade e uma estratégia de agrupamento (Marcacini, 2011). As medidas de proximidade podem calcular tanto a similaridade entre dois documentos textuais, quanto a dissimilaridade entre eles. Existe uma variedade de medidas de proximidade, mas a mais utilizada na mineração de textos é a medida cosseno (Tan et al., 2005). Ela considera o ângulo formado entre os vetores de dois documentos e pode ser calculada como já mencionado na Seção 2.2.1.

As estratégias de agrupamento são os métodos e algoritmos utilizados para a formação dos grupos. Esses algoritmos são geralmente classificados em métodos particionais e métodos hierárquicos (Jain et al., 1999). No agrupamento particional a coleção de documentos é dividida em uma partição de $k$ grupos, na qual $k$ é geralmente informado pelo usuário. O algoritmo k-means é o algoritmo mais conhecido para esse tipo de agrupamento.

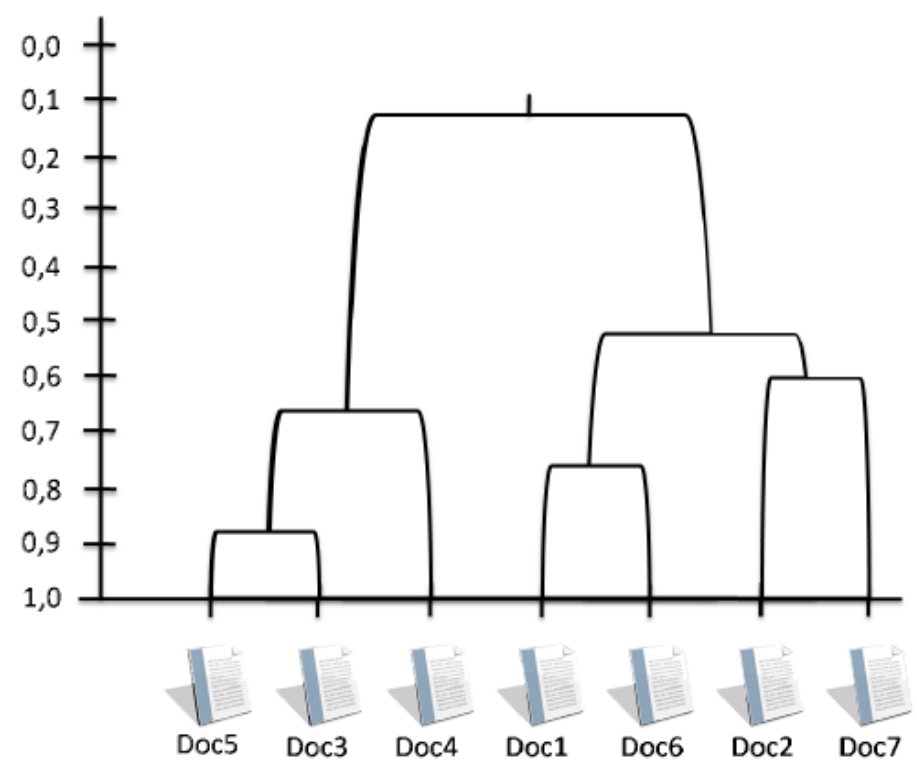

Figura 3.4: Exemplo de um dendrograma do agrupamento hierárquico de documentos (Rossi, 2011).

Já os métodos hierárquicos organizam uma coleção textual em uma hierarquia de grupos e subgrupos. O conhecimento mais genérico é representado por grupos de níveis mais altos na hierarquia, enquanto seus detalhes, ou o conhecimento mais específico, são representados por grupos de níveis mais baixos (Marcacini e Rezende, 2010). Estes métodos organizam os resultados do agrupamento em uma árvore binária conhecida como dendrograma, que é ilustrada na Figura 3.4.

Cada nó do dendrograma representa um grupo de documentos e a altura dos arcos que unem dois subgrupos indica o grau de compactação do grupo formado por eles, isto é, quanto menor a altura, mais compactos são os grupos. Também espera-se em um dendrograma que a proximidade de objetos em grupos distintos seja a menor possível 
(Marcacini, 2011).

Após o agrupamento dos documentos é necessário selecionar descritores que auxiliam a interpretação dos resultados, pois, de acordo com Manning et al. (2009), é necessário indicar o significado de cada grupo para que os usuários possam interagir de forma mais intuitiva. Algumas técnicas utilizam o centróide do grupo para selecionar seus descritores. Abordagens mais simples, selecionam os termos mais frequentes dos grupos. Outra possibilidade é selecionar, como descritores, os termos dos documentos mais próximos ao centróide.

Neste trabalho, a construção de hierarquia de tópicos dos conteúdos de páginas da Web visa organizar essas páginas de tal forma que os tópicos selecionados para os grupos possam ser utilizados em sistemas de recomendação sensíveis ao contexto, como será descrito no Capítulo 4.

\subsubsection{Reconhecimento de Entidades Nomeadas}

De acordo com Sekine (2004), o termo "Entidade Nomeada" (EN) surgiu na Message Understanding Conferece (MUC). A importância do Reconhecimento de Entidades Nomeadas (REN) tem crescido com a propagação de sistemas de extração de informação (Sarmento et al., 2006), uma vez que o pré-processamento da maioria das atividades desses sistemas tem como principal responsabilidade o REN (Nothman et al., 2013). O REN pode ser considerado uma sub-tarefa dos processos de extração de informação e envolve processar um texto e identificar as ocorrências de palavras ou expressões pertencentes às categorias de entidades nomeadas (Mikheev et al., 1999).

As entidades nomeadas incluem todas as entidades que podem ser identificadas por um nome próprio, como pessoas, organizações, lugares, marcas, produtos entre outros (Sarmento et al., 2006; Kozareva, 2006). Além dessas entidades também é possível reconhecer expressões temporais e expressões numéricas. Um exemplo dado em (Mikheev et al., 1999) é:

\section{" $<$ Person $>$ Flavel Donne $</$ Person $>$ is an analyst with $<$ Organization $>$ General Trends </Organization $>$, which has been based in < Localiza- tion > Little Spring </Localization > since < Date > July $1998</$ Date $>$."}

Nesse exemplo "Flavel Donne" é reconhecido como uma pessoa, "General Trends" como uma organização, "Little Spring" como uma localização e "July 1998" uma data. Os termos considerados entidades nomeadas dependem muito da aplicação que utiliza essas anotações. Um exemplo de aplicação é a recuperação de documentos, na qual documentos anotados com informações de entidades nomeadas podem ser buscados com mais precisão do que documentos sem tais anotações (Mikheev et al., 1999). Nesse exemplo, as informações de entidades nomeadas permitem que o usuário busque, por exemplo, por textos que mencionam "Brasil" como seleção de futebol, ignorando documentos sobre "Brasil" como país. 
Segundo Sarmento et al. (2006), o objetivo do Reconhecimento de Entidades Nomeadas é identificar e classificar todas as entidades nomeadas que existem em um texto de acordo com uma hierarquia ou ontologia. De acordo com Ceci et al. (2010), existem muitas técnicas automáticas que auxiliam no processo de reconhecimento de entidades nomeadas, como aplicação de: expressões regulares, thesauros, heurísticas, gazetteers, modelos estatísticos e ontologias. O processo de reconhecimento é o primeiro passo da análise semântica de um texto e é dividido em duas subtarefas (Nothman et al., 2013):

1. Identificação das entidades - em que é feito o reconhecimento das possíveis entidades;

2. Classificação das entidades - subtarefa que determina as classes semânticas que as entidades reconhecidas pertencem no contexto em que elas se encontram.

Alguns problemas enfrentados pelo processo de Reconhecimento de Entidades Nomeadas (REN) podem ser exemplificados pelas seguintes sentenças, retiradas de (Aranha, 2007):

\section{Philip B. Morris}

2. Juiz Nicolau dos Santos Neto

3. Presidente da Câmara dos Vereadores Alcides Barroso

4. Hollywood

Na primeira sentença (1), a abreviação no meio do nome poderia ser considerada como um ponto final, fazendo com que fossem reconhecidas as entidades "Philip B" e "Morris" separadamente. No segundo caso (2), como há a preposição "dos" no meio da sentença, poderiam ser reconhecidas duas entidades distintas: "Juiz Nicolau" e "Santos Neto", sendo que se trata de uma única entidade. No caso (3), existem duas entidades: "Presidente da Câmara dos Vereadores" e "Alcides Barroso", porém não há nenhuma evidência de onde dividir essa sentença. E por fim, o último caso é um exemplo de ambiguidade, pois "Hollywood" pode significar o lugar ou a marca de cigarros.

Em 2003 a Linguateca ${ }^{1}$ começou a planejar o HAREM (Avaliação de Reconhecedores de Entidades Nomeadas)(Santos e Cardoso, 2007), a primeira avaliação conjunta de sistemas de reconhecimento de entidades nomeadas em coleções de documentos em Português, sendo que o primeiro HAREM teve início em 2005. Seu objetivo é incentivar o desenvolvimento de sistemas voltados para a tarefa de identificar e classificar automaticamente nomes próprios em categorias previamente definidas, em textos escritos em Português (Santos e Cardoso, 2007).

A segunda edição do HAREM (Mota e Santos, 2008) avaliou vários sistemas que estão envolvidos no processo de reconhecimento de entidades nomeadas para a Língua

\footnotetext{
${ }^{1}$ A Linguateca é um centro de recursos para o processamento computacional da Língua Portuguesa http://www.linguateca.pt/
} 
Portuguesa, alguns dos quais foram explorados e comparados por Oliveira (2010): CAGE, PorTexTO, Priberam, R3M, REMBRANDT, REMMA, SEI-Geo e XIP.

Neste trabalho é utilizado o sistema REMBRANDT (Cardoso, 2008) para o reconhecimento de entidades nomeadas. Tal sistema anota nos próprios textos as entidades e suas classes, porém para a extração de informações contextuais são utilizadas apenas as entidades. No Capítulo 4 o sistema REMBRANDT é apresentado com mais detalhes, assim como o processo de extração e uso das entidades nomeadas. Assim como as entidades nomeadas, neste trabalho também são utilizados os termos extraídos do conteúdo das páginas da Web. Na próxima subseção é apresentada a extração de termos.

\subsubsection{Extração de Termos}

O termo, que também é chamado de característica ou atributo, pode ser um termo simples ou uma combinação de termos, isto é, um conjunto de palavras. Quando simples, é chamado de unigrama e quando é composto pode ser chamado de n-grama, em que $n$ indica o número de palavras que o compõem, ou pode ser chamado de "conjunto de palavras". O n-grama é formado por palavras que aparecem em sequência na coleção de documentos, enquanto que no "conjunto de palavras", elas podem ou não aparecer em sequência.

Considerar os termos de um documento como independentes pode não ser uma representação fiel da real relação entre eles, pois existem conceitos formados por dois ou mais termos, que, separados, podem possuir significados completamente diferentes. Um exemplo clássico que ilustra bem essa situação é o conceito "inteligência artificial". Considerar apenas as palavras individuais "inteligência" e "artificial" como termos pode levar à perda de informações (Carvalho et al., 2010; Rossi, 2011). Um método simples para encontrar n-gramas em textos é a contagem de ocorrências das palavras em sequências, ou seja, se duas palavras ocorrem diversas vezes juntas, então elas podem ter um significado especial juntas. Já para extrair conjuntos de palavras existem outras técnicas. Um exemplo é o trabalho de Rossi (2011), no qual foi proposta uma abordagem, denominada bag-of-related-words, que gera conjuntos de palavras utilizando regras de associação.

Os termos extraídos devem ser aqueles que representam conceitualmente a coleção de textos da melhor forma. As abordagens tradicionais de extração de termos são:

- Estatística: utiliza métodos baseados em conhecimento estatístico e é utilizada sobre a representação bag-of-words. Os termos são considerados independentes e as inferências são feitas sobre os valores dados a esses termos, como os possíveis valores citados na Seção 3.2.

- Linguística: utiliza métodos que fazem uso de recursos que contêm diferentes informações linguísticas para a extração dos termos. Essas informações podem ser morfológicas (formação das palavras e do texto), morfossintáticas (classes gramaticais das palavras), semânticas (sentido das palavras) e outras. 
- Híbrida: faz uso das duas abordagens.

Independente da abordagem utilizada, a extração de termos pode ser auxiliada por meio de simplificações de termos, que ajudam a reduzir o número de termos utilizados e os restringem a um conjunto mais representativo da coleção. Entre as técnicas de simplificação mais utilizadas encontram-se (Manning et al., 2009): radicalização, lematização e substativação.

A radicalização, também conhecida como Stemming, é uma técnica muito utilizada que reduz cada palavra do texto a seu radical (Manning et al., 2009). O radical é a porção da palavra, sem o prefixo ou o sufixo, que exprime sua ideia geral. Ela pode ser radicalização inflexional ou radicalização para a raiz (Aranha, 2007). Na radicalização inflexional considera-se apenas as remoções de flexões verbais, já na radicalização para a raiz é feita a remoção de todas as formas de prefixos e sufixos dos termos. Um exemplo de radicalização para a raiz dado em (Conrado, 2009) é:

Frase: Brasileiros pesquisam perfil do estudante.

Após remoção de stopwords e radicalização: brasil pesquis perfil estudant

Durante o processo de radicalização podem ocorrer o overstemming, quando parte do radical é removido, ou o understemming, quando não se remove completamente o sufixo e prefixo da palavra (Viera e Virgil, 2007).

Existem vários algoritmos de radicalização. Dentre os mais conhecidos, destinados a diferentes línguas, estão: Método de Lovins (Lovins, 1968), Método de Porter (Porter, 1997) e Método Stemmer S (Harman, 1991). Já especificamente para a língua portuguesa podem ser citados os algoritmos: PortugueseStemmer (Orengo e Huyck, 2001), Pegastemming $^{2}$, Porter - Português ${ }^{3}$ e STEMBR (Alvares et al., 2005).

A lematização, ou Redução à Forma Canônica, agrupa as variantes de um termo em um único lema, ou seja, os verbos são transformados para sua forma no infinitivo e os substantivos e adjetivos para o masculinho singular (Sparck Jones e Willett, 1997), por exemplo, o substantivo "brasileiras" passa a ser "brasileiro" e o verbo "correram" passa a ser "correr".

A técnica de lematização pode ser dividida em dois processos: processo de etiquetagem e processo de redução do termo. No processo de etiquetagem cada termo da coleção de textos é associado a uma etiqueta que corresponde a sua classe gramatical, como, por exemplo, verbo, substantivo e adjetivo. Após a identificação das classes gramaticais, pode ser realizado o processo de redução, no qual as palavras são reduzidas aos seus lemas. Algumas ferramentas para a lematização são: FLANOM (Santana et al., 1999), TreeTagger (Schmid, 1994) e FORMA (Gonzalez et al., 2006).

\footnotetext{
${ }^{2}$ http://www.inf.pucrs.br/ gonzalez/ri/pesqdiss/analise.htm

${ }^{3} \mathrm{O}$ algoritmo Porter - Português foi desenvolvido em 2005 por Porter, o mesmo autor do algoritmo de Porter para a Língua Inglesa
} 
Na substantivação, ou nominalização, as palavras exibem um comportamento sintático/semântico semelhantes ao de um nome (Gonzalez et al., 2006). A maioria das palavras do português podem ser substantivadas utilizando artigos. Um exemplo de substantivação novamente retirado de (Conrado, 2009) é:

Frase: Técnicas relacionadas à Inteligência Artificial.

Após remoção de stopwords e substantivação: tecnica relacionar inteligencia artificial

Neste trabalho, a extração de termos, assim como o reconhecimento de entidades nomeadas, são utilizadas, juntamente com a construção de hierarquia de tópicos, para obter contexto do conteúdo textual das páginas da Web. No Capítulo 4, é apresentada a abordagem de extração de termos utilizada neste trabalho e a forma na qual os termos são empregados no método de extração de contexto proposto.

\subsection{Considerações Finais}

A mineração de textos, conforme mencionado neste capítulo, é um processo que tem como objetivo descobrir padrões desconhecidos em dados não estruturados ou semiestruturados. Este processo pode ser dividido em cinco etapas principais: Identificação do problema, Pré-processamento, Extração de padrões, Pós-processamento e Utilização do conhecimento. Além dessas etapas, também foram detalhadas neste capítulo algumas abordagens de mineração de textos que podem auxiliar no objetivo principal deste projeto de mestrado, que consiste em estudar e propôr formas de extrair informações contextuais de páginas da Web de forma automática. Essas abordagens são: construção de hierarquia de tópicos, reconhecimento de entidades nomeadas (REN) e extração de termos.

No próximo capítulo é apresentado o método proposto para extração automática de contexto utilizando abordagens de mineração de textos. São detalhados todas as etapas do método e as formas nas quais cada abordagem de mineração de textos é utilizada para atingir objetivo do trabalho. 


\section{Capítulo}

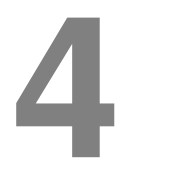

\section{Extração Automática de Contexto Utilizando Mineração de Textos para Sistemas de Recomendação}

\subsection{Considerações Iniciais}

Os sistemas de recomendação tradicionais fazem recomendações baseadas nos itens e nos usuários. Porém, em muitas aplicações, adicionar informações de contexto pode melhorar a qualidade das recomendações. Por exemplo, se um sistema de recomendação de pacotes de viagens considerar, além dos usuários e dos pacotes, a atual estação do ano, ele pode recomendar uma viagem mais adequada para o usuário naquele contexto específico. Como exemplo, também podem ser citados os sistemas recomendadores de filmes, de estabelecimentos, etc. O filme recomendado a um usuário, para ser relevante ao mesmo, pode depender do contexto em que o usuário se encontra. O mesmo ocorre com sistemas recomendadores de estabelecimentos, que atingem uma melhor acurácia na recomendação quando consideram informações contextuais como tempo, local, companhia e outros.

Como uma evolução dos sistemas de recomendação tradicionais, existem os sistemas de recomendação sensíveis ao contexto, que utilizam informações contextuais, além das informações de usuários e itens. Um dos maiores desafios para o uso desse tipo de sistema é a falta de métodos automáticos de aquisição de informação contextual, que possam identificar contexto de forma explícita, implícita ou inferida, conforme explicado na Seção 2.3.2. Nesse sentido, como forma de cobrir parte dessa lacuna e avançar no estado da arte, este trabalho explora a utilização de métodos de aquisição de contexto de forma inferida. As informações contextuais extraídas referem-se aos itens, ou seja, às páginas da 
Web acessadas pelos usuários. Para isso, são utilizadas abordagens de mineração de textos para a aquisição automática de informações contextuais para a construção de sistemas de recomendação de conteúdo Web sensíveis ao contexto.

Neste capítulo é apresentado o método proposto neste trabalho para a extração automática de contexto, utilizando mineração de textos, para sistemas de recomendação. Inicialmente é descrita a visão geral da proposta, que é composta por três etapas principais. A primeira etapa, referente ao pré-processamento dos dados, é descrita na Seção 4.2.1. Na seção seguinte, 4.2.2, é descrita a etapa principal e mais importante desta proposta, na qual é executado o método proposto para extração de contexto. Em tal método são combinadas as abordagens de mineração de textos: construção de hierarquia de tópicos, reconhecimento de entidades nomeadas e extração automática de termos. A etapa de utilização do contexto extraído, é descrita brevemente na Seção 4.2.3, e mais detalhes dessa etapa, que envolve a avaliação do contexto, são apresentados no Capítulo 5.

\subsection{Descrição do Método para Extração Automática de Contexto Utilizando Abordagens de Mineração de Textos}

Este trabalho visa, utilizando uma base de logs de acessos da Web, extrair conteúdos textuais das páginas acessadas pelos usuários e aplicar nesses textos o método proposto, que utiliza abordagens de mineração de textos, para obter informações de contexto automaticamente. Ainda como parte do trabalho, essas informações extraídas são inseridas em sistemas de recomendação sensíveis ao contexto, descritos na Seção 2.3.1, e as recomendações geradas são avaliadas a fim de analisar como a informação contextual utilizada influencia a qualidade das recomendações.

Na Figura 4.1 é ilustrada a visão geral da proposta deste trabalho, que é composta pelas seguintes etapas: Pré-processamento, Extração de Contexto e Utilização do Contexto Extraído, sendo elas detalhadas nas próximas subseções.

\subsubsection{Pré-Processamento da Base de Logs}

O objetivo da etapa de pré-processamento é obter o conteúdo textual das páginas acessadas pelos usuários. A base de dados, que é utilizada como entrada no processo de extração de contexto proposto neste trabalho, consiste em uma base de logs de acessos às páginas da Web. Durante uma sessão de navegação de um usuário, toda atividade é gravada em um arquivo de logs pelo servidor da Web. Cada entrada no arquivo de logs (dependendo do formato do $l o g$ ) pode conter campos identificando data e horário do acesso, endereço de IP do usuário, URL da página acessada, ID do acesso, etc (Liu, 2011; Han e Xia, 2014).

A primeira etapa do pré-processamento dos logs consiste na limpeza, na qual são eliminados acessos repetidos, acessos que não possuem algum campo de informação, etc 


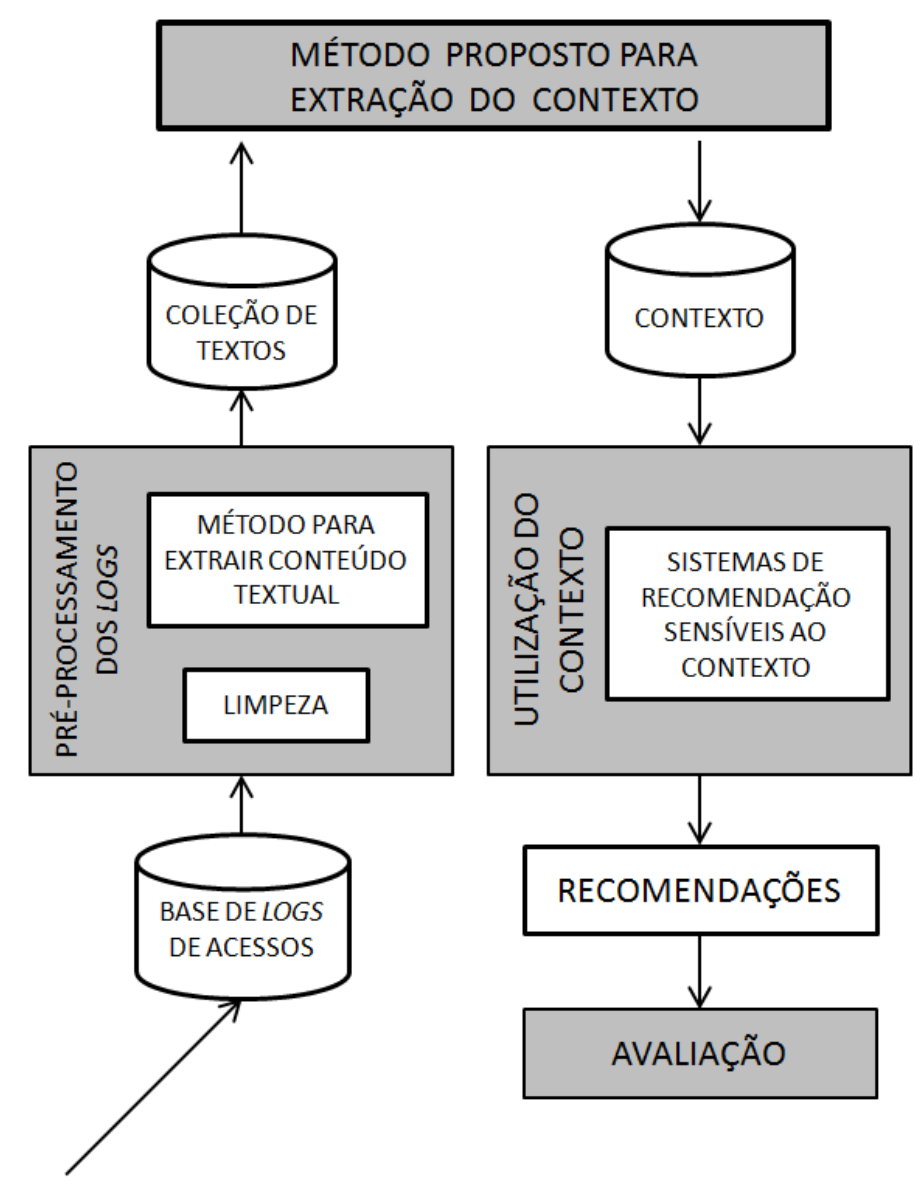

Figura 4.1: Visão geral da proposta deste trabalho de mestrado.

(Han e Xia, 2014). Após a limpeza, é iniciado o método de extração do conteúdo textual das páginas acessadas pelos usuários, ilustrado na Figura 4.2. Esse método abrange duas atividades:

- Obtenção de documentos HTML a partir da base de logs - para a extração do conteúdo textual das páginas da Web, são obtidos documentos HTML a partir da base de logs. Tais documentos são referentes às páginas acessadas pelos usuários. Esta atividade é executada por meio de um script que acessa a base de logs de acessos e, com o programa GNU Wget ${ }^{1}$, faz o download de todas as páginas, constituindo uma base de documentos em formato HTML;

- Extração de conteúdos textuais - com os documentos em HTML referentes às páginas da Web acessadas pelos usuários, o segundo passo é extrair os conteúdos textuais desses documentos. Esta atividade pode ser executada de duas formas:

- Utilizando a ferramenta HtmlAsText ${ }^{2}$ para processar os documentos em formato HTML e extrair o conteúdo textual dos mesmos, gerando a base de textos dos conteúdos das páginas acessadas. Neste caso o conteúdo textual envolve toda a página da Web (cabeçalho, rodapé, etc).

\footnotetext{
${ }^{1}$ http://www.gnu.org/software/wget

${ }^{2}$ http://www.nirsoft.net/utils/htmlastext.html
} 
- Utilizando expressões regulares para extrair apenas o conteúdo textual principal da página da Web (sem cabeçalho, sem rodapé, etc).

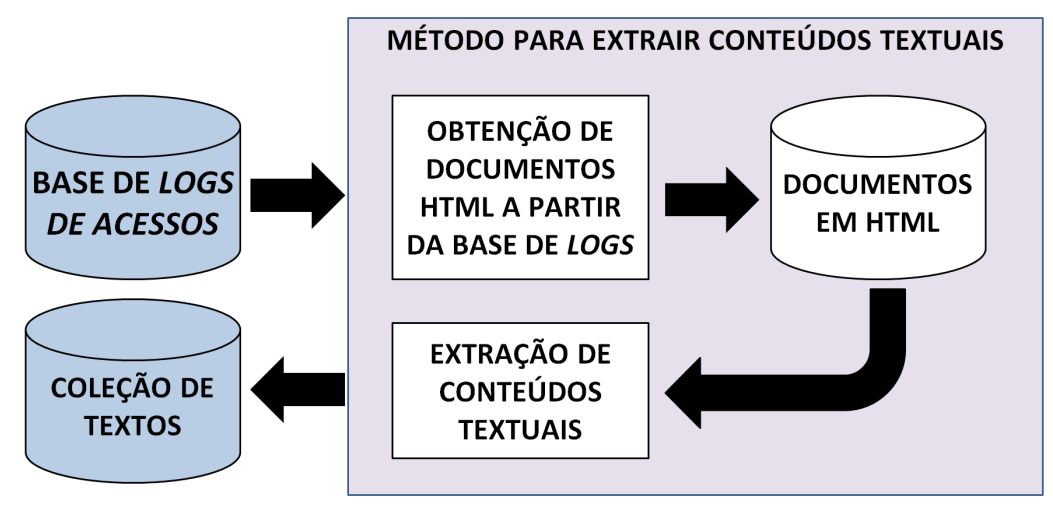

Figura 4.2: Extração do conteúdo textual das páginas da Web.

Após o pré-processamento e com a coleção de textos pronta, é possível então aplicar o método de extração de contexto proposto neste trabalho, que utiliza abordagens de mineração de textos. Esse método é apresentado na próxima seção.

\subsubsection{Método Proposto para Extração de Contexto}

De acordo com Adomavicius et al. (2011), o conceito de contexto tem sido estudado extensivamente nas áreas de computação e outras disciplinas. Contexto pode ser definido de várias formas, dependendo do campo de aplicação. Bazire e Brézillon (2005), depois de examinarem 150 definições diferentes de contexto concluíram que é difícil encontrar uma definição única. Eles levantaram algumas questões, como: "Contexto é uma moldura para um determinado objeto?", "É o conjunto de elementos que tem alguma influência no objeto?", "É algo estático ou dinâmico?" Para Dourish (2004), existem duas visões diferentes de contexto: a visão interacional e a visão representacional. Na visão interacional o contexto é definido dinamicamente e existe uma relação entre o contexto e a atividade, na qual o contexto influencia a atividade e a atividade influencia o contexto. Enquanto que, na visão representacional, o contexto pode ser descrito como um conjunto de atributos conhecidos, cuja estrutura não muda ao longo do tempo.

A informação contextual também pode ser organizada como uma estrutura hierárquica e representada como árvores (Adomavicius et al., 2005; Panniello e Gorgoglione, 2012). Dessa forma, a informação contextual é um conjunto de dimensões contextuais $C$, em que cada dimensão $C$ é definida por um conjunto de $s$ atributos/valores, i.e., $C=\left(c_{1}, c_{2}, \ldots, c_{s}\right)$. Esses atributos possuem uma estrutura hierárquica. Os valores do atributo $c_{s}$ possuem níveis mais altos de granularidade, enquanto $c_{1}$ níveis menores de granularidade. Por exemplo, em Panniello e Gorgoglione (2012), eles representaram o atributo contextual "período do ano" como a estrutura hierárquica ilustrada na Figura 4.3.

Baseando-se na ideia de organizar o contexto de forma hierárquica, neste trabalho descobriu-se nas hierarquias de tópicos, modelos eficientes de extração de contexto. O 


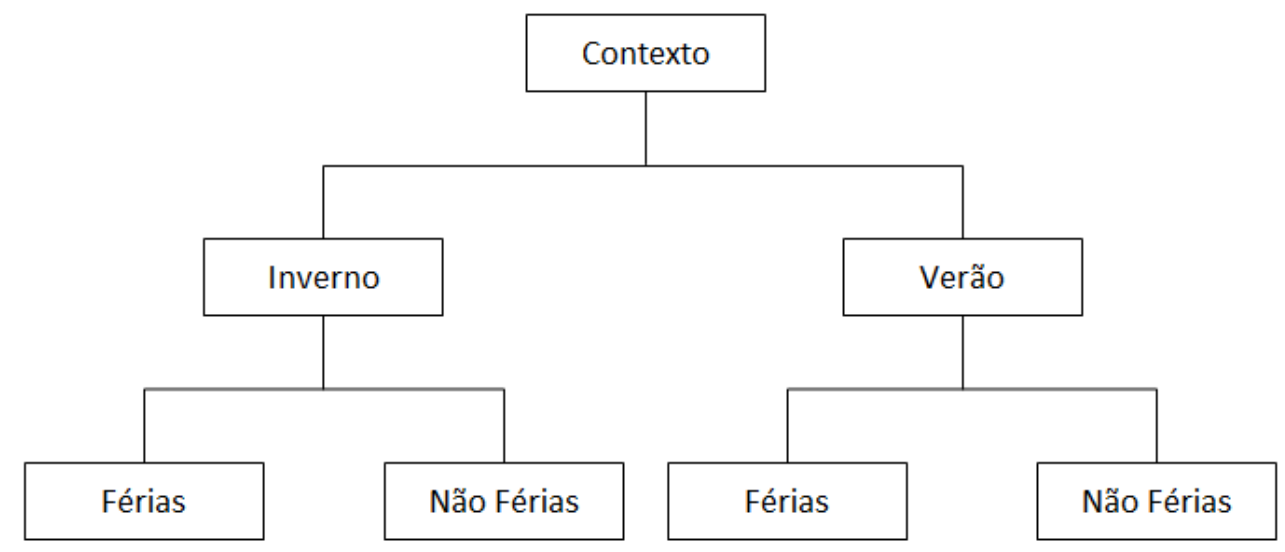

Figura 4.3: Estrutura hierárquica do atributo contextual "periodo do ano" (Panniello e Gorgoglione, 2012).

agrupamento hierárquico dos textos é um método de aprendizado de máquina não supervisionado que permite extração automática de conhecimento de grandes coleções de textos. Tal método permite organizar os documentos em tópicos e subtópicos, em que cada tópico representa um grupo de documentos relacionados uns com os outros. A maioria dos métodos de agrupamento existentes assumem que as coleções de textos são estáticas, o que significa que é necessário repetir todo o processo de agrupamento sempre que nova informação precisa ser adicionada no agrupamento. Além disso, esses métodos geralmente representam a informação textual utilizando somente os termos dos documentos, ou seja, a bag-of-words, também conhecida como informação técnica. Entretanto, existem informações adicionais potenciais nos textos que podem ser utilizadas para complementar a representação bag-of-words tradicional. Essa informação adicional é conhecida como "informação privilegiada" (Vapnik e Vashist, 2009).

Neste trabalho são utilizadas entidades nomeadas e termos do domínio extraídos das páginas da Web como informações privilegiadas para o agrupamento das páginas. As principais razões para utilizar entidades nomeadas e termos do domínio como informações privilegiadas são:

- Entidades nomeadas e termos do domínio não estão explicitamente disponíveis nos dados, então seu correto reconhecimento requer algum processo adicional;

- Entidades nomeadas e termos do domínio representam informação rica sobre o conteúdo dos documentos;

- Entidades nomeadas e termos do domínio estão disponíveis para uma fração de documentos, o que caracteriza informação privilegiada.

Para explorar tais informações privilegiadas, neste trabalho é utilizada um método para construir hierarquia de tópicos proposto por Marcacini e Rezende (2013), ilustrado na Figura 4.4. Esse método, chamado LUPI-based Incremental Hierarchical Clustering (LIHC), estende o paradigma LUPI (Learning Using Privileged Information) (Vapnik e Vashist, 2009). O paradigma LUPI incorpora informação privilegiada na tarefa de 
classificação, enquanto que o método LIHC incorpora informação privilegiada na tarefa de agrupamento.

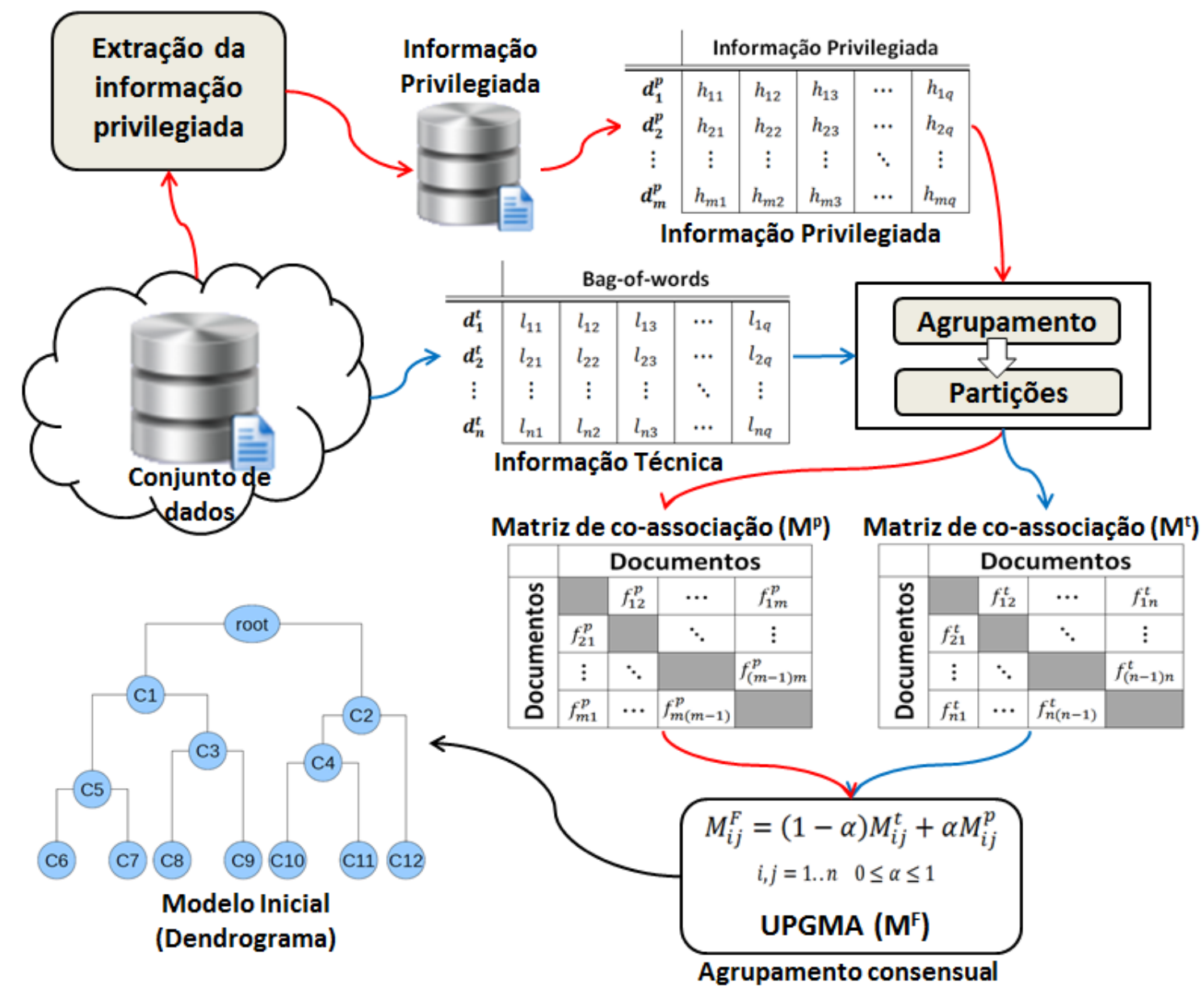

Figura 4.4: Método LIHC proposto por Marcacini e Rezende (2013).

Formalmente, sejam $D^{t}$ e $D^{p}$ dois conjuntos de atributos, em que $D^{t}$ são os atributos da informação técnica e $D^{p}$ são os atributos da informação privilegiada. Sejam $D_{\text {pri }}=\left\{d_{1}^{p}, \ldots, d_{m}^{p}\right\}$ e $D_{\text {tec }}=\left\{d_{1}^{t}, \ldots, d_{m}^{t}, d_{m+1}^{t}, \ldots, d_{n}\right\}$ os conjuntos de documentos com informação privilegiada (totalizando $m$ documentos) e com informação técnica (totalizando $n$ documentos), respectivamente, em que $d^{p} \in D^{p}$ e $d^{t} \in D^{t}$. O subconjunto de documentos com informação privilegiada é representado por $Y=\left\{\left(d_{1}^{t}, d_{1}^{p}\right), \ldots,\left(d_{m}^{t}, d_{m}^{p}\right)\right\}$. Vários algoritmos de agrupamento são executados (ou execuções repetidas do mesmo algoritmo com diferentes valores de parâmetro) para obter vários agrupamentos do subconjunto $Y$. Para agregar os grupos/partições geradas, a abordagem LIHC obtem duas matrizes de co-associação $M^{t}(i, j)$ e $M^{p}(i, j)$, que representam, respectivamente, o modelo de agrupamento da informação técnica (bag-of-words) e o modelo de agrupamento da informação privilegiada (entidades nomeadas ou termos do domínio). As entradas da matriz de co-associação são $M_{i j}=\frac{a_{i j}}{p}$, em que $a_{i j}$ representa o número de vezes que os documentos $i$ e $j$ foram alocados no mesmo grupo e $p$ é o número total de partições geradas. A combinação desses dois modelos de agrupamento é feita utilizando uma matriz 
de co-associação consensual:

$$
M^{F}(i, j)=(1-\alpha) M^{t}(i, j)+\alpha M^{p}(i, j)
$$

para todos os itens $i$ e $j$. Nesse caso, o parâmetro $\alpha$ é um fator de combinação $(0 \leq \alpha \leq 1)$ que indica a importância de cada espaço de atributos na matriz de co-associação final. $\mathrm{O}$ modelo inicial do método LIHC é obtido aplicando algum algoritmo de agrupamento hierárquico a partir da matriz $M^{F}$. Neste trabalho, o algoritmo de agrupamento hierárquico utilizado é o UPGMA (Unweighted Pair-Group Method using Arithmetic Avarages). O método UPGMA utiliza as médias aritméticas (não ponderadas) das medidas de dissimilaridade, ou seja, a distância entre um novo item e um grupo é dada pela média das distâncias entre todos os itens do grupo com o novo item. A construção dos dendrogramas é estabelecida pelos modelos ajustados de menor dissimilaridade (Jain e Dubes, 1988).

Os documentos de texto restantes, isto é, os documentos sem informação privilegiada, são inseridos incrementalmente no agrupamento hierárquico, por exemplo, usando a similaridade entre os novos documentos e os centróides do grupos existentes. Para a construção da hierarquia de tópicos, a extração dos tópicos é feita utilizando uma medida de seleção de atributos (medida F1). Os tópicos do agrupamento hierárquico são utilizados como informação contextual em sistemas de recomendação sensíveis ao contexto, como por exemplo, os sistemas descritos na Seção 2.3.1.

Neste trabalho, as informações privilegiadas foram combinadas com a informação técnica variando o valor do $\alpha$ (fator de combinação). A construção das hierarquias de tópicos foram realizadas de duas formas. Na primeira forma foram construídas hierarquias combinando as entidades nomeadas, como informação privilegiada, com a informação técnica (bag-of-words tradicional). Já na segunda forma, foram considerados os termos extraídos como informação privilegiada, e estes foram combinados com a informação técnica.

A seguir, são descritas as formas nas quais as informações privilegiadas, entidades nomeadas e termos do domínio, são extraídas neste trabalho.

\section{O Reconhecimento da Entidades Nomeadas como Informação Privilegiada}

O reconhecimento de entidades nomeadas é realizado utilizando o sistema REMBRANDT (Cardoso, 2008), que é um sistema de reconhecimento de entidades nomeadas e de detecção de relações entre entidades em textos escritos em Português. Tal sistema foi escolhido neste trabalho devido aos seus bons resultados na segunda avaliação conjunta de sistemas de reconhecimento de entidades nomeadas, o Segundo HAREM (Mota e Santos, 2008) (avaliação já apresentada na Seção 3.3.2, pág. 42), e devido à sua disponibilidade ${ }^{3}$, além do fato dele reconhecer todos os tipos de entidades definidos no HAREM.

O sistema REMBRANDT reconhece as entidades anotando no próprio texto a entidade e sua classe. Entre as classes reconhecidas estão: Abstração, Acontecimento, Coisa, Local,

\footnotetext{
${ }^{3}$ http://xldb.di.fc.ul.pt/Rembrandt/
} 
Obra, Organização, Pessoa, Tempo, Valor e Outro. Na Figura 4.5 está ilustrado o processo de extração de entidades nomeadas das páginas da Web.

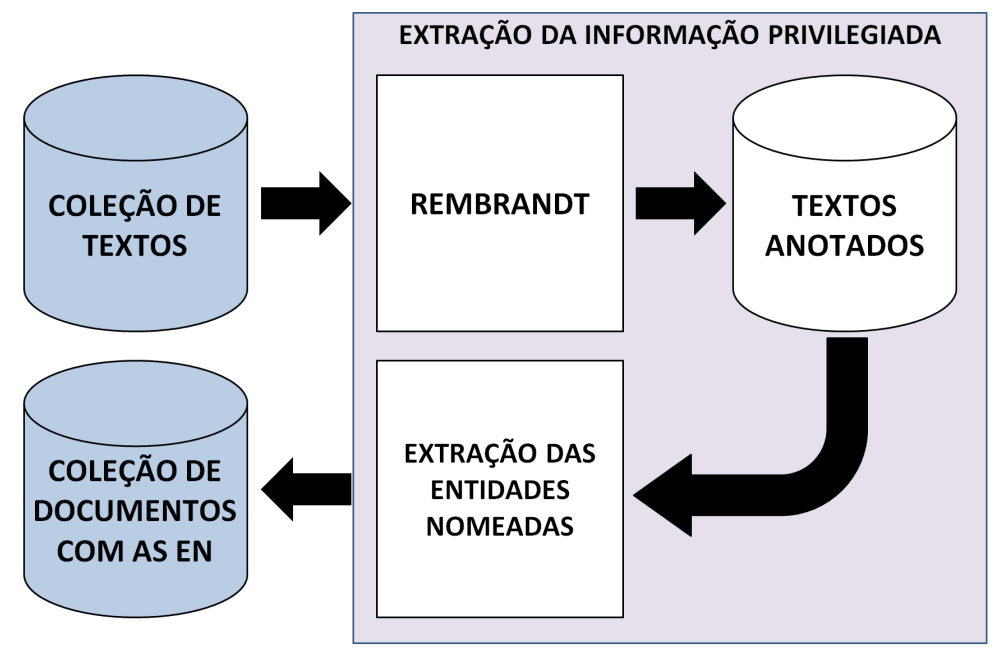

Figura 4.5: Processo de extração de entidades nomeadas.

O sistema REMBRANDT usa a Wikipédia ${ }^{4}$ como base de conhecimento para a classificação de entidades nomeadas e possui uma interface própria, a SASKIA, para interagir com essa base, como pode-se observar na Figura 4.6. O objetivo dessa interface, segundo Cardoso (2008), é facilitar a navegação da estrutura de categorias, ligações e redirecionamentos da Wikipédia.

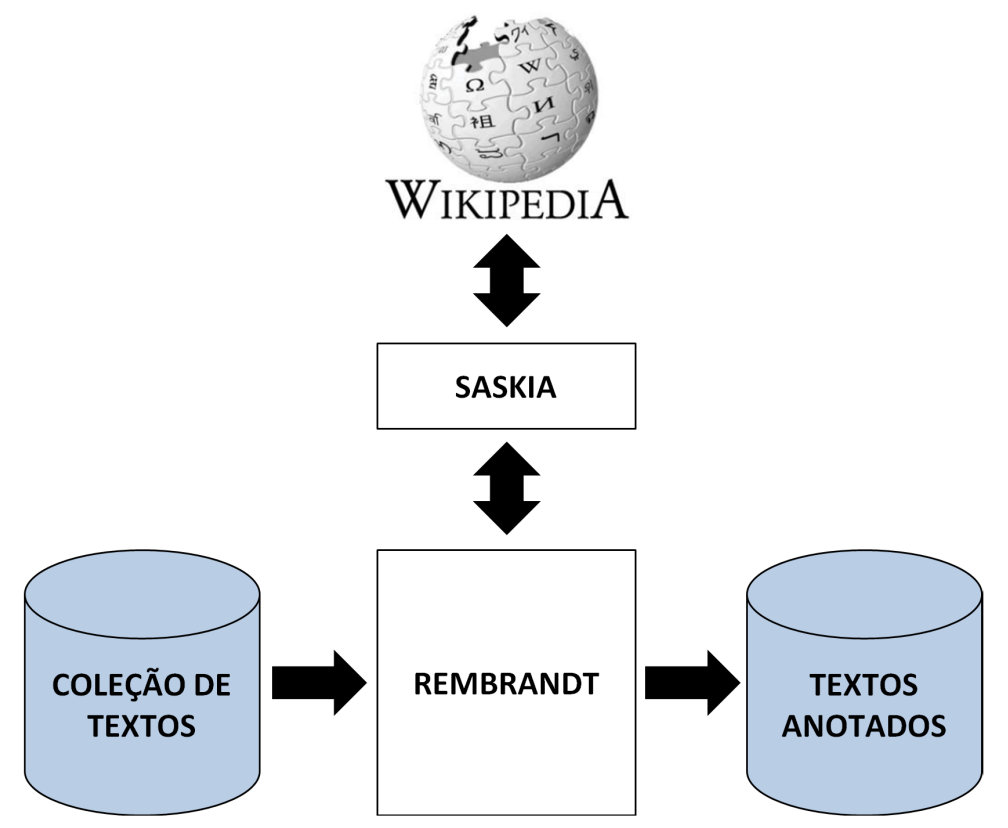

Figura 4.6: Uso do Wikipédia pelo sistema REMBRANDT (Adaptado de Oliveira (2010)).

De acordo com Cardoso (2008), o funcionamento do REMBRANDT pode ser dividido em três etapas, as quais estão esquematizadas na Figura 4.7 e descritas a seguir:

\footnotetext{
${ }^{4}$ WWw. wikipedia.com.br
} 


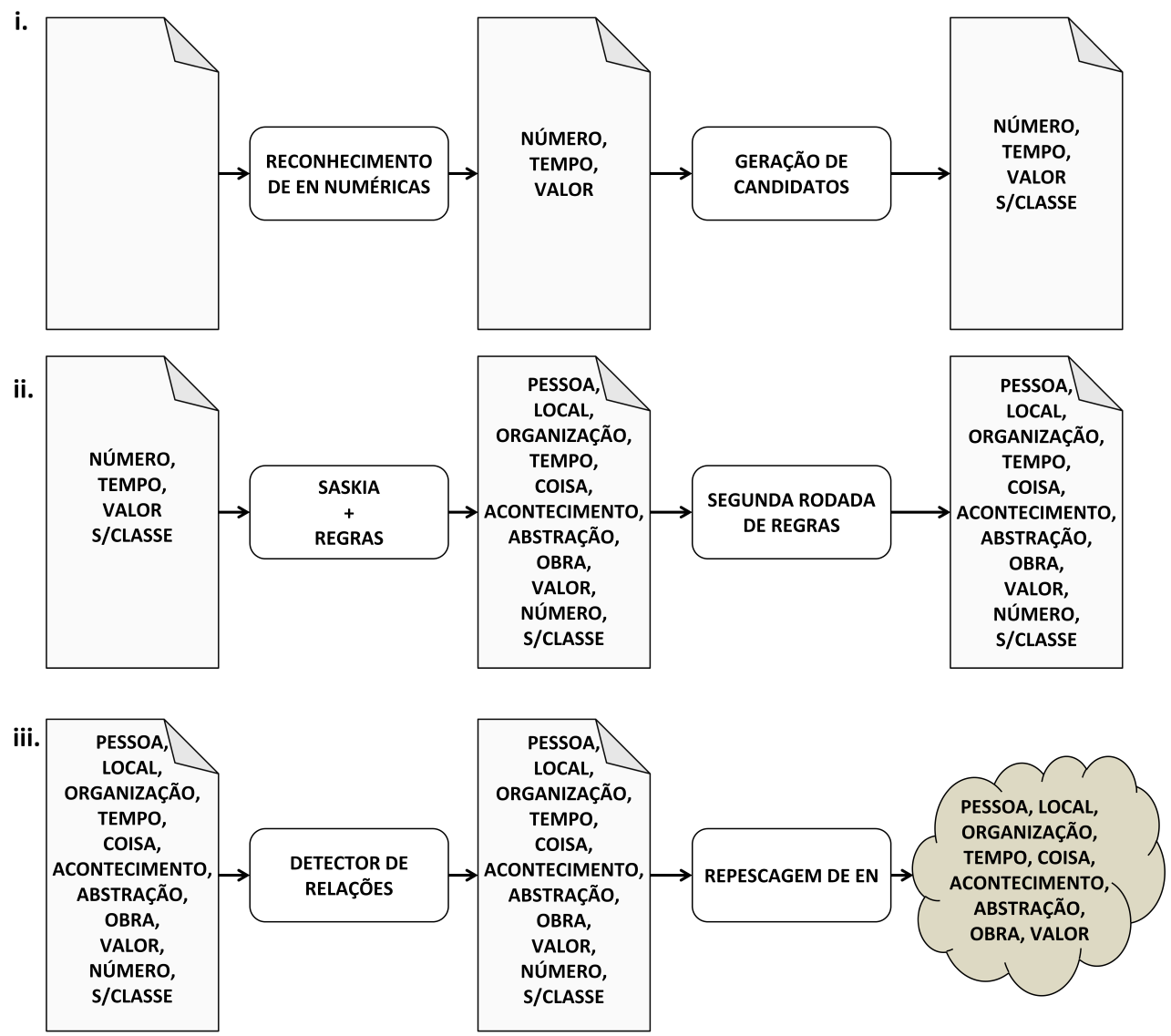

Figura 4.7: Etapas do funcionamento do REMBRANDT (Adaptado de Cardoso (2008)).

(i) Reconhecimento de expressões numéricas e geração de candidatas a EN: é utilizado o atomizador da Linguateca ${ }^{5}$ para dividir os textos em frases e unidades. Primeiramente são aplicadas regras para identificar expressões numéricas no texto e, em seguida, regras para identificar expressões temporais e valores. A geração das candidatas a entidades nomeadas é feita identificando-se sequências contendo letra maiúscula e/ou um algarismo.

(ii) Classificação de EN: as candidatas à EN são classificadas primeiro pela SASKIA e depois são novamente classificadas utilizando regras gramaticais. A SASKIA realiza uma classificação de acordo com vários significados que as EN podem ter e que se encontram nas páginas de desambiguação da Wikipédia. O procedimento de classificação da SASKIA é dividido em três etapas:

(1) associação da EN a uma página da Wikipédia, na qual a SASKIA procura uma página da Wikipédia com o título exatamente igual à EN. Quando encontra, passa para a próxima etapa, do contrário é procurada a página mais relacionada por meio de âncoras cujo texto é idêntico à EN.

(2) recolhimento de categorias associadas à EN, em que a SASKIA analisa o tipo da categoria da página associada na etapa anterior e a adiciona a uma lista de categorias.

${ }^{5}$ http://www. linguateca.pt 
(3) mapeamento das categorias da Wikipédia às classificações do HAREM, etapa na qual a SASKIA aplica regras gramaticais sobre cada uma das categorias para extrair seu significado e sua referência geográfica caso exista. Após a classificação feita pela SASKIA, as EN são novamente classificadas por meio de regras gramaticais. Um exemplo, dado por Cardoso (2008), ilustra o funcionamento das regras: "Eu moro na Rua de Angola", com esta frase a SASKIA classifica a EN Angola como sendo um "país", porém com a aplicação de regras gramaticais a classificação da EN Angola é alterada para "rua".

(iii) Repescagem de EN sem classificação: são utilizadas regras para detectar relações entre EN e, com essas relações, algumas EN sem classificação podem receber a mesma classe das EN relacionadas a elas e já classificadas. Além disso, é utilizada uma lista de nomes comuns de pessoas para classificar outras EN ainda não classificadas. Por fim, as EN que persistem sem classificação são eliminadas.

Neste trabalho, a partir dos documentos anotados com essas classes de entidades, são extraídas apenas as entidades nomeadas para serem utilizadas como informação privilegiada. Ou seja, utilizando como exemplo o texto da Seção 3.3.2, pág. 43, as entidades extraídas são:

- Flavel_Done

- General_Trends

- Little_Spring

- July_1998

O resultado do processo de extração de entidades nomeadas, é a coleção de documentos contendo apenas as entidades. Cada documento é referente a uma página da Web. Dessa forma, tal coleção pode ser utilizada na construção da hierarquia de tópicos, representando a informação privilegiada da coleção de textos.

\section{Extração Automática de Termos como Informação Privilegiada}

Neste trabalho, os termos do domínio são extraídos utilizando a abordagem proposta por Conrado et al. (2013). O processo de extração dos termos está ilustrado na Figura 4.8.

A extração automática de termos, tem como objetivo identificar unidades terminológicas em coleções de textos de domínio específico (Castellví et al., 2001). Essa informação é utilizada em aplicações computacionais como recuperação de informação, extração e sumarização.

Existem quatro grandes problemas relacionados à extração de termos. O primeiro deles é que podem ser extraídos muitos termos que não são considerados termos reais (ruído) ou deixar de extrair os termos que são de fato reais (silêncio). O segundo problema é a dificuldade em lidar com um alto número de candidatos que requer muito tempo para processá-los. O terceiro problema é o esforço humano gasto para validar os candidatos a 


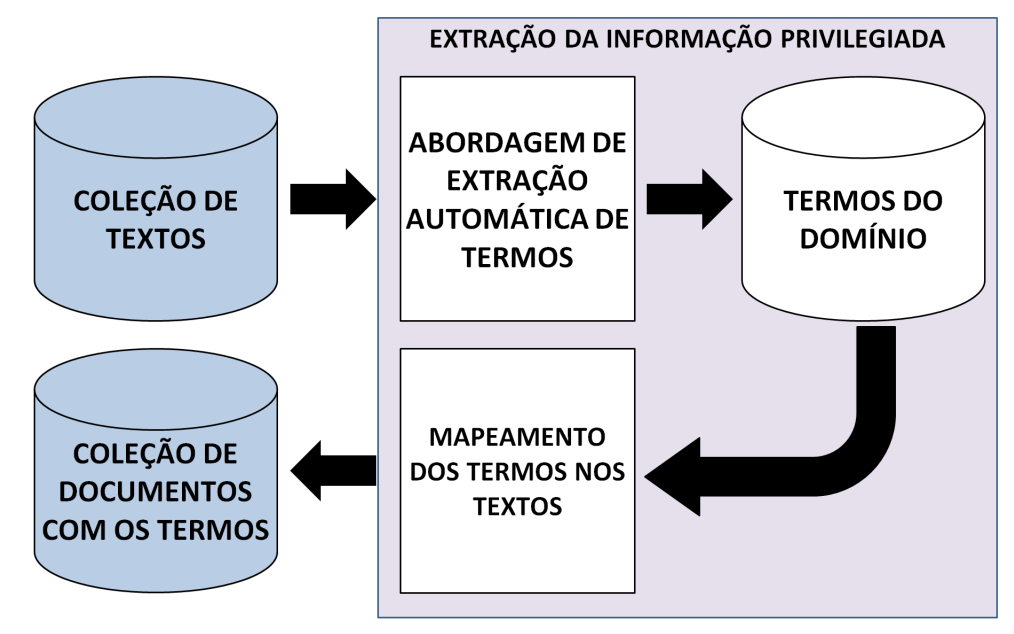

Figura 4.8: Processo de extração de termos do domínio.

termos. E, por fim, o quarto problema é obter um consenso entre os especialistas sobre quais palavras são termos de um domínio específico.

Com o objetivo de solucionar alguns desses problemas, Conrado et al. (2013) propuseram uma abordagem automática de extração de termos que usa aprendizado de máquina incorporando características ricas de candidatos a termos. De acordo com Conrado et al. (2013), sua abordagem se difere de outras abordagens propostas na literatura porque ela adota um conjunto de características ricas usando níveis de conhecimento variados. Essa abordagem pode ser visualizada por meio de algumas etapas ilustradas na Figura 4.9.

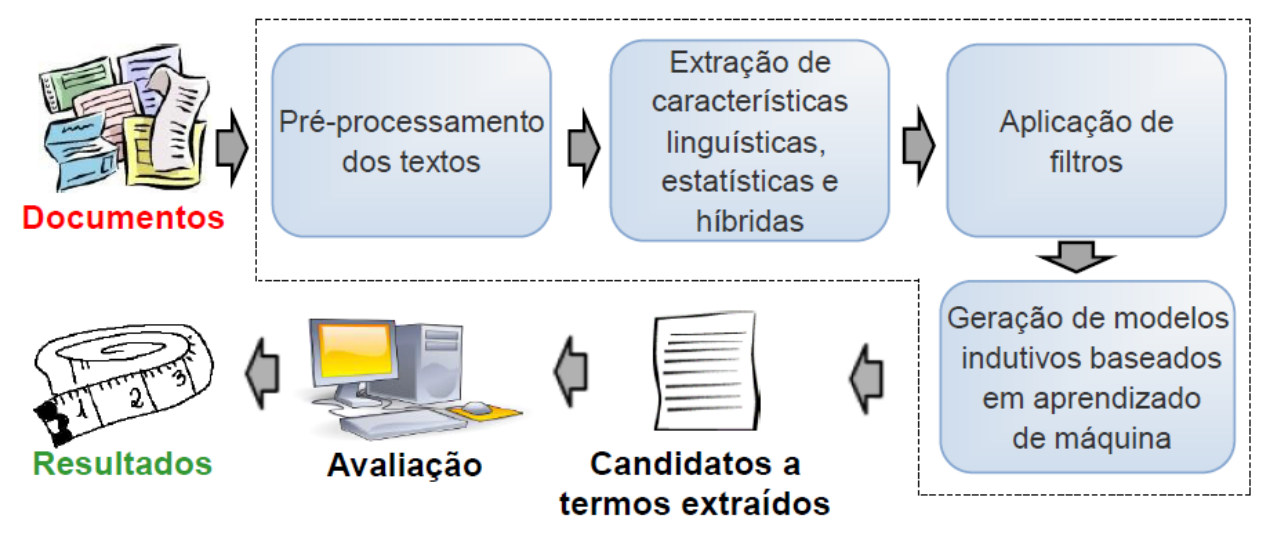

Figura 4.9: Visão geral da abordagem de extração automática de termos (Conrado et al., 2013).

- Pré-processamento dos textos: etapa na qual é feita a etiquetagem gramatical dos textos, a normalização das palavras e a remoção de stopwords. Nos experimentos de Conrado et al. (2013), para a etiquetagem gramatical foi utilizado o parser PALAVRAS (Bick, 2000), e a técnica de radicalização PTStemmer ${ }^{6}$ foi adotada para a normalização dos termos.

\footnotetext{
${ }^{6}$ https://code.google.com/p/ptstemmer
} 
- Extração de características linguísticas, estatísticas e híbridas: consiste em calcular, para cada candidato, diferentes características de diferentes níveis de conhecimento. Os níveis de conhecimento são linguístico, estatístico e híbrido.

- Aplicação de filtros: tem como objetivo selecionar somente os candidatos que têm maior chance de serem termos do domínio. Isso é necessário para diminuir a grande quantidade de candidatos a termos obtidos.

- Geração de modelos indutivos baseados em aprendizado de máquina: objetiva identificar quais candidatos correspondem a termos. Nesta etapa, pode-se classificar candidatos em termos ou não termos utilizando um modelo indutivo. Conrado et al. (2013) escolheram para esta etapa indutores muito conhecidos na área de aprendizado de máquina. Eles representam diferentes paradigmas de aprendizado: JRip (Indução de Regras), Naive Bayes (Probabilístico), J48 (Árvore de decisão), SMO (Aprendizado estatístico). Todos esses algoritmos estão disponíveis no software WEKA?

A entrada da abordagem descrita é a coleção de textos, e a saída é uma lista de termos extraídos para o domínio da coleção. Neste trabalho, conforme apresentado na Figura 4.8, após a extração dos termos, é feito um mapeamento entre os termos e os textos, construindo uma coleção de documentos contendo apenas os termos do domínio. Assim como as entidades nomeadas, cada documento da "Coleção de Documentos com os Termos" representa uma página da Web acessada pelos usuários. Tal coleção é utilizada no método LIHC, como informação privilegiada.

\subsubsection{Utilização do Contexto Extraído}

As hierarquias de tópicos construídas, utilizando o método LIHC, representam os conteúdos das páginas da Web organizados em grupos e subgrupos. Para cada grupo e subgrupo, existem os descritores ou tópicos que indicam o conteúdo principal dos documentos (páginas da Web), presentes nos mesmos. Nos tópicos podem ser encontradas tanto a informação técnica, quanto a informação privilegiada (entidades nomeadas ou termos do domínio). Portanto, neste trabalho, consideram-se informações contextuais de um item (página da Web), os tópicos que representam o grupo ou subgrupo no qual ele está inserido.

Não são considerados todos os tópicos, mas sim selecionados subconjuntos de tópicos utilizando a seguinte configuração de granularidade: $\{x, y\}$, em que o parâmetro $x$ identifica o número mínimo de itens permitido no tópico, enquanto o parâmetro $y$ identifica o número máximo de itens por tópico. Quando um tópico tem poucos items associados, geralmente representa grupos mais específicos. Por outro lado, tópicos com muitos itens, representam grupos mais gerais. Neste trabalho foram consideradas as seguintes configurações de granularidade: $\{50,100\},\{15,20\},\{10,50\}$ e $\{2,7\}$.

\footnotetext{
${ }^{7}$ http://www.cs.waikato.ac.nz/ml/weka/
} 
Essas informações de contexto são utilizadas nos seguintes sistemas de recomendação sensíveis ao contexto: cReduction (Pré-Filtragem Contextual), DaVI-BEST (Modelagem Contextual), Weight PoF e Filter PoF (Pós-Filtragem Contextual), já apresentados na Seção 2.3.1.

\subsection{Avaliação}

As recomendações geradas são avaliadas de forma offline utilizando dois baselines diferente, que são eles:

1. Método Item-Based Colaborative Filtering (IBCF), descrito na Seção 2.2.1, que não utiliza informação de contexto. Na avaliação que utiliza este baseline, as recomendações geradas por ele são comparadas com as recomendações geradas utilizando o contexto extraído pelo método proposto neste trabalho; e

2. Baseline implementado neste trabalho, referido como baseline "metodológico", baseado no trabalho de Li et al. (2010), descrito na Seção 2.3.2. Na avaliação que utiliza este baseline, são comparadas as informações contextuais extraídas pelo método proposto neste trabalho com as informações extraídas pela implementação adaptada do método proposto por Li et al. (2010). Tal baseline metodológico é descrito a seguir.

No trabalho de Li et al. (2010), a informação contextual "Tempo" é extraída utilizando o reconhecedor de entidades nomeadas $\mathrm{ANNIE}^{8}$, um módulo do GATE ${ }^{9}$. Os horários de refeições são classificados nos seguintes tipos: "café da manhã", "almoço", "jantar", "refeição matinal", "chá da manhã" e "chá da tarde". Para isso, é construído um dicionário para essas classes e é utilizado um método de comparação de "strings" para fazer a classificação. Similarmente, neste trabalho de mestrado, é utilizado o sistema REMBRANDT para reconhecer entidades de tempo, mais especificamente do tipo "tempo do calendário". Nessa categoria são reconhecidas entidades como: DD/MM/AAAA, DD/MM/AA, DDMM-AA, DD-MM-AAAA e DD de Mês de AAAA. Tais entidades são classificadas em duas etapas:

- Primeira Etapa - nesta etapa as entidades são classificadas em sete classes referentes ao grupo "Dias da Semana", que são "Domingo", "Segunda-Feira", "Terça-Feira", "Quarta-feira", "Quinta-Feira", "Sexta-Feira" e "Sábado". Tal classificação é feita com apoio de um dicionário construído para as classes mencionadas, um método de comparação de strings e a biblioteca em Java "Calendar";

- Segunda Etapa - nesta segunda etapa, o grupo considerado é "Estações do Ano", no qual estão as classes "Primavera", "Verão", "Outono" e "Inverno". As entidades

\footnotetext{
${ }^{8}$ https://gate.ac.uk/ie/annie.html

${ }^{9}$ http://gate.ac.uk
} 
são classificadas também com o apoio de um dicionário construído para tais classes e um método de comparação de strings.

Por meio do baseline metodológico implementado são extraídos, portanto, dois tipos de informação de contexto: "Dias da Semana" e "Estações do Ano". Essas informações são utilizadas pelos mesmos sistemas de recomendação sensíveis ao contexto mencionados anteriormente e as recomendações geradas são avaliadas separadamente, ou seja, é feita uma avaliação das recomendações geradas utilizando o contexto extraído na Primeira Etapa, e outra avaliação utilizando o contexto extraído na Segunda Etapa.

No próximo capítulo são apresentados mais detalhes sobre as avaliações realizadas neste trabalho, como métricas, ferramentas e bases de dados utilizadas e os resultados obtidos.

\subsection{Considerações Finais}

Neste capítulo foi apresentada a proposta deste mestrado para extração automática de contexto de páginas da Web. Em tal proposta é utilizado o método de construção de hierarquia de tópicos apresentado por Marcacini e Rezende (2013) que utiliza, além da informação técnica (bag-of-words tradicional), também informação privilegiada no processo de agrupamento não supervisionado. Neste trabalho, como informações privilegiadas, são consideras as entidades nomeadas, reconhecidas pelo sistema REMBRANDT, e os termos do domínio extraídos por meio da abordagem proposta por Conrado et al. (2013).

Como contexto dos itens ou páginas da Web, consideram-se os tópicos dos grupos e subgrupos em que eles (itens) estão inseridos. Tais informações contextuais são utilizadas em sistemas de recomendação sensíveis ao contexto e as recomendações produzidas são avaliadas com o objetivo de analisar qual o impacto do contexto extraído pelo método proposto neste mestrado no processo de recomendação.

No próximo capítulo são descritas as formas nas quais o contexto extraído pelo método proposto neste trabalho foi avaliado e são apresentados os resultados obtidos. 
Capítulo

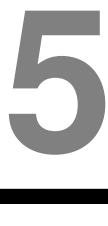

\section{Avaliação do Método Proposto}

\subsection{Considerações Iniciais}

Neste capítulo são apresentadas as avaliações realizadas para analisar o impacto do uso do contexto, extraído pelo método proposto neste trabalho, em sistemas de recomendação sensíveis ao contexto.

Foram realizados experimentos para avaliação considerando dois baselines. O primeiro baseline foi o algoritmo Item-Based Collaborative Filtering, que não usa contexto. $\mathrm{O}$ segundo baseline, denominado baseline "metodológico", foi implementado neste trabalho, para comparar a utilização do contexto extraído pelo método proposto com a utilização de informações contextuais extraídas por outro método da literatura. Em ambas as avaliações foram realizados diversos experimentos, todos de forma offline, e foi calculada a medida MAP para avaliação dos resultados, como explicado na Seção 2.4.

Na Figura 5.1, está ilustrado o processo experimental executado neste trabalho. Foram utilizadas, nos experimentos, duas bases de logs de acessos descritas na próxima seção. Nas seções seguintes são descritas as etapas do processo experimental, referentes à proposta deste mestrado para extração de informação contextual. Na Seção 5.3, é descrito o préprocessamento feito nas duas bases de logs de acessos, que inclui limpeza e extração do conteúdo textual, como pode ser visto na Figura 5.1 - A. Na Seção 5.4, é indicado o método proposto neste mestrado para extração de contexto, ilustrado na parte B da Figura 5.1. Os tópicos, que são considerados informações de contexto das páginas da Web para os sistemas de recomendação, são gerados e representam a saída de B. Observa-se que são gerados tópicos com termos e com entidades nomeadas. Na Seção 5.5, é descrito como o contexto extraído é utilizado, e quais são os sistemas de recomendações sensíveis ao contexto considerados neste trabalho. Essa etapa está ilustrada na Figura 5.1 - C. Na Seção 5.6, é apresentada a metodologia de avaliação das recomendações com contexto, 
referente à parte D da Figura 5.1.

E, por fim, na Seção 5.7 é feita uma breve análise do uso dos diferentes tipos de contexto, e as considerações finais são apresentadas na Seção 5.8.

\subsection{Bases de Logs de Acessos}

Nos experimentos foram utilizadas duas bases de logs de acessos. A primeira base refere-se aos acessos feitos por usuários no site da Agência Embrapa de Informação Tecnológica $^{1}$, pertencente à Embrapa Informática Agropecuária - CNPTIA, no período de novembro de 2012. Tal agência é um repositório de informações tecnológicas validadas da Empresa Brasileira de Pesquisa Agropecuária (Embrapa) e de seus parceiros, organizadas de forma hierárquica numa estrutura ramificada denominada Árvore do Conhecimento. Nos níveis mais superiores dessa hierarquia, estão os conhecimentos mais genéricos, e nos níveis mais inferiores, os mais específicos. As Árvores do Conhecimento da agência Embrapa podem pertencer a uma de quatro categorias: "Cultivos", "Criações", "Temáticas" e "Territórios". Na Tabela 5.1 estão as categorias e as Árvores do Conhecimento pertencentes a cada uma delas.

Tabela 5.1: Árvores do Conhecimento da Agência Embrapa de Informação Tecnológica por categoria

\begin{tabular}{|c|c|}
\hline Categoria & Árvores do Conhecimento \\
\hline Cultivos & $\begin{array}{l}\text { Açaí, Ameixa, Amora, Arroz, Banana, Batata, Caju, } \\
\text { Cana-de-Açúcar, Castanha-do-Brasil, Cebola, Cenoura, } \\
\text { Centeio, Cevada, Coco, Eucalipto, Feijão, Feijão-Caupi, } \\
\text { Gergelim, Mamona, Manga, Mangaba, Milho, Morango, } \\
\text { Pera, Pêssego, Pimenta, Sisal, Soja, Tomate, Trigo, Tri- } \\
\text { ticale, Uva de Mesa e Uva para Processamento }\end{array}$ \\
\hline Criações & $\begin{array}{l}\text { Agronegócio do Leite, Frango de Corte, Ovinos de Corte } \\
\text { e Suínos }\end{array}$ \\
\hline Temáticas & $\begin{array}{l}\text { Agroenergia, Agricultura e Meio Ambiente, Bioma Cer- } \\
\text { rado, Bioma Caatinga, Espécies Arbóreas da Amazônia, } \\
\text { Espécies Arbóreas Brasileiras, Manejo Florestal, Repro- } \\
\text { dução Animal, Sistema Plantio Direto, Solos Tropicais } \\
\text { e Tecnologia de Alimentos }\end{array}$ \\
\hline Territórios & Território Sisal e Território Mata Sul Pernambucana \\
\hline
\end{tabular}

Esse conjunto de dados da Embrapa é formado por 83729 acessos, 4659 usuários e 1633 páginas da Web (itens). Os conteúdos das páginas são sobre agronegócio e estão escritos em Português.

A segunda base de dados é a do site do Dicionário Informal ${ }^{2}$, que é um dicionário online de Português no qual as palavras são definidas pelos usuários. Nesse site são encontrados: Dicionário de Sinônimos, Dicionário de Antônimos, Dicionário de Relacionadas

\footnotetext{
${ }^{1}$ http://www.agencia.cnptia.embrapa.br/

${ }^{2}$ http://www.dicionarioinformal.com.br/
} 


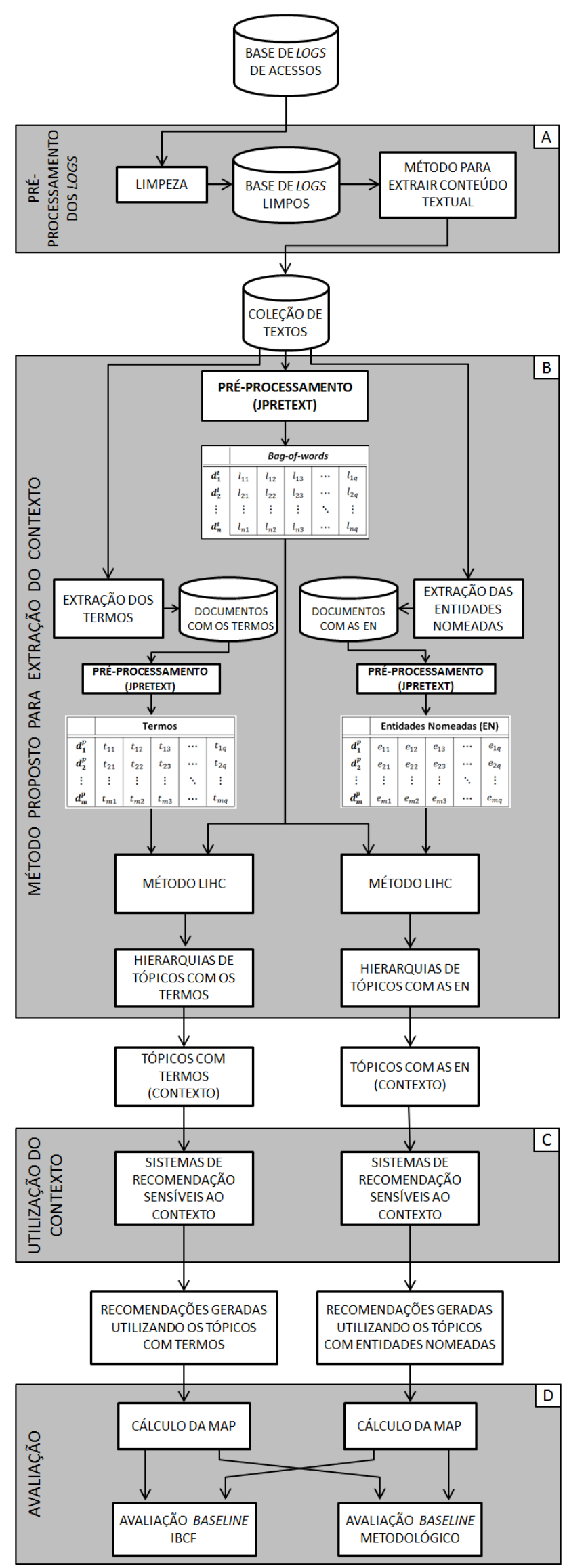

Figura 5.1: Visão geral do processo experimental deste trabalho. 
(relações entre palavras), Dicionário de Exemplos, Dicionário de Rimas, Flexões e Conjugações de Verbos e Caça Palavras/Soletrando. A base é formada por 2440830 usuários, 2456948 acessos e 20435 páginas (itens). Os conteúdos textuais das páginas, escritos em Português, são definições de palavras, rimas, sinônimos, antônimos, conjugações, etc.

\subsection{Pré-Processamento das Bases de Logs}

As bases de logs de acessos, descritas na seção anterior, foram pré-processadas conforme a primeira etapa da proposta deste trabalho. Nesse pré-processamento, o primeiro passo consiste na limpeza dos logs. Na base de logs da Embrapa, após a limpeza de acessos repetidos e com informações faltantes, restaram 15037 acessos e a mesma quantidade de usuários e itens (4659 e 1633 respectivamente). Para a base do Dicionário Informal a limpeza foi mais complexa. A quantidade de acessos em tal base é muito grande, com muitos itens acessados uma única vez e usuários que fizeram apenas um acesso. Em Domingues et al. (2008), foi realizado um estudo sobre o uso de tais acessos na construção e na avaliação de sistemas de recomendação. Os autores concluíram que a presença dos mesmos no conjunto de treinamento tende a ter um impacto negativo sobre a avaliação do sistema. Portanto, tais dados foram eliminados da base, juntamente com os acessos repetidos e com falta de algumas informações. Dessa forma, a base de logs de acessos ao site do Dicionário Informal resultou em uma base com usuários que fizeram mais de um acesso às páginas e com páginas que foram acessadas mais de uma vez, restando um total de 14702 acessos, 10611 usuários e 4610 páginas (itens).

O segundo passo da etapa de pré-processamento, foi a obtenção de documentos HTML a partir da base de logs, como descrito na Seção 4.2.1. A partir desses documentos foi extraído o conteúdo textual das páginas da Web. O conteúdo textual, tanto das páginas da Embrapa quanto do Dicionário Informal, foi extraído por meio da segunda forma para extração de conteúdos textuais, mencionada na Seção 4.2.1. Nessa forma, são utilizadas expressões regulares para a extração do conteúdo sem cabeçalho, rodapé, e tudo que pode ser considerado ruído para a mineração de textos.

Os resultados desta etapa são duas coleções de textos: Coleção de Textos da Embrapa e Coleção de Textos do Dicionário Informal. Tais coleções foram utilizadas para a extração de informações contextuais descrita na próxima seção.

\subsection{Método de Extração de Contexto}

Como descrito na Seção 4.2.2, a extração de informações contextuais foi realizada por meio da construção de hierarquias de tópicos utilizando o método LIHC. Para o préprocessamento e o agrupamento hierárquico dos itens, foram utilizadas as ferramentas: 
JPretext ${ }^{3}$ e LIHC $^{4}$. Elas fazem parte da $\operatorname{Torch}^{5}$, que é um conjunto de ferramentas desenvolvidas para dar suporte para a construção de hierarquias de tópicos. A JPretext transforma a coleção de textos na matriz atributo-valor. Já a ferramenta LIHC implementa o método LUPI-based incremental hierarchical clustering.

Antes da construção das hierarquias, foram extraídas as informações privilegiadas e foram geradas as matrizes atributo-valor de cada informação (privilegiada e técnica), que servem de entrada para o método LIHC. Utilizando o sistema REMBRANDT ${ }^{6}$, foi extraído o primeiro tipo de informação privilegiada, as entidades nomeadas. O segundo tipo, os termos do domínio, foi extraído, seguindo o processo descrito na Seção 4.2.2, por meio da abordagem proposta por Conrado et al. (2013).

Assim sendo, com as informações extraídas, pode-se construir as matrizes atributovalor utilizando a ferramenta JPretext. Foram construídas as seguintes representações: matriz atributo-valor dos textos (bag-of-words tradicional - informação técnica), matriz atributo-valor das entidades nomeadas (primeiro tipo de informação privilegiada) e matriz atributo-valor dos termos (segundo tipo de informação privilegiada). Cada uma dessas representações foi utilizada como entrada para o agrupamento hierárquico dos textos.

Como ilustrado na Figura 5.2, foram construídas cinco hierarquias, para cada coleção de textos, combinando informação privilegiada com informação técnica (utilizando diferentes valores do fator de combinação - $\alpha$ ). Os valores do fator de combinação utilizados foram: $\alpha=0, \alpha=0,3, \alpha=0,5, \alpha=0,7$ e $\alpha=1$. A porcentagem considerada de cada tipo de informação para cada valor do $\alpha$ utilizado está indicado na Figura 5.2.

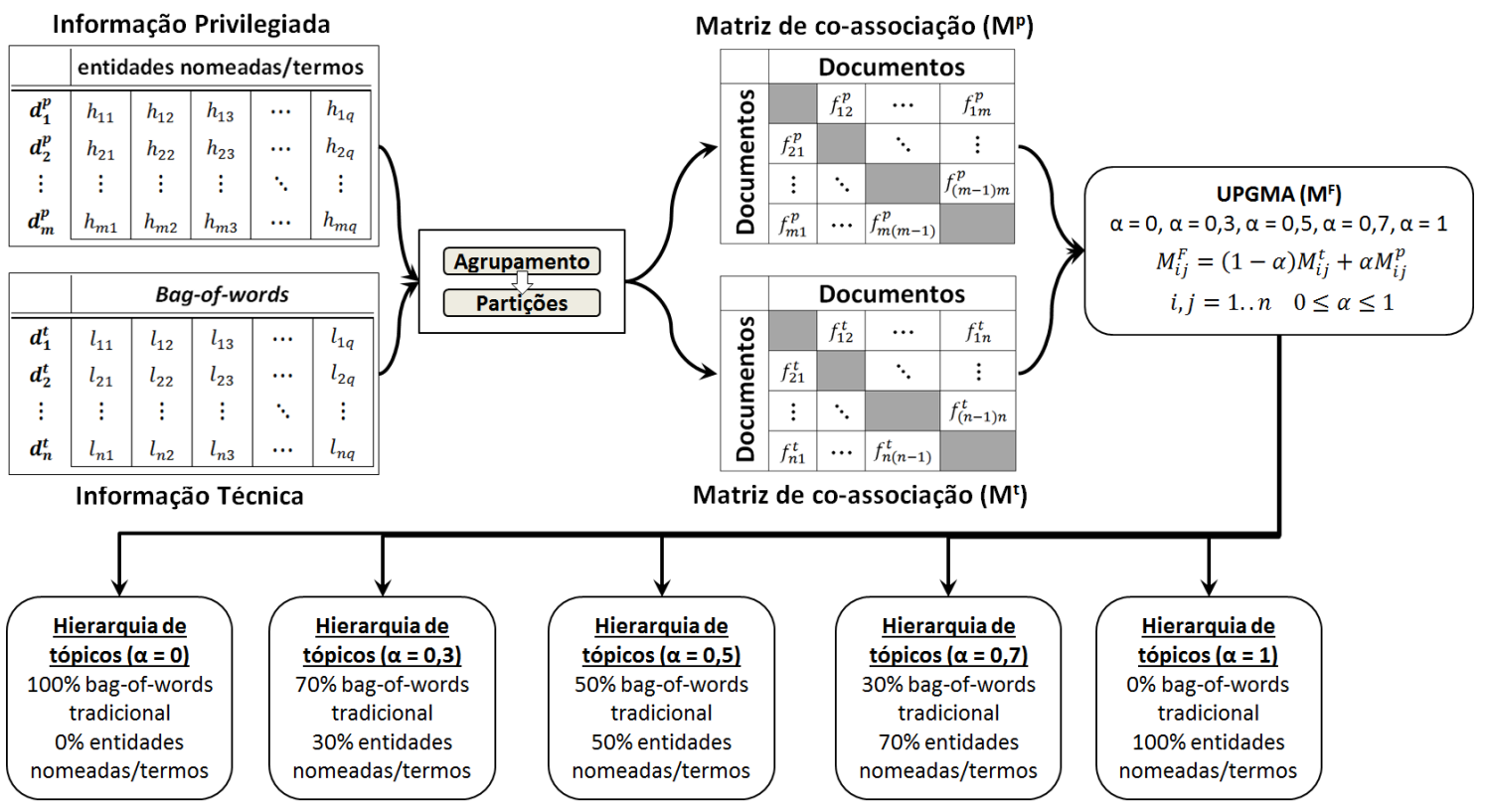

Figura 5.2: Construção das hierarquias de tópicos utilizando as entidades nomeadas ou os termos do domínio como informação privilegiada.

\footnotetext{
${ }^{3}$ http://sites.labic.icmc.usp.br/torch/msd2011/jpretext

${ }^{4}$ http://sites. labic.icmc.usp.br/torch/doceng 2013

${ }^{5}$ http://sites.labic.icmc.usp.br/torch/

${ }^{6}$ http://xldb.di.fc.ul.pt/Rembrandt/?do=home
} 
Com as hierarquias de tópicos construídas, foram extraídos tópicos seguindo configurações de granularidade, como mencionado na Seção 4.2.2. As configurações utilizadas foram: $\{2,7\}$ (são permitidos no mínimo 2 itens e no máximo 7 itens nos tópicos - configuração mais específica); $\{10,50\}$ (são permitidos no mínimo 10 itens e no máximo 50 itens nos tópicos); $\{15,20\}$ (são permitidos no mínimo 15 itens e no máximo 20 itens nos tópicos) e $\{50,100\}$ (são permitidos no mínimo 50 itens e no máximo 100 itens nos tópicos - configuração mais genérica). Essa separação foi feita procurando-se obter grupos de tópicos com diferentes números de itens associados (obtendo grupos/contexto mais genéricos e mais específicos) e possibilitando analisar, posteriormente, o impacto desses tópicos na recomendação. Quando os tópicos apresentam poucos items associados, geralmente representam grupos mais específicos. Por outro lado, tópicos com muitos itens, representam grupos mais gerais. Na Tabela 5.2, estão listados os números de tópicos extraídos por meio de cada configuração de granularidade para cada hierarquia de tópicos.

Tabela 5.2: Número de Tópicos (Informação Contextual) Extraídos das Hierarquias Construídas com Entidades Nomeadas e com Termos

Número de Tópicos Extraídos (Informação Contextual) das Hierarquias Construídas com Entidades Nomeadas dos Textos da Embrapa

\begin{tabular}{|c|c|c|c|c|c|}
\hline Granul. & $\alpha=0$ & $\alpha=0,3$ & $\alpha=0,5$ & $\alpha=0,7$ & $\alpha=1$ \\
\hline$\{50,100\}$ & 44 & 41 & 36 & 37 & 68 \\
\hline$\{15,20\}$ & 46 & 61 & 55 & 64 & 60 \\
\hline$\{10,50\}$ & 223 & 235 & 248 & 248 & 205 \\
\hline$\{2,7\}$ & 866 & 881 & 888 & 821 & 797 \\
\hline
\end{tabular}

Número de Tópicos Extraídos (Informação Contextual) das Hierarquias Construídas com Entidades Nomeadas dos Textos do Dicionário Informal

\begin{tabular}{|c|c|c|c|c|c|}
\hline Granul. & $\alpha=0$ & $\alpha=0,3$ & $\alpha=0,5$ & $\alpha=0,7$ & $\alpha=1$ \\
\hline$\{50,100\}$ & 67 & 77 & 96 & 90 & 83 \\
\hline$\{15,20\}$ & 132 & 141 & 144 & 147 & 209 \\
\hline$\{10,50\}$ & 466 & 542 & 568 & 607 & 480 \\
\hline$\{2,7\}$ & 2590 & 2668 & 2605 & 2596 & 2985 \\
\hline \hline
\end{tabular}

Número de Tópicos Extraídos (Informação Contextual) das Hierarquias Construídas com Termos dos Textos da Embrapa

\begin{tabular}{|c|c|c|c|c|c|}
\hline Granul. & $\alpha=0$ & $\alpha=0,3$ & $\alpha=0,5$ & $\alpha=0,7$ & $\alpha=1$ \\
\hline$\{50,100\}$ & 57 & 41 & 49 & 45 & 41 \\
\hline$\{15,20\}$ & 56 & 67 & 65 & 74 & 69 \\
\hline$\{10,50\}$ & 244 & 266 & 268 & 265 & 260 \\
\hline$\{2,7\}$ & 902 & 873 & 878 & 888 & 878 \\
\hline \hline
\end{tabular}

Número de Tópicos Extraídos (Informação Contextual) das Hierarquias Construídas com Termos dos Textos do Dicionário Informal

\begin{tabular}{|c|c|c|c|c|c|}
\hline Granul. & $\alpha=0$ & $\alpha=0,3$ & $\alpha=0,5$ & $\alpha=0,7$ & $\alpha=1$ \\
\hline$\{50,100\}$ & 65 & 67 & 77 & 88 & 76 \\
\hline$\{15,20\}$ & 155 & 143 & 141 & 126 & 134 \\
\hline$\{10,50\}$ & 519 & 539 & 530 & 543 & 518 \\
\hline$\{2,7\}$ & 2663 & 2574 & 2697 & 2770 & 2809 \\
\hline
\end{tabular}

Na próxima seção é apresentada a etapa de Utilização de Contexto, na qual a informação contextual é utilizada em sistemas de recomendação sensíveis ao contexto. 


\subsection{Utilização do Contexto Extraído}

O contexto considerado neste trabalho são os tópicos gerados para os grupos e subgrupos das hierarquias de tópicos construídas. Considera-se tais tópicos, informações contextuais das páginas da Web (itens da recomendação). Esses tópicos, ou contexto, foram utilizados em sistemas de recomendação sensíveis ao contexto para gerar recomendações contextuais. Neste trabalho foram utilizados 4 algoritmos de sistemas de recomendação, todos já descritos na Seção 2.3.1: cReduction, DaVI-BEST, Filter PoF e Weight PoF.

No algoritmo $c$ Reduction os tópicos são utilizados no início do processo para selecionar segmentos de dados. No algoritmo DaVI-BEST, os tópicos são utilizados no próprio modelo de recomendação. E, nos algoritmos Weight PoF e Filter PoF, os tópicos são utilizados no final do processo, para reordenar ou filtrar as recomendações. Em suas formas originais, os algoritmos Filter PoF e Weight PoF consideram a tarefa de prever os valores das avaliações. Neste trabalho é considerada a tarefa de recomendar os top- $N$ itens mais relevantes. Dessa forma, são utilizadas as adaptações feitas no trabalho de Domingues et al. (2014a).

\subsection{Metodologia de Avaliação das Recomendações com Uso de Contexto}

De acordo com Shani e Gunawardana (2011), um sistema de recomendação pode ser avaliado de três modos diferentes: offline, estudos com usuários e online, como apresentado na Seção 2.4. Neste trabalho, foram realizadas avaliações offline. Nessas avaliações, o objetivo foi demonstrar como a informação contextual produzida pelo método proposto pode influenciar a qualidade das recomendações. Para este tipo de avaliação foram utilizados conjuntos de dados reais, além dos algoritmos de sistemas de recomendação sensíveis ao contexto já mencionados anteriormente.

Para avaliar os sistemas de recomendação foi utilizado o protocolo All But One (Breese et al., 1998) com 10-fold cross validation e métrica Mean Average Precision (MAP) apresentada na Seção 2.4. Para isso o conjunto de documentos foi particionado em 10 subconjuntos. Para cada fold foram usados $n-1$ desses subconjuntos para treinamento e o restante para teste. $\mathrm{O}$ conjunto de treinamento $T_{r}$ foi usado para construir o modelo de recomendação. Para cada usuário no conjunto de teste $T_{e}$, um item foi escondido como um conjunto de um único item $H$. Os itens restantes representam o conjunto de itens observáveis, $O$, utilizados na recomendação. E então foi calculada a métrica MAP@N para $\mathrm{N}$ igual a 5 e 10 recomendações, pois, são os valores de $\mathrm{N}$ mais utilizados na literatura. Os valores de MAP nos 10 folds foram sumarizados utilizando a média. Para comparar dois algoritmos de recomendação, foi aplicado o teste $t$-Student pareado (McDonald, 2014), com $95 \%$ de nível de confiança.

Foram realizados experimentos utilizando dois baselines diferentes, como mencionado 
na Seção 4.2.3. Nos primeiros experimentos, as recomendações geradas com o uso do contexto extraído pelo método proposto neste trabalho foram comparadas com as recomendações geradas pelo método Item-Based Colaborative Filtering, que não utiliza informação de contexto. O conjunto desses experimentos é referido neste trabalho como "Avaliação Considerando o Baseline IBCF". No segundo conjunto de experimentos, referido como "Avaliação Considerando o Baseline Metodológico", foi utilizado o baseline metodológico implementado neste trabalho e descrito na Seção 4.2.3.

A métrica MAP foi calculada para as recomendações geradas, utilizando o contexto extraído pelo método proposto neste trabalho, por cada sistema de recomendação sensível ao contexto, para as recomendações geradas pelo algoritmo IBCF e pelo baseline "metodológico" (utilizando as "Estações do Ano" ou os "Dias da Semana" como contexto). Nas Figuras 5.3, 5.4 e 5.5 estão ilustrados os três processos de cálculo da medida de avaliação MAP.

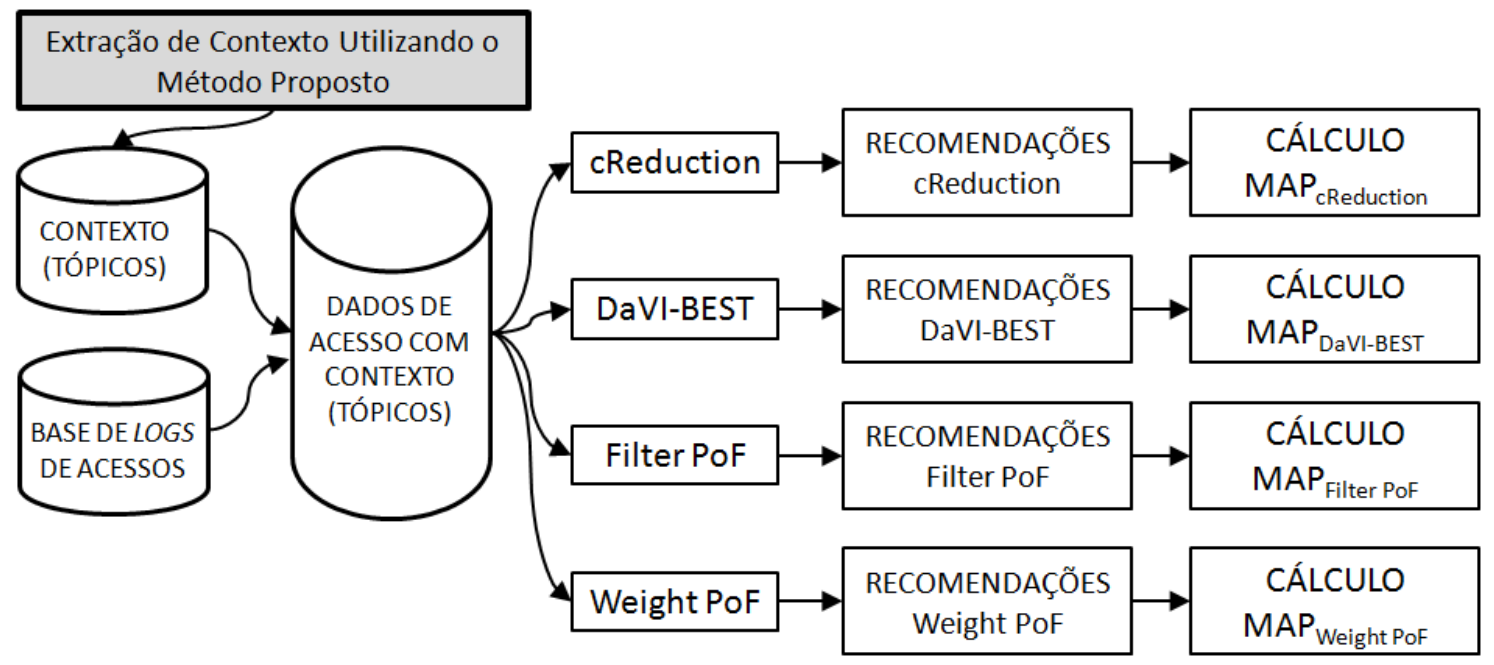

Figura 5.3: Cálculo da MAP para as recomendações geradas pelos sistemas de recomendação sensíveis ao contexto utilizando os tópicos como contexto.

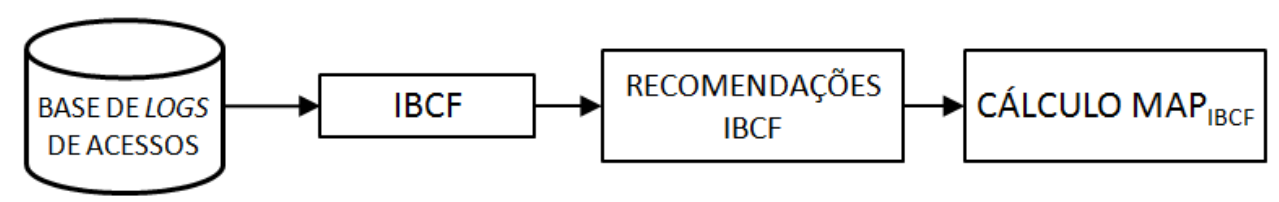

Figura 5.4: Avaliação das recomendações geradas pelo algoritmo IBCF.

\subsubsection{Avaliação Considerando o Baseline IBCF}

No primeiro conjunto de experimentos, após calcular a MAP@N para N igual a 5 e 10 recomendações geradas pelo sistemas sensíveis ao contexto que utilizam os tópicos como contexto e para as recomendações geradas pelo algoritmo IBCF, os valores foram comparados aplicando o teste $t$-Student pareado, com $95 \%$ de nível de confiança. Foram feitas as seguintes comparações: 


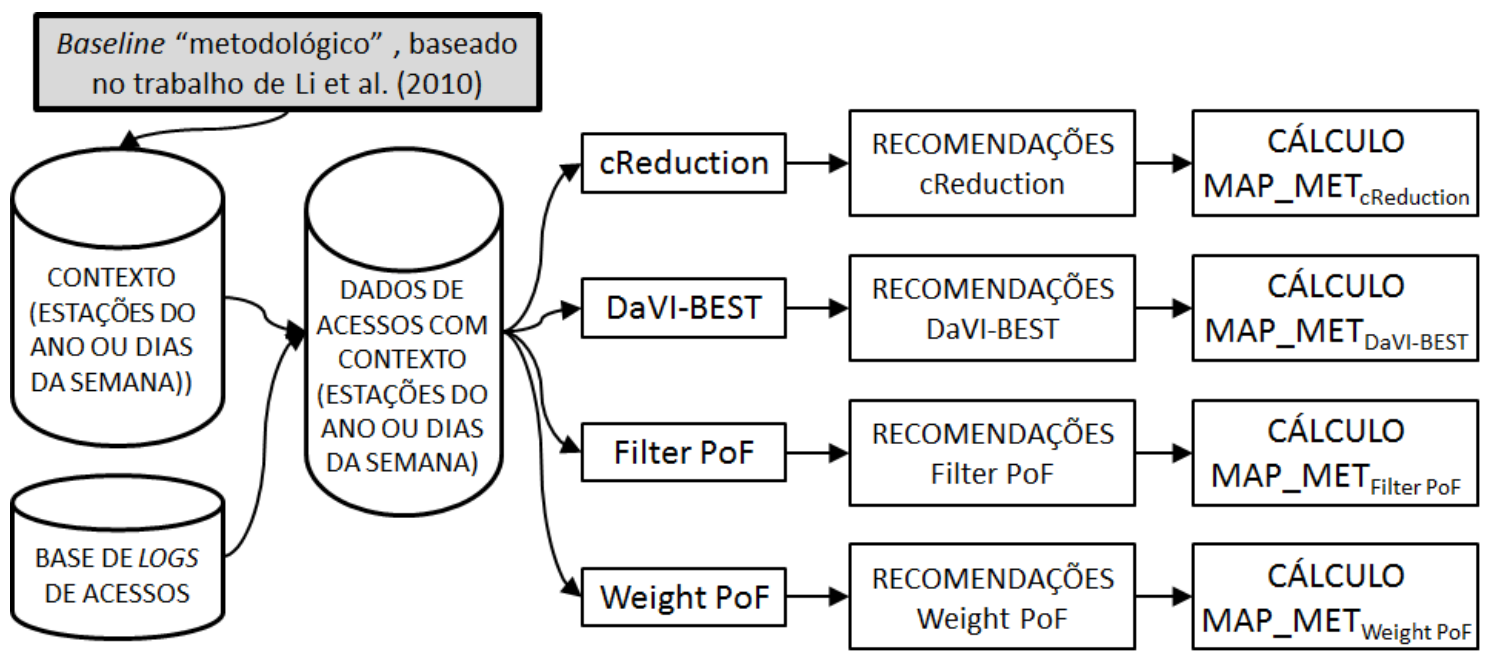

Figura 5.5: Avaliação das recomendações geradas pelos sistemas de recomendação sensíveis ao contexto utilizando as "Estações do Ano" ou os "Dias da Semana" como informações de contexto.

- MAP@ $5_{\text {cReduction }} \mathrm{x}$ MAP@ $5_{I B C F}$;

- MAP@10 $10_{\text {Reduction }}$ x MAP@10 ${ }_{I B C F}$;

- MAP@ $5_{D a V I-B E S T} \times \mathrm{MAP} @ 5_{I B C F}$;

- MAP@10 $10_{D a V I-B E S T} \mathbf{x} \mathrm{MAP} @ 10_{I B C F}$;

- MAP@ $5_{W e i g h t P o F}$ x MAP@ $5_{I B C F}$;

- MAP@10 WeightPoF $\mathbf{x}$ MAP@10 ${ }_{I B C F}$;

- MAP@5 $5_{\text {FilterPoF }} \mathbf{x} \mathrm{MAP} @ 5_{I B C F}$;

- MAP@10 FilterPoF $\mathbf{x}$ MAP@10 1 IBCF.

Esta avaliação foi feita utilizando as duas bases de dados (Embrapa e Dicionário Informal). Das Coleções de Textos obtidas das duas bases, foram extraídas as entidades nomeadas e os termos, totalizando quatro experimentos:

- Primeiro Experimento - base de logs de acessos da Embrapa e entidades nomeadas usadas como informação privilegiada;

- Segundo Experimento - base de logs de acessos do Dicionário Informal e entidades nomeadas usadas como informação privilegiada;

- Terceiro Experimento - base de logs de acessos da Embrapa e termos usados como informação privilegiada;

- Quarto Experimento - base de logs de acessos do Dicionário Informal e termos usados como informação privilegiada.

Os valores de MAP@5 e MAP@10 obtidos, em todos os experimentos, para os algoritmos de recomendação sensíveis ao contexto e para o algoritmo de filtragem colaborativa, são apresentados nas tabelas ao decorrer desta seção. Neste trabalho, pela quantidade muito grande de resultados, foram selecionados alguns desses resultados para serem apresentados neste capítulo. Procurou-se enfatizar as granularidades que apresentaram os 
melhores resultados, para cada fator de combinação. As tabelas com todos os resultados podem ser consultadas no Apêndice A. Os melhores resultados para cada algoritmo estão em negrito, enquanto que os resultados que foram melhores que o baseline, com relevância estatística, estão marcados com asterisco ("*”). Outro ponto que deve ser mencionado é a ausência dos resultados do algoritmo DaVI-BEST nas tabelas. Isso deve-se ao fato dos resultados para esse algoritmo terem sido equivalentes ao IBCF.

Na Tabela 5.3, são apresentados os melhores resultados do Primeiro Experimento, ou seja, no qual as recomendações foram geradas utilizando, como informações contextuais, os tópicos extraídos das hierarquias de tópicos construídas com os textos das páginas da Embrapa e as entidades nomeadas como informação privilegiada.

Nota-se, analisando todos os resultados, que podem ser consultados no Apêndice A, que na maioria dos níveis de granularidade as técnicas sensíveis ao contexto apresentaram resultados estatisticamente melhores que o baseline IBCF, com exceção, do algoritmo Filter PoF, que apresentou valores de MAP menores que os valores obtidos pelo IBCF, em alguns casos. A explicação para esse fato pode ser o valor escolhido de limiar para a probabilidade que é utilizada para filtrar as recomendações. Talvez, o valor utilizado neste trabalho, seja muito alto para esse caso em particular, ou seja, uma grande quantidade das recomendações pode ter sido filtrada diminuindo a acurácia do sistema de recomendação. Na maioria dos casos, o algoritmo Weight PoF possui desempenho melhor que os outros algoritmos.

Com relação às configurações de granularidade, observa-se que os algoritmos $C$. Reduction e Weight PoF apresentaram os melhores resultados na granularidade $\{15,20\}$ para todos os valores de fator de combinação, enquanto o algoritmo Filter PoF apresentou os melhores resultados na granularidade $\{2,7\}$. Examinando os valores de fator de combinação, pode-se concluir que o fator igual a $\alpha=0,7$ apresentou os melhores resultados, ou seja, os tópicos extraídos do agrupamento hierárquico construído com $30 \%$ de informação técnica e 70\% de informação privilegiada (entidades nomeadas) apresentaram resultados melhores que os resultados obtidos utilizando os tópicos extraídos dos outros agrupamentos.

Na Tabela 5.4 são apresentados os melhores resultados do Segundo Experimento. Neste experimento foram avaliadas as recomendações que foram geradas utilizando os tópicos extraídos das hierarquias de tópicos construídas com os textos das páginas do Dicionário Informal e as entidades nomeadas como informação privilegiada.

De forma geral, os resultados para a base do Dicionário Informal não foram tão bons quanto para a base da Embrapa. A explicação para esse fato pode ser o número de usuários e acessos aos itens, isto é, cada usuário fez poucos acessos às páginas. Além disso, os conteúdos textuais de muitas páginas do Dicionário Informal, que são definições, rimas, etc, são muito curtos, ou seja, existe uma pequena quantidade de informação textual para ser utilizada na construção das hierarquias de tópicos, o que pode influenciar negativamente na qualidade dos tópicos extraídos. Portanto, a informação contextual 
Tabela 5.3: Resultados Selecionados do Primeiro Experimento

\begin{tabular}{|c|c|c|c|c|c|c|c|c|}
\hline \multicolumn{9}{|c|}{ alores da MAP para o fator de combinação $\alpha=0$} \\
\hline \multirow{2}{*}{ Granul. } & \multicolumn{4}{|c|}{$M A P @ 5$} & \multicolumn{4}{|c|}{$M A P @ 10$} \\
\hline & IBCF & $\begin{array}{l}\text { cReduc- } \\
\text { tion }\end{array}$ & Weight PoF & Filter PoF & IBCF & $\begin{array}{l}\text { cReduc- } \\
\text { tion }\end{array}$ & Weight PoF & Filter PoF \\
\hline$\{15,20\}$ & 0,2991 & $0,3824 *$ & $0,4244 *$ & $0,3647 *$ & 0,3089 & $0,3894 *$ & $0,4286 *$ & $0,3654 *$ \\
\hline$\{2,7\}$ & 0,2991 & 0,3153 & $0,3763 *$ & $0,4075 *$ & 0,3089 & 0,3229 & $0,3824 *$ & $0,4090 *$ \\
\hline \multicolumn{9}{|c|}{ Valores da MAP para o fator de combinação $\alpha=0,3$} \\
\hline \multirow{2}{*}{ Granul. } & \multicolumn{4}{|c|}{$M A P @ 5$} & \multicolumn{4}{|c|}{ MAP@10 } \\
\hline & IBCF & $\begin{array}{l}\text { cReduc- } \\
\text { tion }\end{array}$ & Weight PoF & Filter PoF & IBCF & $\begin{array}{c}\text { cReduc- } \\
\text { tion }\end{array}$ & Weight PoF & Filter PoF \\
\hline$\{15,20\}$ & 0,2991 & $0,3821 *$ & $0,4147 *$ & 0,2894 & 0,3089 & $0,3890 *$ & $0,4204 *$ & 0,2913 \\
\hline$\{2,7\}$ & 0,2991 & $0,3194 *$ & $0,3643 *$ & $0,3993 *$ & 0,3089 & $0,3279 *$ & $0,3708 *$ & $0,4006 *$ \\
\hline \multicolumn{9}{|c|}{ Valores da MAP para o fator de combinação $\alpha=0,5$} \\
\hline \multirow{2}{*}{ Granul. } & \multicolumn{4}{|c|}{$M A P @ 5$} & \multicolumn{4}{|c|}{$M A P @ 10$} \\
\hline & IBCF & $\begin{array}{l}\text { cReduc- } \\
\text { tion }\end{array}$ & Weight PoF & Filter PoF & IBCF & $\begin{array}{c}\text { cReduc- } \\
\text { tion }\end{array}$ & Weight PoF & Filter PoF \\
\hline$\{15,20\}$ & 0,2991 & $0,3518 *$ & $0,3845 *$ & $0,3412 *$ & 0,3089 & $0,3612 *$ & $0,3926 *$ & $0,3431 *$ \\
\hline$\{2,7\}$ & 0,2991 & $0,3208 *$ & $0,3747 *$ & $0,4135 *$ & 0,3089 & $0,3294 *$ & $0,3817 *$ & $0,4146 *$ \\
\hline \multicolumn{9}{|c|}{ Valores da MAP para o fator de combinação $\alpha=0,7$} \\
\hline \multirow{2}{*}{ Granul. } & \multicolumn{4}{|c|}{$M A P @ 5$} & \multicolumn{4}{|c|}{$M A P @ 10$} \\
\hline & IBCF & $\begin{array}{l}\text { cReduc- } \\
\text { tion }\end{array}$ & Weight PoF & Filter PoF & IBCF & $\begin{array}{l}\text { cReduc- } \\
\text { tion }\end{array}$ & Weight PoF & Filter PoF \\
\hline$\{15,20\}$ & 0,2991 & $0,4454 *$ & $0,4803 *$ & $0,3772 *$ & 0,3089 & $0,4532 *$ & $0,4874 *$ & $0,3793 *$ \\
\hline$\{2,7\}$ & 0,2991 & $0,3277 *$ & $0,3826 *$ & $0,4197 *$ & 0,3089 & $0,3359 *$ & $0,3888 *$ & $0,4208 *$ \\
\hline \multicolumn{9}{|c|}{ "Valores da MAP para o fator de combinação $\alpha=1$} \\
\hline \multirow{2}{*}{ Granul. } & \multicolumn{4}{|c|}{$M A P @ 5$} & \multicolumn{4}{|c|}{$M A P @ 10$} \\
\hline & IBCF & $\begin{array}{l}\text { cReduc- } \\
\text { tion }\end{array}$ & Weight PoF & Filter PoF & IBCF & $\begin{array}{l}\text { cReduc- } \\
\text { tion }\end{array}$ & Weight PoF & Filter PoF \\
\hline$\{15,20\}$ & 0,2991 & $0,3851 *$ & $0,4191 *$ & 0,2556 & 0,3089 & $0,3912 *$ & $0,4245 *$ & 0,2566 \\
\hline$\{2,7\}$ & 0,2991 & $0,3207 *$ & $0,3828 *$ & $0,4139 *$ & 0,3089 & $0,3294 *$ & $0,3895 *$ & $0,4148 *$ \\
\hline
\end{tabular}

extraída dessa base, não foi capaz de melhorar os resultados da recomendação em todos os casos. Em alguns casos houve melhoras, porém, neste Segundo Experimento, sem relevância estatística.

Com relação à granularidade, observa-se que para os fatores de combinação $\alpha=0$ e $\alpha=0,5$, os algoritmos sensíveis ao contexto apresentaram os melhores resultados na granularidade $\{2,7\}$. Para os fatores de combinação $\alpha=0,7$ e $\alpha=1$, os algoritmos $c R e$ duction e Weight PoF apresentaram os melhores resultados na granularidade $\{15,20\}$. E para o fator de combinação $\alpha=0,3$, o algortimo $c$ Reduction apresentou o melhor resultado na granularidade $\{50,100\}$ e Weight $P o F$ na granularidade $\{2,7\}$. Enquanto o algoritmo Filter PoF sempre apresenta os melhores resultados na granularidade $\{2,7\}$. Examinando os valores de fator de combinação, pode-se concluir que o fator igual a $\alpha=0,3$ apresentou os melhores resultados, isto é, os tópicos extraídos dos agrupamentos hierárquicos construídos com $70 \%$ da informação técnica e 30\% de informação privilegiada (entidades nomeadas), apresentaram resultados melhores que os resultados obtidos utilizando os tópicos extraídos pelos outros agrupamentos.

Os melhores resultados do Terceiro Experimento são apresentados na Tabela 5.5. Neste experimento foram avaliadas as recomendações geradas utilizando, como informações contextuais, os tópicos das hierarquias de tópicos construídas com os textos das páginas da Embrapa e com os termos extraídos como informação privilegiada. Os resul- 
Tabela 5.4: Resultados Selecionados do Segundo Experimento

\begin{tabular}{|c|c|c|c|c|c|c|c|c|}
\hline \multicolumn{9}{|c|}{ Valores da MAP para o fator de combinação $\alpha=0$} \\
\hline \multirow{2}{*}{ Granul. } & \multicolumn{4}{|c|}{$M A P @ 5$} & \multicolumn{4}{|c|}{$M A P @ 10$} \\
\hline & IBCF & $\begin{array}{c}\text { cReduc- } \\
\text { tion }\end{array}$ & Weight PoF & Filter PoF & IBCF & $\begin{array}{l}\text { cReduc- } \\
\text { tion }\end{array}$ & Weight PoF & Filter PoF \\
\hline$\{2,7\}$ & 0,0166 & 0,0184 & 0,0194 & 0,0180 & 0,0167 & 0,0184 & 0,0194 & 0,0181 \\
\hline \multicolumn{9}{|c|}{ Valores da MAP para o fator de combinação $\alpha=0,3$} \\
\hline \multirow{2}{*}{ Granul. } & \multicolumn{4}{|c|}{$M A P @ 5$} & \multicolumn{4}{|c|}{$M A P @ 10$} \\
\hline & IBCF & $\begin{array}{l}\text { cReduc- } \\
\text { tion }\end{array}$ & Weight PoF & Filter PoF & IBCF & $\begin{array}{l}\text { cReduc- } \\
\text { tion }\end{array}$ & Weight PoF & Filter PoF \\
\hline$\{50,100\}$ & 0,0166 & 0,0195 & 0,0195 & 0,0074 & 0,0167 & 0,0209 & 0,0209 & 0,0089 \\
\hline$\{2,7\}$ & 0,0166 & 0,0189 & 0,0196 & 0,0228 & 0,0167 & 0,0190 & 0,0197 & 0,0229 \\
\hline \multicolumn{9}{|c|}{\begin{tabular}{c|} 
Valores da MAP para o fator de combinação $\alpha=0,5$ \\
\end{tabular}} \\
\hline \multirow{2}{*}{ Granul. } & \multicolumn{4}{|c|}{$M A P @ 5$} & \multicolumn{4}{|c|}{$M A P @ 10$} \\
\hline & IBCF & $\begin{array}{l}\text { cReduc- } \\
\text { tion }\end{array}$ & Weight PoF & Filter PoF & IBCF & $\begin{array}{l}\text { cReduc- } \\
\text { tion }\end{array}$ & Weight PoF & Filter PoF \\
\hline$\{2,7\}$ & 0,0167 & 0,0146 & 0,0160 & 0,0118 & 0,0167 & 0,0150 & 0,0163 & 0,0122 \\
\hline \multicolumn{9}{|c|}{ Valores da MAP para o fator de combinação $\alpha=0,7$} \\
\hline \multirow{2}{*}{ Granul. } & \multicolumn{4}{|c|}{$M A P @ 5$} & \multicolumn{4}{|c|}{$M A P @ 10$} \\
\hline & IBCF & $\begin{array}{c}\text { cReduc- } \\
\text { tion }\end{array}$ & Weight PoF & Filter PoF & IBCF & $\begin{array}{l}\text { cReduc- } \\
\text { tion }\end{array}$ & Weight PoF & Filter PoF \\
\hline$\{15,20\}$ & 0,0166 & 0,0173 & 0,0177 & 0,0021 & 0,0167 & 0,0176 & 0,0180 & 0,0027 \\
\hline$\{2,7\}$ & 0,0166 & 0,0164 & 0,0171 & 0,0169 & 0,0167 & 0,0167 & 0,0173 & 0,0172 \\
\hline \multicolumn{9}{|c|}{ Valores da MAP para o fator de combinação $\alpha=1$} \\
\hline \multirow{2}{*}{ Granul. } & \multicolumn{4}{|c|}{$M A P @ 5$} & \multicolumn{4}{|c|}{$M A P @ 10$} \\
\hline & IBCF & $\begin{array}{c}\text { cReduc- } \\
\text { tion }\end{array}$ & Weight PoF & Filter PoF & IBCF & $\begin{array}{l}\text { cReduc- } \\
\text { tion }\end{array}$ & Weight PoF & Filter PoF \\
\hline$\{15,20\}$ & 0,0166 & 0,0161 & 0,0170 & 0,0006 & 0,0167 & 0,0162 & 0,0170 & 0,0006 \\
\hline$\{2,7\}$ & 0,0166 & 0,0131 & 0,0142 & 0,0151 & 0,0167 & 0,0132 & 0,0143 & 0,0152 \\
\hline
\end{tabular}

tados foram tão bons quanto os resultados dos experimentos com as entidades nomeadas. Portanto, os algoritmos de recomendação sensíveis ao contexto apresentaram melhores resultados, com significância estatística, que o algoritmo IBCF na maior parte dos casos. Apenas o algoritmo Filter PoF não apresentou bons resultados em alguns casos.

Quanto às granularidades, os algoritmos cReduction e Weight PoF foram melhores na granularidade $\{15,20\}$ e o Filter $P o F$, na granularidade $\{2,7\}$, para todos os valores de fator de combinação. Quanto aos fatores de combinação, os algoritmos cReduction e Weight PoF apresentaram melhores resultados no fator $\alpha=0,5$ (50\% dos termos e $50 \%$ da bag-of-words tradicional), enquanto que o algoritmo Filter PoF, apresentou o melhor resultado no fator de combinação $\alpha=0$ (somente bag-of-words tradicional).

Por fim, na Tabela 5.6, estão apresentados os melhores resultados do Quarto Experimento, o último desta avaliação. Neste experimento, utilizando os tópicos extraídos das hierarquias de tópicos construídas com os textos das páginas do Dicionário Informal e com os termos extraídos, os resultados foram melhores que os experimentos do Dicionário Informal considerando as entidades nomeadas como informação privilegiada. Pode-se observar mais casos nos quais os algoritmos sensíveis ao contexto apresentaram resultados melhores que o IBCF com significância estatística.

Com relação às granularidades, os algoritmos cReduction e Weight PoF apresentaram melhores resultados na granularidade $\{50,100\}$ para os fatores de combinação $\alpha=0$, $\alpha=0,3, \alpha=0,5$ e $\alpha=0,7$. Já para o fator 1 , os melhores resultados de ambos 
Tabela 5.5: Resultados Selecionados do Terceiro Experimento

\begin{tabular}{|c|c|c|c|c|c|c|c|c|}
\hline \multicolumn{9}{|c|}{ Valores da MAP para o fator de combinação $\alpha=0$} \\
\hline \multirow{2}{*}{ Granul. } & \multicolumn{4}{|c|}{$M A P @ 5$} & \multicolumn{4}{|c|}{ MAP@10 } \\
\hline & IBCF & $\begin{array}{l}\text { cReduc- } \\
\text { tion }\end{array}$ & Weight PoF & Filter PoF & IBCF & $\begin{array}{c}\text { cReduc- } \\
\text { tion }\end{array}$ & Weight PoF & Filter PoF \\
\hline$\{15,20\}$ & 0,2991 & $0,3802 *$ & $0,4049 *$ & $0,3240 *$ & 0,3089 & $0,3874 *$ & $0,4110 *$ & $0,3262 *$ \\
\hline$\{2,7\}$ & 0,2991 & $0,3392 *$ & $0,4024 *$ & $0,4314 *$ & 0,3089 & $0,3470 *$ & $0,4088 *$ & $0,4322 *$ \\
\hline \multicolumn{9}{|c|}{ Valores da MAP para o fator de combinação $\alpha=0,3$} \\
\hline \multirow{2}{*}{ Granul. } & \multicolumn{4}{|c|}{$M A P @ 5$} & \multicolumn{4}{|c|}{$M A P @ 10$} \\
\hline & IBCF & $\begin{array}{c}\text { cReduc- } \\
\text { tion }\end{array}$ & Weight PoF & Filter PoF & IBCF & $\begin{array}{l}\text { cReduc- } \\
\text { tion }\end{array}$ & Weight PoF & Filter PoF \\
\hline$\{15,20\}$ & 0,2991 & $0,3923 *$ & $0,4361 *$ & 0,3066 & 0,3089 & $0,3987 *$ & $0,4420 *$ & 0,3082 \\
\hline$\{2,7\}$ & 0,2991 & $0,3195 *$ & $0,3768 *$ & $0,4187 *$ & 0,3089 & $0,3291 *$ & $0,3849 *$ & $0,4201 *$ \\
\hline \multicolumn{9}{|c|}{ Valores da MAP para o fator de combinação $\alpha=0,5$} \\
\hline \multirow{2}{*}{ Granul. } & \multicolumn{4}{|c|}{$M A P @ 5$} & \multicolumn{4}{|c|}{$M A P @ 10$} \\
\hline & IBCF & $\begin{array}{l}\text { cReduc- } \\
\text { tion }\end{array}$ & Weight PoF & Filter PoF & IBCF & $\begin{array}{l}\text { cReduc- } \\
\text { tion }\end{array}$ & Weight PoF & Filter PoF \\
\hline$\{15,20\}$ & 0,2991 & $0,4135 *$ & $0,4479 *$ & 0,2801 & 0,3089 & 0,4189 * & $0,4525 *$ & 0,2818 \\
\hline$\{2,7\}$ & 0,2991 & $0,3287 *$ & $0,3826 *$ & $0,3965 *$ & 0,3089 & $0,3374 *$ & $0,3898 *$ & $0,3983 *$ \\
\hline \multicolumn{9}{|c|}{ Valores da MAP para o fator de combinação $\alpha=0,7$} \\
\hline \multirow{2}{*}{ Granul. } & \multicolumn{4}{|c|}{$M A P @ 5$} & \multicolumn{4}{|c|}{$M A P @ 10$} \\
\hline & IBCF & $\begin{array}{l}\text { cReduc- } \\
\text { tion }\end{array}$ & Weight PoF & Filter PoF & IBCF & $\begin{array}{l}\text { cReduc- } \\
\text { tion }\end{array}$ & Weight PoF & Filter PoF \\
\hline$\{15,20\}$ & 0,2991 & $\mathbf{0 , 3 7 3 3 *}$ & $0,4048 *$ & 0,3498 & 0,3089 & $0,3812 *$ & $0,4120 *$ & 0,3514 \\
\hline$\{2,7\}$ & 0,2991 & $0,3384 *$ & $0,3925 *$ & $0,3816 *$ & 0,3089 & $0,3454 *$ & $0,3978 *$ & $0,3817 *$ \\
\hline \multicolumn{9}{|c|}{ Valores da MAP para o fator de combinação $\alpha=1$} \\
\hline \multirow{2}{*}{ Granul. } & \multicolumn{4}{|c|}{ MAP@5 } & \multicolumn{4}{|c|}{$M A P @ 10$} \\
\hline & IBCF & $\begin{array}{l}\text { cReduc- } \\
\text { tion }\end{array}$ & Weight PoF & Filter PoF & IBCF & $\begin{array}{l}\text { cReduc- } \\
\text { tion }\end{array}$ & Weight PoF & Filter PoF \\
\hline$\{15,20\}$ & 0,2991 & $\mathbf{0 , 3 4 4 9 *}$ & $0,3709 *$ & 0,2922 & 0,3089 & $0,3525 *$ & $0,3773 *$ & 0,2922 \\
\hline$\{2,7\}$ & 0,2991 & $0,3213 *$ & $0,3724 *$ & $0,4061 *$ & 0,3089 & $0,3304 *$ & $0,3798 *$ & $0,4073 *$ \\
\hline
\end{tabular}

algoritmos ocorreram na granularidade $\{15,20\}$. O algoritmo Filter PoF, teve melhores resultados, para a maior parte dos fatores de combinação, na granularidade $\{2,7\}$, sendo que para o fator 1 , seu melhor resultado ocorreu na granularidade $\{15,20\}$.

Analisando os fatores de combinação, os melhores resultados dos algoritmos cReduction e Weight PoF, foram obtidos no fator 1 (considerando apenas os termos extraídos). Já para o algoritmo Filter PoF, o melhor resultado foi obtido no fator 0,7 (70\% dos termos e $30 \%$ da bag-of-words tradicional).

\subsubsection{Avaliação Considerando o Baseline Metodológico}

Na segunda avaliação foi considerado como comparativo o baseline "metodológico", implementado neste trabalho. Tal baseline extrai dois tipos principais de informações de contexto: "Dias da Semana" e "Estações do Ano". Uma síntese dos experimentos realizados nesta avaliação é apresentada na Tabela 5.7. Para cada experimento, foram feitas as seguintes comparações (lembrando que MAP_MET representa os valores da medida MAP calculados para o baseline "metodológico" e apenas MAP, representa os valores da medida calculados para o método proposto):

- $\mathrm{MAP}_{\text {cReduction }} \mathbf{x}$ MAP_MET $\mathrm{MReduction}_{\text {; }}$

- $\mathrm{MAP}_{D a V I-B E S T} \mathbf{x} \mathrm{MAP}_{-} \mathrm{MET}_{D a V I-B E S T}$; 
Tabela 5.6: Resultados Selecionados do Quarto Experimento

\begin{tabular}{|c|c|c|c|c|c|c|c|c|}
\hline \multicolumn{9}{|c|}{ Valores da MAP para o fator de combinação $\alpha=0$} \\
\hline \multirow{2}{*}{ Granul. } & \multicolumn{4}{|c|}{$M A P @ 5$} & \multicolumn{4}{|c|}{$M A P @ 10$} \\
\hline & $\mathrm{IBCF}$ & $\begin{array}{l}\text { cReduc- } \\
\text { tion }\end{array}$ & Weight PoF & Filter PoF & IBCF & $\begin{array}{c}\text { cReduc- } \\
\text { tion }\end{array}$ & Weight PoF & Filter PoF \\
\hline$\{50,100\}$ & 0,0166 & 0,0234 & 0,0234 & 0,0059 & 0,0167 & 0,0236 & 0,0236 & 0,0062 \\
\hline$\{2,7\}$ & 0,0166 & 0,0148 & 0,0151 & 0,0132 & 0,0167 & 0,0149 & 0,0152 & 0,0133 \\
\hline \multicolumn{9}{|c|}{ Valores da MAP para o fator de combinação $\alpha=0,3$} \\
\hline \multirow{2}{*}{ Granul. } & \multicolumn{4}{|c|}{$M A P @ 5$} & \multicolumn{4}{|c|}{$M A P @ 10$} \\
\hline & IBCF & $\begin{array}{l}\text { cReduc- } \\
\text { tion }\end{array}$ & Weight PoF & Filter PoF & IBCF & $\begin{array}{l}\text { cReduc- } \\
\text { tion }\end{array}$ & Weight PoF & Filter PoF \\
\hline$\{50,100\}$ & 0,0166 & $0,0289 *$ & $0,0308 *$ & 0,0121 & 0,0167 & $0,0292 *$ & $0,0311 *$ & 0,0124 \\
\hline$\{2,7\}$ & 0,0166 & 0,0182 & 0,0185 & 0,0194 & 0,0167 & 0,0183 & 0,0186 & 0196 \\
\hline \multicolumn{9}{|c|}{ Valores da MAP para o fator de combinação $\alpha=0,5$} \\
\hline \multirow{2}{*}{ Granul. } & \multicolumn{4}{|c|}{$M A P @ 5$} & \multicolumn{4}{|c|}{$M A P @ 10$} \\
\hline & IBCF & $\begin{array}{l}\text { cReduc- } \\
\text { tion }\end{array}$ & Weight PoF & Filter PoF & IBCF & $\begin{array}{l}\text { cReduc- } \\
\text { tion }\end{array}$ & Weight PoF & Filter PoF \\
\hline$\{50,100\}$ & 0,0166 & $0,0289 *$ & $0,0308 *$ & 0,0121 & 0,0167 & 0,0292 & & 0,0124 \\
\hline$\{2,7\}$ & 0,0166 & 0,02118 & $0,0225 *$ & 0,0213 & 0,0167 & 0,0219 & 0,0225 & 0,0213 \\
\hline \multicolumn{9}{|c|}{ Valores da MAP para o fator de combinação $\alpha=0,7$} \\
\hline \multirow{2}{*}{ Granul. } & \multicolumn{4}{|c|}{$M A P @ 5$} & \multicolumn{4}{|c|}{$M A P @ 10$} \\
\hline & $\mathrm{IBCF}$ & $\begin{array}{l}\text { cReduc- } \\
\text { tion }\end{array}$ & Weight PoF & Filter PoF & IBCF & $\begin{array}{l}\text { cReduc- } \\
\text { tion }\end{array}$ & Weight PoF & Filter PoF \\
\hline$\{50,100\}$ & 0,0166 & $0,0275 *$ & $0,0275 *$ & & 0,0167 & $0,0278 *$ & & \\
\hline$\{2,7\}$ & 0,0166 & 0,0216 & $0,0221 *$ & $0,0262 *$ & 0,0167 & 0,0217 & $0,0223 *$ & $0,0263 *$ \\
\hline \multicolumn{9}{|c|}{ Valores da MAP para o fator de combinação $\alpha=1$} \\
\hline \multirow{2}{*}{ Granul. } & \multicolumn{4}{|c|}{$M A P @ 5$} & \multicolumn{4}{|c|}{ MAP@10 } \\
\hline & IBCF & $\begin{array}{l}\text { cReduc- } \\
\text { tion }\end{array}$ & Weight PoF & Filter PoF & IBCF & $\begin{array}{l}\text { cReduc- } \\
\text { tion }\end{array}$ & Weight PoF & Filter PoF \\
\hline$\{15,20\}$ & 0,0166 & $0,0375 *$ & $0,0375 *$ & 0,0237 & 0,0167 & $0,0378 *$ & $0,0378 *$ & 0,0237 \\
\hline
\end{tabular}

- $\mathrm{MAP}_{\text {FilterPoF}} \mathbf{x}$ MAP_MET $\mathrm{MilterPoF}_{\text {; }}$;

- $\mathrm{MAP}_{W e i g h t P o F} \mathbf{x}$ MAP_MET ${ }_{W e i g h t P o F}$.

Tabela 5.7: Experimentos Realizados Considerando o Baseline "Metodológico"

\begin{tabular}{|c|c|c|c|c|c|c|}
\hline \multirow{2}{*}{ Experimentos } & \multicolumn{2}{|c|}{ Base de Dados } & \multicolumn{2}{c|}{ Informação Privilegiada } & \multicolumn{2}{c|}{$\begin{array}{c}\text { Informação Extraída } \\
\text { pelo Baseline } \\
\text { "Metodológico" }\end{array}$} \\
\cline { 2 - 7 } & Embrapa & $\begin{array}{c}\text { Dicionário } \\
\text { Informal }\end{array}$ & $\begin{array}{c}\text { Entidades } \\
\text { Nomeadas }\end{array}$ & Termos & $\begin{array}{c}\text { Dias da } \\
\text { Semana }\end{array}$ & $\begin{array}{c}\text { Estações do } \\
\text { Ano }\end{array}$ \\
\hline Primeiro & $\mathrm{X}$ & & $\mathrm{X}$ & & $\mathrm{X}$ & \\
\hline Segundo & $\mathrm{X}$ & & $\mathrm{X}$ & & $\mathrm{X}$ & $\mathrm{X}$ \\
\hline Terceiro & $\mathrm{X}$ & & & $\mathrm{X}$ & $\mathrm{X}$ & $\mathrm{X}$ \\
\hline Quarto & $\mathrm{X}$ & & & $\mathrm{X}$ & $\mathrm{X}$ & $\mathrm{X}$ \\
\hline Quinto & & $\mathrm{X}$ & $\mathrm{X}$ & & $\mathrm{X}$ & \\
\hline Sexto & & $\mathrm{X}$ & $\mathrm{X}$ & & $\mathrm{X}$ & $\mathrm{X}$ \\
\hline Sétimo & & $\mathrm{X}$ & & $\mathrm{X}$ & & \\
\hline Oitavo & & $\mathrm{X}$ & & $\mathrm{X}$ & & \\
\hline
\end{tabular}

Em todos os experimentos, como forma de resumir a vasta quantidade de resultados, foi selecionado apenas o fator de combinação que apresentou os melhores resultados para cada caso. As tabelas completas dos resultados desta segunda avaliação podem ser consultadas no Apêndice B.

Na Tabela 5.8, são apresentados os resultados do Primeiro Experimento para o fator de combinação $\alpha=0$. Nesse experimento, foram avaliadas as recomendações geradas 
pelos sistemas de recomendação sensíveis ao contexto, utilizando os tópicos extraídos das hierarquias de tópicos construídas com os textos das páginas da Embrapa e com as entidades nomeadas. Como baseline, foram utilizados os mesmo algoritmos sensíveis ao contexto, porém considerando a informação de contexto "Dias da Semana".

Neste experimento, apenas o algoritmo Filter PoF apresentou ganhos relevantes sobre o baseline. Tais ganhos são observados em todas as granularidades para o fator de combinação 0. Os algoritmos cReduction e Weight PoF apresentaram valores de MAP, melhores que o baseline, mas sem significância estatística, na granularidade $\{15,20\}$ para o fator de combinação $\alpha=0$.

Tabela 5.8: Resultados do Primeiro Experimento para o Fator de Combinação $\alpha=0$

\begin{tabular}{|c|c|c|c|c|c|c|c|c|}
\hline \multicolumn{9}{|c|}{ Valores da MAP para o fator de combinação $\alpha=0$} \\
\hline \multirow{3}{*}{ Granul. } & \multicolumn{4}{|c|}{ cReduction } & \multicolumn{4}{|c|}{ DaVI-BEST } \\
\hline & \multicolumn{2}{|c|}{ MAP@5 } & \multicolumn{2}{|c|}{ MAP@10 } & \multicolumn{2}{|c|}{$M A P @ 5$} & \multicolumn{2}{|c|}{$M A P @ 10$} \\
\hline & Baseline & cReduction & Baseline & cReduction & Baseline & $\begin{array}{l}\text { DaVI- } \\
\text { BEST }\end{array}$ & Baseline & $\begin{array}{l}\text { DaVI- } \\
\text { BEST }\end{array}$ \\
\hline$\{50,100\}$ & 0,3940 & 0,3497 & 0,3864 & 0,3441 & 0,3894 & 0,3512 & 0,3958 & 0,3597 \\
\hline$\{15,20\}$ & 0,3940 & 0,3824 & 0,3864 & 0,3894 & 0,3894 & 0,3824 & 0,3958 & 0,3894 \\
\hline$\{10,50\}$ & 0,3940 & 0,3221 & 0,3864 & 0,3246 & 0,3894 & 0,3209 & 0,3958 & 0,3289 \\
\hline$\{2,7\}$ & 0,3940 & 0,3153 & 0,3864 & 0,3229 & 0,3894 & 0,3153 & 0,3958 & 0,3229 \\
\hline \multirow{3}{*}{ Granul. } & \multicolumn{4}{|c|}{$\begin{array}{c}\text { Filter PoF } \\
\end{array}$} & \multicolumn{4}{|c|}{ Weight PoF } \\
\hline & \multicolumn{2}{|c|}{$M A P @ 5$} & \multicolumn{2}{|c|}{$M A P @ 10$} & \multicolumn{2}{|c|}{$M A P @ 5$} & \multicolumn{2}{|c|}{ MAP@10 } \\
\hline & Baseline & $\begin{array}{l}\text { Filter } \\
\text { PoF }\end{array}$ & Baseline & $\begin{array}{l}\text { Filter } \\
\text { PoF }\end{array}$ & Baseline & $\begin{array}{l}\text { Weight } \\
\text { PoF }\end{array}$ & Baseline & $\begin{array}{l}\text { Weight } \\
\text { PoF }\end{array}$ \\
\hline$\{50,100\}$ & 0,1224 & $0,2117 *$ & 0,1269 & $0,2133 *$ & 0,3991 & 0,3678 & 0,4055 & 0,3755 \\
\hline$\{15,20\}$ & 0,1224 & $0,3647 *$ & 0,1269 & $0,3654 *$ & 0,3991 & 0,4244 & 0,4055 & 0,4286 \\
\hline$\{10,50\}$ & 0,1224 & $0,2403 *$ & 0,1269 & $0,2416 *$ & 0,3991 & 0,3464 & 0,4055 & 0,3538 \\
\hline$\{2,7\}$ & 0,1224 & $0,4075 *$ & 0,1269 & $0,4090 *$ & 0,3991 & 0,3763 & 0,4055 & 0,3824 \\
\hline
\end{tabular}

Os resultados do Segundo Experimento estão relacionados na Tabela 5.9. Neste experimento é comparado o uso dos tópicos com entidades nomeadas com o uso das "Estações do Ano" extraídas pelo baseline "metodológico".

Os resultados foram mais satisfatórios do que no experimento anterior, pois desta vez existem mais casos nos quais os algoritmos sensíveis ao contexto tiveram melhor desempenho utilizando o contexto extraído pelo método proposto neste trabalho, do que utilizando "Estações do Ano" como informação contextual. Novamente, considerando o fator de combinação $\alpha=0$, os algoritmos Filter PoF e Weight PoF, apresentaram valores melhores, estatisticamente, que o baseline em praticamente todas as granularidades. Já os algoritmos cReduction e DaVI-BEST, foram melhores que o baseline nas granularidades $\{15,20\}$ e $\{50,100\}$.

Na Tabela 5.10, são apresentados os resultados do Terceiro Experimento para o fator de combinação $\alpha=0$. Como observado na Tabela 5.7, neste experimento é utilizada a base da Embrapa e é comparado o uso dos tópicos com os termos do domínio, com o uso da informação de contexto "Dias da Semana", extraída pelo baseline "metodológico"

Neste experimento, novamente o algoritmo Filter PoF apresentou ganhos estatisticamente relevantes sobre o baseline em todas as granularidades para o fator de combinação $\alpha=0$. O algoritmo Weight PoF apresentou valores de MAP melhores que o baseline, 
Tabela 5.9: Resultados do Segundo Experimento para o Fator de Combinação $\alpha=0$

\begin{tabular}{|c|c|c|c|c|c|c|c|c|}
\hline \multicolumn{9}{|c|}{ Valores da MAP para o fator de combinação $\alpha=0$} \\
\hline \multirow{3}{*}{ Granul. } & \multicolumn{4}{|c|}{ cReduction } & \multicolumn{4}{|c|}{ DaVI-BEST } \\
\hline & \multicolumn{2}{|c|}{ MAP@5 } & \multicolumn{2}{|c|}{$M A P @ 10$} & \multicolumn{2}{|c|}{ MAP@5 } & \multicolumn{2}{|c|}{$M A P @ 10$} \\
\hline & Baseline & cReduction & Baseline & cReduction & Baseline & $\begin{array}{l}\text { DaVI- } \\
\text { BEST }\end{array}$ & Baseline & $\begin{array}{l}\text { DaVI- } \\
\text { BEST }\end{array}$ \\
\hline$\{50,100\}$ & 0,3089 & $0,3497 *$ & 0,3281 & $0,3441 *$ & 0,3131 & $0,3512 *$ & 0,3254 & $0,3597 *$ \\
\hline$\{15,20\}$ & 0,3089 & $\mathbf{0 , 3 8 2 4 *}$ & 0,3281 & $0,3894 *$ & 0,3131 & $0,3824 *$ & 0,3254 & $0,3894 *$ \\
\hline$\{10,50\}$ & 0,3089 & 0,3221 & 0,3281 & 0,3246 & 0,3131 & 0,3209 & 0,3254 & 0,3289 \\
\hline$\{2,7\}$ & 0,3089 & 0,3153 & 0,3281 & 0,3229 & 0,3131 & 0,3153 & 0,3254 & 0,3229 \\
\hline \multirow{3}{*}{ Granul. } & \multicolumn{4}{|c|}{$\begin{array}{ll}\text { Filter PoF }\end{array}$} & \multicolumn{4}{|c|}{ Weight PoF } \\
\hline & \multicolumn{2}{|c|}{$M A P @ 5$} & \multicolumn{2}{|c|}{$M A P @ 10$} & \multicolumn{2}{|c|}{$M A P @ 5$} & \multicolumn{2}{|c|}{$M A P @ 10$} \\
\hline & Baseline & \begin{tabular}{|l} 
Filter \\
PoF
\end{tabular} & Baseline & $\begin{array}{l}\text { Filter } \\
\text { PoF }\end{array}$ & Baseline & $\begin{array}{l}\text { Weight } \\
\text { PoF }\end{array}$ & Baseline & $\begin{array}{l}\text { Weight } \\
\text { PoF }\end{array}$ \\
\hline$\{50,100\}$ & 0,1713 & $0,2117 *$ & 0,1831 & $0,2133 *$ & 0,3201 & $0,3678 *$ & 0,3324 & $0,3755 *$ \\
\hline$\{15,20\}$ & 0,1713 & $0,3647 *$ & 0,1831 & $0,3654 *$ & 0,3201 & $0,4244 *$ & 0,3324 & $0,4286 *$ \\
\hline$\{10,50\}$ & 0,1713 & $0,2403 *$ & 0,1831 & $0,2416 *$ & 0,3201 & $0,3464 *$ & 0,3324 & 0,3538 \\
\hline$\{2,7\}$ & 0,1713 & $0,4075 *$ & 0,1831 & $0,4090 *$ & 0,3201 & $0,3763 *$ & 0,3324 & $0,3824 *$ \\
\hline
\end{tabular}

mas sem significância estatística, nas granularidades $\{15,20\}$ e $\{2,7\}$.

Tabela 5.10: Resultados do Terceiro Experimento para o Fator de Combinação $\alpha=0$

\begin{tabular}{|c|c|c|c|c|c|c|c|c|}
\hline \multicolumn{9}{|c|}{ Valores da MAP para o fator de combinação $\alpha=0$} \\
\hline \multirow{3}{*}{ Granul. } & \multicolumn{4}{|c|}{ cReduction } & \multicolumn{4}{|c|}{ DaVI-BEST } \\
\hline & \multicolumn{2}{|c|}{ MAP@5 } & \multicolumn{2}{|c|}{$M A P @ 10$} & \multicolumn{2}{|c|}{$M A P @ 5$} & \multicolumn{2}{|c|}{$M A P @ 10$} \\
\hline & Baseline & cReduction & Baseline & cReduction & Baseline & $\begin{array}{l}\text { DaVI- } \\
\text { BEST }\end{array}$ & Baseline & $\begin{array}{l}\text { DaVI- } \\
\text { BEST }\end{array}$ \\
\hline$\{50,100\}$ & 0,3940 & 0,3017 & 0,3864 & 0,3042 & 0,3894 & 0,3022 & 0,3958 & 0,3120 \\
\hline$\{15,20\}$ & 0,3940 & 0,3802 & 0,3864 & 0,3874 & 0,3894 & 0,3802 & 0,3958 & 0,3874 \\
\hline$\{10,50\}$ & 0,3940 & 0,3447 & 0,3864 & 0,3497 & 0,3894 & 0,3447 & 0,3958 & 0,3526 \\
\hline$\{2,7\}$ & 0,3940 & 0,3392 & 0,3864 & 0,3470 & 0,3894 & 0,3392 & 0,3958 & 0,3470 \\
\hline \multirow{3}{*}{ Granul. } & \multicolumn{4}{|c|}{ Filter PoF } & \multicolumn{4}{|c|}{ Weight PoF } \\
\hline & \multicolumn{2}{|c|}{$M A P @ 5$} & \multicolumn{2}{|c|}{$M A P @ 10$} & \multicolumn{2}{|c|}{$M A P @ 5$} & \multicolumn{2}{|c|}{$M A P @ 10$} \\
\hline & Baseline & \begin{tabular}{|l|} 
Filter \\
PoF \\
\end{tabular} & Baseline & $\begin{array}{l}\text { Filter } \\
\text { PoF }\end{array}$ & Baseline & $\begin{array}{l}\text { Weight } \\
\text { PoF }\end{array}$ & Baseline & $\begin{array}{l}\text { Weight } \\
\text { PoF }\end{array}$ \\
\hline$\{50,100\}$ & 0,1224 & $0,1908 *$ & 0,1269 & $0,1922 *$ & 0,3991 & 0,3210 & 0,4055 & 0,3305 \\
\hline$\{15,20\}$ & 0,1224 & $0,3240 *$ & 0,1269 & $0,3262 *$ & 0,3991 & 0,4049 & 0,4055 & 0,4110 \\
\hline$\{10,50\}$ & 0,1224 & $0,2591 *$ & 0,1269 & $0,2606 *$ & 0,3991 & 0,3751 & 0,40551 & 0,3823 \\
\hline$\{2,7\}$ & 0,1224 & $0,4314 *$ & 0,1269 & $0,4322 *$ & 0,3991 & 0,4024 & 0,4055 & 0,4088 \\
\hline
\end{tabular}

Assim como no experimento anterior, no Quarto Experimento também foram avaliadas as recomendações geradas pelos sistemas de recomendação sensíveis ao contexto, utilizando os tópicos extraídos das hierarquias de tópicos construídas com os textos das páginas da Embrapa e com os termos extraídos, porém, como baseline, foram utilizados os mesmos algoritmos sensíveis ao contexto considerando a informação de contexto "Estações do Ano". Na Tabela 5.11, são apresentados os resultados do Quarto Experimento para o fator de combinação $\alpha=0$.

Neste experimento, o algoritmo Filter PoF apresentou ganhos estatisticamente relevantes sobre o baseline em todas as granularidades para o fator de combinação $\alpha=0$. O algoritmo Weight PoF apresentou valores de MAP melhores, estatisticamente, que o baseline, em quase todas as granularidades, com exceção da granularidade $\{50,100\}$. Os valores de MAP@5 para o algoritmo cReduction, também foram melhores que os resultados do baseline nas granularidades $\{2,7\},\{10,50\}$ e $\{15,20\}$. 
Tabela 5.11: Resultados do Quarto Experimento para o Fator de Combinação $\alpha=0$

\begin{tabular}{|c|c|c|c|c|c|c|c|c|}
\hline \multicolumn{9}{|c|}{ Valores da MAP para o fator de combinação $\alpha=0$} \\
\hline \multirow{3}{*}{ Granul. } & \multicolumn{4}{|c|}{ cReduction } & \multicolumn{4}{|c|}{ DaVI-BEST } \\
\hline & \multicolumn{2}{|c|}{ MAP@5 } & \multicolumn{2}{|c|}{$M A P @ 10$} & \multicolumn{2}{|c|}{ MAP@5 } & \multicolumn{2}{|c|}{$M A P @ 10$} \\
\hline & Baseline & cReduction & Baseline & cReduction & Baseline & $\begin{array}{l}\text { DaVI- } \\
\text { BEST }\end{array}$ & Baseline & $\begin{array}{l}\text { DaVI- } \\
\text { BEST }\end{array}$ \\
\hline$\{50,100\}$ & 0,3089 & 0,3017 & 0,3281 & 0,3042 & 0,3131 & 0,3022 & 0,3254 & 0,3120 \\
\hline$\{15,20\}$ & 0,3089 & $0,3802 *$ & 0,3281 & $0,3874 *$ & 0,3131 & $0,3802 *$ & 0,3254 & $0,3874 *$ \\
\hline$\{10,50\}$ & 0,3089 & $0,3447 *$ & 0,3281 & 0,3491 & 0,3131 & 0,3446803 & 0,3254 & 0,3526 \\
\hline$\{2,7\}$ & 0,3089 & $0,3392 *$ & 0,3281 & 0,3470 & 0,3131 & 0,3392 & 0,3254 & 0,3470 \\
\hline \multirow{3}{*}{ Granul. } & \multicolumn{4}{|c|}{ Filter PoF } & \multirow{2}{*}{\multicolumn{4}{|c|}{\begin{tabular}{l}
\multicolumn{3}{c}{ Weight PoF } \\
$M A P @ 5$
\end{tabular}}} \\
\hline & \multicolumn{2}{|c|}{$M A P @ 5$} & \multicolumn{2}{|c|}{$M A P @ 10$} & & & & \\
\hline & Baseline & $\begin{array}{l}\text { Filter } \\
\text { PoF }\end{array}$ & Baseline & $\begin{array}{l}\text { Filter } \\
\text { PoF }\end{array}$ & Baseline & $\begin{array}{l}\text { Weight } \\
\text { PoF }\end{array}$ & Baseline & $\begin{array}{l}\text { Weight } \\
\text { PoF }\end{array}$ \\
\hline$\{50,100\}$ & 0,1713 & $0,1908 *$ & 0,1831 & $0,1922 *$ & 0,3201 & 0,3210 & 0,3324 & 0,3305 \\
\hline$\{15,20\}$ & 0,1713 & $0,3240 *$ & 0,1831 & $0,3262 *$ & 0,3201 & $0,4049 *$ & 0,3324 & $0,4110 *$ \\
\hline$\{10,50\}$ & 0,1713 & $0,2591 *$ & 0,1831 & $0,2606 *$ & 0,3201 & $0,3751 *$ & 0,3324 & $0,3823 *$ \\
\hline$\{2,7\}$ & 0,1713 & $0,4314 *$ & 0,1831 & $0,4322 *$ & 0,3201 & $0,4024 *$ & 0,3324 & $0,4088 *$ \\
\hline
\end{tabular}

No Quinto Experimento, considerando a base do Dicionário Informal, foi utilizada a informação de contexto "Dias da Semana" nos algoritmos sensíveis ao contexto para comparar o uso desta informação com o uso dos tópicos extraídos pelo método proposto neste trabalho. Na Tabela 5.12, são apresentados os resultados deste experimento para o fator de combinação $\alpha=0,3$.

Neste experimento, apenas o algoritmo Filter PoF apresentou ganhos estatisticamente relevantes sobre o baseline. Tais ganhos são observados na granularidade $\{2,7\}$ para o fator de combinação $\alpha=0,3$. Os demais algoritmos apresentaram melhores resultados do que o baseline em alguns casos, porém em nenhum deles com relevância estatística.

Tabela 5.12: Resultados do Quinto Experimento para o Fator de Combinação $\alpha=0,3$

\begin{tabular}{|c|c|c|c|c|c|c|c|c|}
\hline \multicolumn{9}{|c|}{ Valores da MAP para o fator de combinação $\alpha=0,3$} \\
\hline \multirow{3}{*}{ Granul. } & \multicolumn{4}{|c|}{ cReduction } & \multicolumn{4}{|c|}{ DaVI-BEST } \\
\hline & \multicolumn{2}{|c|}{$M A P @ 5$} & \multicolumn{2}{|c|}{ MAP@10 } & \multicolumn{2}{|c|}{$M A P @ 5$} & \multicolumn{2}{|c|}{$M A P @ 10$} \\
\hline & Baseline & cReduction & Baseline & cReduction & Baseline & $\begin{array}{l}\text { DaVI- } \\
\text { BEST }\end{array}$ & Baseline & $\begin{array}{l}\text { DaVI- } \\
\text { BEST }\end{array}$ \\
\hline$\{50,100\}$ & 0,0169 & 0,0195 & 0,0175 & 0,0209 & 0,0169 & 0,0195 & 0,0169 & 0,0209 \\
\hline$\{15,20\}$ & 0,0169 & 0,0077 & 0,0175 & 0,0089 & 0,0169 & 0,0096 & 0,0169 & 0,0105 \\
\hline$\{10,50\}$ & 0,0169 & 0,0178 & 0,0175 & 0,0181 & 0,0169 & 0,0178 & 0,0169 & 0,0181 \\
\hline$\{2,7\}$ & 0,0169 & 0,0189 & 0,0175 & 0,0190 & 0,0169 & 0,0189 & 0,0169 & 0,0190 \\
\hline \multirow{3}{*}{ Granul. } & \multirow{2}{*}{\multicolumn{4}{|c|}{ Filter PoF }} & \multicolumn{4}{|c|}{ Weight PoF } \\
\hline & $M A P @ 5$ & & & $M A P @ 10$ & \multicolumn{2}{|c|}{$M A P @ 5$} & \multicolumn{2}{|c|}{$M A P @ 10$} \\
\hline & Baseline & $\begin{array}{l}\text { Filter } \\
\text { PoF }\end{array}$ & Baseline & $\begin{array}{l}\text { Filter } \\
\text { PoF }\end{array}$ & Baseline & $\begin{array}{l}\text { Weight } \\
\text { PoF }\end{array}$ & Baseline & $\begin{array}{l}\text { Weight } \\
\text { PoF }\end{array}$ \\
\hline$\{50,100\}$ & 0,0085 & 0,0074 & 0,0086 & 0,0089 & 0,0167 & 0,0195 & 0,0168 & 0,0209 \\
\hline$\{15,20\}$ & 0,0085 & 0,0019 & 0,0086 & 0,0035 & 0,0167 & 0,0107 & 0,0168 & 0,0117 \\
\hline$\{10,50\}$ & 0,0085 & 0,0027 & 0,0086 & 0,0030 & 0,0167 & 0,0183 & 0,0168 & 0,0185 \\
\hline$\{2,7\}$ & 0,0085 & $0,0228 *$ & 0,0086 & $0,0229 *$ & 0,0167 & 0,0196 & 0,0168 & 0,0197 \\
\hline
\end{tabular}

Os resultados do Sexto Experimento estão relacionados na Tabela 5.13. Neste experimento é utilizada a base do Dicionário Informal e é avaliado o uso dos tópicos com entidades nomeadas. Como baseline, foram utilizados os algoritmos sensíveis ao contexto considerando a informação de contexto "Estações do Ano". Esses resultados são quase equivalentes aos resultados do experimento anterior, apenas o Filter PoF apresentou 
ganhos estatisticamente relevantes sobre o baseline na granularidade $\{2,7\}$ para o fator de combinação $\alpha=0,3$. Os demais algoritmos apresentaram melhores resultados do que o baseline em alguns casos, porém em nenhum deles com relevância estatística.

Tabela 5.13: Resultados do Sexto Experimento para o Fator de Combinação $\alpha=0,3$

\begin{tabular}{|c|c|c|c|c|c|c|c|c|}
\hline \multicolumn{9}{|c|}{ Valores da MAP para o fator de combinação $\alpha=0,3$} \\
\hline \multirow{3}{*}{ Granul. } & \multicolumn{4}{|c|}{ cReduction } & \multicolumn{4}{|c|}{ DaVI-BEST } \\
\hline & \multicolumn{2}{|c|}{$M A P @ 5$} & \multicolumn{2}{|c|}{ MAP@10 } & \multicolumn{2}{|c|}{$M A P @ 5$} & \multicolumn{2}{|c|}{$M A P @ 10$} \\
\hline & Baseline & cReduction & Baseline & cReduction & Baseline & $\begin{array}{l}\text { DaVI- } \\
\text { BEST }\end{array}$ & Baseline & $\begin{array}{l}\text { DaVI- } \\
\text { BEST }\end{array}$ \\
\hline$\{50,100\}$ & 0,0157 & 0,0195 & 0,0163 & 0,0209 & 0,0163 & 0,0195 & 0,0164 & 0,0209 \\
\hline$\{15,20\}$ & 0,0157 & 0,0077 & 0,0163 & 0,0089 & 0,0163 & 0,0096 & 0,0164 & 0,0105 \\
\hline$\{10,50\}$ & 0,0157 & 0,0178 & 0,0163 & 0,0181 & 0,0163 & 0,0178 & 0,0164 & 0,0181 \\
\hline$\{2,7\}$ & 0,0157 & 0,0189 & 0,0163 & 0,0190 & 0,0163 & 0,0189 & 0,0164 & 0,0190 \\
\hline \multirow{3}{*}{ Granul. } & \multicolumn{4}{|c|}{ Filter PoF } & \multicolumn{4}{|c|}{ Weight PoF } \\
\hline & \multicolumn{2}{|c|}{$M A P @ 5$} & \multicolumn{2}{|c|}{$M A P @ 10$} & \multicolumn{2}{|c|}{$M A P @ 5$} & \multicolumn{2}{|c|}{$M A P @ 10$} \\
\hline & Baseline & $\begin{array}{l}\text { Filter } \\
\text { PoF }\end{array}$ & Baseline & $\begin{array}{l}\text { Filter } \\
\text { PoF }\end{array}$ & Baseline & $\begin{array}{l}\text { Weight } \\
\text { PoF }\end{array}$ & Baseline & $\begin{array}{l}\text { Weight } \\
\text { PoF }\end{array}$ \\
\hline$\{50,100\}$ & 0,0077 & 0,0074 & 0,0078 & 0,0089 & 0,0162 & 0,0195 & 0,0163 & 0,0209 \\
\hline$\{15,20\}$ & 0,0077 & 0,0019 & 0,0078 & 0,0035 & 0,0162 & 0,0107 & 0,0163 & 0,0117 \\
\hline$\{10,50\}$ & 0,0077 & 0,0027 & 0,0078 & 0,0030 & 0,0162 & 0,0183 & 0,0163 & 0,0185 \\
\hline$\{2,7\}$ & 0,0077 & $0,0228 *$ & 0,0078 & $0,0229 *$ & 0,0162 & 0,0196 & 0,0163 & 0,0197 \\
\hline
\end{tabular}

Na Tabela 5.14, são apresentados os resultados do Sétimo Experimento para o fator de combinação $\alpha=1$. Foram avaliadas as recomendações geradas pelos sistemas de recomendação sensíveis ao contexto, utilizando os tópicos extraídos das hierarquias de tópicos construídas com os textos das páginas do Dicionário Informal e com os termos extraídos. Como baseline, foram utilizados os algoritmos sensíveis ao contexto considerando a informação de contexto "Dias da Semana".

Neste experimento, observa-se mais casos nos quais houve ganhos estatístico sobre o baseline. Os algoritmos cReduction, DaVI-BEST e Weight PoF apresentaram valores de MAP, melhores que o baseline, com significância estatística, na granularidade $\{15,20\}$ para o fator de combinação 1. Para o algoritmo Filter PoF ocorre a mesma situação, porém na granularidade $\{2,7\}$.

Tabela 5.14: Resultados do Sétimo Experimento para o fator de combinação $\alpha=1$

\begin{tabular}{|c|c|c|c|c|c|c|c|c|}
\hline \multicolumn{9}{|c|}{ Valores da MAP para o fator de combinação $\alpha=1$} \\
\hline \multirow{3}{*}{ Granul. } & \multicolumn{4}{|c|}{ cReduction } & \multicolumn{4}{|c|}{ DaVI-BEST } \\
\hline & \multicolumn{2}{|c|}{ MAP@5 } & \multicolumn{2}{|c|}{$M A P @ 10$} & \multicolumn{2}{|c|}{ MAP@5 } & \multicolumn{2}{|c|}{$M A P @ 10$} \\
\hline & Baseline & cReduction & Baseline & cReduction & Baseline & $\begin{array}{l}\text { DaVI- } \\
\text { BEST }\end{array}$ & Baseline & $\begin{array}{l}\text { DaVI- } \\
\text { BEST }\end{array}$ \\
\hline$\{50,100\}$ & 0,0169 & 0,0153 & 0,0175 & 0,0157 & 0,0169 & 0,0153 & 0,0169 & 0,0157 \\
\hline$\{15,20\}$ & 0,0169 & $0,0375 *$ & 0,0175 & $0,0378 *$ & 0,0169 & $0,0375 *$ & 0,0169 & $0,0307 *$ \\
\hline$\{10,50\}$ & 0,0169 & 0,0153 & 0,0175 & 0,0156 & 0,0169 & 0,0153 & 0,0169 & 0,0120 \\
\hline$\{2,7\}$ & 0,0169 & 0,0170 & 0,0175 & 0,0171 & 0,0169 & 0,0198 & 0,0169 & 0,0189 \\
\hline \multirow{3}{*}{ Granul. } & \multicolumn{4}{|c|}{ Filter PoF } & \multicolumn{4}{|c|}{ Weight PoF } \\
\hline & \multicolumn{2}{|c|}{$M A P @ 5$} & \multicolumn{2}{|c|}{$M A P @ 10$} & \multicolumn{2}{|c|}{$M A P @ 5$} & \multicolumn{2}{|c|}{$M A P @ 10$} \\
\hline & Baseline & \begin{tabular}{|l|} 
Filter \\
PoF
\end{tabular} & Baseline & $\begin{array}{l}\text { Filter } \\
\text { PoF }\end{array}$ & Baseline & $\begin{array}{l}\text { Weight } \\
\text { PoF }\end{array}$ & Baseline & $\begin{array}{l}\text { Weight } \\
\text { PoF }\end{array}$ \\
\hline$\{50,100\}$ & 0,0085 & 0,0062 & 0,0086 & 0,0065 & 0,0167 & 0,0153 & 0,0168 & 0,0159 \\
\hline$\{15,20\}$ & 0,0085 & 0,0237 & 0,0086 & 0,0237 & 0,0167 & $0,0375 *$ & 0,0168 & $0,0378 *$ \\
\hline$\{10,50\}$ & 0,0085 & 0,0069 & 0,0086 & 0,0072 & 0,0167 & 0,0157 & 0,0168 & 0,0161 \\
\hline$\{2,7\}$ & 0,0085 & $0,0171 *$ & 0,0086 & $0,0172 *$ & 0,0167 & 0,0184 & 0,0168 & 0,0185 \\
\hline
\end{tabular}


Por fim, os resultados do Oitavo Experimento são apresentados na Tabela 5.15. Neste experimento foram avaliados os tópicos com termos extraídos da base do Dicionário Informal. Como baseline, foram utilizados os algoritmos sensíveis ao contexto considerando a informação de contexto "Estações do Ano".

Os algoritmos cReduction, DaVI-BEST e Weight PoF apresentaram valores de MAP, melhores que o baseline, com significância estatística, na granularidade $\{15,20\}$ para o fator de combinação $\alpha=1$ e, para o algoritmo Filter PoF ocorre a mesma situação, porém na granularidade $\{2,7\}$.

Tabela 5.15: Resultados do Oitavo Experimento para o Fator de Combinação $\alpha=1$

\begin{tabular}{|c|c|c|c|c|c|c|c|c|}
\hline \multicolumn{9}{|c|}{ Valores da MAP para o fator de combinação $\alpha=1$} \\
\hline \multirow{3}{*}{ Granul. } & \multicolumn{4}{|c|}{ cReduction } & \multicolumn{4}{|c|}{ DaVI-BEST } \\
\hline & \multicolumn{2}{|c|}{$M A P @ 5$} & \multicolumn{2}{|c|}{$M A P @ 10$} & \multicolumn{2}{|c|}{$M A P @ 5$} & \multicolumn{2}{|c|}{$M A P @ 10$} \\
\hline & Baseline & cReduction & Baseline & cReduction & Baseline & $\begin{array}{l}\text { DaVI- } \\
\text { BEST }\end{array}$ & Baseline & $\begin{array}{l}\text { DaVI- } \\
\text { BEST }\end{array}$ \\
\hline$\{50,100\}$ & 0,0157 & 0,0153 & 0,0163 & 0,0157 & 0,0163 & 0,0153 & 0,0164 & 0,0157 \\
\hline$\{15,20\}$ & 0,0157 & $0,0375 *$ & 0,0163 & $0,0378 *$ & 0,0162 & $0,0375 *$ & 0,0167 & 0,0307 \\
\hline$\{10,50\}$ & 0,0157 & 0,0153 & 0,0163 & 0,0156 & 0,0163 & 0,0153 & 0,0164 & 0,0120 \\
\hline$\{2,7\}$ & 0,0157 & 0,0170 & 0,0163 & 0,0171 & 0,0163 & 0,0198 & 0,0164 & 0,0189 \\
\hline \multirow{3}{*}{ Granul. } & \multicolumn{4}{|c|}{ Filter PoF } & \multicolumn{4}{|c|}{ Weight PoF } \\
\hline & \multicolumn{2}{|c|}{ MAP@5 } & \multicolumn{2}{|c|}{$M A P @ 10$} & \multicolumn{2}{|c|}{$M A P @ 5$} & \multicolumn{2}{|c|}{$M A P @ 10$} \\
\hline & Baseline & $\begin{array}{l}\text { Filter } \\
\text { PoF }\end{array}$ & Baseline & $\begin{array}{l}\text { Filter } \\
\text { PoF }\end{array}$ & Baseline & $\begin{array}{l}\text { Weight } \\
\text { PoF }\end{array}$ & Baseline & $\begin{array}{l}\text { Weight } \\
\text { PoF }\end{array}$ \\
\hline$\{50,100\}$ & 0,0077 & 0,0062 & 0,0078 & 0,0065 & 0,0162 & 0,0153 & 0,0163 & 0,0159 \\
\hline$\{15,20\}$ & 0,0077 & 0,0237 & 0,0078 & 0,0237 & 0,0162 & 0,0375 & 0,0163 & 0,0378 \\
\hline$\{10,50\}$ & 0,0077 & 0,0069 & 0,0078 & 0,0072 & 0,0162 & 0,0157 & 0,0163 & 0,0161 \\
\hline$\{2,7\}$ & 0,0077 & $0,0171 *$ & 0,0078 & $0,0172 *$ & 0,0162 & 0,0184 & 0,0163 & 0,0185 \\
\hline
\end{tabular}

\subsection{Análise Geral da Utilização do Contexto Extraído}

De modo geral, os resultados dos experimentos foram muito satisfatórios e demonstraram que o uso do contexto extraído pelo método proposto neste mestrado ocasionou melhores recomendações (considerando o valor da medida MAP) na maioria dos casos. Os resultados dos experimentos com a base do Dicionário Informal, tanto não utilizando (IBCF) quanto utilizando o contexto extraído, não foram tão bons quanto os resultados com a base da Embrapa. Isso deve-se às características particulares das bases. A base do Dicionário Informal, além de apresentar muitos usuários que fizeram poucos acessos às páginas da Web, o conteúdo textual destas páginas é composto por textos curtos e utilizando pouca informação textual, a qualidade das hierarquias de tópicos pode ser influenciada negativamente.

Analisando os resultados por algoritmo, o cReduction e o Weight PoF tiveram bom desempenho, sendo o algoritmo Weight PoF o que apresentou os melhores resultados. Os resultados do algoritmo DaVI-BEST, foram, nos primeiros experimentos, equivalentes ao IBCF, o que mostra que não houve melhora, para esse algoritmo, utilizando o contexto extraído pelo método proposto neste trabalho. Para o algoritmo Filter PoF, os resultados não foram tão bons, e em vários casos não conseguiram ficar acima do IBCF. Isso deve-se, 
talvez, ao valor da probabilidade utilizado para filtrar as recomendações, que pode ter sido alto para as bases consideradas ocasionando a eliminação de recomendações que poderiam ser importantes para os resultados finais.

Nos experimentos realizados com a base da Embrapa os resultados foram bons, com muitos casos (a maioria deles) melhores que o baseline IBCF. Os resultados com a utilização de entidades nomeadas como informação privilegiada, foram próximos dos resultados utilizando os termos do domínio, entretanto, com a utilização dos termos, foi maior o número de casos nos quais a utilização do contexto gerou melhores resultados que o baseline IBCF. Com relação ao peso dado às informações privilegiadas, isto é, ao valor do fator de combinação $\alpha$, sendo as entidades nomeadas as informações privilegiadas, os algoritmos apresentaram melhores resultados para o $\alpha=0,7$, isto é, quando foi considerado $70 \%$ das entidades, como pode ser observado nos gráficos da Figura 5.6, construídos para as quatro configurações de granularidade. Na mesma figura, nota-se que os fatores de granularidade com melhores resultados foram $\{15,20\}$ para cReduction e Weight PoF e $\{2,7\}$ para Filter PoF, ou seja, os dois primeiros algoritmos tiveram um melhor desempenho quando foram considerados menos tópicos, sendo eles mais gerais, e o algoritmo Filter PoF, teve melhor desempenho com mais tópicos, sendo eles mais específicos. Essa análise foi obtida a partir dos resultados da Tabela A.1.

I

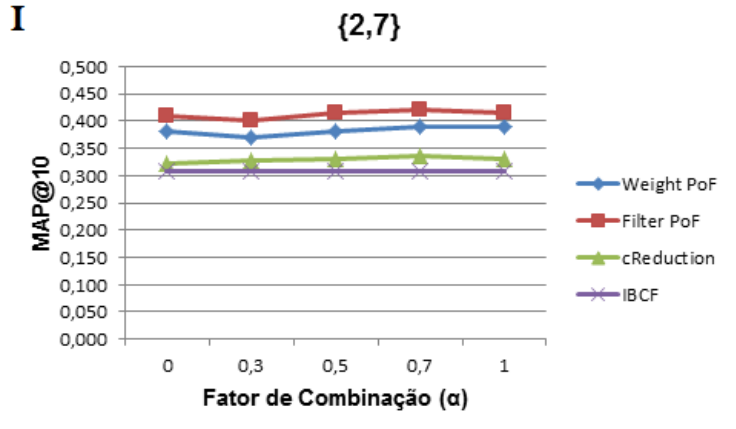

\section{III}

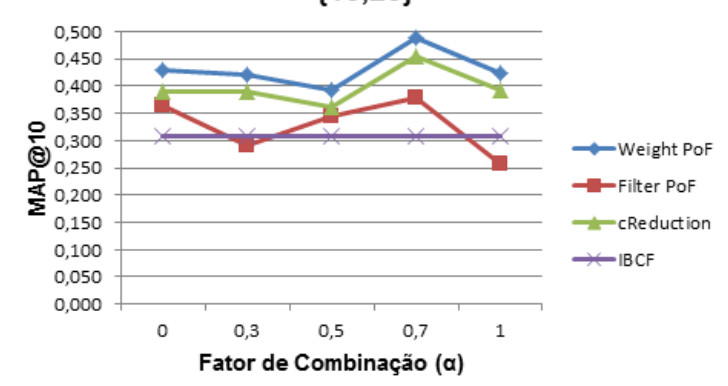

II

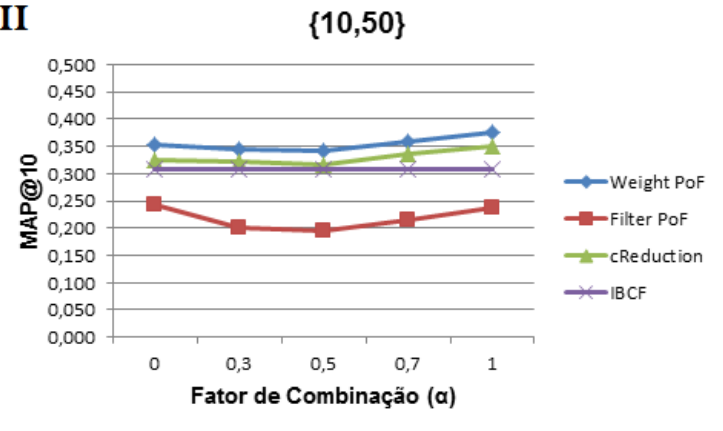

IV

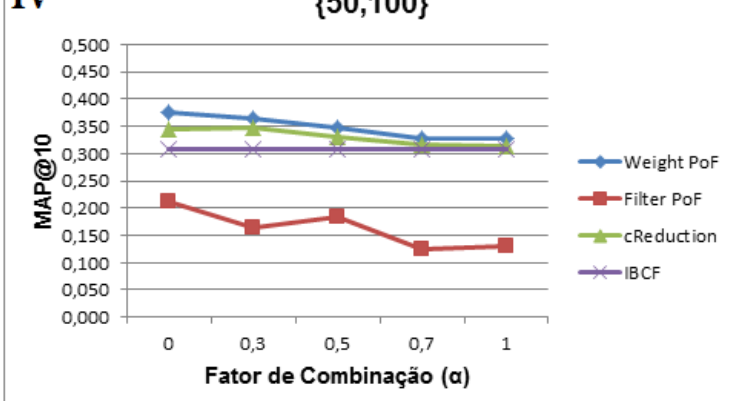

Figura 5.6: Gráficos dos valores da MAP@10 para o experimento dos tópicos com entidades nomeadas da base da Embrapa e considerando o baseline IBCF. I - Granularidade $\{2,7\}$; II - Granularidade $\{10,50\}$; III - Granularidade $\{15,20\}$ e IV - Granularidade $\{50,100\}$.

Observando a Figura 5.7, cujos gráficos foram construídos considerando os resultados da Tabela A.3, nota-se que, quando foram utilizados os termos como informação privilegiada, os algoritmos cReduction e Weight PoF tiveram melhor desempenho no fator de 
combinação $\alpha=0,5$ (50\% da informação técnica e 50\% dos termos). O padrão observado para os fatores de combinação com as entidades nomeadas, também foi observado com os termos, ou seja, os algoritmos cReduction e Weight PoF apresentaram melhor desempenho na granularidade $\{15,20\}$, enquanto o algoritmo Filter PoF apresentou melhores resultados na granularidade $\{2,7\}$.

I

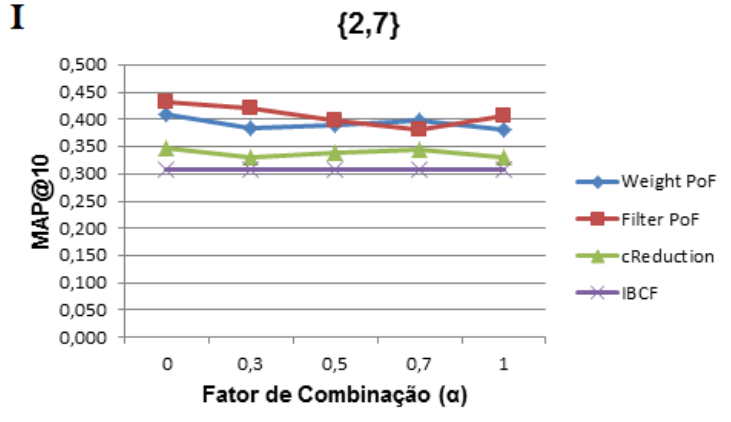

\section{III}

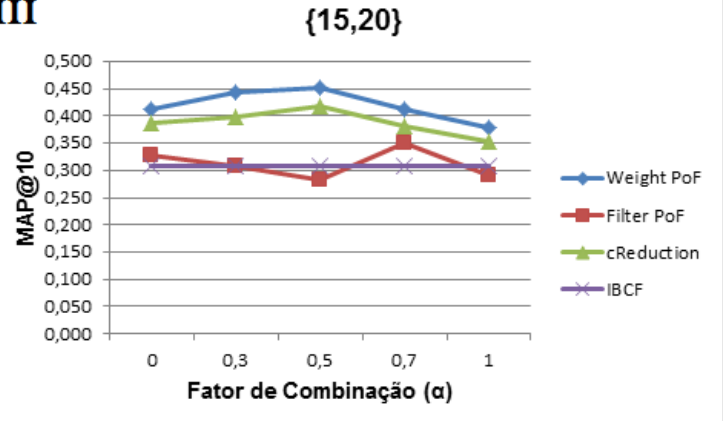

II

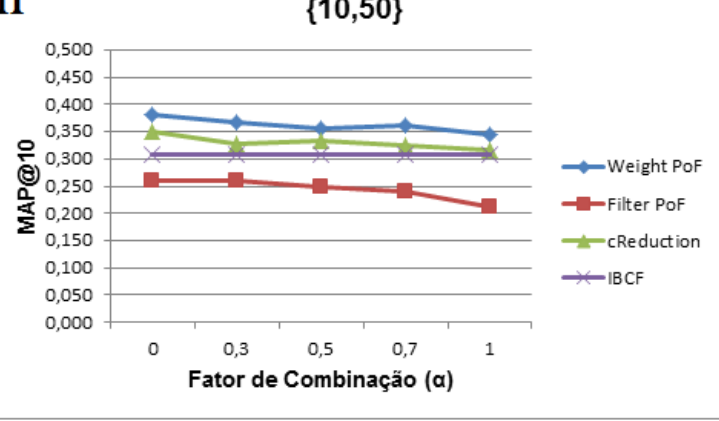

IV

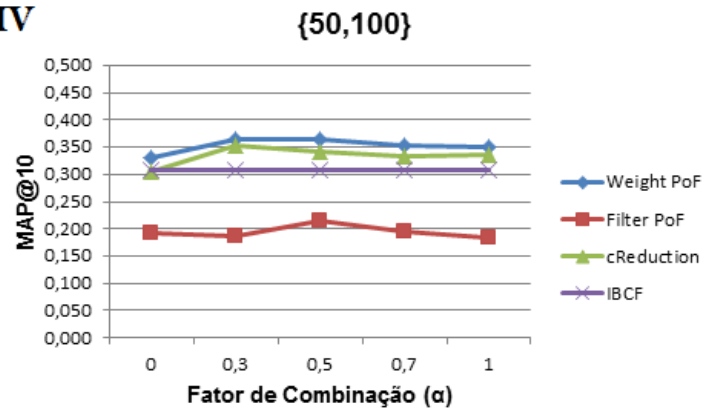

Figura 5.7: Gráficos dos valores da MAP@10 para o experimento dos tópicos com termos da base da Embrapa e considerando o baseline IBCF. I - Granularidade $\{2,7\}$; II Granularidade $\{10,50\}$; III - Granularidade $\{15,20\}$ e IV - Granularidade $\{50,100\}$.

Nos experimentos realizados com a base do Dicionário Informal, como já mencionado, os resultados não foram tão bons quanto os resultados com a base da Embrapa. Considerando as resultados das entidades nomeadas como informação privilegiada, foram construídos os gráficos da Figura 5.8 utilizando os dados da Tabela A.2. Observando esses gráficos, nota-se que não houve casos com resultados melhores, com significância estatística, que o IBCF, sendo o melhor dos casos a configuração de granularidade $\{2,7\}$. Analisando o valor do $\alpha$, considerando as entidades nomeadas (Figura 5.8), o melhor $\alpha$ foi igual a 0,3 para os três algoritmos de recomendação (30\% das entidades nomeadas). Considerando os termos (Figura 5.9 - dados Tabela A.4), os algoritmos cReduction e Filter PoF, tiveram melhor desempenho com $\alpha=0,5$ (50\% dos termos), enquanto que para o algoritmo Filter PoF, o melhor fator foi $\alpha=0,7$ (70\% dos termos). Na maioria dos casos, os fatores de granularidade com melhores resultados foram $\{15,20\}$ para cReduction e Weight PoF e $\{2,7\}$ para Filter PoF, assim como ocorreu nos experimentos com a base da Embrapa.

Para o segundo conjunto de experimentos, nos quais comparou-se o método proposto neste trabalho com o baseline metodológico, os resultados também foram bons, já que os resultados para o uso do contexto extraído pelo método proposto foram melhores ou 
I

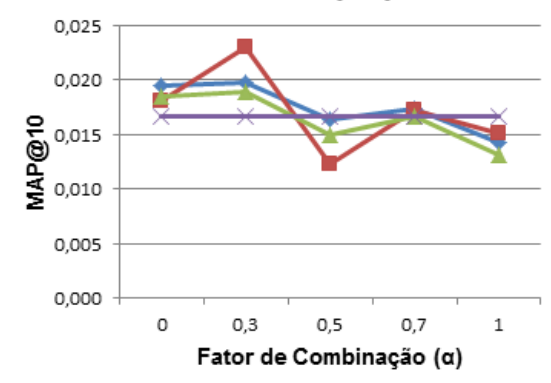

III

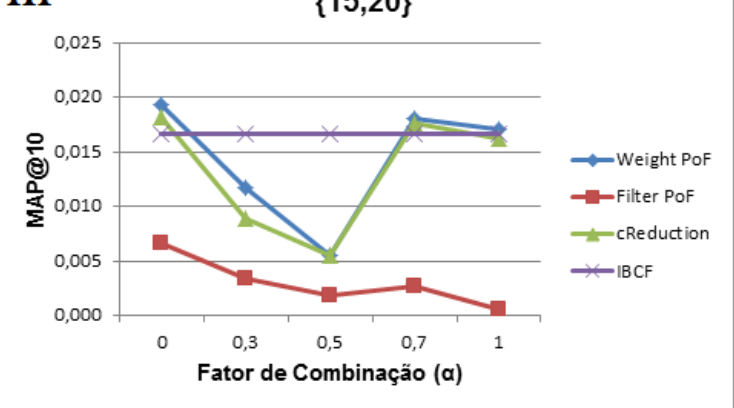

II

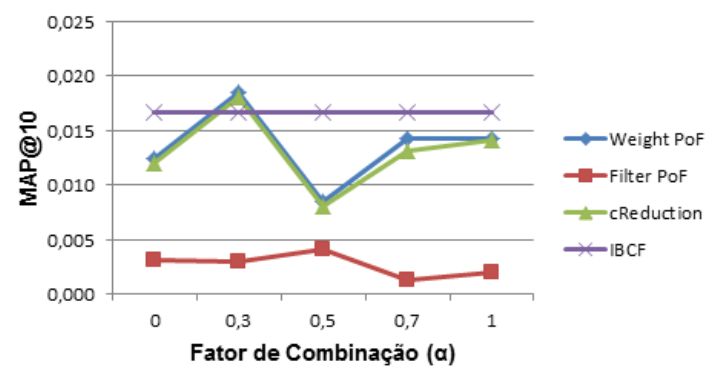

IV

$\{50,100\}$

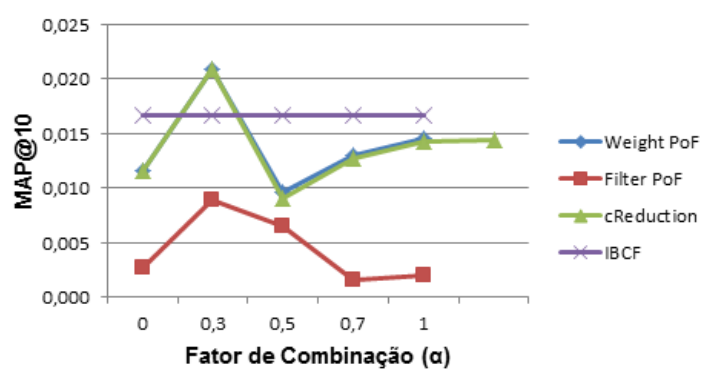

Figura 5.8: Gráficos dos valores da MAP@10 para o experimento dos tópicos com entidades nomeadas da base do Dicionário Informal e considerando o baseline IBCF. I Granularidade $\{2,7\}$; II - Granularidade $\{10,50\}$; III - Granularidade $\{15,20\}$ e IV - Granularidade $\{50,100\}$.

I

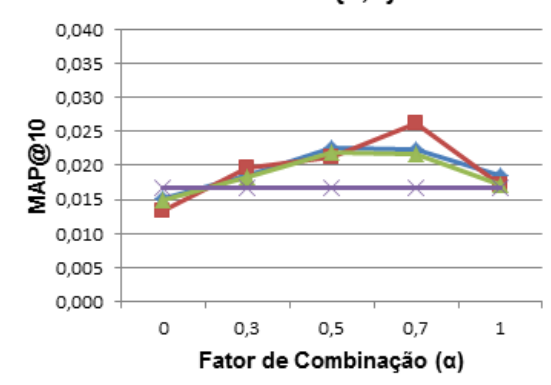

III

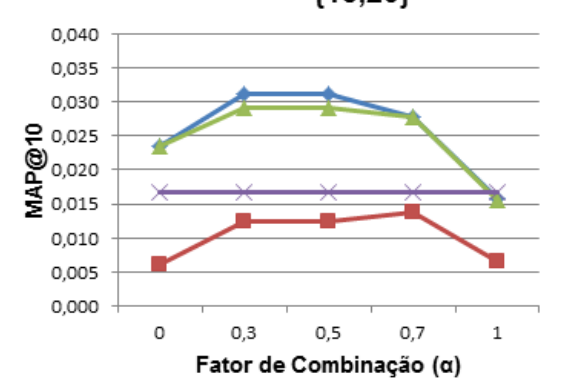

II

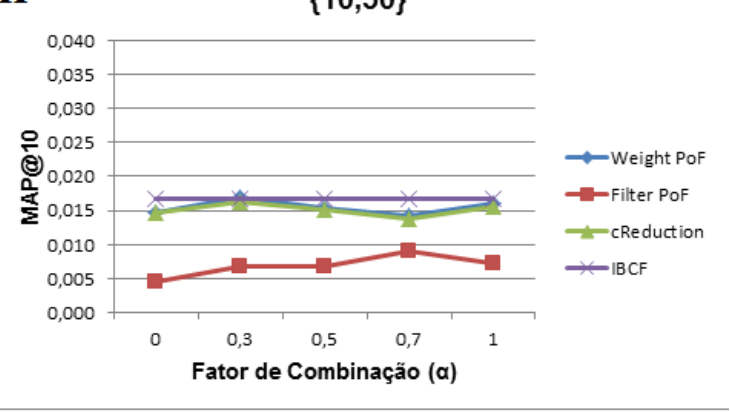

IV

$\{50,100\}$

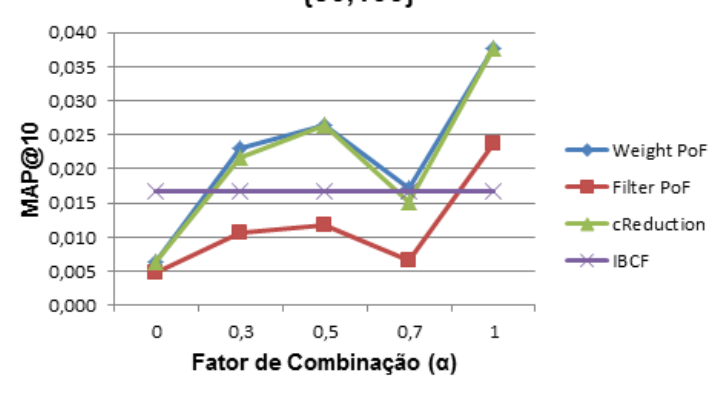

Figura 5.9: Gráficos dos valores da MAP@10 para o experimento dos tópicos com termos da base do Dicionário Informal e considerando o baseline IBCF. I - Granularidade $\{2,7\}$; II - Granularidade $\{10,50\}$; III - Granularidade $\{15,20\}$ e IV - Granularidade $\{50,100\}$. 
equivalentes aos resultados do baseline "metodológico". Foram muitas as comparações e os experimentos, mas de modo geral, o algoritmo Filter PoF, utilizando o contexto extraído pelo método proposto, foi o algoritmo que mais apresentou ganhos sobre o baseline "metodológico". Na Figura 5.10, estão ilustrados os gráficos construídos para o fator de combinação $\alpha=0$ utilizando alguns dados das Tabelas B.2, B.4, B.6 e B.8, no qual foram apresentados os melhores resultados nos experimentos realizados com a base da Embrapa, tanto considerando as entidades nomeadas, quanto os termos. Observa-se que, os melhores resultados para os algoritmos Weight PoF, cReduction e DaVI-BEST ocorreram na configuração de granularidade $\{15,20\}$, já para o algoritmo Filter PoF o mesmo ocorreu na granularidade $\{2,7\}$. Embora o baseline tenha apresentado resultados melhores em alguns casos, não houve diferença estatisticamente relevante sobre o método proposto.

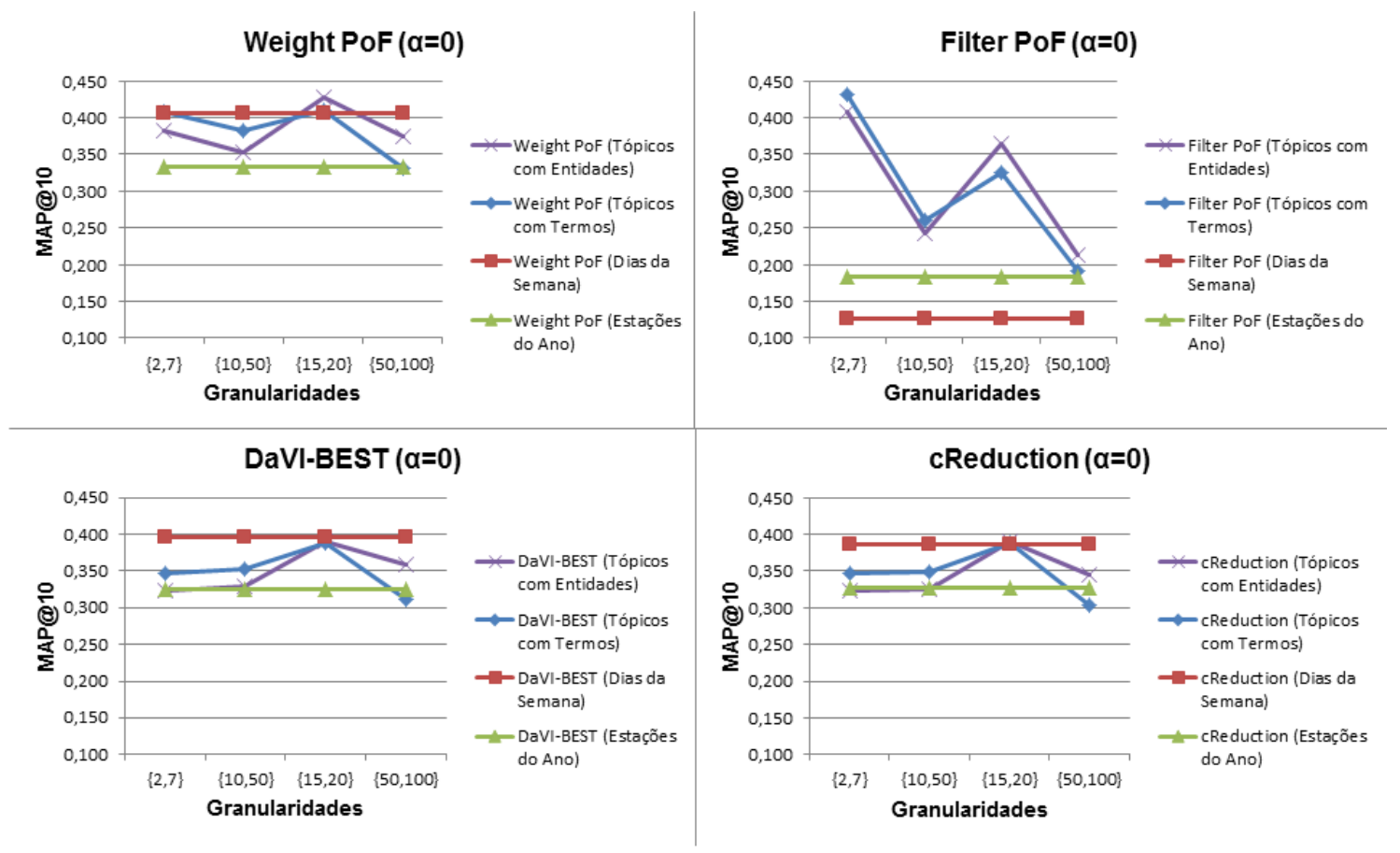

Figura 5.10: Gráficos dos valores de MAP@10 para os experimentos com os tópicos da base da Embrapa, considerando o baseline "metodológico" e o fator de combinação $\alpha=0$.

Para a base da Embrapa foi possível construir gráficos que agregam os resultados tanto dos tópicos com entidades nomeadas, quanto dos tópicos com termos, já que o valor de melhor $\alpha$ foi o mesmo para ambas as informações privilegiadas. Para a base do Dicionário Informal o mesmo não foi possível, sendo portanto construídos dois gráficos, um para cada informação privilegiada. Na Figura 5.11 (dados das Tabelas B.10 e B.12), podem ser analisados os gráficos dos experimentos com o Dicionário Informal considerando os tópicos com as entidades nomeadas, e fator de combinação $\alpha=0,3$, que foi o melhor fator para esses experimentos. Os algoritmos Weight PoF, cReduction e DaVI-BEST, apresentaram melhor desempenho na granularidade $\{50,100\}$ e o algoritmo Filter PoF, mais uma vez, na granularidade $\{2,7\}$.

Considerando os tópicos com termos e ainda a base do Dicionário Informal, na Figura 5.12, na qual estão ilustrados os gráficos dos resultados para o fator de combinação 


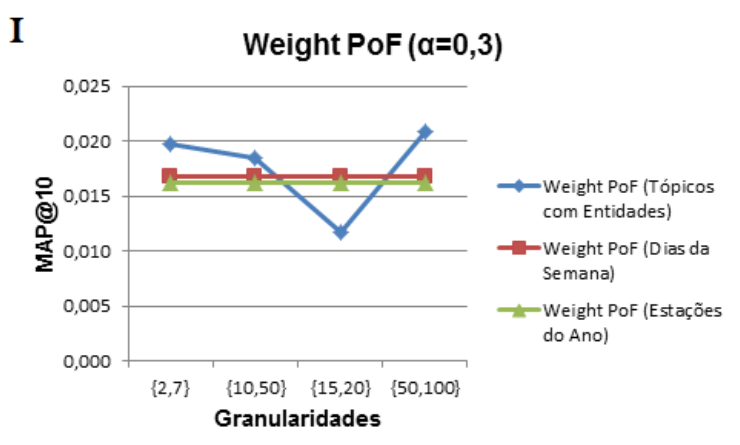

\section{III}

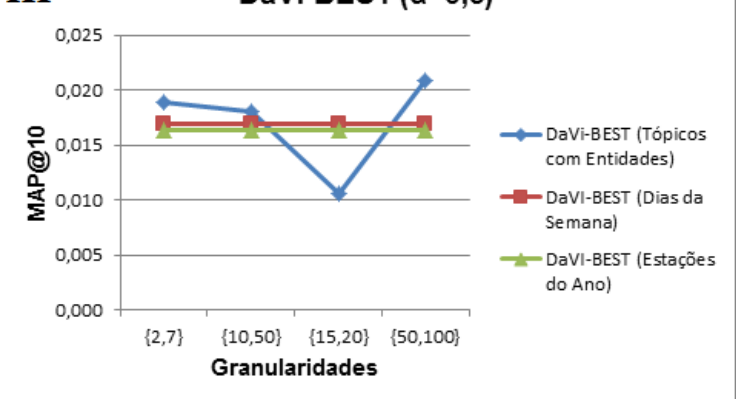

II

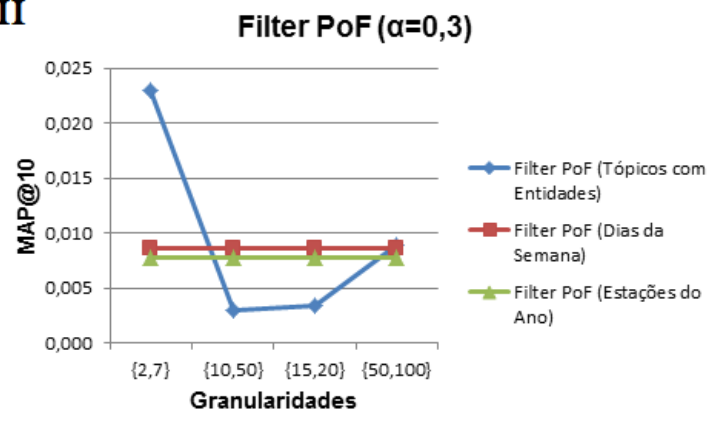

IV cReduction $(\alpha=0,3)$

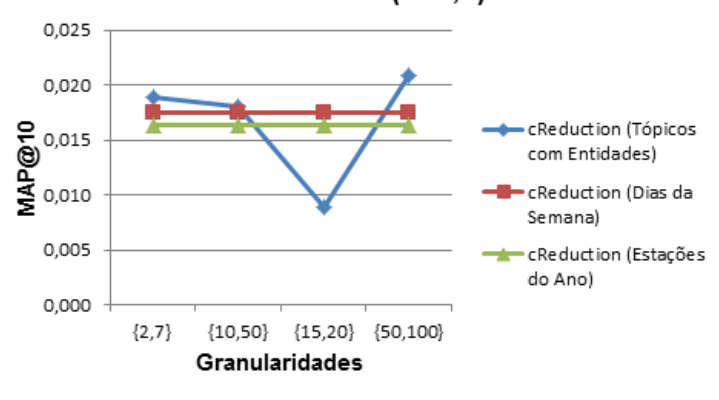

Figura 5.11: Gráficos dos valores de MAP@10 para os experimentos com os tópicos com entidades da base do Dicionário Informal, considerando o baseline "metodológico" e o fator de combinação $\alpha=0,3$.

$\alpha=1$ (dados nas Tabelas B.14 e B.16), pode-se notar que o algortimo Filter PoF apresentou, novamente, melhores resultados na granularidade $\{2,7\}$, enquanto que os outros algoritmos foram melhores na granularidade $\{15,20\}$.
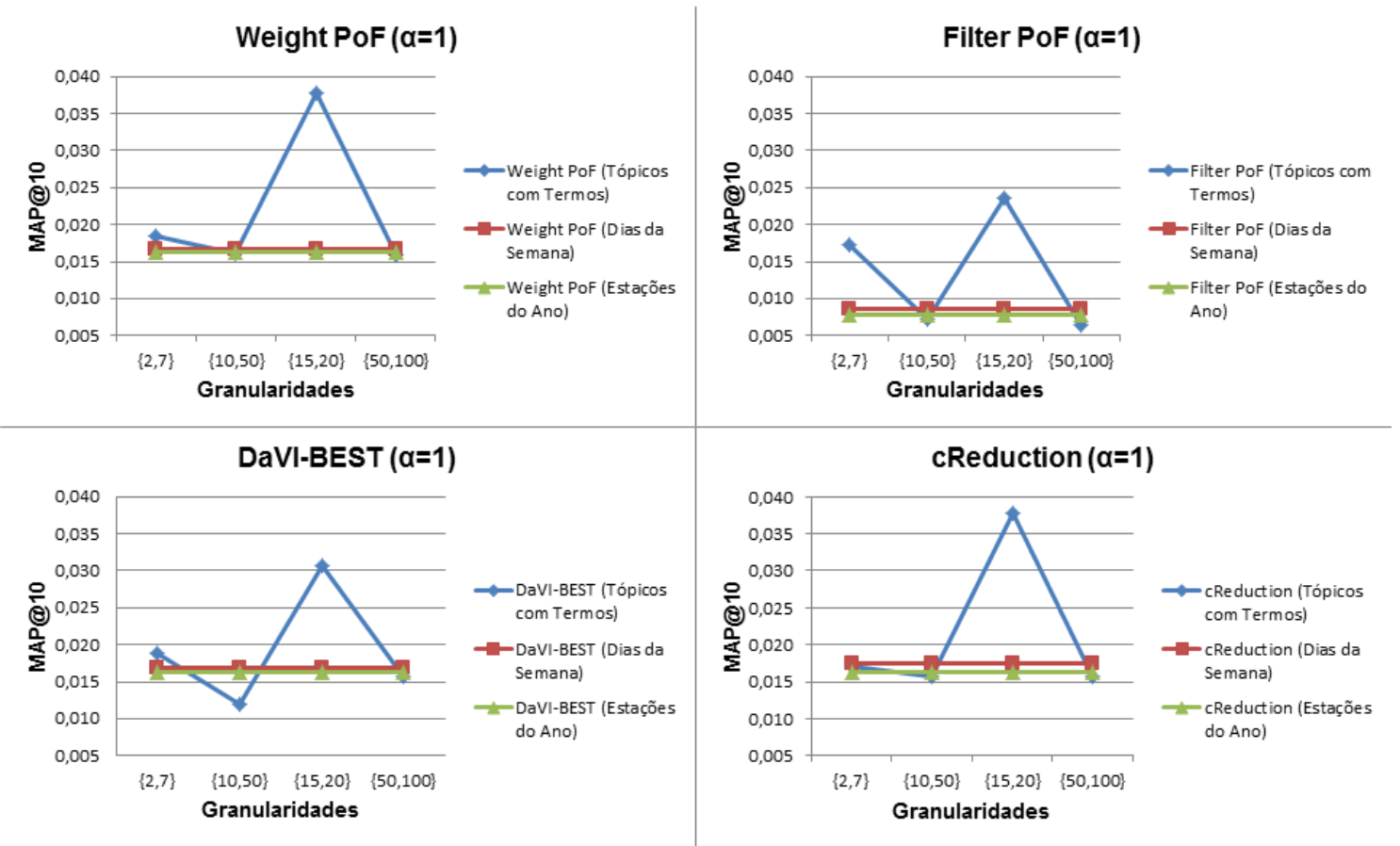

Figura 5.12: Gráficos dos valores de MAP@10 para os experimentos com os tópicos com termos da base do Dicionário Informal, considerando o baseline "metodológico" e o fator de combinação $\alpha=1$. 


\subsection{Considerações Finais}

Neste capítulo foi apresentada a avaliação do método proposto neste trabalho. Foram realizadas todas as etapas propostas no Capítulo 4, começando com o pré-processamento das duas bases de logs de acessos (Embrapa e Dicionário Informal) e finalizando com a avaliação das recomendações geradas utilizando o contexto extraído pelo método proposto. A avaliação foi conduzida de forma offline, utilizando, como comparativo, dois baselines: o algoritmo IBCF e o baseline metodológico implementado neste trabalho. Para a análise comparativa é calculada a medida MAP para as recomendações geradas utilizando o contexto extraído pelo método proposto neste trabalho, para as recomendações geradas pelo algoritmo IBCF (sem contexto) e para as recomendações geradas utilizando os dois tipos de informações extraídas pelo baseline metodológico. Dessa forma, a MAP do método proposto é comparada com a MAP do IBCF e com a MAP do baseline metodológico.

Os resultados demonstraram que o uso do contexto extraído pelo método proposto em sistemas de recomendações sensíveis ao contexto, tende a gerar recomendações mais precisas do que as recomendações geradas sem o uso de contexto. Comparando com outras formas de contexto, como a informações de "Estações do Ano" e "Dias da Semana", o método deste mestrado se mostra equivalente ou melhor.

No próximo capítulo são apresentadas as conclusões desta pesquisa, incluindo contribuições e trabalhos futuros. 


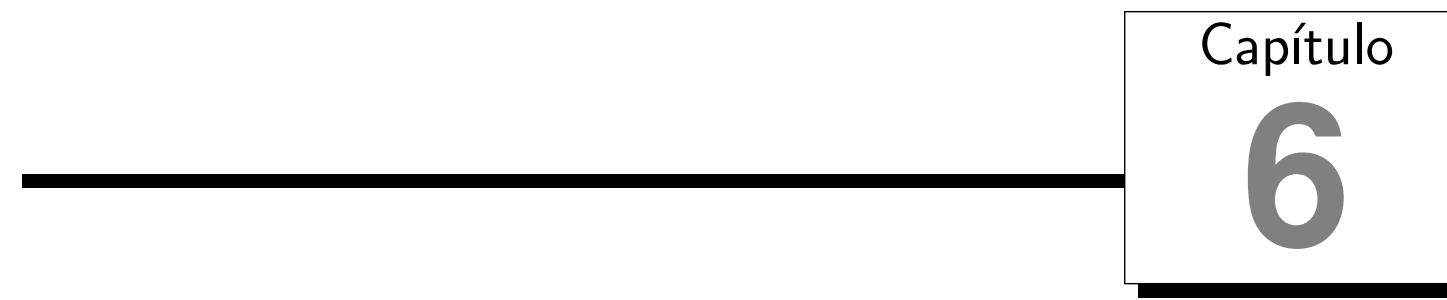

\section{Conclusão}

Neste trabalho foi apresentado o processo proposto para extração de informações contextuais de páginas Web, para serem utilizadas em sistemas de recomendações sensíveis ao contexto. Tal processo consiste em quatro etapas, que são elas: Pré-Processamento da Base de Logs, Método Proposto para Extração do Contexto, Utilização do Contexto e Avaliação.

- Primeira Etapa (Pré-Processamento da Base de Logs) - de forma geral, a primeira etapa é responsável pela limpeza dos logs e pela obtenção dos conteúdos textuais das páginas da Web acessadas pelos usuários;

- Segunda Etapa (Método Proposto para Extração do Contexto) - nesta etapa, considerada a principal, é executado o método proposto neste trabalho de mestrado para a extração do contexto das páginas da Web. Esse método consiste em construir hierarquias de tópicos do conteúdo textual das páginas da Web utilizando informações privilegiadas, e extrair os tópicos dessas hierarquias para serem utilizados como contexto das páginas nos sistemas de recomendação. Como informações privilegiadas são consideradas as entidades nomeadas e os termos extraídos dos textos. Tais informações podem ser combinadas com a bag-of-words tradicional utilizando diferentes valores do fator de combinação $\alpha$, que atribui peso para a informação privilegiada no agrupamento final. Com as hierarquias de tópicos construídas, são extraídos os tópicos dos grupos seguindo algumas configurações de granularidade. Em cada configuração $\{x, y\}, x$ indica o número mínimo de itens por tópicos e $y$ indica o número máximo de itens por tópico. Dessa forma, tal configuração permite a extração de tópicos mais específicos ou tópicos mais gerais, já que, quando um tópico possui mais itens, trata-se de um grupo mais geral, e, por outro lado, quando possui menos itens, é um grupo mais específico;

- Terceira Etapa (Utilização do Contexto) - etapa na qual, os tópicos extraídos 
na etapa anterior são utilizados em sistemas de recomendação sensíveis ao contexto e são geradas recomendações contextuais;

- Quarta Etapa (Avaliação) - nesta etapa, é avaliado o método proposto neste mestrado para extração de contexto. São realizadas análises comparativas, em que são usados dois baselines. O primeiro baseline, o algoritmo Item-Based Collaborative Filtering, gera recomendações sem considerar informações de contexto. Já, o segundo baseline, implementado e denominado neste mestrado baseline "metodológico", é uma adaptação do método apresentado por Li et al. (2010) para extração de contexto. Os resultados obtidos na avaliação das recomendações geradas utilizando o contexto extraído pelo método proposto neste mestrado, são comparados com os resultados tanto das recomendação sem contexto, geradas pelo IBCF, quanto com os resultados das recomendações geradas utilizando o contexto extraído pelo baseline "metodológico".

Essas mesmas etapas foram executadas em experimentos, neste trabalho, utilizando duas bases de logs de acessos: uma base do site da Agência Embrapa de Informação Tecnológica ${ }^{1}$ e outra do site do Dicionário Informal ${ }^{2}$. Para ambas as bases foram executadas todas as etapas do processo proposto, do pré-processamento até a avaliação. No método para extração de contexto foi utilizado o sistema REMBRANDT (Cardoso, 2008) para o reconhecimento das entidades nomeadas e a abordagem de Conrado et al. (2013) para a extração dos termos do domínio. Para a construção das hierarquias de tópicos, foi utilizado o método LUPI-Based Incremental Hierarchical Clustering (Marcacini e Rezende, 2013). No total, foram construídas 5 hierarquias de tópicos utilizando as entidades nomeadas e 5 hierarquias de tópicos utilizando os termos do domínio como informação privilegiada, sendo então 10 hierarquias para cada base de dados. De cada hierarquia construída, foram extraídos 5 grupos de tópicos, dos mais gerais para os mais específicos.

Os tópicos foram utilizados como contexto das páginas da Web em quatro sistemas de recomendação sensíveis ao contexto, que são eles: cReduction (pré-filtragem contextual), DaVI-BEST (modelagem contextual), Filter PoF e Weight PoF (ambos, pós-filtragem contextual). Foram calculados os valores da medida MAP para as recomendações geradas pelos 4 sistemas. O algoritmo IBCF também foi executado, porém sem o uso de contexto e para as recomendações geradas por ele também foi calculada a medida MAP. Para o baseline metodológico, as informações de contexto extraídas ("Dias da Semana" e "Estações do Ano"), foram utilizadas pelos mesmos sistemas de recomendação sensíveis ao contexto mencionados anteriormente, e para as recomendações geradas também foi calculada a MAP. Por fim, as recomendações geradas utilizando o contexto extraído pelo método proposto neste mestrado, foram comparadas com as recomendações do baseline IBCF e do baseline "metodológico".

\footnotetext{
${ }^{1}$ http://www.agencia.cnptia.embrapa.br/

${ }^{2}$ http://www.dicionarioinformal.com.br/
} 
De modo geral, os resultados obtidos com a utilização do contexto extraído pelo método proposto neste trabalho, foram melhores, na maioria dos experimentos, que os baselines considerados. Apenas os resultados do algoritmo DaVI-BEST foram equivalentes ao algoritmo $I B C F$, o que mostra que o uso do contexto extraído pelo método proposto não apresentou bons resultados usando este algoritmo. Para a base da Embrapa e utilizando o algoritmo IBCF como baseline, os resultados apresentados pelo uso do contexto extraído pelo método proposto foram melhores e superiores ao baseline na maioria dos casos. No segundo conjunto de experimentos, considerando o baseline "metodológico", os resultados foram melhores quando comparados com os resultados do contexto "Estações do Ano". Os resultados para a base do Dicionário Informal, não foram tão bons quanto os resultados da Embrapa, devido a algumas características como: acessos feitos pelos usuários (muitos usuários fizeram poucos acessos) e tamanho do conteúdo textual extraído das páginas da Web (a maioria dos textos da base do Dicionário Informal são muito curtos, o que prejudica a qualidade das hierarquias de tópicos construídas).

Analisando as informações privilegiadas utilizadas, concluiu-se que, os termos do domínio apresentaram melhores resultados do que as entidades nomeadas. Entre os algoritmos utilizados, o algoritmo Weight PoF apresentou os melhores resultados, enquanto que o algoritmo Filter PoF, não foi tão bom em alguns casos, talvez devido ao valor considerado de limiar da probabilidade utilizada para filtrar as recomendações. Como um trabalho futuro, existe a necessidade de executar os mesmos experimentos, porém variando o valor do limiar da probabilidade do algoritmo Filter PoF, na tentativa de alcançar melhores resultados para este algoritmo com o uso do contexto extraído. Nos experimentos com o baseline "metodológico", o algoritmo Filter PoF apresentou muitos ganhos estatísticos sobre tal baseline, pois a utilização das informações de contexto extraídas pelo baseline, "Dias da Semana" e "Estações do Ano", não favoreceram as recomendações geradas.

Não houve um valor específico de fator de combinação $\alpha$ que foi determinante na qualidade das recomendações, mas houve valores que mostraram a importância do uso da informação privilegiada no contexto extraído para o bom desempenho da recomendação, ou seja, considerar tais informações, independente da porcentagem, colaborou para bons resultados. Já, quanto às configurações de granularidade, na maioria dos casos, os algoritmos cReduction e Weight PoF, apresentaram os melhores resultados na granularidade $\{15,20\}$, e o algoritmo Filter PoF na granularidade $\{2,7\}$.

\subsection{Contribuições e Trabalhos Futuros}

Considera-se contribuições deste trabalho o método proposto para extração de contexto e alguns trabalhos realizados em parceria com outros pesquisadores da área. O método proposto permite a extração automática de informações de contexto aptas a serem utilizadas em sistemas de recomendações sensíveis ao contexto. Tais informações colaboram positivamente nos resultados das recomendações. Alguns resultados apresen- 
tados neste trabalho de mestrado, foram publicados no artigo Sundermann et al. (2014), apresentado na Brazilian Conference on Inlelligent Systems (BRACIS) - Qualis B2 em 2014. O trabalho foi realizado em parceria com Marcos Aurélio Domingues (ICMC USP), Ricardo Marcondes Marcacini (UFMS) e Solange Oliveira Rezende (ICMC - USP).

Além disso, foram realizados trabalhos com a colaboração de outros pesquisadores, cujos resultados foram publicados nos seguintes artigos:

- (Sinoara et al., 2014) - este trabalho foi executado no início dos experimentos exploratórios deste trabalho de mestrado. Tal trabalhou consistiu em avaliar o uso das entidades nomeadas como informação privilegiada no agrupamento hierárquico. Houve a colaboração dos pesquisadores: Roberta Akemi Sinoara (ICMC - USP), Ricardo Marcondes Marcacini (UFMS), Marcos Aurélio Domingues (ICMC - USP) e Solange Oliveira Rezende (ICMC - USP). O artigo foi publicado e apresentado na International Database Engineering 86 Applications Symposium (IDEAS), realizada em 2014 (Qualis B1);

- (Domingues et al., 2014a) - neste trabalho, foi utilizado o método BC ${ }^{2}$ (Buckshot Consensus Clustering) (Marcacini et al., 2012), que considera apenas a bag-of-words tradicional, para construir hierarquias de tópicos das páginas da Web, e os tópicos foram utilizados como contexto em sistemas de recomendação sensíveis ao contexto. O trabalho foi submetido e publicado na conferência International Conference on Pattern Recognition (ICPR), realizada em 2014. Os colaboradores para a pesquisa foram: Marcos Aurélio Domingues (ICMC - USP), Marcelo Garcia Manzato (ICMC - USP), Ricardo Marcondes Marcacini (UFMS) e Solange Oliveira Rezende (ICMCUSP) (Qualis - A1);

- (Domingues et al., 2014b) - como uma extensão do trabalho anterior, este artigo apresenta os resultados dos tópico gerados pelo método $\mathrm{BC}^{2}$, assim como os resultados do uso das entidades nomeadas como contexto em sistemas de recomendação. Houve novamente a colaboração dos pesquisadores Marcos Aurélio Domingues (ICMC - USP), Marcelo Garcia Manzato (ICMC - USP), Ricardo Marcondes Marcacini (UFMS) e Solange Oliveira Rezende (ICMC - USP). O trabalho foi publicado no WI, International Joint Conferences on Web Intelligence and Intelligent Agent Technologies, realizado em 2014 (Qualis A2).

Os resultados completos deste trabalho de mestrado serão publicados em um artigo de periódico que está em preparação. O título do artigo será "Privileged Contextual Information for Context-Aware Recommender Systems" e a submissão será feita para o journal Expert Systems with Applications. Além desse artigo em produção, existem alguns trabalhos a serem finalizados e trabalhos futuros a serem realizados. Esses trabalhos são importantes para verificar o comportamento do contexto extraído pelo método proposto em outros casos e também para ampliar as contribuições desta pesquisa na área de sistemas de recomendações sensíveis ao contexto. 
- Replicação dos experimentos deste trabalho em novas bases de dados;

- Variação de alguns parâmetros como o limiar da probabilidade do algoritmo Filter PoF, para verificar se ocorre melhoras em seus resultados;

- Uso de informações extraídas por meio da mineração de opiniões como contexto em sistemas de recomendação sensíveis ao contexto (Trabalho a ser realizado no Doutorado da aluna).

Concluindo, este trabalho tem como principal contribuição para a área de sistemas de recomendações sensíveis ao contexto o método proposto para extração de informações contextual. Tal método se mostrou eficiente e o contexto extraído possibilitou bons resultados para as recomendações geradas. 


\section{Referências Bibliográficas}

Aciar, S. (2010). Mining context information from consumer's reviews. In CARS'10: Proceedings of the 2nd Workshop on Context-Aware Recommender Systems.

Adomavicius, G., Mobasher, B., Ricci, F., e Tuzhilin, A. (2011). Context-aware recommender systems. Association for the Advancement of Articial Intelligence, 32(3):67-80.

Adomavicius, G., Sankaranarayanan, R., Sen, S., e Tuzhilin, A. (2005). Incorporating Contextual Information in Recommender Systems Using a Multidimensional Approach. ACM Transactions on Information Systems, 23(1):103-145.

Adomavicius, G. e Tuzhilin, A. (2005a). Personalization Technologies: A Process-oriented Perspective. Communications of the ACM, 48(10):83-90.

Adomavicius, G. e Tuzhilin, A. (2005b). Toward the Next Generation of Recommender Systems: A Survey of the State-of-the-Art and Possible Extensions. IEEE Transactions on Knowledge and Data Engineering, 17(6):734-749.

Adomavicius, G. e Tuzhilin, A. (2011). Context-Aware Recommender Systems. In Ricci, F., Rokach, L., Shapira, B., e Kantor, P. B., editores, Recommender Systems Handbook, pgs. 217-253. Springer.

Alvares, R. V., Garcia, A. C., e Ferraz, I. (2005). STEMBR: A Stemming Algorithm for the Brazilian Portuguese Language. In Bento, C., Cardoso, A., e Dias, G., editores, In EPIA '05: Proceedings of the 12th Portuguese Conference on Progress in Artificial Intelligence, volume 3808 de Lecture Notes in Computer Science, pgs. 693-701. Springer Berlin Heidelberg.

Aranha, C. N. (2007). Uma Abordagem de Pré-Processamento Automático para Mineração de Textos em Português. Tese de doutorado, Pontífica Universidade Católica do Rio de Janeiro - PUC-RIO.

Balabanovic, M. e Shoham, Y. (1997). Fab: Content-based, Collaborative Recommendation. Communications of the ACM, 40(3):66-72. 
Bauman, K. e Tuzhilin, A. (2014). Discovering Contextual Information from User Reviews for Recommendation Purposes. In CBRecSys '14: Proceedings of Workshop on New Trends in Content-based Recommender Systems, pgs. 2-9.

Bazire, M. e Brézillon, P. (2005). Understanding context before using it. In CONTEXT '05: Proceedings of the 5th International Conference on Modeling and Using Context, pgs. 29-40, Berlin, Heidelberg. Springer-Verlag.

Berry, M. W. e Castellanos, M., editores (2007). Survey of Text Mining: Clustering, Classification, and Retrieval. Springer, 2nd. edition.

Bick, E. (2000). The Parsing System "Palavras": Automatic Grammatical Analysis of Portuguese in a Constraint Grammar Framework. Tese de doutorado, University of Aarhus, Aarhus.

Blei, D. M., Ng, A. Y., e Jordan, M. I. (2003). Latent Dirichlet Allocation. Journal of Machine Learning Research, 3:993-1022.

Bobadilla, J., Ortega, F., Hernando, A., e Gutiérrez, A. (2013). Recommender Systems Survey. Knowledge-Based Systems, 46:109-132.

Breese, J. S., Heckerman, D., e Kadie, C. (1998). Empirical Analysis of Predictive Algorithms for Collaborative Filtering. In UAI'98: Proceedings of the Fourteenth Conference on Uncertainty in Artificial Intelligence, pgs. 43-52, San Francisco, CA, USA. Morgan Kaufmann Publishers Inc.

Burke, R. (2007). Hybrid Web Recommender Systems. In Brusilovsky, P., Kobsa, A., e Nejdl, W., editores, The Adaptive Web, pgs. 377-408. Springer-Verlag, Berlin, Heidelberg.

Cardoso, N. (2008). REMBRANDT - Reconhecimento de Entidades Mencionadas Baseado em Relações e ANálise Detalhada do Texto. In Mota, C. e Santos, D., editores, Desafios na avaliação conjunta do reconhecimento de entidades mencionadas: O Segundo HAREM, pgs. 195-211. Linguateca.

Carvalho, A. L. C., de Moura, E. S., e Calado, P. (2010). Using Statistical Features to Find Phrasal Terms in Text Collections. Journal of Information and Data Management, $1(3): 583-597$.

Castellví, M. T. C., Bagot, R. E., e Palagtresi, J. V. (2001). Automatic Term Detection: A Review of Current Systems. In Bourigault, D., Jacquemin, C., e L'Homme, M.-C., editores, Recent Advances in Computational Terminology, capítulo 3, pgs. 53-88. John Benjamins Publishing Company. 
Ceci, F., da Silva, D. C., Sell, D., e Gonçalves, A. (2010). Towards a Semi-Automatic Approach for Ontology Maintenance. In CONTECSI '10: Proceedings of International Conference on Information Systems and Technology Management, pgs. 3673-3695.

Claypool, M., Le, P., Wased, M., e Browns, D. (2001). Implicit Interest Indicators. In IUI '01: Proceedings of the 6th International Conference on Intelligent User Interfaces, pgs. 33-40, New York, NY, USA. ACM.

Conrado, M. S. (2009). O efeito do uso de diferentes formas de extração de termos na compreensibilidade e na representatividade dos termos em coleções textuais na língua portuguesa. Dissertação de mestrado, Instituto de Ciências Matemáticas e de Computação - Universidade de São Paulo - USP.

Conrado, M. S., Pardo, T. A. S., e Rezende, S. O. (2013). A Machine Learning Approach to Automatic Term Extraction using a Rich Feature Set. In NAACL-HLT-SRW '13: Proceedings of the Conference of the North American Chapter of the Association for Computational Linguistics: Human Language Technologies - Student Research Workshop, pgs. 16-23, Atlanta, Georgia. Association for Computational Linguistics.

Cunningham, H., Maynard, D., Bontcheva, K., e Tablan, V. (2002). GATE: an Architecture for Development of Robust HLT Applications. In $A C L$ '02: Proceedings of the 40th Annual Meeting on Association for Computational Linguistics, pgs. 168-175, Stroudsburg, PA, USA. Association for Computational Linguistics.

Deshpande, M. e Karypis, G. (2004). Item-based top-N Recommendation Algorithms. ACM Transaction on Information System, 22(1):143-177.

Desrosiers, C. e Karypis, G. (2011). A comprehensive survey of neighborhood-based recommendation methods. In Ricci, F., Rokach, L., Shapira, B., e Kantor, P. B., editores, Recommender Systems Handbook, pgs. 107-144. Springer US.

Dey, A. K. (2001). Understanding and Using Context. Personal and Ubiquitous Computing, 5(1):4-7.

Domingues, M. A., Jorge, A. M., e Soares, C. (2013). Dimensions As Virtual Items: Improving the Predictive Ability of top-N Recommender Systems. Information Processing \& Management, 49(3):698-720.

Domingues, M. A., Manzato, M. G., Marcacini, R. M., Sundermann, C. V., e Rezende, S. O. (2014a). Using contextual information from topic hierarchies to improve contextaware recommender systems. In ICPR '14: Proceedings of the 22nd International Conference on Pattern Recognition, pgs. 3606-3611.

Domingues, M. A., Soares, C., e Jorge, A. M. (2008). An empirical study on the impact of singleton web accesses on the accuracy of recommender systems. In SBIA '08: 
Proceedings of the SBIA 2008 First Workshop on Web andText Intelligence (WTI 08), pgs. 43-50, Salvador, Bahia, Brazil.

Domingues, M. A., Sundermann, C. V., Manzato, M. G., Marcacini, R. M., e Rezende, S. O. (2014b). Exploiting text mining techniques for contextual recommendations. In WI '14: IEEE/WIC/ACM International Joint Conferences on Web Intelligence and Intelligent Agent Technologies, volume 2, pgs. 210-217.

Dourish, P. (2004). What we talk about when we talk about context. Personal Ubiquitous Comput., 8(1):19-30.

Ekstrand, M. D., Riedl, J. T., e Konstan, J. A. (2011). Collaborative Filtering Recommender Systems. Foundations and Trends in Human-Computer Interaction, 4(2):81-173.

Everitt, B. S., Landau, S., Leese, M., e Stahl, D. (2011). Cluster Analysis. Wiley Publishing, London, UK, 5th edition.

Fayyad, U. M., Piatetsky-Shapiro, G., e Smyth, P. (1996). From data mining to knowledge discovery: an overview. In Fayyad, U. M., Piatetsky-Shapiro, G., Smyth, P., e Uthurusamy, R., editores, Advances in knowledge discovery and data mining, pgs. 1-34. American Association for Artificial Intelligence, Menlo Park, CA, USA.

Feldman, R. e Sanger, J. (2007). The Text Mining Handbook: Advanced Approaches in Analysing Unstructured Data. Cambridge University Press.

Gonzalez, M. A. I., de Lima, V. L. S., e de Lima, J. V. (2006). Tools for Nominalization: An Alternative for Lexical Normalization. In Vieira, R., Quaresma, P., Nunes, M. d. G. V., Mamede, N. J.and Oliveira, C., e Dias, M. C., editores, PROPOR '06: Proceedings of the 7th International Conference on Computational Processing of the Portuguese Language, volume 3960 de Lecture Notes in Computer Science, pgs. 100109. Springer Berlin Heidelberg.

Han, Y. e Xia, K. (2014). Data preprocessing method based on user characteristic of interests for web log mining. In IMCCC '14: Proceedings of the Fourth International Conference on Instrumentation and Measurement, Computer, Communication and Control, pgs. 867-872.

Hariri, N., Mobasher, B., Burke, R., e Zheng, Y. (2011). Context-Aware Recommendation Based on Review Mining. In Anand, S. S., Jannach, D., Mobasher, B., e Kobsa, A., editores, ITWP '11: Proceedings of the 9th Workshop On Intelligent Techniques for Web Personalization and Recommender Systems, pgs. 30-36, Barcelona, Spain.

Harman, D. (1991). How effective is suffixing? Journal of the American Society for Information Science, 42(1):7-15. 
Herlocker, J. L., Konstan, J. A., Terveen, L. G., e Riedl, J. T. (2004). Evaluating collaborative filtering recommender systems. ACM Transactions on Information Systems, $22: 5-53$.

Ho, S.-S., Lieberman, M., Wang, P., e Samet, H. (2012). Mining Future Spatiotemporal Events and Their Sentiment from Online News Articles for Location-aware Recommendation System. In MobiGIS '12: Proceedings of the First ACM SIGSPATIAL International Workshop on Mobile Geographic Information Systems, pgs. 25-32, New York, NY, USA. ACM.

Jain, A. K. e Dubes, R. C. (1988). Algorithms for Clustering Data. Prentice-Hall, Inc., Upper Saddle River, NJ, USA.

Jain, A. K., Murty, M. N., e Flynn, P. J. (1999). Data Clustering: A Review. ACM Computing Surveys, 31(3):264-323.

Kozareva, Z. (2006). Bootstrapping Named Entity Recognition with Automatically Generated Gazetteer Lists. In EACL '06: Proceedings of the Eleventh Conference of the European Chapter of the Association for Computational Linguistics: Student Research Workshop, pgs. 15-21, Stroudsburg, PA, USA. Association for Computational Linguistics.

Kroeze, J. H. e Matthee, M. C. (2009). Discovering Unknow Patterns in Free Text. In Wang, J., editor, Encyclopedia of Data Warehousing and Mining, pgs. 669-675. Information Science Reference, 2nd edition.

Lee, D., Park, S. E., Kahng, M., Lee, S., e Lee, S. G. (2010). Exploiting Contextual Information from Event Logs for Personalized Recommendation. In Lee, R., editor, Computer and Information Science 2010, volume 317 de Studies in Computational Intelligence, pgs. 121-139. Springer Berlin Heidelberg, Yamagata, Japan.

Li, Y., Nie, J., e Zhang, Y. (2010). Contextual Recommendation Based on Text Mining. In COLING '10: Proceedings of the 23rd International Conference on Computational Linguistics: Posters, pgs. 692-700, Stroudsburg, PA, USA. Association for Computational Linguistics.

Linden, G., Smith, B., e York, J. (2003). Amazon.com Recommendations: Item-to-Item Collaborative Filtering. IEEE Internet Computing, 7(1):76-80.

Liu, B. (2011). Web Data Mining: Exploring Hyperlinks, Contents, and Usage Data. Springer Publishing Company, Incorporated, 2nd edition.

Liu, X., Wei, F., Zhang, S., e Zhou, M. (2013). Named Entity Recognition for Tweets. ACM Transactions on Intelligent Systems and Technology, 4(3):1-15. 
Lovins, J. B. (1968). Development of a Stemming Algorithm. Mechanical Translation and Computational Linguistics, 11:22-31.

Lu, L., Medo, M., Yeung, C. H., Zhang, Y. C., Zhang, Z. K., e Zhou, T. (2012). Recommender systems. Physics Reports, 519(1):1-49.

Makrehchi, M. e Kamel, M. S. (2008). Automatic Extraction of Domain-Specific Stopwords from Labeled Documents. In ECIR '08: Proceedings of the IR Research, 30th European Conference on Advances in Information Retrieval, volume 4956 de Lecture Notes in Computer Science, pgs. 222-233. Springer Berlin Heidelberg.

Manning, C. D., Raghavan, P., e Schutze, H. (2009). An Introduction to Information Retrieval. Cambridge University Press, New York, NY, USA.

Marcacini, R. e Rezende, S. O. (2013). Incremental Hierarchical Text Clustering with Privileged Information. In DocEng '13: Proceedings of the 2013 ACM Symposium on Document Engineering, New York, NY, USA. ACM.

Marcacini, R. M. (2011). Aprendizado não supervisionado de hierarquias de tópicos a partir de coleções textuais dinâmicas. Dissertação de mestrado, Instituto de Ciências Matemáticas e de Computação - Universidade de São Paulo - USP.

Marcacini, R. M., Hruschka, E. R., e Rezende, S. O. (2012). On the Use of Consensus Clustering for Incremental Learning of Topic Hierarchies. In SBIA '12: Advances in Artificial Intelligence - 21th Brazilian Symposium on Artificial Intelligence, Lecture Notes in Computer Science, pgs. 112-121, Curitiba, Brazil. Springer Berlin Heidelberg.

Marcacini, R. M. e Rezende, S. O. (2010). Incremental Construction of Topic Hierarchies Using Hierarchical Term Clustering. In SEKE '10: Proceedings of the 22nd International Conference on Software Engineering 8 Knowledge Engineering, pgs. 553-558, San Francisco Bay, CA, USA. Redwood City.

McDonald, J. H. (2014). Handbook of Biological Statistics. Sparky House Publishing, Baltimore, Maryland, U.S.A., third edition.

Mikheev, A., Moens, M., e Grover, C. (1999). Named Entity Recognition without Gazetteers. In EACL '99: Proceedings of the Ninth Conference on European Chapter of the Association for Computational Linguistics, pgs. 1-8, Stroudsburg, PA, USA. Association for Computational Linguistics.

Mota, C. e Santos, D., editores (2008). Desafios na avaliação conjunta do reconhecimento de entidades mencionadas: O Segundo HAREM. Linguateca. ISBN: 978-989-20-1656-6.

Nothman, J., Ringland, N., Radford, W., Murphy, T., e Curran, J. R. (2013). Learning multilingual named entity recognition from wikipedia. Artificial Intelligence, 194(0):151-175. 
Oliveira, D. C. (2010). Extraction and Classification of Named Entities. Dissertação de mestrado, Universidade Técnica de Lisboa.

Orengo, V. M. e Huyck, C. (2001). A Stemming Algorithm for Portuguese Language. In SPIRE '01: Proceedings of Eighth International Symposium on String Processing and Information Retrieval, pgs. 186-193.

Panniello, U. e Gorgoglione, M. (2012). Incorporating Context into Recommender Systems: An Empirical Comparison of Context-based Approaches. Eletronic Commerce Research, 12(1):1-30.

Pazzani, M. J. (1999). A Framework for Collaborative, Content-Based and Demographic Filtering. Artificial Intelligence Review, 13:393-408.

Porter, M. F. (1997). An Algorithm for Suffix Stripping. In Readings in Information Retrieval, pgs. 313-316. Morgan Kaufmann Publishers Inc., San Francisco, CA, USA.

Ramage, D., Hall, D., Nallapati, R., e Manning, C. D. (2009). Labeled LDA: a supervised topic model for credit attribution in multi-labeled corpora. In EMNLP '09: Proceedings of the 2009 Conference on Empirical Methods in Natural Language Processing, pgs. 248-256, Singapore. Association for Computational Linguistics.

Refaeilzadeh, P., Tang, L., e Liu, H. (2009). Cross-Validation. In Liu, L. e Ozsu, M., editores, Encyclopedia of Database Systems, pgs. 532-538. Springer US.

Rezende, S. O., editor (2003). Sistemas Inteligentes: fundamentos e aplicações. Editora Manole.

Ricci, F., Rokach, L., Shapira, B., e Kantor, P. B., editores (2011). Recommender System Handbook. Springer.

Robertson, S. (2004). Understanding inverse document frequency: On theoretical arguments for IDF. Journal of Documentation, 60:503-520.

Rossi, R. G. (2011). Representação de coleções de documentos textuais por meio de regras de associação. Dissertação de mestrado, Instituto de Ciências Matemáticas e de Computação - Universidade de São Paulo - USP.

Salton, G. e McGill, M. J. (1983). Introduction to Modern Information Retrieval. McGrawHill, Inc., New York, NY, USA.

Santana, O., Pérez, J., Carreras, F., Duque, J. D., Hernández, Z., e Rodríguez, G. (1999). FLANOM: Flexionador y lematizador automático de formas nominales. Lingüística Española Actual XXI, 2:253-297. 
Santos, D. e Cardoso, N., editores (2007). Reconhecimento de entidades mencionadas em português: Documentação e actas do HAREM, a primeira avaliação conjunta na área. Linguateca. ISBN 978-989-20-0731-1.

Sarmento, L., Pinto, A. S., e Cabral, L. (2006). REPENTINO - A Wide-Scope Gazetteer for Entity Recognition in Portuguese. In PROPOR '06: Proceedings of the 7th International Conference on Computational Processing of the Portuguese Language, volume 3960 de Lecture Notes in Computer Science, pgs. 31-40. Springer Berlin Heidelberg.

Schafer, J. B., Frankowski, D., Herlocker, J., e Sen, S. (2007). Collaborative Filtering Recommender Systems. In The Adaptive Web, pgs. 291-324. Springer-Verlag, Berlin, Heidelberg.

Schafer, J. B., Konstan, J. A., e Riedl, J. (2001). E-Commerce Recommendation Applications. Data Mining and Knowledge Discovery, 5(1-2):115-153.

Schmid, H. (1994). Probabilistic Part-of-Speech Tagging Using Decision Trees. In NeMLaP '94: Proceedings of International Conference on New Methods in Language Processing, pgs. 44-49, Manchester, UK.

Sekine, S. (2004). Named entity: History and future. Proteus project report.

Shani, G. e Gunawardana, A. (2011). Evaluating Recommender Systems. In Ricci, F., Rokach, L., Shapira, B., e Kantor, P. B., editores, Recommender Systems Handbook, pgs. 257-297. Springer.

Sinoara, R. A., Sundermann, C. V., Marcacini, R. M., Domingues, M. A., e Rezende, S. O. (2014). Named entities as privileged information for hierarchical text clustering. In IDEAS '14: Proceedings of the 18th International Database Engineering \& Applications Symposium, pgs. 57-66, New York, NY, USA. ACM.

Sparck Jones, K. e Willett, P., editores (1997). Readings in Information Retrieval. Morgan Kaufmann Publishers Inc., San Francisco, CA, USA.

Sparling, E. I. e Sen, S. (2011). Rating: How difficult is it? In RecSys '11: Proceedings of the Fifth ACM Conference on Recommender Systems, pgs. 149-156, New York, NY, USA. ACM.

Sundermann, C., Domingues, M., Marcacini, R., e Rezende, S. (2014). Using topic hierarchies with privileged information to improve context-aware recommender systems. In BRACIS '14: Proceedings of Brazilian Conference on Intelligent Systems, pgs. 61-66.

Tan, P. N., Steinbach, M., e Kuman, V. (2005). Introduction to Data Mining. AddisonWesley Longman Publishing Co., Inc., Boston, MA, USA.

Vapnik, V. e Vashist, A. (2009). A new learning paradigm: Learning using privileged information. Neural Networks, 22:544-557. 
Viera, A. F. G. e Virgil, J. (2007). Uma revisão dos algoritmos de radicalização em língua portuguesa. Information Research, 12(3).

Weiss, S. M., Indurkhya, N., Zhang, T., e Damerau, F. J. (2005). Text Mining: Predictive Methods for Analyzing Unstructured Information. Springer. 


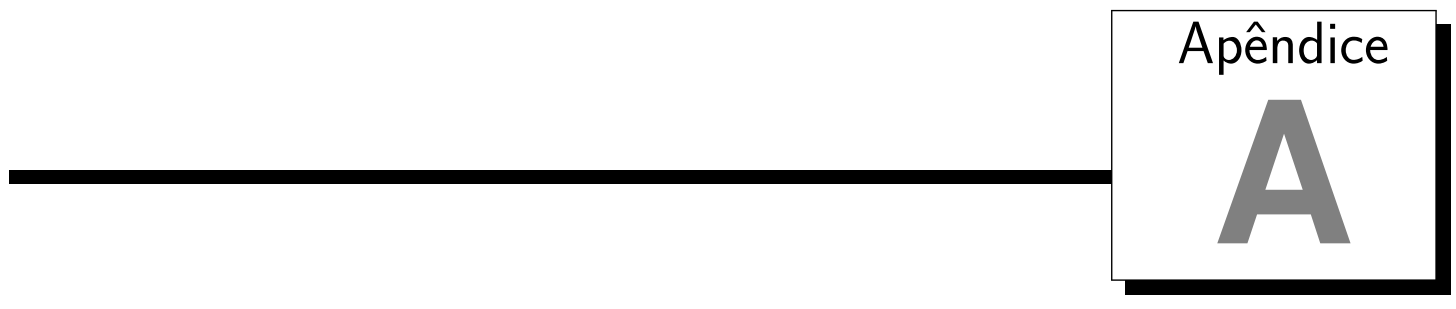

\section{Resultados Obtidos nos Experimentos da Avaliação Considerando o Baseline IBCF}

Neste trabalho de mestrado, uma das formas utilizadas para avaliar o contexto extraído pelo método proposto, foi comparar os valores da medida MAP obtidos para as recomendações geradas utilizando esse contexto, com os valores de MAP obtidos para as recomendações geradas pelo algoritmo Item-Based Collaborative Filtering, que não utiliza informação de contexto. Neste apêndice estão indicados, em quatro tabelas, todos os resultados obtidos nessa avaliação. Para facilitar o acompanhamento dos resultados, segue uma relação de cada experimento e sua respectiva tabela:

- Primeiro Experimento - base de logs de acessos da Embrapa e entidades nomeadas usadas como informação privilegiada (Tabela A.1);

- Segundo Experimento - base de logs de acessos do Dicionário Informal e entidades nomeadas usadas como informação privilegiada (Tabela A.2);

- Terceiro Experimento - base de logs de acessos da Embrapa e termos usados como informação privilegiada (Tabela A.3);

- Quarto Experimento - base de logs de acessos do Dicionário Informal e termos usados como informação privilegiada (Tabela A.4).

A seguir estão as tabelas com todos os resultados da avaliação utilizando o baseline IBCF. 
Tabela A.1: Resultados Completos do Primeiro Experimento na Avaliação Baseline IBCF

\begin{tabular}{|c|c|c|c|c|c|c|c|c|}
\hline \multicolumn{9}{|c|}{ Valores da MAP para o fator de combinação $\alpha=0$} \\
\hline \multirow{2}{*}{ Granul. } & \multicolumn{4}{|c|}{$M A P @ 5$} & \multicolumn{4}{|c|}{$M A P @ 10$} \\
\hline & $\mathrm{IBCF}$ & $\begin{array}{l}\text { cReduc- } \\
\text { tion }\end{array}$ & Weight PoF & Filter PoF & IBCF & $\begin{array}{l}\text { cReduc- } \\
\text { tion }\end{array}$ & Weight PoF & Filter PoF \\
\hline$\{50,100\}$ & 0,2991 & $0,3497 *$ & $0,3678 *$ & 0,2117 & 0,3089 & $0,3441 *$ & $0,3755 *$ & 0,2133 \\
\hline$\{15,20\}$ & 0,2991 & $0,3825 *$ & $0,4244 *$ & $0,3647 *$ & 0,3089 & $0,3894 *$ & $0,4286 *$ & $0,3654 *$ \\
\hline$\{10,50\}$ & 0,2991 & $0,3221 *$ & $0,3464 *$ & 0,2403 & 0,3089 & $0,3246 *$ & $0,3538 *$ & 0,2416 \\
\hline$\{2,7\}$ & 0,2991 & 0,3153 & $0,3763 *$ & $0,4075 *$ & 0,3089 & 0,3229 & $0,3824 *$ & $0,4090 *$ \\
\hline \multicolumn{9}{|c|}{ Valores da MAP para o fator de combinação $\alpha=0,3$} \\
\hline \multirow{2}{*}{ Granul. } & \multicolumn{4}{|c|}{$M A P @ 5$} & \multicolumn{4}{|c|}{$M A P @ 10$} \\
\hline & $\mathrm{IBCF}$ & $\begin{array}{l}\text { cReduc- } \\
\text { tion }\end{array}$ & Weight PoF & Filter PoF & IBCF & $\begin{array}{l}\text { cReduc- } \\
\text { tion }\end{array}$ & Weight PoF & Filter PoF \\
\hline$\{50,100\}$ & 0,2991 & $0,3334 *$ & $0,3564 *$ & 0,1613 & 0,3089 & $0,3467 *$ & $0,3651 *$ & 0,1631 \\
\hline$\{15,20\}$ & 0,2991 & $0,3821 *$ & $0,4147 *$ & 0,2894 & 0,3089 & $0,3890 *$ & $0,4204 *$ & 0,2913 \\
\hline$\{10,50\}$ & 0,2991 & 0,3154 & $0,3383 *$ & 0,1987 & 0,3089 & 0,3230 & $0,3452 *$ & 0,1994 \\
\hline$\{2,7\}$ & 0,2991 & $0,3194 *$ & $0,3643 *$ & $0,3993 *$ & 0,3089 & $0,3279 *$ & $0,3708 *$ & $0,4006 *$ \\
\hline \multicolumn{9}{|c|}{ Valores da MAP para o fator de combinação $\alpha=0,5$} \\
\hline \multirow{2}{*}{ Granul. } & \multicolumn{4}{|c|}{$M A P @ 5$} & \multicolumn{4}{|c|}{$M A P @ 10$} \\
\hline & $\mathrm{IBCF}$ & $\begin{array}{l}\text { cReduc- } \\
\text { tion }\end{array}$ & Weight PoF & Filter PoF & IBCF & $\begin{array}{l}\text { cReduc- } \\
\text { tion }\end{array}$ & Weight PoF & Filter PoF \\
\hline$\{50,100\}$ & 0,2991 & 0,3199 & $0,3368 *$ & 0,1828 & 0,3089 & 0,3298 & $0,3463 *$ & 0,1845 \\
\hline$\{15,20\}$ & 0,2991 & $0,3518 *$ & $0,3845 *$ & $0,3412 *$ & 0,3089 & $0,3612 *$ & $0,3926 *$ & $0,3431 *$ \\
\hline$\{10,50\}$ & 0,2991 & 0,3062 & $0,3336 *$ & 0,1947 & 0,3089 & 0,3164 & $0,3425 *$ & 0,1958 \\
\hline$\{2,7\}$ & 0,2991 & $0,3208 *$ & $0,3747 *$ & $0,4135 *$ & 0,3089 & $0,3294 *$ & $0,3817 *$ & $0,4146 *$ \\
\hline \multicolumn{9}{|c|}{ Valores da MAP para o fator de combinação $\alpha=0,7$} \\
\hline \multirow{2}{*}{ Granul. } & \multicolumn{4}{|c|}{$M A P @ 5$} & \multicolumn{4}{|c|}{$M A P @ 10$} \\
\hline & $\mathrm{IBCF}$ & $\begin{array}{l}\text { cReduc- } \\
\text { tion }\end{array}$ & Weight PoF & Filter PoF & IBCF & $\begin{array}{l}\text { cReduc- } \\
\text { tion }\end{array}$ & Weight PoF & Filter PoF \\
\hline$\{50,100\}$ & 0,2991 & 0,3052 & $0,3180 *$ & 0,1231 & 0,3089 & 0,3159 & $0,3281 *$ & 0,1245 \\
\hline$\{15,20\}$ & 0,2991 & $0,4454 *$ & $0,4803 *$ & $0,3772 *$ & 0,3089 & $0,4532 *$ & $0,4874 *$ & $0,3793 *$ \\
\hline$\{10,50\}$ & 0,2991 & 0,3262 & $0,3496 *$ & 0,2143 & 0,3089 & 0,3354 & $0,3582 *$ & 0,2156 \\
\hline$\{2,7\}$ & 0,2991 & $0,3277 *$ & $0,3826 *$ & $0,4197 *$ & 0,3089 & $0,3359 *$ & $0,3888 *$ & $0,4208 *$ \\
\hline \multicolumn{9}{|c|}{ Valores da MAP para o fator de combinação $\alpha=1$} \\
\hline \multirow{2}{*}{ Granul. } & \multicolumn{4}{|c|}{$M A P @ 5$} & \multicolumn{4}{|c|}{$M A P @ 10$} \\
\hline & $\mathrm{IBCF}$ & $\begin{array}{l}\text { cReduc- } \\
\text { tion }\end{array}$ & Weight PoF & Filter PoF & IBCF & $\begin{array}{l}\text { cReduc- } \\
\text { tion }\end{array}$ & Weight PoF & Filter PoF \\
\hline$\{50,100\}$ & 0,2991 & 0,3019 & 0,3171 & 0,1299 & 0,3089 & 0,3137 & 0,3280 & 0,1314 \\
\hline$\{15,20\}$ & 0,2991 & $0,3851 *$ & $0,4191 *$ & 0,2556 & 0,3089 & $0,3912 *$ & $0,4245 *$ & 0,2566 \\
\hline$\{10,50\}$ & 0,2991 & $0,3390 *$ & $0,3662 *$ & 0,2350 & 0,3089 & $0,3493 *$ & $0,3756 *$ & 0,2363 \\
\hline$\{2,7\}$ & 0,2991 & $0,3207 *$ & $0,3828 *$ & $0,4139 *$ & 0,3089 & $0,3294 *$ & $0,3895 *$ & $0,4148 *$ \\
\hline
\end{tabular}


Tabela A.2: Resultados Completos do Segundo Experimento na Avaliação Baseline IBCF

\begin{tabular}{|c|c|c|c|c|c|c|c|c|}
\hline \multicolumn{9}{|c|}{ Valores da MAP para o fator de combinação $\alpha=0$} \\
\hline \multirow{2}{*}{ Granul. } & \multicolumn{4}{|c|}{$M A P @ 5$} & \multicolumn{4}{|c|}{$M A P @ 10$} \\
\hline & IBCF & $\begin{array}{l}\text { cReduc- } \\
\text { tion }\end{array}$ & Weight PoF & Filter PoF & $\mathrm{IBCF}$ & $\begin{array}{l}\text { cReduc- } \\
\text { tion }\end{array}$ & Weight PoF & Filter PoF \\
\hline$\{50,100\}$ & 0,0166 & 0,0113 & 0,0113 & 0,0022 & 0,0167 & 0,0116 & 0,0116 & 0,0027 \\
\hline$\{15,20\}$ & 0,0166 & 0,0176 & 0,0187 & 0,0060 & 0,0167 & 0,0182 & 0,0193 & 0,0066 \\
\hline$\{10,50\}$ & 0,0166 & 0,0119 & 0,0122 & 0,0030 & 0,0167 & 0,0120 & 0,0124 & 0,0031 \\
\hline$\{2,7\}$ & 0,0166 & 0,0184 & 0,0194 & 0,0180 & 0,0167 & 0,0184 & 0,0194 & 0,0181 \\
\hline \multicolumn{9}{|c|}{ Valores da MAP para o fator de combinação $\alpha=0,3$} \\
\hline \multirow{2}{*}{ Granul. } & \multicolumn{4}{|c|}{$M A P @ 5$} & \multicolumn{4}{|c|}{$M A P @ 10$} \\
\hline & IBCF & $\begin{array}{l}\text { cReduc- } \\
\text { tion }\end{array}$ & Weight PoF & Filter PoF & $\mathrm{IBCF}$ & $\begin{array}{l}\text { cReduc- } \\
\text { tion }\end{array}$ & Weight PoF & Filter PoF \\
\hline$\{50,100\}$ & 0,0166 & 0,0195 & 0,0195 & 0,0074 & 0,0167 & 0,0209 & 0,0209 & 0,0089 \\
\hline$\{15,20\}$ & 0,0166 & 0,0077 & 0,0107 & 0,0019 & 0,0167 & 0,0089 & 0,0117 & 0,0035 \\
\hline$\{10,50\}$ & 0,0166 & 0,0178 & 0,0183 & 0,0027 & 0,0167 & 0,0181 & 0,0185 & 0,0030 \\
\hline$\{2,7\}$ & 0,0166 & 0,0189 & 0,0196 & 0,0228 & 0,0167 & 0,0190 & 0,0197 & 0,0229 \\
\hline \multicolumn{9}{|c|}{ Valores da MAP para o fator de combinação $\alpha=0,5$} \\
\hline \multirow{2}{*}{ Granul. } & \multicolumn{4}{|c|}{$M A P @ 5$} & \multicolumn{4}{|c|}{$M A P @ 10$} \\
\hline & IBCF & $\begin{array}{l}\text { cReduc- } \\
\text { tion }\end{array}$ & Weight PoF & Filter PoF & $\mathrm{IBCF}$ & $\begin{array}{l}\text { cReduc- } \\
\text { tion }\end{array}$ & Weight PoF & Filter PoF \\
\hline$\{50,100\}$ & 0,0166 & 0,0085 & 0,0090 & 0,0061 & 0,0167 & 0,0090 & 0,0096 & 0,0065 \\
\hline$\{15,20\}$ & 0,0166 & 0,0048 & 0,0048 & 0,0011 & 0,0167 & 0,0056 & 0,0056 & 0,0019 \\
\hline$\{10,50\}$ & 0,0166 & 0,0079 & 0,0083 & 0,0039 & 0,0167 & 0,0081 & 0,0085 & 0,0042 \\
\hline$\{2,7\}$ & 0,0166 & 0,0146 & 0,0160 & 0,0118 & 0,0167 & 0,0150 & 0,0163 & 0,0122 \\
\hline \multicolumn{9}{|c|}{ Valores da MAP para o fator de combinação $\alpha=0,7$} \\
\hline \multirow{2}{*}{ Granul. } & \multicolumn{4}{|c|}{$M A P @ 5$} & \multicolumn{4}{|c|}{$M A P @ 10$} \\
\hline & IBCF & $\begin{array}{l}\text { cReduc- } \\
\text { tion }\end{array}$ & Weight PoF & Filter PoF & $\mathrm{IBCF}$ & $\begin{array}{l}\text { cReduc- } \\
\text { tion }\end{array}$ & Weight PoF & Filter PoF \\
\hline$\{50,100\}$ & 0,0166 & 0,0121 & 0,0124 & 0,0007 & 0,0167 & 0,0127 & 0,0130 & 0,0016 \\
\hline$\{15,20\}$ & 0,0166 & 0,0173 & 0,0177 & 0,0021 & 0,0167 & 0,0176 & 0,0180 & 0,0027 \\
\hline$\{10,50\}$ & 0,0166 & 0,0129 & 0,0139 & 0,0010 & 0,0167 & 0,0131 & 0,0142 & 0,0013 \\
\hline$\{2,7\}$ & 0,0166 & 0,0164 & 0,0171 & 0,0169 & 0,0167 & 0,0167 & 0,0173 & 0,0172 \\
\hline \multicolumn{9}{|c|}{ Valores da MAP para o fator de combinação $\alpha=1$} \\
\hline \multirow{2}{*}{ Granul. } & \multicolumn{4}{|c|}{$M A P @ 5$} & \multicolumn{4}{|c|}{$M A P @ 10$} \\
\hline & IBCF & $\begin{array}{l}\text { cReduc- } \\
\text { tion }\end{array}$ & Weight $\mathrm{PoF}$ & Filter PoF & $\mathrm{IBCF}$ & $\begin{array}{l}\text { cReduc- } \\
\text { tion }\end{array}$ & Weight PoF & Filter PoF \\
\hline$\{50,100\}$ & 0,0166 & 0,0139 & 0,0142 & 0,0019 & 0,0167 & 0,0143 & 0,0146 & 0,0020 \\
\hline$\{15,20\}$ & 0,0166 & 0,0161 & 0,0170 & 0,0006 & 0,0167 & 0,0162 & 0,0170 & 0,0006 \\
\hline$\{10,50\}$ & 0,0166 & 0,0139 & 0,0141 & 0,0018 & 0,0167 & 0,0141 & 0,0143 & 0,0019 \\
\hline$\{2,7\}$ & 0,0166 & 0,0131 & 0,0142 & 0,0151 & 0,0167 & 0,0132 & 0,0143 & 0,0152 \\
\hline
\end{tabular}


Tabela A.3: Resultados Completos do Terceiro Experimento na Avaliação Baseline IBCF

\begin{tabular}{|c|c|c|c|c|c|c|c|c|}
\hline \multicolumn{9}{|c|}{ Valores da MAP para o fator de combinação $\alpha=0$} \\
\hline \multirow{2}{*}{ Granul. } & \multicolumn{4}{|c|}{$M A P @ 5$} & \multicolumn{4}{|c|}{$M A P @ 10$} \\
\hline & IBCF & $\begin{array}{l}\text { cReduc- } \\
\text { tion }\end{array}$ & Weight PoF & Filter PoF & IBCF & $\begin{array}{l}\text { cReduc- } \\
\text { tion }\end{array}$ & Weight PoF & Filter PoF \\
\hline$\{50,100\}$ & 0,2991 & $0,3017 *$ & $0,3210 *$ & 0,1908 & 0,3089 & $0,3042 *$ & $0,3305 *$ & 0,1922 \\
\hline$\{15,20\}$ & 0,2991 & $0,3802 *$ & $0,4049 *$ & $0,3240 *$ & 0,3089 & $0,3874 *$ & $0,4110 *$ & $0,3262 *$ \\
\hline$\{10,50\}$ & 0,2991 & $0,3447 *$ & $0,3751 *$ & 0,2591 & 0,3089 & $0,3491 *$ & $0,3823 *$ & 0,2606 \\
\hline$\{2,7\}$ & 0,2991 & $0,3392 *$ & $0,4024 *$ & $0,4314 *$ & 0,3089 & $0,3470 *$ & $0,4088 *$ & $0,4322 *$ \\
\hline \multicolumn{9}{|c|}{ Valores da MAP para o fator de combinação $\alpha=0,3$} \\
\hline \multirow{2}{*}{ Granul. } & \multicolumn{4}{|c|}{$M A P @ 5$} & \multicolumn{4}{|c|}{$M A P @ 10$} \\
\hline & IBCF & $\begin{array}{l}\text { cReduc- } \\
\text { tion }\end{array}$ & Weight PoF & Filter PoF & $\mathrm{IBCF}$ & $\begin{array}{l}\text { cReduc- } \\
\text { tion }\end{array}$ & Weight PoF & Filter PoF \\
\hline$\{50,100\}$ & 0,2991 & $0,3440 *$ & $0,3556 *$ & 0,1840 & 0,3089 & $0,3527 *$ & $0,3639 *$ & 0,1854 \\
\hline$\{15,20\}$ & 0,2991 & $0,3923 *$ & $0,4361 *$ & 0,3066 & 0,3089 & $0,3987 *$ & $0,4420 *$ & 0,3082 \\
\hline$\{10,50\}$ & 0,2991 & $0,3233 *$ & $0,3590 *$ & 0,2589 & 0,3089 & $0,3272 *$ & $0,3667 *$ & 0,2596 \\
\hline$\{2,7\}$ & 0,2991 & $0,3195 *$ & $0,3768 *$ & $0,4187 *$ & 0,3089 & $0,3291 *$ & $0,3849 *$ & $0,4201 *$ \\
\hline \multicolumn{9}{|c|}{ Valores da MAP para o fator de combinação $\alpha=0,5$} \\
\hline \multirow{2}{*}{ Granul. } & \multicolumn{4}{|c|}{$M A P @ 5$} & \multicolumn{4}{|c|}{$M A P @ 10$} \\
\hline & IBCF & $\begin{array}{l}\text { cReduc- } \\
\text { tion }\end{array}$ & Weight PoF & Filter PoF & $\mathrm{IBCF}$ & $\begin{array}{l}\text { cReduc- } \\
\text { tion }\end{array}$ & Weight PoF & Filter PoF \\
\hline$\{50,100\}$ & 0,2991 & $0,3339 *$ & $0,3544 *$ & 0,2125 & 0,3089 & $0,3424 *$ & $0,3628 *$ & 0,2135 \\
\hline$\{15,20\}$ & 0,2991 & $0,4135 *$ & $0,4479 *$ & 0,2801 & 0,3089 & $0,4189 *$ & $0,4525 *$ & 0,2818 \\
\hline$\{10,50\}$ & 0,2991 & $0,3240 *$ & $0,3473 *$ & 0,2466 & 0,3089 & $0,3322 *$ & $0,3556 *$ & 0,2473 \\
\hline$\{2,7\}$ & 0,2991 & $0,3287 *$ & $0,3826 *$ & $0,3965 *$ & 0,3089 & $0,3374 *$ & $0,3898 *$ & $0,3983 *$ \\
\hline \multicolumn{9}{|c|}{ Valores da MAP para o fator de combinação $\alpha=0,7$} \\
\hline \multirow{2}{*}{ Granul. } & \multicolumn{4}{|c|}{$M A P @ 5$} & \multicolumn{4}{|c|}{$M A P @ 10$} \\
\hline & IBCF & $\begin{array}{l}\text { cReduc- } \\
\text { tion }\end{array}$ & Weight PoF & Filter PoF & $\mathrm{IBCF}$ & $\begin{array}{c}\text { cReduc- } \\
\text { tion }\end{array}$ & Weight PoF & Filter PoF \\
\hline$\{50,100\}$ & 0,2991 & $0,3251 *$ & $0,3436 *$ & 0,1934 & 0,3089 & $0,3341 *$ & $0,3523 *$ & 0,1951 \\
\hline$\{15,20\}$ & 0,2991 & $0,3733 *$ & $0,4048 *$ & $0,3498 *$ & 0,3089 & $0,3812 *$ & $0,4120 *$ & $0,3514 *$ \\
\hline$\{10,50\}$ & 0,2991 & $0,3161 *$ & $0,3528 *$ & 0,2386 & 0,3089 & $0,3261 *$ & $0,3613 *$ & 0,2400 \\
\hline$\{2,7\}$ & 0,2991 & $0,3384 *$ & $0,3925 *$ & $0,3816 *$ & 0,3089 & $0,3454 *$ & $0,3978 *$ & $0,3817 *$ \\
\hline \multicolumn{9}{|c|}{ Valores da MAP para o fator de combinação $\alpha=1$} \\
\hline \multirow{2}{*}{ Granul. } & \multicolumn{4}{|c|}{$M A P @ 5$} & \multicolumn{4}{|c|}{$M A P @ 10$} \\
\hline & IBCF & $\begin{array}{l}\text { cReduc- } \\
\text { tion }\end{array}$ & Weight PoF & Filter PoF & IBCF & $\begin{array}{l}\text { cReduc- } \\
\text { tion }\end{array}$ & Weight PoF & Filter PoF \\
\hline$\{50,100\}$ & 0,2991 & $0,3266 *$ & $0,3400 *$ & 0,1828 & 0,3089 & $0,3360 *$ & $0,3487 *$ & 0,1847 \\
\hline$\{15,20\}$ & 0,2991 & $0,3449 *$ & $0,3709 *$ & 0,2922 & 0,3089 & $0,3525 *$ & $0,3773 *$ & 0,2922 \\
\hline$\{10,50\}$ & 0,2991 & 0,3100 & $0,3378 *$ & 0,2114 & 0,3089 & 0,3172 & $0,3442 *$ & 0,2114 \\
\hline$\{2,7\}$ & 0,2991 & $0,3213 *$ & $0,3724 *$ & $0,4061 *$ & 0,3089 & $0,3304 *$ & $0,3798 *$ & $0,4073 *$ \\
\hline
\end{tabular}


Tabela A.4: Resultados Completos do Quarto Experimento na Avaliação Baseline IBCF

\begin{tabular}{|c|c|c|c|c|c|c|c|c|}
\hline \multicolumn{9}{|c|}{ Valores da MAP para o fator de combinação $\alpha=0$} \\
\hline \multirow{2}{*}{ Granul. } & \multicolumn{4}{|c|}{$M A P @ 5$} & \multicolumn{4}{|c|}{$M A P @ 10$} \\
\hline & IBCF & $\begin{array}{l}\text { cReduc- } \\
\text { tion }\end{array}$ & Weight PoF & Filter PoF & IBCF & $\begin{array}{l}\text { cReduc- } \\
\text { tion }\end{array}$ & Weight PoF & Filter PoF \\
\hline$\{50,100\}$ & 0,0166 & 0,0234 & 0,0234 & 0,0059 & 0,0167 & 0,0236 & 0,0236 & 0,0062 \\
\hline$\{15,20\}$ & 0,0166 & 0,0059 & 0,0059 & 0,0041 & 0,0167 & 0,0064 & 0,0064 & 0,0047 \\
\hline$\{10,50\}$ & 0,0166 & 0,0146 & 0,0146 & 0,0045 & 0,0167 & 0,0147 & 0,0147 & 0,0046 \\
\hline$\{2,7\}$ & 0,0166 & 0,0148 & 0,0151 & 0,0132 & 0,0167 & 0,0149 & 0,0152 & 0,0133 \\
\hline \multicolumn{9}{|c|}{ Valores da MAP para o fator de combinação $\alpha=0,3$} \\
\hline \multirow{2}{*}{ Granul. } & \multicolumn{4}{|c|}{$M A P @ 5$} & \multicolumn{4}{|c|}{$M A P @ 10$} \\
\hline & IBCF & $\begin{array}{l}\text { cReduc- } \\
\text { tion }\end{array}$ & Weight PoF & Filter PoF & IBCF & $\begin{array}{l}\text { cReduc- } \\
\text { tion }\end{array}$ & Weight PoF & Filter PoF \\
\hline$\{50,100\}$ & 0,0166 & $0,0289 *$ & $0,0308 *$ & 0,0121 & 0,0167 & $0,0292 *$ & $0,0311 *$ & 0,0124 \\
\hline$\{15,20\}$ & 0,0166 & 0,0214 & 0,0228 & 0,0106 & 0,0167 & 0,0216 & 0,0230 & 0,0106 \\
\hline$\{10,50\}$ & 0,0166 & 0,0160 & 0,0168 & 0,0067 & 0,0167 & 0,0162 & 0,0170 & 0,0069 \\
\hline$\{2,7\}$ & 0,0166 & 0,0182 & 0,0185 & 0,0194 & 0,0167 & 0,0183 & 0,0186 & 0,0196 \\
\hline \multicolumn{9}{|c|}{ Valores da MAP para o fator de combinação $\alpha=0,5$} \\
\hline \multirow{2}{*}{ Granul. } & \multicolumn{4}{|c|}{$M A P @ 5$} & \multicolumn{4}{|c|}{$M A P @ 10$} \\
\hline & IBCF & $\begin{array}{l}\text { cReduc- } \\
\text { tion }\end{array}$ & Weight PoF & Filter PoF & IBCF & $\begin{array}{l}\text { cReduc- } \\
\text { tion }\end{array}$ & Weight PoF & Filter PoF \\
\hline$\{50,100\}$ & 0,0166 & $0,0289 *$ & $0,0308 *$ & 0,0121 & 0,0167 & $0,0292 *$ & $0,0311 *$ & 0,0124 \\
\hline$\{15,20\}$ & 0,0166 & 0,0262 & 0,0262 & 0,00115 & 0,0167 & 0,0265 & 0,0265 & 0,00119 \\
\hline$\{10,50\}$ & 0,0166 & 0,0149 & 0,0151 & 0,0064 & 0,0167 & 0,0152 & 0,0154 & 0,0068 \\
\hline$\{2,7\}$ & 0,0166 & 0,02118 & $0,0225 *$ & 0,0213 & 0,0167 & 0,0219 & $0,0225 *$ & 0,0213 \\
\hline \multicolumn{9}{|c|}{ Valores da MAP para o fator de combinação $\alpha=0,7$} \\
\hline \multirow{2}{*}{ Granul. } & \multicolumn{4}{|c|}{$M A P @ 5$} & \multicolumn{4}{|c|}{$M A P @ 10$} \\
\hline & IBCF & $\begin{array}{l}\text { cReduc- } \\
\text { tion }\end{array}$ & Weight PoF & Filter PoF & IBCF & $\begin{array}{l}\text { cReduc- } \\
\text { tion }\end{array}$ & Weight PoF & Filter PoF \\
\hline$\{50,100\}$ & 0,0166 & $0,0275 *$ & $0,0275 *$ & 0,0136 & 0,0167 & $0,0278 *$ & $0,0278 *$ & 0,0138 \\
\hline$\{15,20\}$ & 0,0166 & 0,0152 & 0,0168 & 0,0066 & 0,0167 & 0,0152 & 0,0171 & 0,0066 \\
\hline$\{10,50\}$ & 0,0166 & 0,0135 & 0,0138 & 0,0090 & 0,0167 & 0,0138 & 0,0142 & 0,0090 \\
\hline$\{2,7\}$ & 0,0166 & 0,0216 & $0,0221 *$ & $0,0262 *$ & 0,0167 & 0,0217 & $0,0223 *$ & $0,0263 *$ \\
\hline \multicolumn{9}{|c|}{ Valores da MAP para o fator de combinação $\alpha=1$} \\
\hline \multirow{2}{*}{ Granul. } & \multicolumn{4}{|c|}{$M A P @ 5$} & \multicolumn{4}{|c|}{$M A P @ 10$} \\
\hline & IBCF & $\begin{array}{l}\text { cReduc- } \\
\text { tion }\end{array}$ & Weight PoF & Filter PoF & IBCF & $\begin{array}{c}\text { cReduc- } \\
\text { tion }\end{array}$ & Weight PoF & Filter PoF \\
\hline$\{50,100\}$ & 0,0166 & 0,0153 & 0,0153 & 0,0062 & 0,0167 & 0,0157 & 0,0159 & 0,0065 \\
\hline$\{15,20\}$ & 0,0166 & $\mathbf{0 , 0 3 7 5 *}$ & $0,0375 *$ & 0,0237 & 0,0167 & $0,0378 *$ & $0,0378 *$ & 0,0237 \\
\hline$\{10,50\}$ & 0,0166 & 0,0153 & 0,0157 & 0,0069 & 0,0167 & 0,0156 & 0,0161 & 0,0072 \\
\hline$\{2,7\}$ & 0,0166 & 0,0170 & 0,0184 & 0,0171 & 0,0167 & 0,0171 & 0,0185 & 0,0172 \\
\hline
\end{tabular}




\section{Apêndice}

\section{Resultados Obtidos nos Experimentos da Avaliação Considerando o Baseline "Metodológico"}

Como segunda forma de avaliar o contexto extraído pelo método proposto neste trabalho de mestrado, foi utilizado o método de extração de contexto proposto por Li et al. (2010) como baseline em um segundo conjunto de experimentos. Esse baseline, referido neste trabalho como baseline "metodológico", extrai como informação de contexto os "Dias da Semana" e as "Estações do Ano". Neste apêndice estão indicados todos os resultados dessa avaliação. Para acompanhar os resultados com maior clareza, segue a Tabela B.1, que é uma adaptação da tabela já apresentada no Capítulo 5 (Seção 5.6) que descreve os experimentos. Nessa tabela foram acrescentadas as referências das tabelas com os resultados de cada experimento.

Tabela B.1: Experimentos Realizados Considerando o Baseline "Metodológico" e Suas Respectivas Tabelas de Resultados

\begin{tabular}{|c|c|c|c|c|c|c|c|}
\hline \multirow{2}{*}{ Experimentos } & \multicolumn{2}{|c|}{ Base de Dados } & \multicolumn{2}{|c|}{ Informação Privilegiada } & \multicolumn{2}{|c|}{$\begin{array}{l}\text { Informação Extraída } \\
\text { pelo Baseline } \\
\text { "Metodológico" }\end{array}$} & \multirow[t]{2}{*}{ Tabelas } \\
\hline & Embrapa & $\begin{array}{c}\text { Dicionário } \\
\text { Informal }\end{array}$ & $\begin{array}{l}\text { Entidades } \\
\text { Nomeadas }\end{array}$ & Termos & $\begin{array}{l}\text { Dias da } \\
\text { Semana }\end{array}$ & $\begin{array}{c}\text { Estações } \\
\text { do Ano }\end{array}$ & \\
\hline Primeiro & $\mathrm{X}$ & & $\mathrm{X}$ & & $\mathrm{X}$ & & B.2 e B.3 \\
\hline Segundo & $\mathrm{X}$ & & $\mathrm{X}$ & & & $\mathrm{X}$ & B.4 e B.5 \\
\hline Terceiro & $\mathrm{X}$ & & & $\mathrm{X}$ & $\mathrm{X}$ & & B.6 e B.7 \\
\hline Quarto & $\mathrm{X}$ & & & $\mathrm{X}$ & & $\mathrm{X}$ & B.8 e B.9 \\
\hline Quinto & & $\mathrm{X}$ & $\mathrm{X}$ & & $\mathrm{X}$ & & B.10 e B.11 \\
\hline Sexto & & $\mathrm{X}$ & $\mathrm{X}$ & & & $\mathrm{X}$ & B.12 e B.13 \\
\hline Sétimo & & $\mathrm{X}$ & & $\mathrm{X}$ & $\mathrm{X}$ & & B.14 e B.15 \\
\hline Oitavo & & $\mathrm{X}$ & & $\mathrm{X}$ & & $\mathrm{X}$ & B.16 e B.17 \\
\hline
\end{tabular}


Tabela B.2: Resultados do Primeiro Experimento da Avaliação Comparando com o Baseline "Metodológico" para os Fatores de Combinação $\alpha=0$ e $\alpha=0,3$

\begin{tabular}{|c|c|c|c|c|c|c|c|c|}
\hline \multicolumn{9}{|c|}{ Valores da MAP para o fator de combinação $\alpha=0$} \\
\hline \multirow{3}{*}{ Granul. } & \multicolumn{4}{|c|}{ cReduction } & \multicolumn{4}{|c|}{ DaVI-BEST } \\
\hline & \multicolumn{2}{|c|}{ MAP@5 } & \multicolumn{2}{|c|}{$M A P @ 10$} & \multicolumn{2}{|c|}{ MAP@5 } & \multicolumn{2}{|c|}{$M A P @ 10$} \\
\hline & Baseline & $\begin{array}{l}\text { cReduc- } \\
\text { tion }\end{array}$ & Baseline & $\begin{array}{l}\text { cReduc- } \\
\text { tion }\end{array}$ & Baseline & $\begin{array}{l}\text { DaVI- } \\
\text { BEST }\end{array}$ & Baseline & $\begin{array}{l}\text { DaVI- } \\
\text { BEST }\end{array}$ \\
\hline$\{50,100\}$ & 0,3940 & 0,3497 & 0,3864 & 0,3441 & 0,3894 & 0,3512 & 0,3958 & 0,3597 \\
\hline$\{15,20\}$ & 0,3940 & 0,3824 & 0,3864 & 0,3894 & 0,3894 & 0,3824 & 0,3958 & 0,3894 \\
\hline$\{10,50\}$ & 0,3940 & 0,3221 & 0,3864 & 0,3246 & 0,3894 & 0,3209 & 0,3958 & 0,3289 \\
\hline$\{2,7\}$ & 0,3940 & 0,3153 & 0,3864 & 0,3230 & 0,3894 & 0,3153 & 0,3958 & 0,3230 \\
\hline \multirow{3}{*}{ Granul. } & \multicolumn{4}{|c|}{ Filter PoF } & \multicolumn{4}{|c|}{ Weight PoF } \\
\hline & \multicolumn{2}{|c|}{ MAP@5 } & \multicolumn{2}{|c|}{$M A P @ 10$} & \multicolumn{2}{|c|}{$M A P @ 5$} & \multicolumn{2}{|c|}{$M A P @ 10$} \\
\hline & Baseline & $\begin{array}{l}\text { Filter } \\
\text { PoF }\end{array}$ & Baseline & $\begin{array}{c}\text { Filter } \\
\text { PoF }\end{array}$ & Baseline & $\begin{array}{c}\text { Weight } \\
\text { PoF }\end{array}$ & Baseline & $\begin{array}{l}\text { Weight } \\
\text { PoF }\end{array}$ \\
\hline$\{50,100\}$ & 0,1224 & $0,2117 *$ & 0,1269 & $0,2133 *$ & 0,3991 & 0,3678 & 0,4055 & 0,3755 \\
\hline$\{15,20\}$ & 0,1224 & $0,3647 *$ & 0,1269 & $0,3654 *$ & 0,3991 & 0,4244 & 0,4055 & 0,4286 \\
\hline$\{10,50\}$ & 0,1224 & $0,2403 *$ & 0,1269 & $0,2416 *$ & 0,3991 & 0,3464 & 0,4055 & 0,3538 \\
\hline$\{2,7\}$ & 0,1224 & $0,4075 *$ & 0,1269 & $0,4090 *$ & 0,3991 & 0,3763 & 0,4055 & 0,3824 \\
\hline \multicolumn{9}{|c|}{ Valores da MAP para o fator de combinação $\alpha=0,3$} \\
\hline \multirow{3}{*}{ Granul. } & \multicolumn{4}{|c|}{ cReduction } & \multicolumn{4}{|c|}{ DaVI-BEST } \\
\hline & \multicolumn{2}{|c|}{ MAP@5 } & \multicolumn{2}{|c|}{$M A P @ 10$} & \multicolumn{2}{|c|}{$M A P @ 5$} & \multicolumn{2}{|c|}{$M A P @ 10$} \\
\hline & Baseline & $\begin{array}{l}\text { cReduc- } \\
\text { tion }\end{array}$ & Baseline & $\begin{array}{l}\text { cReduc- } \\
\text { tion }\end{array}$ & Baseline & $\begin{array}{l}\text { DaVI- } \\
\text { BEST }\end{array}$ & Baseline & $\begin{array}{l}\text { DaVI- } \\
\text { BEST }\end{array}$ \\
\hline$\{50,100\}$ & 0,3940 & 0,3334 & 0,3864 & 0,3467 & 0,3894 & 0,3376 & 0,3958 & 0,3467 \\
\hline$\{15,20\}$ & 0,3940 & 0,3821 & 0,3864 & 0,3890 & 0,3894 & 0,3821 & 0,3958 & 0,3890 \\
\hline$\{10,50\}$ & 0,3940 & 0,3154 & 0,3864 & 0,3230 & 0,3894 & 0,3154 & 0,3958 & 0,3230 \\
\hline$\{2,7\}$ & 0,3940 & 0,3193 & 0,3864 & 0,3279 & 0,3894 & 0,3194 & 0,3958 & 0,3279 \\
\hline \multirow{3}{*}{ Granul. } & \multicolumn{4}{|c|}{ Filter PoF } & \multicolumn{4}{|c|}{ Weight PoF } \\
\hline & \multicolumn{2}{|c|}{ MAP@5 } & \multicolumn{2}{|c|}{ MAP@10 } & \multicolumn{2}{|c|}{ MAP@5 } & \multicolumn{2}{|c|}{ MAP@10 } \\
\hline & Baseline & $\begin{array}{c}\text { Filter } \\
\text { PoF }\end{array}$ & Baseline & $\begin{array}{c}\text { Filter } \\
\text { PoF }\end{array}$ & Baseline & $\begin{array}{c}\text { Weight } \\
\text { PoF }\end{array}$ & Baseline & $\begin{array}{l}\text { Weight } \\
\text { PoF }\end{array}$ \\
\hline$\{50,100\}$ & 0,1224 & 0,1613 & 0,1269 & 0,1631 & 0,3991 & 0,3564 & 0,4055 & 0,3651 \\
\hline$\{15,20\}$ & 0,1224 & $0,2894 *$ & 0,1269 & $0,2913 *$ & 0,3991 & 0,4147 & 0,4055 & 0,4204 \\
\hline$\{10,50\}$ & 0,1224 & $0,1987 *$ & 0,1269 & $0,1994 *$ & 0,3991 & 0,3383 & 0,4055 & 0,3452 \\
\hline$\{2,7\}$ & 0,1224 & $0,3993 *$ & 0,1269 & $0,4006 *$ & 0,3991 & 0,3643 & 0,4055 & 0,3708 \\
\hline
\end{tabular}


Tabela B.3: Resultados do Primeiro Experimento da Avaliação Comparando com o Baseline "Metodológico" para os Fatores de Combinação $\alpha=0,5, \alpha=0,7$ e $\alpha=1$

\begin{tabular}{|c|c|c|c|c|c|c|c|c|}
\hline \multicolumn{9}{|c|}{ Valores da MAP para o fator de combinação $\alpha=0,5$} \\
\hline \multirow{3}{*}{ Granul. } & \multicolumn{4}{|c|}{ cReduction } & \multicolumn{4}{|c|}{ DaVI-BEST } \\
\hline & \multicolumn{2}{|c|}{$M A P @ 5$} & \multicolumn{2}{|c|}{$M A P @ 10$} & \multicolumn{2}{|c|}{$M A P @ 5$} & \multicolumn{2}{|c|}{$M A P @ 10$} \\
\hline & Baseline & $\begin{array}{l}\text { cReduc- } \\
\text { tion }\end{array}$ & Baseline & $\begin{array}{l}\text { cReduc- } \\
\text { tion }\end{array}$ & Baseline & $\begin{array}{l}\text { DaVI- } \\
\text { BEST }\end{array}$ & Baseline & $\begin{array}{l}\text { DaVI- } \\
\text { BEST }\end{array}$ \\
\hline$\{50,100\}$ & 0,3940 & 0,3199 & 0,3864 & 0,3298 & 0,3894 & 0,3199 & 0,3958 & 0,3298 \\
\hline$\{15,20\}$ & 0,3940 & 0,3518 & 0,3864 & 0,3612 & 0,3894 & 0,3518 & 0,3958 & 0,3612 \\
\hline$\{10,50\}$ & 0,3940 & 0,3062 & 0,3864 & 0,3164 & 0,3894 & 0,3062 & 0,3958 & 0,3164 \\
\hline$\{2,7\}$ & 0,3940 & 0,3208 & 0,3864 & 0,3294 & 0,3894 & 0,3208 & 0,3958 & 0,3294 \\
\hline \multirow{3}{*}{ Granul. } & \multicolumn{4}{|c|}{ Filter PoF } & \multicolumn{4}{|c|}{ Weight PoF } \\
\hline & \multicolumn{2}{|c|}{$M A P @ 5$} & \multicolumn{2}{|c|}{$M A P @ 10$} & \multicolumn{2}{|c|}{$M A P @ 5$} & \multicolumn{2}{|c|}{$M A P @ 10$} \\
\hline & Baseline & $\begin{array}{c}\text { Filter } \\
\text { PoF }\end{array}$ & Baseline & $\begin{array}{c}\text { Filter } \\
\text { PoF }\end{array}$ & Baseline & $\begin{array}{c}\text { Weight } \\
\text { PoF }\end{array}$ & Baseline & $\begin{array}{c}\text { Weight } \\
\text { PoF }\end{array}$ \\
\hline$\{50,100\}$ & 0,1224 & 0,1828 & 0,1269 & 0,1845 & 0,3991 & 0,3368 & 0,4055 & 0,3463 \\
\hline$\{15,20\}$ & 0,1224 & $0,3412 *$ & 0,1269 & $0,3431 *$ & 0,3991 & 0,3845 & 0,4055 & 0,3926 \\
\hline$\{10,50\}$ & 0,1224 & 0,1947 & 0,1269 & 0,1958 & 0,3991 & 0,3336 & 0,4055 & 0,3425 \\
\hline$\{2,7\}$ & 0,1224 & $0,4135 *$ & 0,1269 & $0,4146 *$ & 0,3991 & 0,3747 & 0,4055 & 0,3817 \\
\hline \multicolumn{9}{|c|}{ Valores da MAP para o fator de combinação $\alpha=0,7$} \\
\hline \multirow{3}{*}{ Granul. } & \multicolumn{4}{|c|}{ cReduction } & \multicolumn{4}{|c|}{ DaVI-BEST } \\
\hline & \multicolumn{2}{|c|}{$M A P @ 5$} & \multicolumn{2}{|c|}{$M A P @ 10$} & \multicolumn{2}{|c|}{$M A P @ 5$} & $M A$ & $\$ 10$ \\
\hline & Baseline & $\begin{array}{l}\text { cReduc- } \\
\text { tion }\end{array}$ & Baseline & $\begin{array}{l}\text { cReduc- } \\
\text { tion }\end{array}$ & Baseline & $\begin{array}{l}\text { DaVI- } \\
\text { BEST }\end{array}$ & Baseline & $\begin{array}{l}\text { DaVI- } \\
\text { BEST }\end{array}$ \\
\hline$\{50,100\}$ & 0,3940 & 0,3052 & 0,3864 & 0,3159 & 0,3894 & 0,3052 & 0,3958 & 0,3159 \\
\hline$\{15,20\}$ & 0,3940 & 0,4454 & 0,3864 & 0,4532 & 0,3894 & 0,4454 & 0,3958 & 0,4532 \\
\hline$\{10,50\}$ & 0,3940 & 0,3262 & 0,3864 & 0,3354 & 0,3894 & 0,3262 & 0,3958 & 0,3354 \\
\hline$\{2,7\}$ & 0,3940 & 0,3277 & 0,3864 & 0,3359 & 0,3894 & 0,3277 & 0,3958 & 0,3359 \\
\hline & & Filt & $\mathrm{PoF}$ & & & Wei & PoF & \\
\hline Granul. & & @ @5 & $M A$ & $@ 10$ & $M A$ & @5 & $M A$ & ఏ10 \\
\hline & Baseline & $\begin{array}{c}\text { Filter } \\
\text { PoF }\end{array}$ & Baseline & $\begin{array}{c}\text { Filter } \\
\text { PoF }\end{array}$ & Baseline & $\begin{array}{c}\text { Weight } \\
\text { PoF }\end{array}$ & Baseline & $\begin{array}{c}\text { Weight } \\
\text { PoF }\end{array}$ \\
\hline$\{50,100\}$ & 0,1224 & 0,1231 & 0,1269 & 0,1245 & 0,3991 & 0,3180 & 0,4055 & 0,3281 \\
\hline$\{15,20\}$ & 0,1224 & $0,3772 *$ & 0,1269 & $0,3793 *$ & 0,3991 & 0,4803 & 0,4055 & 0,4874 \\
\hline$\{10,50\}$ & 0,1224 & $0,2143 *$ & 0,1269 & $0,2156 *$ & 0,3991 & 0,3496 & 0,4055 & 0,3582 \\
\hline$\{2,7\}$ & 0,1224 & $0,4197 *$ & 0,1269 & $0, \mathbf{0 , 4 2 0 8 *}$ & 0,3991 & 0,3826 & 0,4055 & 0,3888 \\
\hline & & Valore & a MAP p & o fator de & ombinaçã & $x=1$ & & \\
\hline & & $\mathrm{cRe}$ & tion & & & $\mathrm{DaV}$ & BEST & \\
\hline Granul. & & @ 5 & $M A$ & $@ 10$ & $M A$ & @5 & $M A$ & $\$ 10$ \\
\hline & Baseline & $\begin{array}{l}\text { cReduc- } \\
\text { tion }\end{array}$ & Baseline & $\begin{array}{l}\text { cReduc- } \\
\text { tion }\end{array}$ & Baseline & $\begin{array}{l}\text { DaVI- } \\
\text { BEST }\end{array}$ & Baseline & $\begin{array}{l}\text { DaVI- } \\
\text { BEST }\end{array}$ \\
\hline$\{50,100\}$ & 0,3940 & 0,3019 & 0,3864 & 0,3137 & 0,3894 & 0,3019 & 0,3958 & 0,3137 \\
\hline$\{15,20\}$ & 0,3940 & 0,3851 & 0,3864 & 0,3912 & 0,3894 & 0,3851 & 0,3958 & 0,3912 \\
\hline$\{10,50\}$ & 0,3940 & 0,3390 & 0,3864 & 0,3493 & 0,3894 & 0,3390 & 0,3958 & 0,3493 \\
\hline$\{2,7\}$ & 0,3940 & 0,3207 & 0,3864 & 0,3294 & 0,3894 & 0,3207 & 0,3958 & 0,3294 \\
\hline & & Filt & $\mathrm{PoF}$ & & & Wei & $\mathrm{PoF}$ & \\
\hline Granul. & & D@5 & $M A$ & @10 & $M A$ & @5 & $M A$ & $\$ 10$ \\
\hline & Baseline & $\begin{array}{c}\text { Filter } \\
\text { PoF }\end{array}$ & Baseline & $\begin{array}{c}\text { Filter } \\
\text { PoF }\end{array}$ & Baseline & $\begin{array}{c}\text { Weight } \\
\text { PoF }\end{array}$ & Baseline & $\begin{array}{c}\text { Weight } \\
\text { PoF }\end{array}$ \\
\hline$\{50,100\}$ & 0,1224 & 0,1299 & 0,1269 & 0,1314 & 0,3991 & 0,3171 & 0,4055 & 0,3280 \\
\hline$\{15,20\}$ & 0,1224 & $0,2556 *$ & 0,1269 & $0,2566 *$ & 0,3991 & 0,4191 & 0,4055 & 0,4245 \\
\hline$\{10,50\}$ & 0,1224 & $0,2350 *$ & 0,1269 & $0,2363 *$ & 0,3991 & 0,3662 & 0,4055 & 0,3756 \\
\hline$\{2,7\}$ & 0,1224 & $0,4139 *$ & 0,1269 & $\mathbf{0 , 4 1 4 9} *$ & 0,3991 & 0,3828 & 0,4055 & 0,3895 \\
\hline
\end{tabular}


Tabela B.4: Resultados do Segundo Experimento da Avaliação Comparando com o Baseline "Metodológico" para os Fatores de Combinação $\alpha=0$ e $\alpha=0,3$

\begin{tabular}{|c|c|c|c|c|c|c|c|c|}
\hline \multicolumn{9}{|c|}{ Valores da MAP para o fator de combinação $\alpha=0$} \\
\hline \multirow{3}{*}{ Granul. } & \multicolumn{4}{|c|}{ cReduction } & \multicolumn{4}{|c|}{ DaVI-BEST } \\
\hline & \multicolumn{2}{|c|}{$M A P @ 5$} & \multicolumn{2}{|c|}{$M A P @ 10$} & \multicolumn{2}{|c|}{$M A P @ 5$} & \multicolumn{2}{|c|}{$M A P @ 10$} \\
\hline & Baseline & $\begin{array}{l}\text { cReduc- } \\
\text { tion }\end{array}$ & Baseline & $\begin{array}{l}\text { cReduc- } \\
\text { tion }\end{array}$ & Baseline & $\begin{array}{l}\text { DaVI- } \\
\text { BEST }\end{array}$ & Baseline & $\begin{array}{l}\text { DaVI- } \\
\text { BEST }\end{array}$ \\
\hline$\{50,100\}$ & 0,3089 & $0,3497 *$ & 0,3281 & 0,3441 & 0,3131 & $0,3512 *$ & 0,3254 & $0,3597 *$ \\
\hline$\{15,20\}$ & 0,3089 & $0,3824 *$ & 0,3281 & $0,3894 *$ & 0,3131 & $0,3824 *$ & 0,3254 & $0,3894 *$ \\
\hline$\{10,50\}$ & 0,3089 & 0,3221 & 0,3281 & 0,3246 & 0,3131 & 0,3209 & 0,3254 & 0,3289 \\
\hline$\{2,7\}$ & 0,3089 & 0,3153 & 0,3281 & 0,3230 & 0,3131 & 0,3153 & 0,3254 & 0,3230 \\
\hline \multirow{3}{*}{ Granul. } & \multicolumn{4}{|c|}{ Filter PoF } & \multicolumn{4}{|c|}{ Weight PoF } \\
\hline & \multicolumn{2}{|c|}{ MAP@5 } & \multicolumn{2}{|c|}{$M A P @ 10$} & \multicolumn{2}{|c|}{$M A P @ 5$} & \multicolumn{2}{|c|}{$M A P @ 10$} \\
\hline & Baseline & $\begin{array}{c}\text { Filter } \\
\text { PoF }\end{array}$ & Baseline & $\begin{array}{c}\text { Filter } \\
\text { PoF }\end{array}$ & Baseline & $\begin{array}{l}\text { Weight } \\
\text { PoF }\end{array}$ & Baseline & $\begin{array}{c}\text { Weight } \\
\text { PoF }\end{array}$ \\
\hline$\{50,100\}$ & 0,1713 & $0,2117 *$ & 0,1831 & $0,2133 *$ & 0,3201 & $0,3678 *$ & 0,3324 & $0,3755 *$ \\
\hline$\{15,20\}$ & 0,1713 & $0,3647 *$ & 0,1831 & $0,3654 *$ & 0,3201 & $0,4244 *$ & 0,3324 & $0,4286 *$ \\
\hline$\{10,50\}$ & 0,1713 & $0,2403 *$ & 0,1831 & $0,2416 *$ & 0,3201 & $0,3464 *$ & 0,3324 & 0,3538 \\
\hline$\{2,7\}$ & 0,1713 & $0,4075 *$ & 0,1831 & $0,4090 *$ & 0,3201 & $0,3763 *$ & 0,3324 & $0,3824 *$ \\
\hline \multicolumn{9}{|c|}{ Valores da MAP para o fator de combinação $\alpha=0,3$} \\
\hline \multirow{3}{*}{ Granul. } & \multicolumn{4}{|c|}{ cReduction } & \multicolumn{4}{|c|}{ DaVI-BEST } \\
\hline & \multicolumn{2}{|c|}{ MAP@5 } & \multicolumn{2}{|c|}{$M A P @ 10$} & \multicolumn{2}{|c|}{$M A P @ 5$} & \multicolumn{2}{|c|}{ MAP@10 } \\
\hline & Baseline & $\begin{array}{l}\text { cReduc- } \\
\text { tion }\end{array}$ & Baseline & $\begin{array}{l}\text { cReduc- } \\
\text { tion }\end{array}$ & Baseline & $\begin{array}{l}\text { DaVI- } \\
\text { BEST }\end{array}$ & Baseline & $\begin{array}{l}\text { DaVI- } \\
\text { BEST }\end{array}$ \\
\hline$\{50,100\}$ & 0,3089 & 0,3334 & 0,3281 & 0,3467 & 0,3131 & 0,3376 & 0,3254 & 0,3467 \\
\hline$\{15,20\}$ & 0,3089 & $0,3821 *$ & 0,3281 & $0,3890 *$ & 0,3131 & 0,3821 * & 0,3254 & $0,3890 *$ \\
\hline$\{10,50\}$ & 0,3089 & 0,3154 & 0,3281 & 0,3230 & 0,3131 & 0,3154 & 0,3254 & 0,3230 \\
\hline$\{2,7\}$ & 0,3089 & 0,3194 & 0,3281 & 0,3280 & 0,3131 & 0,3194 & 0,3254 & 0,3280 \\
\hline \multirow{3}{*}{ Granul. } & \multicolumn{4}{|c|}{ Filter PoF } & \multicolumn{4}{|c|}{ Weight PoF } \\
\hline & \multicolumn{2}{|c|}{ MAP@5 } & \multicolumn{2}{|c|}{$M A P @ 10$} & \multicolumn{2}{|c|}{$M A P @ 5$} & \multicolumn{2}{|c|}{$M A P @ 10$} \\
\hline & Baseline & $\begin{array}{c}\text { Filter } \\
\text { PoF }\end{array}$ & Baseline & $\begin{array}{l}\text { Filter } \\
\text { PoF }\end{array}$ & Baseline & $\begin{array}{l}\text { Weight } \\
\text { PoF }\end{array}$ & Baseline & $\begin{array}{c}\text { Weight } \\
\text { PoF }\end{array}$ \\
\hline$\{50,100\}$ & 0,1713 & 0,1613 & 0,1831 & 0,1631 & 0,3201 & $0,3564 *$ & 0,3324 & $0,3651 *$ \\
\hline$\{15,20\}$ & 0,1713 & $0,2894 *$ & 0,1831 & $0,2913 *$ & 0,3201 & $0,4147 *$ & 0,3324 & $0,4204 *$ \\
\hline$\{10,50\}$ & 0,1713 & $0,1987 *$ & 0,1831 & 0,1994 & 0,3201 & 0,3383 & 0,3324 & 0,3452 \\
\hline$\{2,7\}$ & 0,1713 & $0,3993 *$ & 0,1831 & $0,4006 *$ & 0,3201 & $0,3643 *$ & 0,3324 & $0,3708 *$ \\
\hline
\end{tabular}


Tabela B.5: Resultados do Segundo Experimento da Avaliação Comparando com o Baseline "Metodológico" para os Fatores de Combinação $\alpha=0,5, \alpha=0,7$ e $\alpha=1$

\begin{tabular}{|c|c|c|c|c|c|c|c|c|}
\hline \multicolumn{9}{|c|}{ Valores da MAP para o fator de combinação $\alpha=0,5$} \\
\hline \multirow{3}{*}{ Granul. } & \multicolumn{4}{|c|}{ cReduction } & \multicolumn{4}{|c|}{ DaVI-BEST } \\
\hline & \multicolumn{2}{|c|}{$M A P @ 5$} & \multicolumn{2}{|c|}{$M A P @ 10$} & \multicolumn{2}{|c|}{$M A P @ 5$} & \multicolumn{2}{|c|}{$M A P @ 10$} \\
\hline & Baseline & $\begin{array}{l}\text { cReduc- } \\
\text { tion }\end{array}$ & Baseline & $\begin{array}{l}\text { cReduc- } \\
\text { tion }\end{array}$ & Baseline & $\begin{array}{l}\text { DaVI- } \\
\text { BEST }\end{array}$ & Baseline & $\begin{array}{l}\text { DaVI- } \\
\text { BEST }\end{array}$ \\
\hline$\{50,100\}$ & 0,3089 & 0,3199 & 0,3281 & 0,3298 & 0,3131 & 0,3199 & 0,3254 & 0,3298 \\
\hline$\{15,20\}$ & 0,3089 & $0,3518 *$ & 0,3281 & 0,3612 & 0,3131 & 0,3518 & 0,3254 & 0,3612 \\
\hline$\{10,50\}$ & 0,3089 & 0,3062 & 0,3281 & 0,3164 & 0,3131 & 0,3062 & 0,3254 & 0,3164 \\
\hline$\{2,7\}$ & 0,3089 & 0,3208 & 0,3281 & 0,3294 & 0,3131 & 0,3208 & 0,3254 & 0,3294 \\
\hline \multirow{3}{*}{ Granul. } & \multicolumn{4}{|c|}{ Filter PoF } & \multicolumn{4}{|c|}{ Weight PoF } \\
\hline & \multicolumn{2}{|c|}{$M A P @ 5$} & \multicolumn{2}{|c|}{$M A P @ 10$} & \multicolumn{2}{|c|}{$M A P @ 5$} & \multicolumn{2}{|c|}{$M A P @ 10$} \\
\hline & Baseline & $\begin{array}{c}\text { Filter } \\
\text { PoF }\end{array}$ & Baseline & $\begin{array}{c}\text { Filter } \\
\text { PoF }\end{array}$ & Baseline & $\begin{array}{c}\text { Weight } \\
\text { PoF }\end{array}$ & Baseline & $\begin{array}{c}\text { Weight } \\
\text { PoF }\end{array}$ \\
\hline$\{50,100\}$ & 0,1713 & 0,1828 & 0,1831 & 0,1845 & 0,3201 & 0,3368 & 0,3324 & 0,3463 \\
\hline$\{15,20\}$ & 0,1713 & $0,3412 *$ & 0,1831 & $0,3431 *$ & 0,3201 & $0,3845 *$ & 0,3324 & $0,3926 *$ \\
\hline$\{10,50\}$ & 0,1713 & 0,1947 & 0,1831 & 0,1958 & 0,3201 & 0,3336 & 0,3324 & 0,3425 \\
\hline$\{2,7\}$ & 0,1713 & $0,4135 *$ & 0,1831 & $0,4146 *$ & 0,3201 & $0,3747 *$ & 0,3324 & $0,3817 *$ \\
\hline \multicolumn{9}{|c|}{ Valores da MAP para o fator de combinação $\alpha=0,7$} \\
\hline \multirow{3}{*}{ Granul. } & \multicolumn{4}{|c|}{ cReduction } & \multicolumn{4}{|c|}{ DaVI-BEST } \\
\hline & \multicolumn{2}{|c|}{$M A P @ 5$} & \multicolumn{2}{|c|}{ MAP@10 } & \multicolumn{2}{|c|}{$M A P @ 5$} & $M A$ & @10 \\
\hline & Baseline & $\begin{array}{c}\text { cReduc- } \\
\text { tion }\end{array}$ & Baseline & $\begin{array}{c}\text { cReduc- } \\
\text { tion }\end{array}$ & Baseline & $\begin{array}{l}\text { DaVI- } \\
\text { BEST }\end{array}$ & Baseline & $\begin{array}{l}\text { DaVI- } \\
\text { BEST }\end{array}$ \\
\hline$\{50,100\}$ & 0,3089 & 0,3052 & 0,3281 & 0,3159 & 0,3131 & 0,3052 & 0,3254 & 0,3159 \\
\hline$\{15,20\}$ & 0,3089 & $0,4454 *$ & 0,3281 & $0,4532 *$ & 0,3131 & $0,4454 *$ & 0,3254 & $0,4532 *$ \\
\hline$\{10,50\}$ & 0,3089 & 0,3262 & 0,3281 & 0,3354 & 0,3131 & 0,3262 & 0,3254 & 0,3354 \\
\hline$\{2,7\}$ & 0,3089 & 0,3277 & 0,3281 & 0,3359 & 0,3131 & 0,3277 & 0,3254 & 0,3359 \\
\hline & & Filt & $\mathrm{PoF}$ & & & Weig & PoF & \\
\hline Granul. & $M$ & @5 & $M A$ & @10 & $M A$ & @5 & $M A$ & @10 \\
\hline & Baseline & $\begin{array}{c}\text { Filter } \\
\text { PoF }\end{array}$ & Baseline & $\begin{array}{c}\text { Filter } \\
\text { PoF }\end{array}$ & Baseline & $\begin{array}{c}\text { Weight } \\
\text { PoF }\end{array}$ & Baseline & $\begin{array}{c}\text { Weight } \\
\text { PoF }\end{array}$ \\
\hline$\{50,100\}$ & 0,1713 & 0,1231 & 0,1831 & 0,1245 & 0,3201 & 0,3180 & 0,3324 & 0,3281 \\
\hline$\{15,20\}$ & 0,1713 & $0,3772 *$ & 0,1831 & 0,3793* & 0,3201 & $0,4803 *$ & 0,3324 & $0,4874 *$ \\
\hline$\{10,50\}$ & 0,1713 & $0,2143 *$ & 0,1831 & 0,2156 & 0,3201 & 0,3496 & 0,3324 & 0,3582 \\
\hline$\{2,7\}$ & 0,1713 & $0,4197 *$ & 0,1831 & $0,4208 *$ & 0,3201 & $0,3826 *$ & 0,3324 & $0,3888 *$ \\
\hline & & Valore & aAP $\mathrm{p}$ & o fator $\mathrm{c}$ & ombinaçã & $\alpha=1$ & & \\
\hline & & $\mathrm{cRe}$ & tion & & & $\mathrm{DaV}$ & BEST & \\
\hline Granul. & $M$ & @5 & $M A$ & @10 & $M A$ & @5 & $M A$ & a10 \\
\hline & Baseline & $\begin{array}{c}\text { cReduc- } \\
\text { tion }\end{array}$ & Baseline & $\begin{array}{c}\text { cReduc- } \\
\text { tion }\end{array}$ & Baseline & $\begin{array}{l}\text { DaVI- } \\
\text { BEST }\end{array}$ & Baseline & $\begin{array}{l}\text { DaVI- } \\
\text { BEST }\end{array}$ \\
\hline$\{50,100\}$ & 0,3089 & 0,3019 & 0,3281 & 0,3137 & 0,3131 & 0,3019 & 0,3254 & 0,31367 \\
\hline$\{15,20\}$ & 0,3089 & $0,3851 *$ & 0,3281 & 0,3912* & 0,3131 & $0,3851 *$ & 0,3254 & $0,3912 *$ \\
\hline$\{10,50\}$ & 0,3089 & 0,3390 & 0,3281 & 0,3493 & 0,3131 & 0,3390 & 0,3254 & 0,3493 \\
\hline$\{2,7\}$ & 0,3089 & 0,3207 & 0,3281 & 0,3294 & 0,3131 & 0,3207 & 0,3254 & 0,3294 \\
\hline & & Filt & $\overline{\mathrm{PoF}}$ & & & Weig & $\mathrm{PoF}$ & \\
\hline Granul. & $M$ & @ & $M A$ & @10 & $M A$ & @5 & $M A$ & a 10 \\
\hline & Baseline & $\begin{array}{c}\text { Filter } \\
\text { PoF }\end{array}$ & Baseline & $\begin{array}{c}\text { Filter } \\
\text { PoF }\end{array}$ & Baseline & $\begin{array}{c}\text { Weight } \\
\text { PoF }\end{array}$ & Baseline & $\begin{array}{c}\text { Weight } \\
\text { PoF }\end{array}$ \\
\hline$\{50,100\}$ & 0,1713 & 0,1299 & 0,1831 & 0,1314 & 0,3201 & 0,3171 & 0,3324 & 0,3280 \\
\hline$\{15,20\}$ & 0,1713 & 0,2556* & 0,1831 & 0,2566* & 0,3201 & 0,4191* & 0,3324 & $0,4245 *$ \\
\hline$\{10,50\}$ & 0,1713 & $0,2350 *$ & 0,1831 & $0,2363 *$ & 0,3201 & $0,3662 *$ & 0,3324 & $0,3756 *$ \\
\hline$\{2,7\}$ & 0,1713 & $0,4139 *$ & 0,1831 & $0,4148 *$ & 0,3201 & $0,3828 *$ & 0,3324 & $0,3895 *$ \\
\hline
\end{tabular}


Tabela B.6: Resultados do Terceiro Experimento da Avaliação Comparando com o Baseline "Metodológico" para os Fatores de Combinação $\alpha=0$ e $\alpha=0,3$

\begin{tabular}{|c|c|c|c|c|c|c|c|c|}
\hline \multicolumn{9}{|c|}{ Valores da MAP para o fator de combinação $\alpha=0$} \\
\hline \multirow{3}{*}{ Granul. } & \multicolumn{4}{|c|}{ cReduction } & \multicolumn{4}{|c|}{ DaVI-BEST } \\
\hline & \multicolumn{2}{|c|}{$M A P @ 5$} & \multicolumn{2}{|c|}{$M A P @ 10$} & \multicolumn{2}{|c|}{ MAP@5 } & \multicolumn{2}{|c|}{$M A P @ 10$} \\
\hline & Baseline & $\begin{array}{l}\text { cReduc- } \\
\text { tion }\end{array}$ & Baseline & $\begin{array}{l}\text { cReduc- } \\
\text { tion }\end{array}$ & Baseline & $\begin{array}{l}\text { DaVI- } \\
\text { BEST }\end{array}$ & Baseline & $\begin{array}{l}\text { DaVI- } \\
\text { BEST }\end{array}$ \\
\hline$\{50,100\}$ & 0,3940 & 0,3017 & 0,3864 & 0,3042 & 0,3894 & 0,3022 & 0,3958 & 0,3120 \\
\hline$\{15,20\}$ & 0,3940 & 0,3802 & 0,3864 & 0,3874 & 0,3894 & 0,3802 & 0,3958 & 0,3874 \\
\hline$\{10,50\}$ & 0,3940 & 0,3447 & 0,3864 & 0,3491 & 0,3894 & 0,3447 & 0,3958 & 0,3527 \\
\hline$\{2,7\}$ & 0,3940 & 0,3392 & 0,3864 & 0,3470 & 0,3894 & 0,3392 & 0,3958 & 0,3470 \\
\hline \multirow{3}{*}{ Granul. } & \multicolumn{4}{|c|}{ Filter PoF } & \multicolumn{4}{|c|}{ Weight PoF } \\
\hline & \multicolumn{2}{|c|}{ MAP@5 } & \multicolumn{2}{|c|}{$M A P @ 10$} & \multicolumn{2}{|c|}{$M A P @ 5$} & \multicolumn{2}{|c|}{$M A P @ 10$} \\
\hline & Baseline & $\begin{array}{c}\text { Filter } \\
\text { PoF }\end{array}$ & Baseline & $\begin{array}{l}\text { Filter } \\
\text { PoF }\end{array}$ & Baseline & $\begin{array}{l}\text { Weight } \\
\text { PoF }\end{array}$ & Baseline & $\begin{array}{l}\text { Weight } \\
\text { PoF }\end{array}$ \\
\hline$\{50,100\}$ & 0,1224 & $0,1908 *$ & 0,1269 & $0,1922 *$ & 0,3991 & 0,3210 & 0,4055 & 0,3305 \\
\hline$\{15,20\}$ & 0,1224 & $0,3240 *$ & 0,1269 & $0,3262 *$ & 0,3991 & 0,4049 & 0,4055 & 0,4110 \\
\hline$\{10,50\}$ & 0,1224 & $0,2591 *$ & 0,1269 & $0,2606 *$ & 0,3991 & 0,3751 & 0,4055 & 0,3823 \\
\hline$\{2,7\}$ & 0,1224 & $0,4314 *$ & 0,1269 & $0,4322 *$ & 0,3991 & 0,4024 & 0,4055 & 0,4088 \\
\hline \multicolumn{9}{|c|}{ Valores da MAP para o fator de combinação $\alpha=0,3$} \\
\hline \multirow{3}{*}{ Granul. } & \multicolumn{4}{|c|}{ cReduction } & \multicolumn{4}{|c|}{ DaVI-BEST } \\
\hline & \multicolumn{2}{|c|}{ MAP@5 } & \multicolumn{2}{|c|}{$M A P @ 10$} & \multicolumn{2}{|c|}{$M A P @ 5$} & \multicolumn{2}{|c|}{$M A P @ 10$} \\
\hline & Baseline & $\begin{array}{l}\text { cReduc- } \\
\text { tion }\end{array}$ & Baseline & $\begin{array}{l}\text { cReduc- } \\
\text { tion }\end{array}$ & Baseline & $\begin{array}{l}\text { DaVI- } \\
\text { BEST }\end{array}$ & Baseline & $\begin{array}{l}\text { DaVI- } \\
\text { BEST }\end{array}$ \\
\hline$\{50,100\}$ & 0,3940 & 0,3440 & 0,3864 & 0,3527 & 0,3894 & 0,3440 & 0,3958 & 0,3527 \\
\hline$\{15,20\}$ & 0,3940 & 0,3923 & 0,3864 & 0,3987 & 0,3894 & 0,3923 & 0,3958 & 0,3987 \\
\hline$\{10,50\}$ & 0,3940 & 0,3233 & 0,3864 & 0,3272 & 0,3894 & 0,3222 & 0,3958 & 0,3318 \\
\hline$\{2,7\}$ & 0,3940 & 0,3195 & 0,3864 & 0,3291 & 0,3894 & 0,3195 & 0,3958 & 0,3291 \\
\hline \multirow{3}{*}{ Granul. } & \multicolumn{4}{|c|}{ Filter PoF } & \multicolumn{4}{|c|}{ Weight PoF } \\
\hline & \multicolumn{2}{|c|}{ MAP@5 } & \multicolumn{2}{|c|}{$M A P @ 10$} & \multicolumn{2}{|c|}{$M A P @ 5$} & \multicolumn{2}{|c|}{$M A P @ 10$} \\
\hline & Baseline & $\begin{array}{l}\text { Filter } \\
\text { PoF }\end{array}$ & Baseline & $\begin{array}{c}\text { Filter } \\
\text { PoF }\end{array}$ & Baseline & $\begin{array}{c}\text { Weight } \\
\text { PoF }\end{array}$ & Baseline & $\begin{array}{l}\text { Weight } \\
\text { PoF }\end{array}$ \\
\hline$\{50,100\}$ & 0,1224 & $0,1840 *$ & 0,1269 & $0,1854 *$ & 0,3991 & 0,3556 & 0,4055 & 0,3639 \\
\hline$\{15,20\}$ & 0,1224 & $0,3066 *$ & 0,1269 & $0,3082 *$ & 0,3991 & 0,4361 & 0,4055 & 0,4420 \\
\hline$\{10,50\}$ & 0,1224 & $0,2589 *$ & 0,1269 & $0,2596 *$ & 0,3991 & 0,3590 & 0,4055 & 0,3667 \\
\hline$\{2,7\}$ & 0,1224 & $\mathbf{0 , 4 1 8 7 *}$ & 0,1269 & 0,4200 & 0,3991 & 0,3768 & 0,4055 & 0,3849 \\
\hline
\end{tabular}


Tabela B.7: Resultados do Terceiro Experimento da Avaliação Comparando com o Baseline "Metodológico" para os Fatores de Combinação $\alpha=0,5, \alpha=0,7$ e $\alpha=1$

\begin{tabular}{|c|c|c|c|c|c|c|c|c|}
\hline \multicolumn{9}{|c|}{ Valores da MAP para o fator de combinação $\alpha=0,5$} \\
\hline \multirow{3}{*}{ Granul. } & \multicolumn{4}{|c|}{ cReduction } & \multicolumn{4}{|c|}{ DaVI-BEST } \\
\hline & \multicolumn{2}{|c|}{$M A P @ 5$} & \multicolumn{2}{|c|}{$M A P @ 10$} & \multicolumn{2}{|c|}{$M A P @ 5$} & \multicolumn{2}{|c|}{$M A P @ 10$} \\
\hline & Baseline & $\begin{array}{l}\text { cReduc- } \\
\text { tion }\end{array}$ & Baseline & $\begin{array}{l}\text { cReduc- } \\
\text { tion }\end{array}$ & Baseline & $\begin{array}{l}\text { DaVI- } \\
\text { BEST }\end{array}$ & Baseline & $\begin{array}{l}\text { DaVI- } \\
\text { BEST }\end{array}$ \\
\hline$\{50,100\}$ & 0,3940 & 0,3339 & 0,3864 & 0,3424 & 0,3894 & 0,3339 & 0,3958 & 0,3424 \\
\hline$\{15,20\}$ & 0,3940 & 0,4135 & 0,3864 & 0,4189 & 0,3894 & 0,4135 & 0,3958 & 0,3725 \\
\hline$\{10,50\}$ & 0,3940 & 0,3240 & 0,3864 & 0,3322 & 0,3894 & 0,3240 & 0,3958 & 0,3328 \\
\hline$\{2,7\}$ & 0,3940 & 0,3287 & 0,3864 & 0,3374 & 0,3894 & 0,3287 & 0,3958 & 0,3374 \\
\hline \multirow{3}{*}{ Granul. } & \multicolumn{4}{|c|}{ Filter PoF } & \multicolumn{4}{|c|}{ Weight PoF } \\
\hline & \multicolumn{2}{|c|}{$M A P @ 5$} & \multicolumn{2}{|c|}{$M A P @ 10$} & \multicolumn{2}{|c|}{$M A P @ 5$} & \multicolumn{2}{|c|}{$M A P @ 10$} \\
\hline & Baseline & $\begin{array}{c}\text { Filter } \\
\text { PoF }\end{array}$ & Baseline & $\begin{array}{c}\text { Filter } \\
\text { PoF }\end{array}$ & Baseline & $\begin{array}{c}\text { Weight } \\
\text { PoF }\end{array}$ & Baseline & $\begin{array}{c}\text { Weight } \\
\text { PoF }\end{array}$ \\
\hline$\{50,100\}$ & 0,1224 & $0,2125 *$ & 0,1269 & $0,2135 *$ & 0,3991 & 0,3544 & 0,4055 & 0,3628 \\
\hline$\{15,20\}$ & 0,1224 & $0,2801 *$ & 0,1269 & $0,2818 *$ & 0,3991 & 0,4479 & 0,4055 & 0,4525 \\
\hline$\{10,50\}$ & 0,1224 & $0,2466 *$ & 0,1269 & $0,2473 *$ & 0,3991 & 0,3473 & 0,4055 & 0,3556 \\
\hline$\{2,7\}$ & 0,1224 & $0,3965 *$ & 0,1269 & $0,3983 *$ & 0,3991 & 0,3826 & 0,4055 & 0,3898 \\
\hline \multicolumn{9}{|c|}{ Valores da MAP para o fator de combinação $\alpha=0,7$} \\
\hline \multirow{3}{*}{ Granul. } & \multicolumn{4}{|c|}{ cReduction } & \multicolumn{4}{|c|}{ DaVI-BEST } \\
\hline & \multicolumn{2}{|c|}{$M A P @ 5$} & \multicolumn{2}{|c|}{$M A P @ 10$} & \multicolumn{2}{|c|}{$M A P @ 5$} & $M A$ & ఏ10 \\
\hline & Baseline & $\begin{array}{l}\text { cReduc- } \\
\text { tion }\end{array}$ & Baseline & $\begin{array}{l}\text { cReduc- } \\
\text { tion }\end{array}$ & Baseline & $\begin{array}{l}\text { DaVI- } \\
\text { BEST }\end{array}$ & Baseline & $\begin{array}{l}\text { DaVI- } \\
\text { BEST }\end{array}$ \\
\hline$\{50,100\}$ & 0,3940 & 0,3251 & 0,3864 & 0,3341 & 0,3894 & 0,3251 & 0,3958 & 0,3341 \\
\hline$\{15,20\}$ & 0,3940 & 0,3733 & 0,3864 & 0,3812 & 0,3894 & 0,3733 & 0,3958 & 0,3812 \\
\hline$\{10,50\}$ & 0,3940 & 0,3161 & 0,3864 & 0,3261 & 0,3894 & 0,3161 & 0,3958 & 0,3261 \\
\hline$\{2,7\}$ & 0,3940 & 0,3384 & 0,3864 & 0,3451 & 0,3894 & 0,3384 & 0,3958 & 0,3451 \\
\hline & & Filt & $\mathrm{PoF}$ & & & Wei & $\mathrm{PoF}$ & \\
\hline Granul. & $M_{2}$ & ○) 5 & $M A$ & Q10 & $M A$ & & $M A$ & ఏ10 \\
\hline & Baseline & $\begin{array}{c}\text { Filter } \\
\text { PoF }\end{array}$ & Baseline & $\begin{array}{c}\text { Filter } \\
\text { PoF }\end{array}$ & Baseline & $\begin{array}{c}\text { Weight } \\
\text { PoF }\end{array}$ & Baseline & $\begin{array}{c}\text { Weight } \\
\text { PoF }\end{array}$ \\
\hline$\{50,100\}$ & 0,1224 & $0,1934 *$ & 0,1269 & $0,1951 *$ & 0,3991 & 0,3436 & 0,4055 & 0,3523 \\
\hline$\{15,20\}$ & 0,1224 & $0,3498 *$ & 0,1269 & $0,3514 *$ & 0,3991 & 0,4048 & 0,4055 & 0,4120 \\
\hline$\{10,50\}$ & 0,1224 & $0,2386 *$ & 0,1269 & $0,2400 *$ & 0,3991 & 0,3528 & 0,4055 & 0,3613 \\
\hline$\{2,7\}$ & 0,1224 & $0,3816 *$ & 0,1269 & $0,3817 *$ & 0,3991 & 0,3925 & 0,4055 & 0,3978 \\
\hline & & Valore & MAP $\mathrm{p}$ & o fator $\mathrm{c}$ & ombinaçã & $k=1$ & & \\
\hline & & $\mathrm{cRe}$ & tion & & & $\mathrm{DaV}$ & $\mathrm{EST}$ & \\
\hline Granul. & $M$ & D@5 & $M A$ & @ 10 & $M A$ & & $M A$ & @10 \\
\hline & Baseline & $\begin{array}{l}\text { cReduc- } \\
\text { tion }\end{array}$ & Baseline & $\begin{array}{l}\text { cReduc- } \\
\text { tion }\end{array}$ & Baseline & $\begin{array}{l}\text { DaVI- } \\
\text { BEST }\end{array}$ & Baseline & $\begin{array}{l}\text { DaVI- } \\
\text { BEST }\end{array}$ \\
\hline$\{50,100\}$ & 0,3940 & 0,3267 & 0,3864 & 0,3360 & 0,3894 & 0,3266 & 0,3958 & 0,3360 \\
\hline$\{15,20\}$ & 0,3940 & 0,3449 & 0,3864 & 0,3525 & 0,3894 & 0,3449 & 0,3958 & 0,3525 \\
\hline$\{10,50\}$ & 0,3940 & 0,3100 & 0,3864 & 0,3172 & 0,3894 & 0,3100 & 0,3958 & 0,3172 \\
\hline$\{2,7\}$ & 0,3940 & 0,3213 & 0,3864 & 0,3304 & 0,3894 & 0,3213 & 0,3958 & 0,3304 \\
\hline & & Filt & $\overline{\mathrm{PoF}}$ & & & Wei & PoF & \\
\hline Granul. & $M_{2}$ & @ 5 & $M A$ & @10 & $M A$ & & $M A$ & $\$ 10$ \\
\hline & Baseline & $\begin{array}{c}\text { Filter } \\
\text { PoF }\end{array}$ & Baseline & $\begin{array}{c}\text { Filter } \\
\text { PoF }\end{array}$ & Baseline & $\begin{array}{c}\text { Weight } \\
\text { PoF }\end{array}$ & Baseline & $\begin{array}{c}\text { Weight } \\
\text { PoF }\end{array}$ \\
\hline$\{50,100\}$ & 0,1224 & $0,1828 *$ & 0,1269 & 0,1847 & 0,3991 & 0,3400 & 0,4055 & 0,3487 \\
\hline$\{15,20\}$ & 0,1224 & $0,2922 *$ & 0,1269 & $0,2922 *$ & 0,3991 & 0,3709 & 0,4055 & 0,3773 \\
\hline$\{10,50\}$ & 0,1224 & $0,2114 *$ & 0,1269 & 0,2114* & 0,3991 & 0,3378 & 0,4055 & 0,3442 \\
\hline$\{2,7\}$ & 0,1224 & $0,4061 *$ & 0,1269 & $0,4073 *$ & 0,3991 & 0,3724 & 0,4055 & 0,3798 \\
\hline
\end{tabular}


Tabela B.8: Resultados do Quarto Experimento da Avaliação Comparando com o Baseline "Metodológico" para os Fatores de Combinação $\alpha=0$ e $\alpha=0,3$

\begin{tabular}{|c|c|c|c|c|c|c|c|c|}
\hline \multicolumn{9}{|c|}{ Valores da MAP para o fator de combinação $\alpha=0$} \\
\hline \multirow{3}{*}{ Granul. } & \multicolumn{4}{|c|}{ cReduction } & \multicolumn{4}{|c|}{ DaVI-BEST } \\
\hline & \multicolumn{2}{|c|}{$M A P @ 5$} & \multicolumn{2}{|c|}{$M A P @ 10$} & \multicolumn{2}{|c|}{$M A P @ 5$} & \multicolumn{2}{|c|}{$M A P @ 10$} \\
\hline & Baseline & $\begin{array}{l}\text { cReduc- } \\
\text { tion }\end{array}$ & Baseline & $\begin{array}{l}\text { cReduc- } \\
\text { tion }\end{array}$ & Baseline & $\begin{array}{l}\text { DaVI- } \\
\text { BEST }\end{array}$ & Baseline & $\begin{array}{l}\text { DaVI- } \\
\text { BEST }\end{array}$ \\
\hline$\{50,100\}$ & 0,3089 & 0,3017 & 0,3281 & 0,3042 & 0,3131 & 0,3022 & 0,3254 & 0,3120 \\
\hline$\{15,20\}$ & 0,3089 & $0,3802 *$ & 0,3281 & $0,3874 *$ & 0,3131 & $0,3802 *$ & 0,3254 & $0,3874 *$ \\
\hline$\{10,50\}$ & 0,3089 & $0,3447 *$ & 0,3281 & 0,3491 & 0,3131 & 0,3447 & 0,3254 & 0,3526 \\
\hline$\{2,7\}$ & 0,3089 & $0,3392 *$ & 0,3281 & 0,3470 & 0,3131 & 0,3392 & 0,3254 & 0,3470 \\
\hline \multirow{3}{*}{ Granul. } & \multicolumn{4}{|c|}{ Filter PoF } & \multicolumn{4}{|c|}{ Weight PoF } \\
\hline & \multicolumn{2}{|c|}{$M A P @ 5$} & \multicolumn{2}{|c|}{$M A P @ 10$} & \multicolumn{2}{|c|}{$M A P @ 5$} & \multicolumn{2}{|c|}{$M A P @ 10$} \\
\hline & Baseline & $\begin{array}{c}\text { Filter } \\
\text { PoF }\end{array}$ & Baseline & $\begin{array}{c}\text { Filter } \\
\text { PoF }\end{array}$ & Baseline & $\begin{array}{c}\text { Weight } \\
\text { PoF }\end{array}$ & Baseline & $\begin{array}{c}\text { Weight } \\
\text { PoF }\end{array}$ \\
\hline$\{50,100\}$ & 0,1713 & $0,1908 *$ & 0,1831 & $0,1922 *$ & 0,3201 & 0,3210 & 0,3324 & 0,3305 \\
\hline$\{15,20\}$ & 0,1713 & $0,3240 *$ & 0,1831 & $0,3262 *$ & 0,3201 & $\mathbf{0 , 4 0 4 9} *$ & 0,3324 & $0,4110 *$ \\
\hline$\{10,50\}$ & 0,1713 & $0,2591 *$ & 0,1831 & $0,2606 *$ & 0,3201 & $0,3751 *$ & 0,3324 & $0,3823 *$ \\
\hline$\{2,7\}$ & 0,1713 & $0,4314 *$ & 0,1831 & $0,4322 *$ & 0,3201 & $0,4024 *$ & 0,3324 & $0,4088 *$ \\
\hline \multicolumn{9}{|c|}{ Valores da MAP para o fator de combinação $\alpha=0,3$} \\
\hline \multirow{3}{*}{ Granul. } & \multicolumn{4}{|c|}{ cReduction } & \multicolumn{4}{|c|}{ DaVI-BEST } \\
\hline & \multicolumn{2}{|c|}{$M A P @ 5$} & \multicolumn{2}{|c|}{$M A P @ 10$} & \multicolumn{2}{|c|}{$M A P @ 5$} & \multicolumn{2}{|c|}{$M A P @ 10$} \\
\hline & Baseline & $\begin{array}{l}\text { cReduc- } \\
\text { tion }\end{array}$ & Baseline & $\begin{array}{c}\text { cReduc- } \\
\text { tion }\end{array}$ & Baseline & $\begin{array}{l}\text { DaVI- } \\
\text { BEST }\end{array}$ & Baseline & $\begin{array}{l}\text { DaVI- } \\
\text { BEST }\end{array}$ \\
\hline$\{50,100\}$ & 0,3089 & 0,3440 & 0,3281 & 0,3527 & 0,3131 & 0,3440 & 0,3254 & 0,3527 \\
\hline$\{15,20\}$ & 0,3089 & $0,3923 *$ & 0,3281 & $0,3987 *$ & 0,3131 & $0,3923 *$ & 0,3254 & $0,3987 *$ \\
\hline$\{10,50\}$ & 0,3089 & 0,3233 & 0,3281 & 0,3272 & 0,3131 & 0,3222 & 0,3254 & 0,3318 \\
\hline$\{2,7\}$ & 0,3089 & 0,3195 & 0,3281 & 0,3291 & 0,3131 & 0,3195 & 0,3254 & 0,3291 \\
\hline \multirow{3}{*}{ Granul. } & \multicolumn{4}{|c|}{ Filter PoF } & \multicolumn{4}{|c|}{ Weight PoF } \\
\hline & \multicolumn{2}{|c|}{$M A P @ 5$} & \multicolumn{2}{|c|}{$M A P @ 10$} & \multicolumn{2}{|c|}{$M A P @ 5$} & \multicolumn{2}{|c|}{$M A P @ 10$} \\
\hline & Baseline & $\begin{array}{c}\text { Filter } \\
\text { PoF }\end{array}$ & Baseline & $\begin{array}{c}\text { Filter } \\
\text { PoF }\end{array}$ & Baseline & $\begin{array}{c}\text { Weight } \\
\text { PoF }\end{array}$ & Baseline & $\begin{array}{c}\text { Weight } \\
\text { PoF }\end{array}$ \\
\hline$\{50,100\}$ & 0,1713 & 0,1840 & 0,1831 & 0,1854 & 0,3201 & 0,3556 & 0,3324 & 0,3639 \\
\hline$\{15,20\}$ & 0,1713 & 0,3066* & 0,1831 & $0,3082 *$ & 0,3201 & $0,4361 *$ & 0,3324 & $0,4420 *$ \\
\hline$\{10,50\}$ & 0,1713 & $0,2589 *$ & 0,1831 & $0,2596 *$ & 0,3201 & $0,3590 *$ & 0,3324 & $0,3667 *$ \\
\hline$\{2,7\}$ & 0,1713 & $0,4187 *$ & 0,1831 & $0,4201 *$ & 0,3201 & $0,3768 *$ & 0,3324 & $0,3849 *$ \\
\hline
\end{tabular}


Tabela B.9: Resultados do Terceiro Experimento da Avaliação Comparando com o Baseline "Metodológico" para os Fatores de Combinação $\alpha=0,5, \alpha=0,7$ e $\alpha=1$

\begin{tabular}{|c|c|c|c|c|c|c|c|c|}
\hline \multicolumn{9}{|c|}{ Valores da MAP para o fator de combinação $\alpha=0,5$} \\
\hline \multirow{3}{*}{ Granul. } & \multicolumn{4}{|c|}{ cReduction } & \multicolumn{4}{|c|}{ DaVI-BEST } \\
\hline & \multicolumn{2}{|c|}{$M A P @ 5$} & \multicolumn{2}{|c|}{$M A P @ 10$} & \multicolumn{2}{|c|}{$M A P @ 5$} & \multicolumn{2}{|c|}{$M A P @ 10$} \\
\hline & Baseline & $\begin{array}{l}\text { cReduc- } \\
\text { tion }\end{array}$ & Baseline & $\begin{array}{l}\text { cReduc- } \\
\text { tion }\end{array}$ & Baseline & $\begin{array}{l}\text { DaVI- } \\
\text { BEST }\end{array}$ & Baseline & $\begin{array}{l}\text { DaVI- } \\
\text { BEST }\end{array}$ \\
\hline$\{50,100\}$ & 0,3089 & 0,3339 & 0,3281 & 0,3424 & 0,3131 & 0,3339 & 0,3254 & 0,3424 \\
\hline$\{15,20\}$ & 0,3089 & $0,4135 *$ & 0,3281 & $0,4189 *$ & 0,3131 & $0,4135 *$ & 0,3254 & $0,3725 *$ \\
\hline$\{10,50\}$ & 0,3089 & 0,3240 & 0,3281 & 0,3322 & 0,3131 & 0,3240 & 0,3254 & 0,3328 \\
\hline$\{2,7\}$ & 0,3089 & 0,3287 & 0,3281 & 0,3374 & 0,3131 & 0,3287 & 0,3254 & 0,3374 \\
\hline \multirow{3}{*}{ Granul. } & \multicolumn{4}{|c|}{ Filter PoF } & \multicolumn{4}{|c|}{ Weight PoF } \\
\hline & \multicolumn{2}{|c|}{$M A P @ 5$} & \multicolumn{2}{|c|}{$M A P @ 10$} & \multicolumn{2}{|c|}{$M A P @ 5$} & \multicolumn{2}{|c|}{$M A P @ 10$} \\
\hline & Baseline & $\begin{array}{c}\text { Filter } \\
\text { PoF }\end{array}$ & Baseline & $\begin{array}{c}\text { Filter } \\
\text { PoF }\end{array}$ & Baseline & $\begin{array}{c}\text { Weight } \\
\text { PoF }\end{array}$ & Baseline & $\begin{array}{c}\text { Weight } \\
\text { PoF }\end{array}$ \\
\hline$\{50,100\}$ & 0,1713 & 0,2125 & 0,1831 & 0,2135 & 0,3201 & 0,3544 & 0,3324 & 0,3628 \\
\hline$\{15,20\}$ & 0,1713 & $0,2801 *$ & 0,1831 & $0,2818 *$ & 0,3201 & $0,4479 *$ & 0,3324 & $0,4525 *$ \\
\hline$\{10,50\}$ & 0,1713 & $0,2466 *$ & 0,1831 & $0,2473 *$ & 0,3201 & 0,3473 & 0,3324 & 0,3556 \\
\hline$\{2,7\}$ & 0,1713 & $0,3965 *$ & 0,1831 & $0,3983 *$ & 0,3201 & $0,3826 *$ & 0,3324 & $0,3898 *$ \\
\hline \multicolumn{9}{|c|}{ Valores da MAP para o fator de combinação $\alpha=0,7$} \\
\hline \multirow{3}{*}{ Granul. } & \multicolumn{4}{|c|}{ cReduction } & \multicolumn{4}{|c|}{ DaVI-BEST } \\
\hline & \multicolumn{2}{|c|}{$M A P @ 5$} & \multicolumn{2}{|c|}{ MAP@10 } & \multicolumn{2}{|c|}{$M A P @ 5$} & $M A$ & Q10 \\
\hline & Baseline & $\begin{array}{c}\text { cReduc- } \\
\text { tion }\end{array}$ & Baseline & $\begin{array}{c}\text { cReduc- } \\
\text { tion }\end{array}$ & Baseline & $\begin{array}{l}\text { DaVI- } \\
\text { BEST }\end{array}$ & Baseline & $\begin{array}{l}\text { DaVI- } \\
\text { BEST }\end{array}$ \\
\hline$\{50,100\}$ & 0,3089 & 0,3251 & 0,3281 & 0,3341 & 0,3131 & 0,3251 & 0,3254 & 0,3341 \\
\hline$\{15,20\}$ & 0,3089 & $0,3733 *$ & 0,3281 & $0,3812 *$ & 0,3131 & $0,3733 *$ & 0,3254 & $0,3812 *$ \\
\hline$\{10,50\}$ & 0,3089 & 0,3161 & 0,3281 & 0,3261 & 0,3131 & 0,3161 & 0,3254 & 0,3261 \\
\hline$\{2,7\}$ & 0,3089 & 0,3384 & 0,3281 & 0,3451 & 0,3131 & 0,3384 & 0,3254 & 0,3451 \\
\hline & & Filt & $\mathrm{PoF}$ & & & Weig & PoF & \\
\hline Granul. & $M$ & @5 & $M A$ & @10 & $M A$ & @5 & $M A$ & a10 \\
\hline & Baseline & $\begin{array}{c}\text { Filter } \\
\text { PoF }\end{array}$ & Baseline & $\begin{array}{c}\text { Filter } \\
\text { PoF }\end{array}$ & Baseline & $\begin{array}{c}\text { Weight } \\
\text { PoF }\end{array}$ & Baseline & $\begin{array}{c}\text { Weight } \\
\text { PoF }\end{array}$ \\
\hline$\{50,100\}$ & 0,1713 & 0,1934 & 0,1831 & 0,1951 & 0,3201 & 0,3436 & 0,4055 & 0,3523 \\
\hline$\{15,20\}$ & 0,1713 & 0,3498* & 0,1831 & $0,3514 *$ & 0,3201 & 0,4048* & 0,3324 & $0,4120 *$ \\
\hline$\{10,50\}$ & 0,1713 & $0,2386 *$ & 0,1831 & $0,2400 *$ & 0,3201 & 0,3528 & 0,3324 & 0,3613 \\
\hline$\{2,7\}$ & 0,1713 & $0,3816 *$ & 0,1831 & $0,3817 *$ & 0,3201 & $0,3925 *$ & 0,3324 & $0,3978 *$ \\
\hline & & Valore & aAP $\mathrm{p}$ & o fator $\mathrm{c}$ & ombinaçã & $\alpha=1$ & & \\
\hline & & $\mathrm{cRe}$ & tion & & & $\mathrm{DaV}$ & BEST & \\
\hline Granul. & $M$ & @5 & $M A$ & @10 & $M A$ & @5 & $M A$ & a10 \\
\hline & Baseline & $\begin{array}{c}\text { cReduc- } \\
\text { tion }\end{array}$ & Baseline & $\begin{array}{c}\text { cReduc- } \\
\text { tion }\end{array}$ & Baseline & $\begin{array}{l}\text { DaVI- } \\
\text { BEST }\end{array}$ & Baseline & $\begin{array}{l}\text { DaVI- } \\
\text { BEST }\end{array}$ \\
\hline$\{50,100\}$ & 0,3089 & 0,3266 & 0,3281 & 0,3360 & 0,3131 & 0,3266 & 0,3254 & 0,3360 \\
\hline$\{15,20\}$ & 0,3089 & $0,3449 *$ & 0,3281 & 0,3525* & 0,3131 & $0,3449 *$ & 0,3254 & $0,3525 *$ \\
\hline$\{10,50\}$ & 0,3089 & 0,3100 & 0,3281 & 0,3172 & 0,3131 & 0,3100 & 0,3254 & 0,3172 \\
\hline$\{2,7\}$ & 0,3089 & 0,3213 & 0,3281 & 0,3304 & 0,3131 & 0,3213 & 0,3254 & 0,3304 \\
\hline & & Filt & $\overline{\mathrm{PoF}}$ & & & Weig & $\mathrm{PoF}$ & \\
\hline Granul. & $M$ & @ & $M A$ & @10 & $M A$ & @5 & $M A$ & @10 \\
\hline & Baseline & $\begin{array}{c}\text { Filter } \\
\text { PoF }\end{array}$ & Baseline & $\begin{array}{c}\text { Filter } \\
\text { PoF }\end{array}$ & Baseline & $\begin{array}{c}\text { Weight } \\
\text { PoF }\end{array}$ & Baseline & $\begin{array}{c}\text { Weight } \\
\text { PoF }\end{array}$ \\
\hline$\{50,100\}$ & 0,1713 & $0,1828 *$ & 0,1831 & 0,1847 & 0,3201 & 0,3400 & 0,3324 & 0,3487 \\
\hline$\{15,20\}$ & 0,1713 & $0,2922 *$ & 0,1831 & $0,2922 *$ & 0,3201 & $0,3709 *$ & 0,3324 & $0,3773 *$ \\
\hline$\{10,50\}$ & 0,1713 & $0,2114 *$ & 0,1831 & $0,2114 *$ & 0,3201 & $0,3378 *$ & 0,3324 & 0,3442 \\
\hline$\{2,7\}$ & 0,1713 & $0,4061 *$ & 0,1831 & $0,4073 *$ & 0,3201 & $0,3724 *$ & 0,3324 & $0,3798 *$ \\
\hline
\end{tabular}


Tabela B.10: Resultados do Quinto Experimento da Avaliação Comparando com o Baseline "Metodológico" para os Fatores de Combinação $\alpha=0$ e $\alpha=0,3$

\begin{tabular}{|c|c|c|c|c|c|c|c|c|}
\hline \multicolumn{9}{|c|}{ Valores da MAP para o fator de combinação $\alpha=0$} \\
\hline \multirow{3}{*}{ Granul. } & \multicolumn{4}{|c|}{ cReduction } & \multicolumn{4}{|c|}{ DaVI-BEST } \\
\hline & \multicolumn{2}{|c|}{$M A P @ 5$} & \multicolumn{2}{|c|}{ MAP@10 } & \multicolumn{2}{|c|}{ MAP@5 } & \multicolumn{2}{|c|}{$M A P @ 10$} \\
\hline & Baseline & $\begin{array}{c}\text { cReduc- } \\
\text { tion }\end{array}$ & Baseline & $\begin{array}{l}\text { cReduc- } \\
\text { tion }\end{array}$ & Baseline & $\begin{array}{l}\text { DaVI- } \\
\text { BEST }\end{array}$ & Baseline & $\begin{array}{l}\text { DaVI- } \\
\text { BEST }\end{array}$ \\
\hline$\{50,100\}$ & 0,0169 & 0,0113 & 0,0175 & 0,0116 & 0,0169 & 0,0113 & 0,0169 & 0,0116 \\
\hline$\{15,20\}$ & 0,0169 & 0,0176 & 0,0175 & 0,0182 & 0,0169 & 0,0176 & 0,0169 & 0,0182 \\
\hline$\{10,50\}$ & 0,0169 & 0,0119 & 0,0175 & 0,0120 & 0,0169 & 0,0119 & 0,0169 & 0,0116 \\
\hline$\{2,7\}$ & 0,0169 & $0,0184 *$ & 0,0175 & $0,0184 *$ & 0,0169 & 0,0198 & 0,0169 & 0,0217 \\
\hline \multirow{3}{*}{ Granul. } & \multicolumn{4}{|c|}{ Filter PoF } & \multicolumn{4}{|c|}{ Weight PoF } \\
\hline & \multicolumn{2}{|c|}{$M A P @ 5$} & \multicolumn{2}{|c|}{$M A P @ 10$} & \multicolumn{2}{|c|}{$M A P @ 5$} & \multicolumn{2}{|c|}{$M A P @ 10$} \\
\hline & Baseline & $\begin{array}{c}\text { Filter } \\
\text { PoF }\end{array}$ & Baseline & $\begin{array}{c}\text { Filter } \\
\text { PoF }\end{array}$ & Baseline & $\begin{array}{c}\text { Weight } \\
\text { PoF }\end{array}$ & Baseline & $\begin{array}{l}\text { Weight } \\
\text { PoF }\end{array}$ \\
\hline$\{50,100\}$ & 0,0085 & 0,0022 & 0,0086 & 0,0027 & 0,0167 & 0,0113 & 0,0168 & 0,0116 \\
\hline$\{15,20\}$ & 0,0085 & 0,0060 & 0,0086 & 0,0066 & 0,0167 & 0,0187 & 0,0168 & 0,0193 \\
\hline$\{10,50\}$ & 0,0085 & 0,0030 & 0,0086 & 0,0031 & 0,0167 & 0,0122 & 0,0168 & 0,0124 \\
\hline$\{2,7\}$ & 0,0085 & $0,0180 *$ & 0,0086 & $0,0181 *$ & 0,0167 & 0,0194 & 0,0168 & 0,0194 \\
\hline \multicolumn{9}{|c|}{ Valores da MAP para o fator de combinação $\alpha=0,3$} \\
\hline \multirow{3}{*}{ Granul. } & \multicolumn{4}{|c|}{ cReduction } & \multicolumn{4}{|c|}{ DaVI-BEST } \\
\hline & \multicolumn{2}{|c|}{$M A P @ 5$} & \multicolumn{2}{|c|}{$M A P @ 10$} & \multicolumn{2}{|c|}{$M A P @ 5$} & \multicolumn{2}{|c|}{$M A P @ 10$} \\
\hline & Baseline & $\begin{array}{l}\text { cReduc- } \\
\text { tion }\end{array}$ & Baseline & $\begin{array}{l}\text { cReduc- } \\
\text { tion }\end{array}$ & Baseline & $\begin{array}{l}\text { DaVI- } \\
\text { BEST }\end{array}$ & Baseline & $\begin{array}{l}\text { DaVI- } \\
\text { BEST }\end{array}$ \\
\hline$\{50,100\}$ & 0,0169 & 0,0195 & 0,0175 & 0,0209 & 0,0169 & 0,0195 & 0,0169 & 0,0209 \\
\hline$\{15,20\}$ & 0,0169 & 0,0077 & 0,0175 & 0,0089 & 0,0169 & 0,0096 & 0,0169 & 0,0105 \\
\hline$\{10,50\}$ & 0,0169 & 0,0178 & 0,0175 & 0,0181 & 0,0169 & 0,0178 & 0,0169 & 0,0181 \\
\hline$\{2,7\}$ & 0,0169 & 0,0189 & 0,0175 & 0,0190 & 0,0169 & 0,0189 & 0,0169 & 0,0190 \\
\hline \multirow{3}{*}{ Granul. } & \multicolumn{4}{|c|}{ Filter PoF } & \multicolumn{4}{|c|}{ Weight PoF } \\
\hline & \multicolumn{2}{|c|}{ MAP@5 } & \multicolumn{2}{|c|}{ MAP@10 } & \multicolumn{2}{|c|}{$M A P @ 5$} & \multicolumn{2}{|c|}{ MAP@10 } \\
\hline & Baseline & $\begin{array}{c}\text { Filter } \\
\text { PoF }\end{array}$ & Baseline & $\begin{array}{c}\text { Filter } \\
\text { PoF }\end{array}$ & Baseline & $\begin{array}{c}\text { Weight } \\
\text { PoF }\end{array}$ & Baseline & $\begin{array}{l}\text { Weight } \\
\text { PoF }\end{array}$ \\
\hline$\{50,100\}$ & 0,0085 & 0,0074 & 0,0086 & 0,0089 & 0,0167 & 0,0195 & 0,0168 & 0,0209 \\
\hline$\{15,20\}$ & 0,0085 & 0,0019 & 0,0086 & 0,0035 & 0,0167 & 0,0107 & 0,0168 & 0,0117 \\
\hline$\{10,50\}$ & 0,0085 & 0,0027 & 0,0086 & 0,0030 & 0,0167 & 0,0183 & 0,0168 & 0,0185 \\
\hline$\{2,7\}$ & 0,0085 & $0,0228 *$ & 0,0086 & $0,0229 *$ & 0,0167 & 0,0196 & 0,0168 & 0,0197 \\
\hline
\end{tabular}


Tabela B.11: Resultados do Quinto Experimento da Avaliação Comparando com o Baseline "Metodológico" para os Fatores de Combinação $\alpha=0,5, \alpha=0,7$ e $\alpha=1$

\begin{tabular}{|c|c|c|c|c|c|c|c|c|}
\hline \multicolumn{9}{|c|}{ Valores da MAP para o fator de combinação $\alpha=0,5$} \\
\hline \multirow{3}{*}{ Granul. } & \multicolumn{4}{|c|}{ cReduction } & \multicolumn{4}{|c|}{ DaVI-BEST } \\
\hline & \multicolumn{2}{|c|}{$M A P @ 5$} & \multicolumn{2}{|c|}{$M A P @ 10$} & \multicolumn{2}{|c|}{$M A P @ 5$} & \multicolumn{2}{|c|}{$M A P @ 10$} \\
\hline & Baseline & $\begin{array}{l}\text { cReduc- } \\
\text { tion }\end{array}$ & Baseline & $\begin{array}{l}\text { cReduc- } \\
\text { tion }\end{array}$ & Baseline & $\begin{array}{l}\text { DaVI- } \\
\text { BEST }\end{array}$ & Baseline & $\begin{array}{l}\text { DaVI- } \\
\text { BEST }\end{array}$ \\
\hline$\{50,100\}$ & 0,0169 & 0,0085 & 0,0175 & 0,0090 & 0,0169 & 0,0085 & 0,0169 & 0,0090 \\
\hline$\{15,20\}$ & 0,0169 & 0,0048 & 0,0175 & 0,0056 & 0,0169 & 0,0048 & 0,0169 & 0,0056 \\
\hline$\{10,50\}$ & 0,0169 & 0,0079 & 0,0175 & 0,0081 & 0,0169 & 0,0079 & 0,0169 & 0,0081 \\
\hline$\{2,7\}$ & 0,0169 & 0,0146 & 0,0175 & 0,0150 & 0,0169 & 0,0163 & 0,0169 & 0,0162 \\
\hline \multirow{3}{*}{ Granul. } & \multicolumn{4}{|c|}{ Filter PoF } & \multicolumn{4}{|c|}{ Weight PoF } \\
\hline & \multicolumn{2}{|c|}{$M A P @ 5$} & \multicolumn{2}{|c|}{$M A P @ 10$} & \multicolumn{2}{|c|}{$M A P @ 5$} & \multicolumn{2}{|c|}{$M A P @ 10$} \\
\hline & Baseline & $\begin{array}{c}\text { Filter } \\
\text { PoF }\end{array}$ & Baseline & $\begin{array}{c}\text { Filter } \\
\text { PoF }\end{array}$ & Baseline & $\begin{array}{c}\text { Weight } \\
\text { PoF }\end{array}$ & Baseline & $\begin{array}{c}\text { Weight } \\
\text { PoF }\end{array}$ \\
\hline$\{50,100\}$ & 0,0085 & 0,0061 & 0,0086 & 0,0065 & 0,0167 & 0,0090 & 0,0168 & 0,0096 \\
\hline$\{15,20\}$ & 0,0085 & 0,0011 & 0,0086 & 0,0019 & 0,0167 & 0,0048 & 0,0168 & 0,0056 \\
\hline$\{10,50\}$ & 0,0085 & 0,0039 & 0,0086 & 0,0042 & 0,0167 & 0,0083 & 0,0168 & 0,0085 \\
\hline$\{2,7\}$ & 0,0085 & 0,0118 & 0,0086 & 0,0122 & 0,0167 & 0,0160 & 0,0168 & 0,0163 \\
\hline \multicolumn{9}{|c|}{ Valores da MAP para o fator de combinação $\alpha=0,7$} \\
\hline \multirow{3}{*}{ Granul. } & \multicolumn{4}{|c|}{ cReduction } & \multicolumn{4}{|c|}{ DaVI-BEST } \\
\hline & \multicolumn{2}{|c|}{$M A P @ 5$} & \multicolumn{2}{|c|}{$M A P @ 10$} & \multicolumn{2}{|c|}{$M A P @ 5$} & $M A$ & $\$ 10$ \\
\hline & Baseline & $\begin{array}{l}\text { cReduc- } \\
\text { tion }\end{array}$ & Baseline & $\begin{array}{l}\text { cReduc- } \\
\text { tion }\end{array}$ & Baseline & $\begin{array}{l}\text { DaVI- } \\
\text { BEST }\end{array}$ & Baseline & $\begin{array}{l}\text { DaVI- } \\
\text { BEST }\end{array}$ \\
\hline$\{50,100\}$ & 0,0169 & 0,0121 & 0,0175 & 0,0127 & 0,0169 & 0,0121 & 0,0169 & 0,0127 \\
\hline$\{15,20\}$ & 0,0169 & 0,0173 & 0,0175 & 0,0176 & 0,0169 & 0,0143 & 0,0169 & 0,0152 \\
\hline$\{10,50\}$ & 0,0169 & 0,0129 & 0,0175 & 0,0131 & 0,0169 & 0,0129 & 0,0169 & 0,0131 \\
\hline$\{2,7\}$ & 0,0169 & 0,0164 & 0,0175 & 0,0167 & 0,0169 & 0,0164 & 0,0169 & 0,0167 \\
\hline & & Filt & $\mathrm{PoF}$ & & & Wei & PoF & \\
\hline Granul. & & @ @5 & $M A$ & @10 & $M A$ & & $M A$ & ఏ10 \\
\hline & Baseline & $\begin{array}{c}\text { Filter } \\
\text { PoF }\end{array}$ & Baseline & $\begin{array}{c}\text { Filter } \\
\text { PoF }\end{array}$ & Baseline & $\begin{array}{c}\text { Weight } \\
\text { PoF }\end{array}$ & Baseline & $\begin{array}{c}\text { Weight } \\
\text { PoF }\end{array}$ \\
\hline$\{50,100\}$ & 0,0085 & 0,0007 & 0,0086 & 0,0016 & 0,0167 & 0,0124 & 0,0168 & 0,0130 \\
\hline$\{15,20\}$ & 0,0085 & 0,0021 & 0,0086 & 0,0027 & 0,0167 & 0,0177 & 0,0168 & 0,0180 \\
\hline$\{10,50\}$ & 0,0085 & 0,0010 & 0,0086 & 0,0013 & 0,0167 & 0,0139 & 0,0168 & 0,0142 \\
\hline$\{2,7\}$ & 0,0085 & $0,0169 *$ & 0,0086 & $0,0172 *$ & 0,0167 & 0,0171 & 0,0168 & 0,0173 \\
\hline & & Valore & a MAP $\mathrm{p}$ & o fator $\mathrm{c}$ & ombinaçã & $=1$ & & \\
\hline & & $\mathrm{cRe}$ & tion & & & $\mathrm{DaV}$ & BEST & \\
\hline Granul. & & @ 5 & $M A$ & @10 & $M A$ & & $M A$ & $\$ 10$ \\
\hline & Baseline & $\begin{array}{l}\text { cReduc- } \\
\text { tion }\end{array}$ & Baseline & $\begin{array}{l}\text { cReduc- } \\
\text { tion }\end{array}$ & Baseline & $\begin{array}{l}\text { DaVI- } \\
\text { BEST }\end{array}$ & Baseline & $\begin{array}{l}\text { DaVI- } \\
\text { BEST }\end{array}$ \\
\hline$\{50,100\}$ & 0,0169 & 0,0139 & 0,0175 & 0,0143 & 0,0169 & 0,0139 & 0,0169 & 0,0143 \\
\hline$\{15,20\}$ & 0,0169 & 0,0161 & 0,0175 & 0,0162 & 0,0169 & 0,0161 & 0,0169 & 0,0162 \\
\hline$\{10,50\}$ & 0,0169 & 0,0139 & 0,0175 & 0,0141 & 0,0169 & 0,0139 & 0,0169 & 0,0141 \\
\hline$\{2,7\}$ & 0,0169 & 0,0131 & 0,0175 & 0,0132 & 0,0169 & 0,0131 & 0,0169 & 0,0132 \\
\hline & & Filt & $\mathrm{PoF}$ & & & Wei & PoF & \\
\hline Granul. & & D@5 & $M A$ & @10 & $M A$ & & $M A$ & $\$ 10$ \\
\hline & Baseline & $\begin{array}{c}\text { Filter } \\
\text { PoF }\end{array}$ & Baseline & $\begin{array}{c}\text { Filter } \\
\text { PoF }\end{array}$ & Baseline & $\begin{array}{c}\text { Weight } \\
\text { PoF }\end{array}$ & Baseline & $\begin{array}{c}\text { Weight } \\
\text { PoF }\end{array}$ \\
\hline$\{50,100\}$ & 0,0085 & 0,0019 & 0,0086 & 0,0020 & 0,0167 & 0,0142 & 0,0168 & 0,0146 \\
\hline$\{15,20\}$ & 0,0085 & 0,0006 & 0,0086 & 0,0006 & 0,0167 & 0,0170 & 0,0168 & 0,0170 \\
\hline$\{10,50\}$ & 0,0085 & 0,0018 & 0,0086 & 0,0019 & 0,0167 & 0,0141 & 0,0168 & 0,0143 \\
\hline$\{2,7\}$ & 0,0085 & $0,0151 *$ & 0,0086 & $0,0152 *$ & 0,0167 & 0,0142 & 0,0168 & 0,0143 \\
\hline
\end{tabular}


Tabela B.12: Resultados do Sexto Experimento da Avaliação Comparando com o Baseline "Metodológico" para os Fatores de Combinação $\alpha=0$ e $\alpha=0,3$

\begin{tabular}{|c|c|c|c|c|c|c|c|c|}
\hline \multicolumn{9}{|c|}{ Valores da MAP para o fator de combinação $\alpha=0$} \\
\hline \multirow{3}{*}{ Granul. } & \multicolumn{4}{|c|}{ cReduction } & \multicolumn{4}{|c|}{ DaVI-BEST } \\
\hline & \multicolumn{2}{|c|}{$M A P @ 5$} & \multicolumn{2}{|c|}{$M A P @ 10$} & \multicolumn{2}{|c|}{$M A P @ 5$} & \multicolumn{2}{|c|}{$M A P @ 10$} \\
\hline & Baseline & $\begin{array}{l}\text { cReduc- } \\
\text { tion }\end{array}$ & Baseline & $\begin{array}{c}\text { cReduc- } \\
\text { tion }\end{array}$ & Baseline & $\begin{array}{l}\text { DaVI- } \\
\text { BEST }\end{array}$ & Baseline & $\begin{array}{l}\text { DaVI- } \\
\text { BEST }\end{array}$ \\
\hline$\{50,100\}$ & 0,0157 & 0,0113 & 0,0163 & 0,0116 & 0,0163 & 0,0113 & 0,0164 & 0,0116 \\
\hline$\{15,20\}$ & 0,0157 & 0,0176 & 0,0163 & 0,0182 & 0,0163 & 0,0176 & 0,0164 & 0,0182 \\
\hline$\{10,50\}$ & 0,0157 & 0,0119 & 0,0163 & 0,0120 & 0,0163 & 0,0119 & 0,0164 & 0,0116 \\
\hline$\{2,7\}$ & 0,0157 & 0,0184 & 0,0163 & 0,0184 & 0,0163 & 0,0200 & 0,0164 & 0,0217 \\
\hline \multirow{3}{*}{ Granul. } & \multicolumn{4}{|c|}{ Filter PoF } & \multicolumn{4}{|c|}{ Weight PoF } \\
\hline & \multicolumn{2}{|c|}{$M A P @ 5$} & \multicolumn{2}{|c|}{$M A P @ 10$} & \multicolumn{2}{|c|}{$M A P @ 5$} & \multicolumn{2}{|c|}{$M A P @ 10$} \\
\hline & Baseline & $\begin{array}{c}\text { Filter } \\
\text { PoF }\end{array}$ & Baseline & $\begin{array}{c}\text { Filter } \\
\text { PoF }\end{array}$ & Baseline & $\begin{array}{l}\text { Weight } \\
\text { PoF }\end{array}$ & Baseline & $\begin{array}{l}\text { Weight } \\
\text { PoF }\end{array}$ \\
\hline$\{50,100\}$ & 0,0077 & 0,0022 & 0,0078 & 0,0027 & 0,0161 & 0,0113 & 0,0163 & 0,0116 \\
\hline$\{15,20\}$ & 0,0077 & 0,0060 & 0,0078 & 0,0066 & 0,0161 & 0,0187 & 0,0163 & 0,0193 \\
\hline$\{10,50\}$ & 0,0077 & 0,0030 & 0,0078 & 0,0031 & 0,0161 & 0,0122 & 0,0163 & 0,0124 \\
\hline$\{2,7\}$ & 0,0077 & $0,0180 *$ & 0,0078 & $0,0181 *$ & 0,0161 & 0,0194 & 0,0163 & 0,0194 \\
\hline \multicolumn{9}{|c|}{ Valores da MAP para o fator de combinação $\alpha=0,3$} \\
\hline \multirow{3}{*}{ Granul. } & \multicolumn{4}{|c|}{ cReduction } & \multicolumn{4}{|c|}{ DaVI-BEST } \\
\hline & \multicolumn{2}{|c|}{$M A P @ 5$} & \multicolumn{2}{|c|}{$M A P @ 10$} & \multicolumn{2}{|c|}{$M A P @ 5$} & \multicolumn{2}{|c|}{$M A P @ 10$} \\
\hline & Baseline & $\begin{array}{l}\text { cReduc- } \\
\text { tion }\end{array}$ & Baseline & $\begin{array}{l}\text { cReduc- } \\
\text { tion }\end{array}$ & Baseline & $\begin{array}{l}\text { DaVI- } \\
\text { BEST }\end{array}$ & Baseline & $\begin{array}{l}\text { DaVI- } \\
\text { BEST }\end{array}$ \\
\hline$\{50,100\}$ & 0,0157 & 0,0195 & 0,0163 & 0,0209 & 0,0163 & 0,0195 & 0,0164 & 0,0209 \\
\hline$\{15,20\}$ & 0,0157 & 0,0077 & 0,0163 & 0,0089 & 0,0163 & 0,0096 & 0,0164 & 0,0105 \\
\hline$\{10,50\}$ & 0,0157 & 0,0178 & 0,0163 & 0,0181 & 0,0163 & 0,0178 & 0,0164 & 0,0181 \\
\hline$\{2,7\}$ & 0,0157 & 0,0189 & 0,0163 & 0,0190 & 0,0163 & 0,0189 & 0,0164 & 0,0190 \\
\hline \multirow{3}{*}{ Granul. } & \multicolumn{4}{|c|}{ Filter PoF } & \multicolumn{4}{|c|}{ Weight PoF } \\
\hline & \multicolumn{2}{|c|}{$M A P @ 5$} & \multicolumn{2}{|c|}{$M A P @ 10$} & \multicolumn{2}{|c|}{$M A P @ 5$} & \multicolumn{2}{|c|}{$M A P @ 10$} \\
\hline & Baseline & $\begin{array}{c}\text { Filter } \\
\text { PoF }\end{array}$ & Baseline & $\begin{array}{c}\text { Filter } \\
\text { PoF }\end{array}$ & Baseline & $\begin{array}{c}\text { Weight } \\
\text { PoF }\end{array}$ & Baseline & $\begin{array}{c}\text { Weight } \\
\text { PoF }\end{array}$ \\
\hline$\{50,100\}$ & 0,0077 & 0,0074 & 0,0078 & 0,0089 & 0,0161 & 0,0195 & 0,0163 & 0,0209 \\
\hline$\{15,20\}$ & 0,0077 & 0,0019 & 0,0078 & 0,0035 & 0,0161 & 0,0107 & 0,0163 & 0,0117 \\
\hline$\{10,50\}$ & 0,0077 & 0,0027 & 0,0078 & 0,0030 & 0,0161 & 0,0183 & 0,0163 & 0,0185 \\
\hline$\{2,7\}$ & 0,0077 & $0,0228 *$ & 0,0078 & $0,0229 *$ & 0,0161 & 0,0196 & 0,0163 & 0,0197 \\
\hline
\end{tabular}


Tabela B.13: Resultados do Sexto Experimento da Avaliação Comparando com o Baseline "Metodológico" para os Fatores de Combinação $\alpha=0,5, \alpha=0,7$ e $\alpha=1$

\begin{tabular}{|c|c|c|c|c|c|c|c|c|}
\hline \multicolumn{9}{|c|}{ Valores da MAP para o fator de combinação $\alpha=0,5$} \\
\hline \multirow{3}{*}{ Granul. } & \multicolumn{4}{|c|}{ cReduction } & \multicolumn{4}{|c|}{ DaVI-BEST } \\
\hline & \multicolumn{2}{|c|}{$M A P @ 5$} & \multicolumn{2}{|c|}{$M A P @ 10$} & \multicolumn{2}{|c|}{$M A P @ 5$} & \multicolumn{2}{|c|}{$M A P @ 10$} \\
\hline & Baseline & $\begin{array}{c}\text { cReduc- } \\
\text { tion }\end{array}$ & Baseline & $\begin{array}{c}\text { cReduc- } \\
\text { tion }\end{array}$ & Baseline & $\begin{array}{l}\text { DaVI- } \\
\text { BEST }\end{array}$ & Baseline & $\begin{array}{l}\text { DaVI- } \\
\text { BEST }\end{array}$ \\
\hline$\{50,100\}$ & 0,0157 & 0,0085 & 0,0163 & 0,0090 & 0,0163 & 0,0085 & 0,0164 & 0,0090 \\
\hline$\{15,20\}$ & 0,0157 & 0,0048 & 0,0163 & 0,0056 & 0,0163 & 0,0048 & 0,0164 & 0,0056 \\
\hline$\{10,50\}$ & 0,0157 & 0,0079 & 0,0163 & 0,0081 & 0,0163 & 0,0079 & 0,0164 & 0,0081 \\
\hline$\{2,7\}$ & 0,0157 & 0,0146 & 0,0163 & 0,0150 & 0,0163 & 0,0163 & 0,0164 & 0,0162 \\
\hline \multirow{3}{*}{ Granul. } & \multicolumn{4}{|c|}{ Filter PoF } & \multicolumn{4}{|c|}{ Weight PoF } \\
\hline & \multicolumn{2}{|c|}{$M A P @ 5$} & \multicolumn{2}{|c|}{$M A P @ 10$} & \multicolumn{2}{|c|}{$M A P @ 5$} & \multicolumn{2}{|c|}{$M A P @ 10$} \\
\hline & Baseline & $\begin{array}{c}\text { Filter } \\
\text { PoF }\end{array}$ & Baseline & $\begin{array}{c}\text { Filter } \\
\text { PoF }\end{array}$ & Baseline & $\begin{array}{c}\text { Weight } \\
\text { PoF }\end{array}$ & Baseline & $\begin{array}{c}\text { Weight } \\
\text { PoF }\end{array}$ \\
\hline$\{50,100\}$ & 0,0077 & 0,0061 & 0,0078 & 0,0065 & 0,0161 & 0,0090 & 0,0163 & 0,0096 \\
\hline$\{15,20\}$ & 0,0077 & 0,0011 & 0,0078 & 0,0019 & 0,0161 & 0,0048 & 0,0163 & 0,0056 \\
\hline$\{10,50\}$ & 0,0077 & 0,0039 & 0,0078 & 0,0042 & 0,0161 & 0,0083 & 0,0163 & 0,0085 \\
\hline$\{2,7\}$ & 0,0077 & 0,0118 & 0,0078 & 0,0122 & 0,0161 & 0,0160 & 0,0163 & 0,0163 \\
\hline \multicolumn{9}{|c|}{ Valores da MAP para o fator de combinação $\alpha=0,7$} \\
\hline \multirow{3}{*}{ Granul. } & \multicolumn{4}{|c|}{ cReduction } & \multicolumn{4}{|c|}{ DaVI-BEST } \\
\hline & \multicolumn{2}{|c|}{$M A P @ 5$} & \multicolumn{2}{|c|}{$M A P @ 10$} & \multicolumn{2}{|c|}{$M A P @ 5$} & $M A$ & a10 \\
\hline & Baseline & $\begin{array}{l}\text { cReduc- } \\
\text { tion }\end{array}$ & Baseline & $\begin{array}{l}\text { cReduc- } \\
\text { tion }\end{array}$ & Baseline & $\begin{array}{l}\text { DaVI- } \\
\text { BEST }\end{array}$ & Baseline & $\begin{array}{l}\text { DaVI- } \\
\text { BEST }\end{array}$ \\
\hline$\{50,100\}$ & 0,0157 & 0,0121 & 0,0163 & 0,0127 & 0,0163 & 0,0121 & 0,0164 & 0,0127 \\
\hline$\{15,20\}$ & 0,0157 & 0,0173 & 0,0163 & 0,0176 & 0,0163 & 0,0143 & 0,0164 & 0,0152 \\
\hline$\{10,50\}$ & 0,0157 & 0,0129 & 0,0163 & 0,0131 & 0,0163 & 0,0129 & 0,0164 & 0,0131 \\
\hline$\{2,7\}$ & 0,0157 & 0,0164 & 0,0163 & 0,0167 & 0,0163 & 0,0164 & 0,0164 & 0,0167 \\
\hline & & Filt & $\mathrm{PoF}$ & & & Weig & PoF & \\
\hline Granul. & $M$ & $@ 5$ & $M A$ & @10 & $M A$ & @5 & $M A$ & a10 \\
\hline & Baseline & $\begin{array}{c}\text { Filter } \\
\text { PoF }\end{array}$ & Baseline & $\begin{array}{c}\text { Filter } \\
\text { PoF }\end{array}$ & Baseline & $\begin{array}{c}\text { Weight } \\
\text { PoF }\end{array}$ & Baseline & $\begin{array}{c}\text { Weight } \\
\text { PoF }\end{array}$ \\
\hline$\{50,100\}$ & 0,0077 & 0,0007 & 0,0078 & 0,0016 & 0,0161 & 0,0124 & 0,0163 & 0,0130 \\
\hline$\{15,20\}$ & 0,0077 & 0,0021 & 0,0078 & 0,0027 & 0,0161 & 0,0177 & 0,0163 & 0,0180 \\
\hline$\{10,50\}$ & 0,0077 & 0,0010 & 0,0078 & 0,0013 & 0,0161 & 0,0139 & 0,0163 & 0,0142 \\
\hline$\{2,7\}$ & 0,0077 & $0,0169 *$ & 0,0078 & $0,0172 *$ & 0,0161 & 0,0171 & 0,0163 & 0,0173 \\
\hline & & Valore & a MAP p & o fator $\mathrm{d}$ & ombinaçã & $\alpha=1$ & & \\
\hline & & $M$ & @5 & & & $M A$ & @10 & \\
\hline Granul. & $M$ & $@ 5$ & $M A$ & @10 & $M A$ & @5 & $M A$ & a10 \\
\hline & Baseline & $\begin{array}{l}\text { cReduc- } \\
\text { tion }\end{array}$ & Baseline & $\begin{array}{l}\text { cReduc- } \\
\text { tion }\end{array}$ & Baseline & $\begin{array}{l}\text { DaVI- } \\
\text { BEST }\end{array}$ & Baseline & $\begin{array}{l}\text { DaVI- } \\
\text { BEST }\end{array}$ \\
\hline$\{50,100\}$ & 0,0157 & 0,0139 & 0,0163 & 0,0143 & 0,0163 & 0,0139 & 0,0164 & 0,0143 \\
\hline$\{15,20\}$ & 0,0157 & 0,0161 & 0,0163 & 0,0162 & 0,0163 & 0,0161 & 0,0164 & 0,0162 \\
\hline$\{10,50\}$ & 0,0157 & 0,0139 & 0,0163 & 0,0141 & 0,0163 & 0,0139 & 0,0164 & 0,0141 \\
\hline$\{2,7\}$ & 0,0157 & 0,0131 & 0,0163 & 0,0132 & 0,0163 & 0,0131 & 0,0164 & 0,0132 \\
\hline & & Filt & PoF & & & Weig & PoF & \\
\hline Granul. & $M$ & $@ 5$ & $M A$ & @10 & $M A$ & @5 & $M A$ & a 10 \\
\hline & Baseline & $\begin{array}{c}\text { Filter } \\
\text { PoF }\end{array}$ & Baseline & $\begin{array}{c}\text { Filter } \\
\text { PoF }\end{array}$ & Baseline & $\begin{array}{l}\text { Weight } \\
\text { PoF }\end{array}$ & Baseline & $\begin{array}{c}\text { Weight } \\
\text { PoF }\end{array}$ \\
\hline$\{50,100\}$ & 0,0077 & 0,0019 & 0,0078 & 0,0020 & 0,0161 & 0,0142 & 0,0163 & 0,0146 \\
\hline$\{15,20\}$ & 0,0077 & 0,0006 & 0,0078 & 0,0006 & 0,0161 & 0,0170 & 0,0163 & 0,0170 \\
\hline$\{10,50\}$ & 0,0077 & 0,0018 & 0,0078 & 0,0019 & 0,0161 & 0,0141 & 0,0163 & 0,0143 \\
\hline$\{2,7\}$ & 0,0077 & $0,0151 *$ & 0,0078 & $0,0152 *$ & 0,0161 & 0,0142 & 0,0163 & 0,0143 \\
\hline
\end{tabular}


Tabela B.14: Resultados do Sétimo Experimento da Avaliação Comparando com o Baseline "Metodológico" para os Fatores de Combinação $\alpha=0$ e $\alpha=0,3$

\begin{tabular}{|c|c|c|c|c|c|c|c|c|}
\hline \multicolumn{9}{|c|}{ Valores da MAP para o fator de combinação $\alpha=0$} \\
\hline \multirow{3}{*}{ Granul. } & \multicolumn{4}{|c|}{ cReduction } & \multicolumn{4}{|c|}{ DaVI-BEST } \\
\hline & \multicolumn{2}{|c|}{$M A P @ 5$} & \multicolumn{2}{|c|}{ MAP@10 } & \multicolumn{2}{|c|}{ MAP@5 } & \multicolumn{2}{|c|}{$M A P @ 10$} \\
\hline & Baseline & $\begin{array}{l}\text { cReduc- } \\
\text { tion }\end{array}$ & Baseline & $\begin{array}{l}\text { cReduc- } \\
\text { tion }\end{array}$ & Baseline & $\begin{array}{l}\text { DaVI- } \\
\text { BEST }\end{array}$ & Baseline & $\begin{array}{l}\text { DaVI- } \\
\text { BEST }\end{array}$ \\
\hline$\{50,100\}$ & 0,0169 & 0,0234 & 0,0175 & 0,0236 & 0,0169 & 0,0234 & 0,0169 & 0,0236 \\
\hline$\{15,20\}$ & 0,0169 & 0,0059 & 0,0175 & 0,0064 & 0,0169 & 0,059 & 0,0169 & 0,0094 \\
\hline$\{10,50\}$ & 0,0169 & 0,0146 & 0,0175 & 0,0147 & 0,0169 & 0,0146 & 0,0169 & 0,0147 \\
\hline$\{2,7\}$ & 0,0169 & 0,0148 & 0,0175 & 0,0149 & 0,0169 & 0,0182 & 0,0169 & 0,0187 \\
\hline \multirow{3}{*}{ Granul. } & \multicolumn{4}{|c|}{ Filter PoF } & \multicolumn{4}{|c|}{ Weight PoF } \\
\hline & \multicolumn{2}{|c|}{ MAP@5 } & \multicolumn{2}{|c|}{$M A P @ 10$} & \multicolumn{2}{|c|}{$M A P @ 5$} & \multicolumn{2}{|c|}{$M A P @ 10$} \\
\hline & Baseline & $\begin{array}{c}\text { Filter } \\
\text { PoF }\end{array}$ & Baseline & $\begin{array}{c}\text { Filter } \\
\text { PoF }\end{array}$ & Baseline & $\begin{array}{c}\text { Weight } \\
\text { PoF }\end{array}$ & Baseline & $\begin{array}{l}\text { Weight } \\
\text { PoF }\end{array}$ \\
\hline$\{50,100\}$ & 0,0085 & 0,0059 & 0,0086 & 0,0062 & 0,0167 & 0,0234 & 0,0163 & 0,0236 \\
\hline$\{15,20\}$ & 0,0085 & 0,0041 & 0,0086 & 0,0047 & 0,0167 & 0,0059 & 0,0168 & 0,0064 \\
\hline$\{10,50\}$ & 0,0085 & 0,0045 & 0,0086 & 0,0046 & 0,0167 & 0,0146 & 0,0168 & 0,0147 \\
\hline$\{2,7\}$ & 0,0085 & 0,0132 & 0,0086 & 0,0133 & 0,0162 & 0,0167 & 0,0168 & 0,0152 \\
\hline \multicolumn{9}{|c|}{ Valores da MAP para o fator de combinação $\alpha=0,3$} \\
\hline \multirow{3}{*}{ Granul. } & \multicolumn{4}{|c|}{ cReduction } & \multirow{2}{*}{\multicolumn{4}{|c|}{\begin{tabular}{c}
\multicolumn{2}{c|}{ DaVI-BEST } \\
$M A P @ 5$
\end{tabular}}} \\
\hline & \multicolumn{2}{|c|}{$M A P @ 5$} & \multicolumn{2}{|c|}{$M A P @ 10$} & & & & $M A P @ 10$ \\
\hline & Baseline & $\begin{array}{l}\text { cReduc- } \\
\text { tion }\end{array}$ & Baseline & $\begin{array}{l}\text { cReduc- } \\
\text { tion }\end{array}$ & Baseline & $\begin{array}{l}\text { DaVI- } \\
\text { BEST }\end{array}$ & Baseline & $\begin{array}{l}\text { DaVI- } \\
\text { BEST }\end{array}$ \\
\hline$\{50,100\}$ & 0,0169 & 0,0289 & 0,0175 & 0,0292 & 0,0169 & 0,0289 & 0,0169 & 0,0292 \\
\hline$\{15,20\}$ & 0,0169 & 0,0214 & 0,0175 & 0,0216 & 0,0169 & 0,0214 & 0,0169 & 0,0191 \\
\hline$\{10,50\}$ & 0,0169 & 0,0160 & 0,0175 & 0,0162 & 0,0169 & 0,0160 & 0,0169 & 0,0132 \\
\hline$\{2,7\}$ & 0,0169 & 0,0182 & 0,0175 & 0,0183 & 0,0169 & 0,0233 & 0,0169 & 0,0215 \\
\hline \multirow{3}{*}{ Granul. } & \multicolumn{4}{|c|}{ Filter PoF } & \multicolumn{4}{|c|}{ Weight PoF } \\
\hline & \multicolumn{2}{|c|}{ MAP@5 } & \multicolumn{2}{|c|}{ MAP@10 } & \multicolumn{2}{|c|}{ MAP@5 } & \multicolumn{2}{|c|}{$M A P @ 10$} \\
\hline & Baseline & $\begin{array}{c}\text { Filter } \\
\text { PoF }\end{array}$ & Baseline & $\begin{array}{c}\text { Filter } \\
\text { PoF }\end{array}$ & Baseline & $\begin{array}{c}\text { Weight } \\
\text { PoF }\end{array}$ & Baseline & $\begin{array}{c}\text { Weight } \\
\text { PoF }\end{array}$ \\
\hline$\{50,100\}$ & 0,0085 & 0,0121 & 0,0086 & 0,0124 & 0,0167 & 0,0308 & 0,0168 & 0,0311 \\
\hline$\{15,20\}$ & 0,0085 & 0,0106 & 0,0086 & 0,0106 & 0,0167 & 0,0228 & 0,0168 & 0,0230 \\
\hline$\{10,50\}$ & 0,0085 & 0,0067 & 0,0086 & 0,0069 & 0,0167 & 0,0168 & 0,0168 & 0,0170 \\
\hline$\{2,7\}$ & 0,0085 & $0,0194 *$ & 0,0086 & $0,0196 *$ & 0,0167 & 0,0185 & 0,0168 & 0,0186 \\
\hline
\end{tabular}


Tabela B.15: Resultados do Sétimo Experimento da Avaliação Comparando com o Baseline "Metodológico" para os Fatores de Combinação $\alpha=0,5, \alpha=0,7$ e $\alpha=1$

\begin{tabular}{|c|c|c|c|c|c|c|c|c|}
\hline \multicolumn{9}{|c|}{ Valores da MAP para o fator de combinação $\alpha=0,5$} \\
\hline \multirow{3}{*}{ Granul. } & \multicolumn{4}{|c|}{ cReduction } & \multicolumn{4}{|c|}{ DaVI-BEST } \\
\hline & \multicolumn{2}{|c|}{$M A P @ 5$} & \multicolumn{2}{|c|}{$M A P @ 10$} & \multicolumn{2}{|c|}{$M A P @ 5$} & \multicolumn{2}{|c|}{$M A P @ 10$} \\
\hline & Baseline & $\begin{array}{l}\text { cReduc- } \\
\text { tion }\end{array}$ & Baseline & $\begin{array}{l}\text { cReduc- } \\
\text { tion }\end{array}$ & Baseline & $\begin{array}{l}\text { DaVI- } \\
\text { BEST }\end{array}$ & Baseline & $\begin{array}{l}\text { DaVI- } \\
\text { BEST }\end{array}$ \\
\hline$\{50,100\}$ & 0,0169 & 0,0221 & 0,0175 & 0,0224 & 0,0169 & 0,0221 & 0,0169 & 0,0224 \\
\hline$\{15,20\}$ & 0,0169 & 0,0262 & 0,0175 & 0,0265 & 0,0169 & 0,0243 & 0,0169 & 0,0163 \\
\hline$\{10,50\}$ & 0,0169 & 0,0149 & 0,0175 & 0,0152 & 0,0169 & 0,0149 & 0,0169 & 0,0152 \\
\hline$\{2,7\}$ & 0,0169 & 0,02118 & 0,0175 & 0,0219 & 0,0169 & 0,0215 & 0,0169 & 0,0226 \\
\hline \multirow{3}{*}{ Granul. } & \multicolumn{4}{|c|}{ Filter PoF } & \multicolumn{4}{|c|}{ Weight PoF } \\
\hline & \multicolumn{2}{|c|}{$M A P @ 5$} & \multicolumn{2}{|c|}{$M A P @ 10$} & \multicolumn{2}{|c|}{$M A P @ 5$} & \multicolumn{2}{|c|}{$M A P @ 10$} \\
\hline & Baseline & $\begin{array}{c}\text { Filter } \\
\text { PoF }\end{array}$ & Baseline & $\begin{array}{c}\text { Filter } \\
\text { PoF }\end{array}$ & Baseline & $\begin{array}{c}\text { Weight } \\
\text { PoF }\end{array}$ & Baseline & $\begin{array}{c}\text { Weight } \\
\text { PoF }\end{array}$ \\
\hline$\{50,100\}$ & 0,0085 & 0,0079 & 0,0086 & 0,0090 & 0,0167 & 0,0216 & 0,0168 & 0,0220 \\
\hline$\{15,20\}$ & 0,0085 & 0,0115 & 0,0086 & 0,0119 & 0,0167 & 0,0262 & 0,0168 & 0,0265 \\
\hline$\{10,50\}$ & 0,0085 & 0,0064 & 0,0086 & 0,0068 & 0,0167 & 0,0151 & 0,0168 & 0,0154 \\
\hline$\{2,7\}$ & 0,0085 & $0,0213 *$ & 0,0086 & $0,0213 *$ & 0,0167 & 0,0225 & 0,0168 & 0,0225 \\
\hline \multicolumn{9}{|c|}{ Valores da MAP para o fator de combinação $\alpha=0,7$} \\
\hline \multirow{3}{*}{ Granul. } & \multicolumn{4}{|c|}{ cReduction } & \multicolumn{4}{|c|}{ DaVI-BEST } \\
\hline & \multicolumn{2}{|c|}{$M A P @ 5$} & \multicolumn{2}{|c|}{$M A P @ 10$} & \multicolumn{2}{|c|}{$M A P @ 5$} & $M A$ & @10 \\
\hline & Baseline & $\begin{array}{l}\text { cReduc- } \\
\text { tion }\end{array}$ & Baseline & $\begin{array}{l}\text { cReduc- } \\
\text { tion }\end{array}$ & Baseline & $\begin{array}{l}\text { DaVI- } \\
\text { BEST }\end{array}$ & Baseline & $\begin{array}{l}\text { DaVI- } \\
\text { BEST }\end{array}$ \\
\hline$\{50,100\}$ & 0,0169 & 0,0275 & 0,0175 & 0,0278 & 0,0169 & 0,0275 & 0,0169 & 0,0278 \\
\hline$\{15,20\}$ & 0,0169 & 0,0152 & 0,0175 & 0,0153 & 0,0169 & 0,0119 & 0,0169 & 0,0153 \\
\hline$\{10,50\}$ & 0,0169 & 0,0135 & 0,0175 & 0,0138 & 0,0169 & 0,0135 & 0,0169 & 0,0138 \\
\hline$\{2,7\}$ & 0,0169 & 0,0216 & 0,0175 & 0,0217 & 0,0169 & 0,0206 & 0,0169 & 0,0208 \\
\hline & & Fil & $\overline{P o F}$ & & & $W e i$ & $P o F$ & \\
\hline Granul. & $M_{t}$ & ○@5 & $M A$ & a10 & $M A$ & @5 & $M A$ & $\$ 10$ \\
\hline & Baseline & $\begin{array}{c}\text { Filter } \\
\text { PoF }\end{array}$ & Baseline & $\begin{array}{c}\text { Filter } \\
\text { PoF }\end{array}$ & Baseline & $\begin{array}{c}\text { Weight } \\
\text { PoF }\end{array}$ & Baseline & $\begin{array}{c}\text { Weight } \\
\text { PoF }\end{array}$ \\
\hline$\{50,100\}$ & 0,0085 & 0,0136 & 0,0086 & 0,0138 & 0,0167 & 0,0275 & 0,0168 & 0,0278 \\
\hline$\{15,20\}$ & 0,0085 & 0,0066 & 0,0086 & 0,0066 & 0,0167 & 0,0168 & 0,0168 & 0,0171 \\
\hline$\{10,50\}$ & 0,0085 & 0,0090 & 0,0086 & 0,0090 & 0,0167 & 0,0138 & 0,0168 & 0,0142 \\
\hline$\{2,7\}$ & 0,0085 & $0,0262 *$ & 0,0086 & $0,0263 *$ & 0,0167 & 0,0221 & 0,0168 & 0,0223 \\
\hline & & Valore & a MAP p & o fator $\mathrm{c}$ & ombinaçã & $x=1$ & & \\
\hline & & $\mathrm{cRe}$ & tion & & & $\mathrm{DaV}$ & $\mathrm{EST}$ & \\
\hline Granul. & $M_{L}$ & @ 5 & $M A$ & @10 & $M A$ & @5 & $M A$ & $\$ 10$ \\
\hline & Baseline & $\begin{array}{l}\text { cReduc- } \\
\text { tion }\end{array}$ & Baseline & $\begin{array}{l}\text { cReduc- } \\
\text { tion }\end{array}$ & Baseline & $\begin{array}{l}\text { DaVI- } \\
\text { BEST }\end{array}$ & Baseline & $\begin{array}{l}\text { DaVI- } \\
\text { BEST }\end{array}$ \\
\hline$\{50,100\}$ & 0,0169 & 0,0153 & 0,0175 & 0,0157 & 0,0169 & 0,0153 & 0,0169 & 0,0157 \\
\hline$\{15,20\}$ & 0,0169 & $0,0375 *$ & 0,0175 & $0,0378 *$ & 0,0169 & $0,0375 *$ & 0,0169 & 0,0307 \\
\hline$\{10,50\}$ & 0,0169 & 0,0153 & 0,0175 & 0,0156 & 0,0169 & 0,0153 & 0,0169 & 0,0120 \\
\hline$\{2,7\}$ & 0,0169 & 0,0170 & 0,0175 & 0,0171 & 0,0169 & 0,0198 & 0,0169 & 0,0189 \\
\hline & & Filt & $\overline{\mathrm{PoF}}$ & & & $\overline{\text { Wei }}$ & PoF & \\
\hline Granul. & $M_{2}$ & D@5 & $M A$ & @10 & $M A$ & @5 & $M A$ & \$10 \\
\hline & Baseline & $\begin{array}{c}\text { Filter } \\
\text { PoF }\end{array}$ & Baseline & $\begin{array}{c}\text { Filter } \\
\text { PoF }\end{array}$ & Baseline & $\begin{array}{c}\text { Weight } \\
\text { PoF }\end{array}$ & Baseline & $\begin{array}{c}\text { Weight } \\
\text { PoF }\end{array}$ \\
\hline$\{50,100\}$ & 0,0085 & 0,0062 & 0,0086 & 0,0065 & 0,0167 & 0,0153 & 0,0168 & 0,0159 \\
\hline$\{15,20\}$ & 0,0085 & 0,0237 & 0,0086 & 0,0237 & 0,0167 & 0,0375 & 0,0168 & 0,0378 \\
\hline$\{10,50\}$ & 0,0085 & 0,0069 & 0,0086 & 0,0072 & 0,0167 & 0,0157 & 0,0168 & 0,0161 \\
\hline$\{2,7\}$ & 0,0085 & $0,0171 *$ & 0,0086 & $0,0172 *$ & 0,0167 & 0,0184 & 0,0168 & 0,0185 \\
\hline
\end{tabular}


Tabela B.16: Resultados do Oitavo Experimento da Avaliação Comparando com o Baseline "Metodológico" para os Fatores de Combinação $\alpha=0$ e $\alpha=0,3$

\begin{tabular}{|c|c|c|c|c|c|c|c|c|}
\hline \multicolumn{9}{|c|}{ Valores da MAP para o fator de combinação $\alpha=0$} \\
\hline \multirow{3}{*}{ Granul. } & \multicolumn{4}{|c|}{ cReduction } & \multicolumn{4}{|c|}{ DaVI-BEST } \\
\hline & \multicolumn{2}{|c|}{$M A P @ 5$} & \multicolumn{2}{|c|}{ MAP@10 } & \multicolumn{2}{|c|}{ MAP@5 } & \multicolumn{2}{|c|}{$M A P @ 10$} \\
\hline & Baseline & $\begin{array}{l}\text { cReduc- } \\
\text { tion }\end{array}$ & Baseline & $\begin{array}{l}\text { cReduc- } \\
\text { tion }\end{array}$ & Baseline & $\begin{array}{l}\text { DaVI- } \\
\text { BEST }\end{array}$ & Baseline & $\begin{array}{l}\text { DaVI- } \\
\text { BEST }\end{array}$ \\
\hline$\{50,100\}$ & 0,0157 & 0,0234 & 0,0163 & 0,0236 & 0,0163 & 0,0234 & 0,0164 & 0,0236 \\
\hline$\{15,20\}$ & 0,0157 & 0,0059 & 0,0163 & 0,0064 & 0,0163 & 0,0059 & 0,0164 & 0,0094 \\
\hline$\{10,50\}$ & 0,0157 & 0,0146 & 0,0163 & 0,0147 & 0,0163 & 0,0146 & 0,0164 & 0,0147 \\
\hline$\{2,7\}$ & 0,0157 & 0,0158 & 0,0163 & 0,0149 & 0,0163 & 0,0182 & 0,0164 & 0,0187 \\
\hline \multirow{3}{*}{ Granul. } & \multicolumn{4}{|c|}{ Filter PoF } & \multicolumn{4}{|c|}{ Weight PoF } \\
\hline & \multicolumn{2}{|c|}{ MAP@5 } & \multicolumn{2}{|c|}{$M A P @ 10$} & \multicolumn{2}{|c|}{$M A P @ 5$} & \multicolumn{2}{|c|}{$M A P @ 10$} \\
\hline & Baseline & $\begin{array}{c}\text { Filter } \\
\text { PoF }\end{array}$ & Baseline & $\begin{array}{c}\text { Filter } \\
\text { PoF }\end{array}$ & Baseline & $\begin{array}{c}\text { Weight } \\
\text { PoF }\end{array}$ & Baseline & $\begin{array}{l}\text { Weight } \\
\text { PoF }\end{array}$ \\
\hline$\{50,100\}$ & 0,0077 & 0,0059 & 0,0078 & 0,0062 & 0,0162 & 0,0234 & 0,0163 & 0,0236 \\
\hline$\{15,20\}$ & 0,0077 & 0,0041 & 0,0078 & 0,0047 & 0,0162 & 0,0059 & 0,0163 & 0,0064 \\
\hline$\{10,50\}$ & 0,0077 & 0,0045 & 0,0078 & 0,0046 & 0,0162 & 0,0146 & 0,0163 & 0,0147 \\
\hline$\{2,7\}$ & 0,0077 & $0,0132 *$ & 0,0078 & $0,0133 *$ & 0,0162 & 0,0151 & 0,0163 & 0,0152 \\
\hline \multicolumn{9}{|c|}{ Valores da MAP para o fator de combinação $\alpha=0,3$} \\
\hline \multirow{3}{*}{ Granul. } & \multicolumn{4}{|c|}{ cReduction } & \multirow{2}{*}{\multicolumn{4}{|c|}{\begin{tabular}{c}
\multicolumn{2}{c|}{ DaVI-BEST } \\
$M A P @ 5$
\end{tabular}}} \\
\hline & \multicolumn{2}{|c|}{$M A P @ 5$} & \multicolumn{2}{|c|}{$M A P @ 10$} & & & & $M A P @ 10$ \\
\hline & Baseline & $\begin{array}{l}\text { cReduc- } \\
\text { tion }\end{array}$ & Baseline & $\begin{array}{l}\text { cReduc- } \\
\text { tion }\end{array}$ & Baseline & $\begin{array}{l}\text { DaVI- } \\
\text { BEST }\end{array}$ & Baseline & $\begin{array}{l}\text { DaVI- } \\
\text { BEST }\end{array}$ \\
\hline$\{50,100\}$ & 0,0157 & 0,0289 & 0,0163 & 0,0292 & 0,0163 & 0,0289 & 0,0164 & 0,0292 \\
\hline$\{15,20\}$ & 0,0157 & 0,0214 & 0,0163 & 0,0216 & 0,0163 & 0,0214 & 0,0164 & 0,0197 \\
\hline$\{10,50\}$ & 0,0157 & 0,0160 & 0,0163 & 0,0162 & 0,0163 & 0,0160 & 0,0164 & 0,0132 \\
\hline$\{2,7\}$ & 0,0157 & 0,0182 & 0,0163 & 0,0183 & 0,0163 & 0,0233 & 0,0164 & 0,0215 \\
\hline \multirow{3}{*}{ Granul. } & \multicolumn{4}{|c|}{ Filter PoF } & \multicolumn{4}{|c|}{ Weight PoF } \\
\hline & \multicolumn{2}{|c|}{ MAP@5 } & \multicolumn{2}{|c|}{ MAP@10 } & \multicolumn{2}{|c|}{ MAP@5 } & \multicolumn{2}{|c|}{$M A P @ 10$} \\
\hline & Baseline & $\begin{array}{c}\text { Filter } \\
\text { PoF }\end{array}$ & Baseline & $\begin{array}{c}\text { Filter } \\
\text { PoF }\end{array}$ & Baseline & $\begin{array}{c}\text { Weight } \\
\text { PoF }\end{array}$ & Baseline & $\begin{array}{c}\text { Weight } \\
\text { PoF }\end{array}$ \\
\hline$\{50,100\}$ & 0,0077 & 0,0121 & 0,0078 & 0,0124 & 0,0162 & 0,0308 & 0,0163 & 0,0311 \\
\hline$\{15,20\}$ & 0,0077 & 0,0106 & 0,0078 & 0,0106 & 0,0162 & 0,0228 & 0,0163 & 0,0230 \\
\hline$\{10,50\}$ & 0,0077 & 0,0067 & 0,0078 & 0,0069 & 0,0162 & 0,0168 & 0,0163 & 0,0170 \\
\hline$\{2,7\}$ & 0,0077 & $0,0194 *$ & 0,0078 & $0,0196 *$ & 0,0162 & 0,0185 & 0,0163 & 0,0186 \\
\hline
\end{tabular}


Tabela B.17: Resultados do Oitavo Experimento da Avaliação Comparando com o Baseline "Metodológico" para os Fatores de Combinação $\alpha=0,5, \alpha=0,7$ e $\alpha=1$

\begin{tabular}{|c|c|c|c|c|c|c|c|c|}
\hline \multicolumn{9}{|c|}{ Valores da MAP para o fator de combinação $\alpha=0,5$} \\
\hline \multirow{3}{*}{ Granul. } & \multicolumn{4}{|c|}{ cReduction } & \multicolumn{4}{|c|}{ DaVI-BEST } \\
\hline & \multicolumn{2}{|c|}{$M A P @ 5$} & \multicolumn{2}{|c|}{$M A P @ 10$} & \multicolumn{2}{|c|}{$M A P @ 5$} & \multicolumn{2}{|c|}{$M A P @ 10$} \\
\hline & Baseline & $\begin{array}{l}\text { cReduc- } \\
\text { tion }\end{array}$ & Baseline & $\begin{array}{l}\text { cReduc- } \\
\text { tion }\end{array}$ & Baseline & $\begin{array}{l}\text { DaVI- } \\
\text { BEST }\end{array}$ & Baseline & $\begin{array}{l}\text { DaVI- } \\
\text { BEST }\end{array}$ \\
\hline$\{50,100\}$ & 0,0157 & $0,0221 *$ & 0,0163 & 0,0224 & 0,0163 & 0,0221 & 0,0164 & 0,0224 \\
\hline$\{15,20\}$ & 0,0157 & 0,0262 & 0,0163 & 0,0265 & 0,0163 & 0,0243 & 0,0164 & 0,0163 \\
\hline$\{10,50\}$ & 0,0157 & 0,0149 & 0,0163 & 0,0152 & 0,0163 & 0,0149 & 0,0164 & 0,0152 \\
\hline$\{2,7\}$ & 0,0157 & 0,0212 & 0,0163 & 0,0219 & 0,0163 & 0,0215 & 0,0164 & 0,0226 \\
\hline \multirow{3}{*}{ Granul. } & \multicolumn{4}{|c|}{ Filter PoF } & \multicolumn{4}{|c|}{ Weight PoF } \\
\hline & \multicolumn{2}{|c|}{$M A P @ 5$} & \multicolumn{2}{|c|}{$M A P @ 10$} & \multicolumn{2}{|c|}{$M A P @ 5$} & \multicolumn{2}{|c|}{$M A P @ 10$} \\
\hline & Baseline & $\begin{array}{c}\text { Filter } \\
\text { PoF }\end{array}$ & Baseline & $\begin{array}{c}\text { Filter } \\
\text { PoF }\end{array}$ & Baseline & $\begin{array}{c}\text { Weight } \\
\text { PoF }\end{array}$ & Baseline & $\begin{array}{c}\text { Weight } \\
\text { PoF }\end{array}$ \\
\hline$\{50,100\}$ & 0,0077 & 0,0079 & 0,0078 & 0,0090 & 0,0162 & 0,0216 & 0,0163 & 0,0220 \\
\hline$\{15,20\}$ & 0,0077 & 0,0115 & 0,0078 & 0,0119 & 0,0162 & 0,0262 & 0,0163 & 0,0265 \\
\hline$\{10,50\}$ & 0,0077 & 0,0064 & 0,0078 & 0,0068 & 0,0162 & 0,0151 & 0,0163 & 0,0154 \\
\hline$\{2,7\}$ & 0,0077 & 0,0213 & 0,0078 & 0,0213 & 0,0162 & $0,0225 *$ & 0,0163 & $0,0225 *$ \\
\hline \multicolumn{9}{|c|}{ Valores da MAP para o fator de combinação $\alpha=0,7$} \\
\hline \multirow{3}{*}{ Granul. } & \multicolumn{4}{|c|}{ cReduction } & \multicolumn{4}{|c|}{ DaVI-BEST } \\
\hline & \multicolumn{2}{|c|}{$M A P @ 5$} & \multicolumn{2}{|c|}{$M A P @ 10$} & \multicolumn{2}{|c|}{$M A P @ 5$} & $M A$ & Q10 \\
\hline & Baseline & $\begin{array}{l}\text { cReduc- } \\
\text { tion }\end{array}$ & Baseline & $\begin{array}{l}\text { cReduc- } \\
\text { tion }\end{array}$ & Baseline & $\begin{array}{l}\text { DaVI- } \\
\text { BEST }\end{array}$ & Baseline & $\begin{array}{l}\text { DaVI- } \\
\text { BEST }\end{array}$ \\
\hline$\{50,100\}$ & 0,1573 & 0,0275 & 0,0163 & 0,0278 & 0,0163 & 0,0275 & 0,0164 & 0,0278 \\
\hline$\{15,20\}$ & 0,1573 & 0,0152 & 0,0163 & 0,0153 & 0,0163 & 0,0119 & 0,0164 & 0,0153 \\
\hline$\{10,50\}$ & 0,1573 & 0,0135 & 0,0163 & 0,0138 & 0,0163 & 0,0135 & 0,0164 & 0,0138 \\
\hline$\{2,7\}$ & 0,1573 & 0,0216 & 0,0163 & 0,0217 & 0,0163 & 0,0206 & 0,0164 & 0,0208 \\
\hline & & Filt & $\overline{P o F}$ & & & Wei & $\overline{\mathrm{tPoF}}$ & \\
\hline Granul. & $M_{t}$ & D@5 & $M A$ & a10 & $M A$ & @5 & $M A$ & a10 \\
\hline & Baseline & $\begin{array}{c}\text { Filter } \\
\text { PoF }\end{array}$ & Baseline & $\begin{array}{c}\text { Filter } \\
\text { PoF }\end{array}$ & Baseline & $\begin{array}{c}\text { Weight } \\
\text { PoF }\end{array}$ & Baseline & $\begin{array}{c}\text { Weight } \\
\text { PoF }\end{array}$ \\
\hline$\{50,100\}$ & 0,0077 & 0,0136 & 0,0078 & 0,0138 & 0,0162 & 0,0275 & 0,0163 & 0,0278 \\
\hline$\{15,20\}$ & 0,0077 & 0,0066 & 0,0078 & 0,0066 & 0,0162 & 0,0168 & 0,0163 & 0,0171 \\
\hline$\{10,50\}$ & 0,0077 & 0,0090 & 0,0078 & 0,0899 & 0,0162 & 0,0138 & 0,0163 & 0,0142 \\
\hline$\{2,7\}$ & 0,0077 & $0,0262 *$ & 0,0078 & $0,0263 *$ & 0,0162 & 0,0221 & 0,0163 & 0,0223 \\
\hline & & Valore & a MAP $p$ & o fator $\mathrm{c}$ & ombinaçã & $x=1$ & & \\
\hline & & $\mathrm{cRe}$ & tion & & & $\mathrm{DaV}$ & BEST & \\
\hline Granul. & $M_{L}$ & @ 5 & $M A$ & @10 & $M A$ & @5 & $M A$ & a10 \\
\hline & Baseline & $\begin{array}{l}\text { cReduc- } \\
\text { tion }\end{array}$ & Baseline & $\begin{array}{l}\text { cReduc- } \\
\text { tion }\end{array}$ & Baseline & $\begin{array}{l}\text { DaVI- } \\
\text { BEST }\end{array}$ & Baseline & $\begin{array}{l}\text { DaVI- } \\
\text { BEST }\end{array}$ \\
\hline$\{50,100\}$ & 0,0157 & 0,0153 & 0,0163 & 0,0157 & 0,0163 & 0,0153 & 0,0164 & 0,0157 \\
\hline$\{15,20\}$ & 0,0157 & $0,0375 *$ & 0,0163 & $0,0378 *$ & 0,0163 & $0,0375 *$ & 0,0164 & 0,0307 \\
\hline$\{10,50\}$ & 0,0157 & 0,0153 & 0,0163 & 0,0156 & 0,0163 & 0,0153 & 0,0164 & 0,0120 \\
\hline$\{2,7\}$ & 0,0157 & 0,0170 & 0,0163 & 0,0171 & 0,0163 & 0,0198 & 0,0164 & 0,0189 \\
\hline & & Filt & $\overline{\mathrm{PoF}}$ & & & $\overline{\text { Wei }}$ & PoF & \\
\hline Granul. & $M_{2}$ & D@5 & $M A$ & @10 & $M A$ & @5 & $M A$ & a 10 \\
\hline & Baseline & $\begin{array}{c}\text { Filter } \\
\text { PoF }\end{array}$ & Baseline & $\begin{array}{c}\text { Filter } \\
\text { PoF }\end{array}$ & Baseline & $\begin{array}{c}\text { Weight } \\
\text { PoF }\end{array}$ & Baseline & $\begin{array}{c}\text { Weight } \\
\text { PoF }\end{array}$ \\
\hline$\{50,100\}$ & 0,0770 & 0,0062 & 0,0078 & 0,0065 & 0,0162 & 0,0153 & 0,0163 & 0,0159 \\
\hline$\{15,20\}$ & 0,0770 & 0,0237 & 0,0078 & 0,0237 & 0,0162 & $0,0375 *$ & 0,0163 & $0,0378 *$ \\
\hline$\{10,50\}$ & 0,0770 & 0,0069 & 0,0078 & 0,0072 & 0,0162 & 0,0157 & 0,0163 & 0,0161 \\
\hline$\{2,7\}$ & 0,0770 & $0,0171 *$ & 0,0078 & $0,0172 *$ & 0,0162 & 0,0184 & 0,0163 & 0,0185 \\
\hline
\end{tabular}

